UNIVERSIDADE DE SÃO PAULO

INSTITUTO DE ASTRONOMIA, GEOFÍSICA E CIÊNCIAS ATMOSFÉRICAS

DEPARTAMENTO DE GEOFÍSICA

\title{
IRIS FERNANDES
}

Investigações GPR em apoio à arqueologia pré-histórica na área de influência do aproveitamento hidrelétrico de Dardanelos, MT

São Paulo

2014

Versão Corrigida. O original encontra-se disponível na Unidade. 


\section{IRIS FERNANDES}

Investigações GPR em apoio à arqueologia pré-histórica na área de influência do aproveitamento hidrelétrico de Dardanelos, MT

Dissertação apresentada ao Instituto de Astronomia, Geofísica e Ciências Atmosféricas da Universidade de São Paulo para obtenção do título de Mestre em Ciências.

Área de concentração: Geofísica Aplicada

Orientador: Prof. Dr. Jorge Luís Porsani

São Paulo

2014 
"Não despreze a tradição que vem de anos longínquos; talvez as velhas avós guardem na memória relatos sobre coisas que alguma vez foram úteis para o conhecimento dos sábios."

(J.R.R. Tolkien) 


\section{AGRADECIMENTOS}

Agradeço imensuravelmente a todos que participaram de forma direta e indireta tanto em minha trajetória acadêmica quanto pessoal.

Agradeço imensamente ao meu orientador Professor Doutor Jorge Luis Porsani que acreditou em mim e foi paciente diante das adversidades pelas quais passei durante este período de minha vida. Ter chegado até aqui representa uma grande vitória e, por isso, sou muito agradecida por todo o aprendizado que pude ter durante este período. Agradeço aos conselhos e a preocupação que teve comigo, pela qual lembrarei para sempre com muito carinho. Somado a isso, ele foi, de maneira indubitável, uma pessoa que marcou minha vida por ter feito parte desta etapa da minha trajetória me ajudando com a obtenção deste trabalho e será sempre lembrado com bastante afeto e eterna gratidão.

Agradeço à CAPES (Coordenação de Aperfeiçoamento de Ensino Superior) pela concessão da bolsa de mestrado.

A todos do Departamento de Geofísica do Instituto de Astronomia, Geofísica e Ciências Atmosféricas pela oportunidade de realizar estes estudos de pesquisa: às secretárias Teca e Virgínia, aos professores Eder, Leila, Liliana, Vagner, Marcelo e Yara que participaram da minha formação.

Agradeço ao Vinícius, ao técnico Ernande e a toda equipe envolvida pela aquisição dos dados.

Agradeço ao meu pai. Sem ele eu, literalmente, não seria nada. Meu pai, que tantas vezes abdicou de si mesmo para me apoiar e ainda o faz. Admiro sua capacidade de sacrifício no qual faz com uma imensa e inexplicável alegria e contentamento. Se eu posso dizer que um dia eu soube o que foi ser amada incondicionalmente, soube através dele. Se existe alguém que realmente acredita em mim como pessoa, esse alguém é ele. Não posso medir o quanto agradeço e o amo por isso.

Agradeço à minha mãe. Sem ela também não teria chegado até aqui. Ela é a pessoa capaz de me tranquilizar, me acalmar e me curar de aflições só com o som de sua voz. Seu amor incondicional e compreensão me fazem sentir que, não importa o que haja ou onde eu esteja 
sempre haverá alguém que estará me apoiando. Por isso, só tenho a agradecer e retribuir todo o amor que recebi.

Agradeço também à minha tia, minha segunda mãe. Seus conselhos, exemplos e postura me inspiram a sentir que sempre há esperança e que os problemas existem para que se possam ser superados.

Agradeço ao meu avô, que mesmo não enxergando mais há tanto tempo, sempre diz como sou linda e fico mais linda a cada dia que passa. Nunca irei compreender onde cabe tanta ternura em uma só pessoa. Talvez eu tenha muito mais a agradecer ao meu avô do que ele mesmo possa imaginar. Ele mudou e ainda mudará minha vida... Gostaria que ele pudesse ler este agradecimento ou, ao menos, se lembrar dele quando ouvisse. Pena que isso não é mais possível.

Agradeço aos meus amigos Pablo e Moacir por sempre estarem juntos comigo nos momentos em que somente eles saberiam me entender. Aos momentos de risadas e lamúrias que sempre são de um jeito ou de outro inesquecíveis.

Não gostaria de esquecer-me de ninguém, mas é impossível citar todos os nomes que fazem parte e influenciam em nossa vida. A todos os amigos, familiares e colaboradores do instituto, sintam-se lembrados por mim, pois tudo e todos impactaram na minha vida de alguma forma.

Simplesmente obrigada. 


\section{SUMÁRIO}

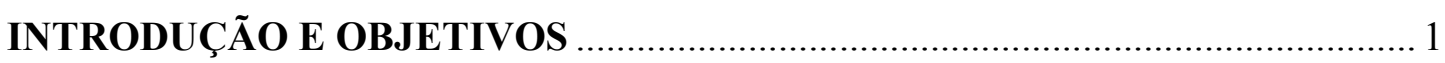

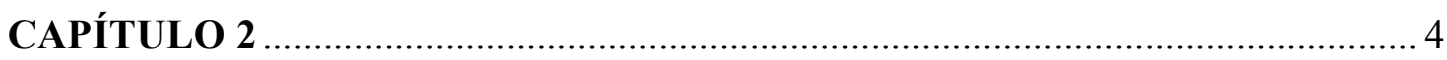

ÁREA DE ESTUDO

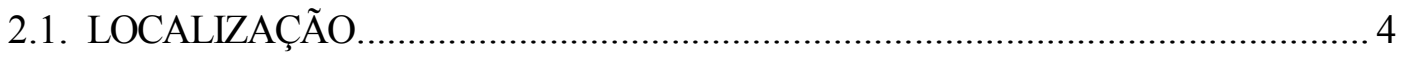

2.2. CARACTERÍSTICAS FISIOGRÁFICAS DA ÁREA DE ESTUDO ………………..... 6

2.3. OCORRÊNCIAS ARQUEOLÓGICAS NA REGIÃO........................................ 12

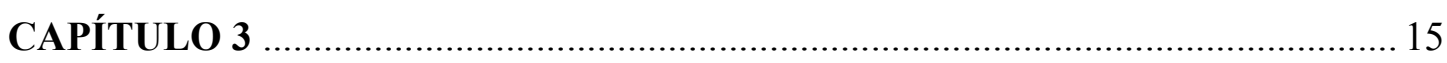

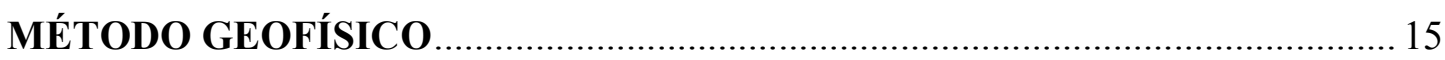

3.1. GEOFÍSICA APLICADA À ARQUEOLOGIA …………………………….... 15

3.2. O MÉTODO GPR - GROUND PENETRATING RADAR …………….... 18

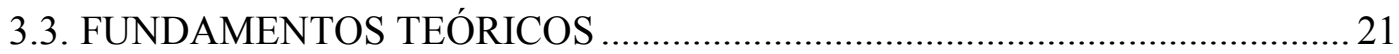

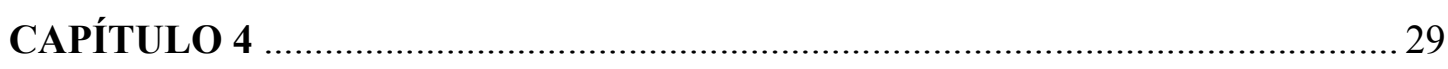

AQUISIÇÃO E PROCESSAMENTO DOS DADOS …………………………........2

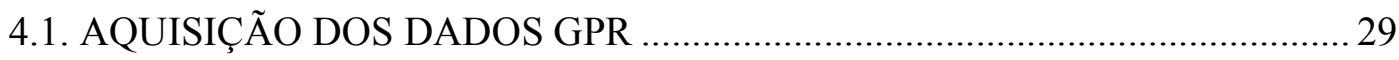

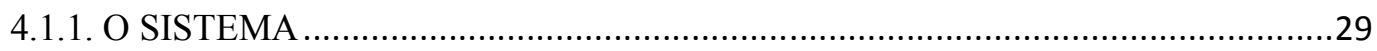

4.1.2. RECONHECIMENTO DAS ÁREAS DE INTERESSE …………………….........31

4.1.3 AQUISIÇÃO NAS ÁREAS DE INTERESSE.....................................................33

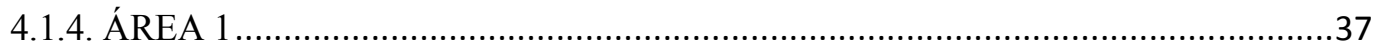

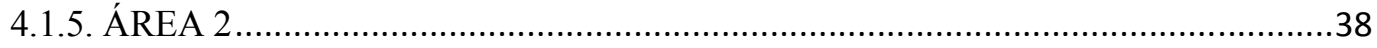

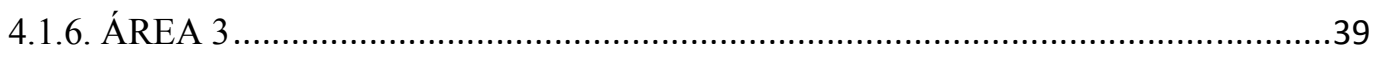

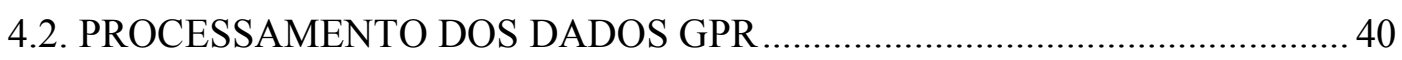

4.2.1. PROCESSAMENTO DOS PERFIS 2D ............................................................40 


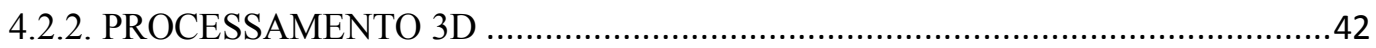

CAPÍTULO 5

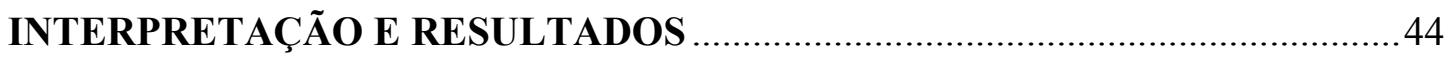

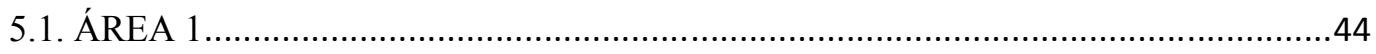

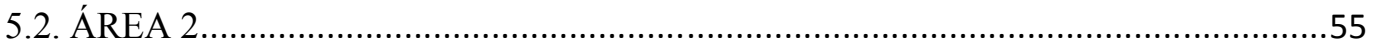

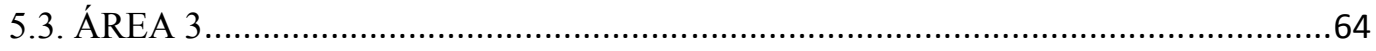

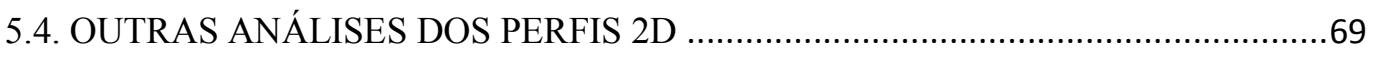

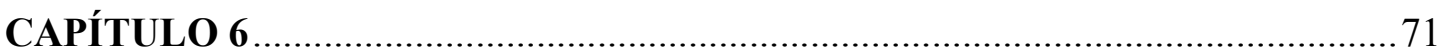

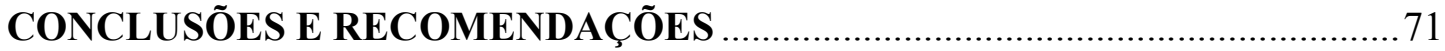

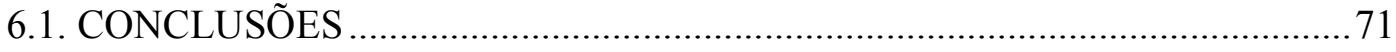

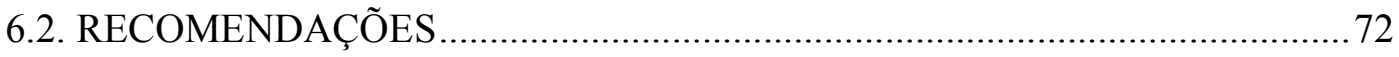

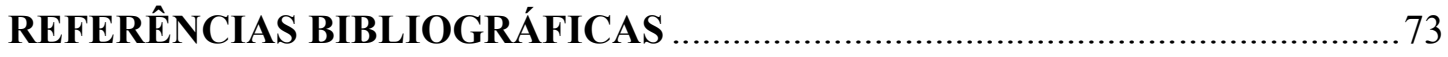

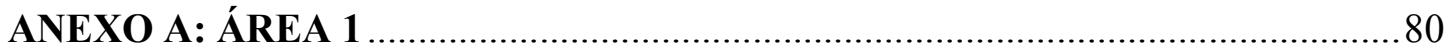

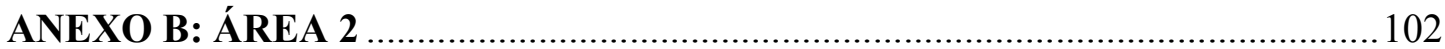

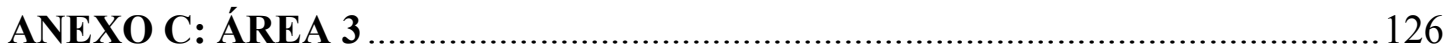

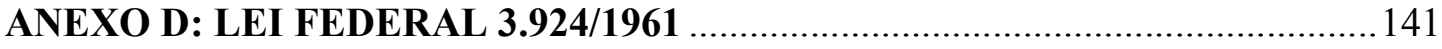

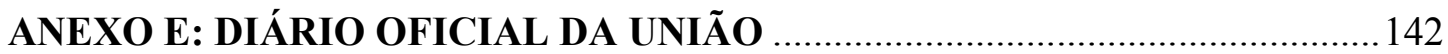




\section{ÍNDICE DE FIGURAS}

Figura 2. 1. LocAlizaÇÃo da ÁREA de estudo no maPa do Brasil. (Fonte: Google

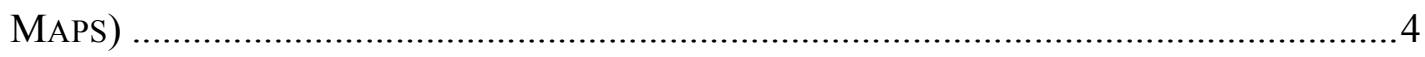

FIGURA 2. 2 - LoCALIZAÇ̃̃o GEOGRÁFICA dAS ÁREAS. (Fonte: GOOGLE MAPS) ..................... 6

Figura 2. 3 - Salto de Dardanelos (ESQuerda) e Salto das Andorinhas (Direita)

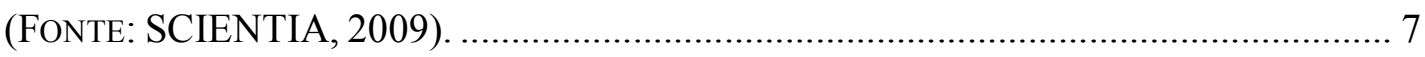

Figura 2. 4 - MAPA DA COBERTURA VEGETAL E USO DO SOLO NA BACIA DO RIO ARIPUANÃ

(Fonte: THEMAG ENGENHARIA, 2011 - BACIA HidROGRÁfICA DO Rio ARIPUANÃ). 8

Figura 2. 5 - MAPA DAS UNIDADES DE RELEVO NA BACIA DO RIO ARIPUANÃ (Fonte:

THEMAG ENGENHARIA, 2011 - BACIA HidRogrÁFICA Do Rio ARIPUANÃ)................ 10

FIGURA 2. 6 - MAPA DAS UNIDADES DE CONSERVAÇÃO E TERRAS INDÍGENAS NA BACIA DO RIO Aripuanã (Fonte: THEMAG Engenharia, 2011 - BaCia Hidrográfica do Rio ARIPUANÃ). 11

Figura 2. 7 - Perfil eStratigráfico ilustrando UM PALEOSOlO ANTRÓPiCO (TERRA PRETA) (FONTE: MILLER, 1992). 13

FIGURA 3. 1 - ESQUEMA DE TRANSMISSÃo GPR (ADAPTADO DE SANTOS, 2009).............. 20

Figura 4. 1- Esquema de funcionamento do GPR ............................................................. 30

Figura 4. 2 - Equipamento GPR sendo retirado do pequeno avião. .................................... 31

Figura 4. 3 - Reconhecimento aéreo da região............................................................. 32

Figura 4. 4 - Testes preparatórios na região dos sítios arqueológicos................................ 33

Figura 4. 5 - Áreas escolhidas para aquisição dos dados. (Fonte: Google Maps) ................ 34

Figura 4. 6 - Áreas em maior detalhe escolhidas para a aquisição dos dados. (Fonte: Google

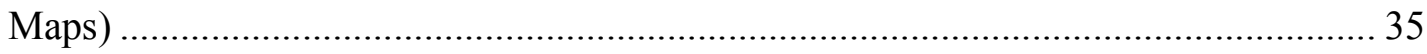

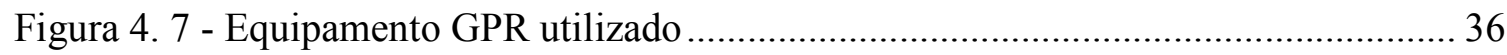

Figura 4. 8 - Esquema de montagem para a aquisição dos grids 3D ………...................... 36

Figura 4. 9 - Esquema da aquisição da área 1 e seu detalhe ................................................. 37

Figura 4. 10 - Esquema da aquisição da área 2 ................................................................... 38

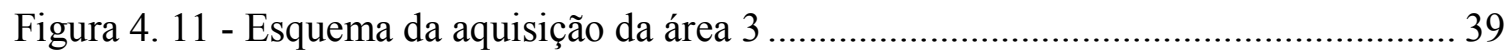


Figura 4. 12 - Fluxograma das etapas de processamento GPR.

Figura 5. 1 - Perfil GPR de $200 \mathrm{MHz}$ número 18 na direção y para a área 1 indicando algumas anomalias hiperbólicas em tons de vermelho, azul e branco

Figura 5. 2 - Perfil GPR de $200 \mathrm{MHz}$ número 18 na direção y para a área 1 indicando algumas anomalias hiperbólicas em tons de cinza..... 46

Figura 5. 3 - Perfil GPR de $200 \mathrm{MHz}$ número 18 na direção y para a área 1 dentro do cubo $3 \mathrm{D}$ gerado. 47

Figura 5. 4 -Depth-slice GPR de $200 \mathrm{MHz}$ para a área 1 (profundidade $0 \mathrm{~m}$ ). .48

Figura 5. 5 - Depth-slice GPR de $200 \mathrm{MHz}$ para a área 1 (profundidade $0 \mathrm{~m}$ ). 49

Figura 5. 6 -Depth-slice GPR de $200 \mathrm{MHz}$ para a área 1 (profundidade 1,3 m). 50

Figura 5.7 - Resultado das escavações indicadas pelo perfil GPR número 18 na direção y.51 Figura 5. 8 - Perfil GPR de $200 \mathrm{MHz}$ número 16 na direção y para a área 1 indicando uma anomalia hiperbólica em tons de vermelho, azul e branco .52

Figura 5. 9 - Perfil GPR de $200 \mathrm{MHz}$ número 16 na direção y para a área 1 indicando uma anomalia hiperbólica em tons de cinza .53

Figura 5. 10 -Depth-slice GPR de $200 \mathrm{MHz}$ para a área 1 (profundidade 2,0 m). .53

Figura 5. 11 - Urna funerária encontrada como resultado indicada pelo perfil GPR número 16 na direção y. 54

Figura 5. 12 - Perfil GPR de $200 \mathrm{MHz}$ número 6 na direção y para a área 2 indicando uma anomalias hiperbólicas e uma delimitação de uma antiga escavação em tons de vermelho, azul e branco 56

Figura 5. 13 - Perfil GPR de $200 \mathrm{MHz}$ número 6 na direção y para a área 2 indicando uma anomalias hiperbólicas e uma delimitação de uma antiga escavação em tons de cinza57

Figura 5. 14 -Depth-slice GPR de $200 \mathrm{MHz}$ para a área 2 (profundidade $0 \mathrm{~m}$ ).................58

Figura 5. 15 - Raiz de árvore próxima à superfície indicada no depth-slice 3D..................59

Figura 5. 16 - Perfil GPR de $200 \mathrm{MHz}$ número 4 na direção y para a área 2 indicando duas anomalias hiperbólicas. 60

Figura 5. 17 - Perfil GPR de $200 \mathrm{MHz}$ número 4 na direção y para a área 2 indicando duas anomalias hiperbólicas. 61

Figura 5. 18 -Depth-slice GPR de $200 \mathrm{MHz}$ para a área 2 (profundidade 0,9 m). 62 
Figura 5. 19 - Depth-slice GPR de $200 \mathrm{MHz}$ para a área 2 (profundidade 2,1 m). 63

Figura 5. 20 - Resultado da escavação indicada pelos perfis GPR de $200 \mathrm{MHz}$ número 4 na direção y. 64

Figura 5. 21 - Perfil GPR de $200 \mathrm{MHz}$ número 12 na direção x para a área 3 indicando uma anomalia hiperbólica. 65

Figura 5. 22 - Perfil GPR de $200 \mathrm{MHz}$ número 12 na direção x para a área 3 indicando anomalias hiperbólicas. 66

Figura 5. 23 - Depth-slice GPR de $200 \mathrm{MHz}$ para a área 2 (profundidade $0 \mathrm{~m}$ )................. 66

Figura 5. 24 - Depth-slice GPR de $200 \mathrm{MHz}$ para a área 3 (profundidade 1,1 m). 67

Figura 5. 25 - Resultado da escavação indicada pelo perfil GPR de $200 \mathrm{MHz}$ número 12 na direção $\mathrm{x}$ 68

Figura 5. 26 - Escavação para análise estratigráfica........................................................ 70

Anexo A 1 - Perfil GPR de 200 MHz número 1 na direção y para a área 1 ........................ 80

Anexo A 2 - Perfil GPR de 200 MHz número 2 na direção y para a área 1 ....................... 81

Anexo A 3 - Perfil GPR de 200 MHz número 3 na direção y para a área .......................... 81

Anexo A 4 - Perfil GPR de 200 MHz número 4 na direção y para a área 1 ........................ 82

Anexo A 5 - Perfil GPR de 200 MHz número 5 na direção y para a área 1 ...................... 82

Anexo A 6 - Perfil GPR de 200 MHz número 6 na direção y para a área 1 ........................ 83

Anexo A 7 - Perfil GPR de 200 MHz número 7 na direção y para a área 1 ....................... 83

Anexo A 8 - Perfil GPR de 200 MHz número 8 na direção y para a área 1 ........................ 84

Anexo A 9 - Perfil GPR de 200 MHz número 9 na direção y para a área 1 ....................... 84

Anexo A 10 - Perfil GPR de $200 \mathrm{MHz}$ número 10 na direção y para a área 1 ................... 85

Anexo A 11 - Perfil GPR de 200 MHz número 11 na direção y para a área 1 .................... 85

Anexo A 12 - Perfil GPR de 200 MHz número 12 na direção y para a área 1 ................... 86

Anexo A 13 - Perfil GPR de 200 MHz número 13 na direção y para a área 1 ................... 86

Anexo A 14 - Perfil GPR de 200 MHz número 14 na direção y para a área 1 .................... 87

Anexo A 15 - Perfil GPR de $200 \mathrm{MHz}$ número 15 na direção y para a área 1 .................... 87

Anexo A 16 - Perfil GPR de 200 MHz número 17 na direção y para a área 1 .................... 88

Anexo A 17 - Perfil GPR de $200 \mathrm{MHz}$ número 19 na direção y para a área 1 ................... 88

Anexo A 18 - Perfil GPR de $200 \mathrm{MHz}$ número 20 na direção y para a área 1 ................... 89 
Anexo A 19 - Perfil GPR de 200 MHz número 21 na direção y para a área 1 .89

Anexo A 20 - Depth-slice GPR de $200 \mathrm{MHz}$ para a área 1 (profundidade 0,1 m) ..............90

Anexo A 21 - Depth-slice GPR de $200 \mathrm{MHz}$ para a área 1 (profundidade 0,2 m) .............90

Anexo A 22 - Depth-slice GPR de $200 \mathrm{MHz}$ para a área 1 (profundidade 0,3 m) ..............91

Anexo A 23 - Depth-slice GPR de $200 \mathrm{MHz}$ para a área 1 (profundidade 0,4 m) ..............91

Anexo A 24 - Depth-slice GPR de $200 \mathrm{MHz}$ para a área 1 (profundidade 0,5 m) .............. 92

Anexo A 25 - Depth-slice GPR de $200 \mathrm{MHz}$ para a área 1 (profundidade 0,6 m) .............. 92

Anexo A 26 - Depth-slice GPR de $200 \mathrm{MHz}$ para a área 1 (profundidade 0,7 m) ..............93

Anexo A 27 - Depth-slice GPR de $200 \mathrm{MHz}$ para a área 1 (profundidade 0,8 m) ..............93

Anexo A 28 - Depth-slice GPR de $200 \mathrm{MHz}$ para a área 1 (profundidade 0,9 m) .............. 94

Anexo A 29 - Depth-slice GPR de $200 \mathrm{MHz}$ para a área 1 (profundidade 1,0 m) .............. 94

Anexo A 30 - Depth-slice GPR de $200 \mathrm{MHz}$ para a área 1 (profundidade 1,1 m) ..............95

Anexo A 31 - Depth-slice GPR de $200 \mathrm{MHz}$ para a área 1 (profundidade 1,2 m) ..............95

Anexo A 32 - Depth-slice GPR de $200 \mathrm{MHz}$ para a área 1 (profundidade 1,4 m) ..............96

Anexo A 33 - Depth-slice GPR de $200 \mathrm{MHz}$ para a área 1 (profundidade 1,5 m) ..............96

Anexo A 34 - Depth-slice GPR de $200 \mathrm{MHz}$ para a área 1 (profundidade 1,6 m) ..............97

Anexo A 35 - Depth-slice GPR de $200 \mathrm{MHz}$ para a área 1 (profundidade 1,7 m) ..............97

Anexo A 36 - Depth-slice GPR de $200 \mathrm{MHz}$ para a área 1 (profundidade 1,8 m) (.............98

Anexo A 37 - Depth-slice GPR de $200 \mathrm{MHz}$ para a área 1 (profundidade 1,9 m) ..............98

Anexo A 38 - Depth-slice GPR de $200 \mathrm{MHz}$ para a área 1 (profundidade 2,1 m) .............. 99

Anexo A 39 - Depth-slice GPR de $200 \mathrm{MHz}$ para a área 1 (profundidade 2,2 m) ............. 99

Anexo A 40 - Depth-slice GPR de $200 \mathrm{MHz}$ para a área 1 (profundidade 2,3 m) ............ 100

Anexo A 41 - Depth-slice GPR de $200 \mathrm{MHz}$ para a área 1 (profundidade 2,4 m) ............ 100

Anexo A 42 - Depth-slice GPR de $200 \mathrm{MHz}$ para a área 1 (profundidade 2,5 m) ............ 101

Anexo B 1 - Perfil GPR de 200 MHz número 1 na direção y para a área 2 ....................... 102

Anexo B 2 - Perfil GPR de $200 \mathrm{MHz}$ número 2 na direção y para a área 2 ...................... 103

Anexo B 3 - Perfil GPR de 200 MHz número 3 na direção y para a área 2 ....................... 103

Anexo B 4 - Perfil GPR de 200 MHz número 5 na direção y para a área 2 ....................... 104

Anexo B 5 - Perfil GPR de 200 MHz número 7 na direção y para a área 2 ....................... 104

Anexo B 6 - Perfil GPR de 200 MHz número 8 na direção y para a área 2 ...................... 105 
Anexo B 7 - Perfil GPR de 200 MHz número 9 na direção y para a área 2...................... 105

Anexo B 8 - Perfil GPR de 200 MHz número 10 na direção y para a área 2 .................... 106

Anexo B 9 - Perfil GPR de 200 MHz número 11 na direção y para a área 2 .................... 106

Anexo B 10 - Perfil GPR de 200 MHz número 12 na direção y para a área 2 ................... 107

Anexo B 11 - Perfil GPR de 200 MHz número 13 na direção y para a área 2 .................. 107

Anexo B 12 - Perfil GPR de 200 MHz número 14 na direção y para a área 2 .................. 108

Anexo B 13 - Perfil GPR de 200 MHz número 15 na direção y para a área 2.................. 108

Anexo B 14 - Perfil GPR de 200 MHz número 16 na direção y para a área 2 .................. 109

Anexo B 15 - Perfil GPR de 200 MHz número 17 na direção y para a área 2.................. 109

Anexo B 16 - Perfil GPR de 200 MHz número 18 na direção y para a área 2 .................. 110

Anexo B 17 - Perfil GPR de $200 \mathrm{MHz}$ número 19 na direção y para a área 2 …............... 110

Anexo B 18 - Perfil GPR de 200 MHz número 20 na direção y para a área 2 ................... 111

Anexo B 19 - Perfil GPR de 200 MHz número 21 na direção y para a área 2 .................. 111

Anexo B 20 - Perfil GPR de 200 MHz número 22 na direção y para a área 2 .................. 112

Anexo B 21 - Perfil GPR de 200 MHz número 23 na direção y para a área 2 .................. 112

Anexo B 22 - Perfil GPR de 200 MHz número 24 na direção y para a área 2 .................. 113

Anexo B 23 - Perfil GPR de 200 MHz número 25 na direção y para a área 2.................. 113

Anexo B 24 - Depth-slice GPR de $200 \mathrm{MHz}$ para a área 2 (profundidade 0,1 m)........... 114

Anexo B 25 - Depth-slice GPR de $200 \mathrm{MHz}$ para a área 2 (profundidade 0,2 m)........... 114

Anexo B 26 - Depth-slice GPR de $200 \mathrm{MHz}$ para a área 2 (profundidade 0,3 m) ............ 115

Anexo B 27 - Depth-slice GPR de $200 \mathrm{MHz}$ para a área 2 (profundidade 0,4 m) ............ 115

Anexo B 28 - Depth-slice GPR de $200 \mathrm{MHz}$ para a área 2 (profundidade 0,5 m) ............ 116

Anexo B 29 - Depth-slice GPR de $200 \mathrm{MHz}$ para a área 2 (profundidade 0,6 m) ............ 116

Anexo B 30 - Depth-slice GPR de $200 \mathrm{MHz}$ para a área 2 (profundidade 0,7 m) ........... 117

Anexo B 31 - Depth-slice GPR de $200 \mathrm{MHz}$ para a área 2 (profundidade 0,8 m) ........... 117

Anexo B 32 - Depth-slice GPR de $200 \mathrm{MHz}$ para a área 2 (profundidade 1,0 m)............ 118

Anexo B 33 - Depth-slice GPR de $200 \mathrm{MHz}$ para a área 2 (profundidade 1,1 m) ........... 118

Anexo B 34 - Depth-slice GPR de $200 \mathrm{MHz}$ para a área 2 (profundidade 1,2 m) ............ 119

Anexo B 35 - Depth-slice GPR de $200 \mathrm{MHz}$ para a área 2 (profundidade 1,3 m) ............ 119

Anexo B 36 - Depth-slice GPR de $200 \mathrm{MHz}$ para a área 2 (profundidade 1,4 m) ............ 120 
Anexo B 37 - Depth-slice GPR de $200 \mathrm{MHz}$ para a área 2 (profundidade 1,5 m). 120

Anexo B 38 - Depth-slice GPR de $200 \mathrm{MHz}$ para a área 2 (profundidade 1,6 m)

Anexo B 39 Depth-slice GPR de $200 \mathrm{MHz}$ para a área 2 (profundidade 1,7 m)

Anexo B 40 - Depth-slice GPR de $200 \mathrm{MHz}$ para a área 2 (profundidade 1,8 m) ............ 122

Anexo B 41 - Depth-slice GPR de $200 \mathrm{MHz}$ para a área 2 (profundidade 1,9 m) ............ 122

Anexo B 42 - Depth-slice GPR de $200 \mathrm{MHz}$ para a área 2 (profundidade 2,0 m) ........... 123

Anexo B 43 - Depth-slice GPR de $200 \mathrm{MHz}$ para a área 2 (profundidade 2,2 m) ............ 123

Anexo B 44 - Depth-slice GPR de $200 \mathrm{MHz}$ para a área 2 (profundidade 2,3 m) ............ 124

Anexo B 45 - Depth-slice GPR de $200 \mathrm{MHz}$ para a área 2 (profundidade 2,4 m) ............ 124

Anexo B 46 - Depth-slice GPR de $200 \mathrm{MHz}$ para a área 2 (profundidade 2,5 m) ........... 125

Anexo C 1 - Perfil GPR de 200 MHz número 1 na direção x para a área 3 ....................... 126

Anexo C 2 - Perfil GPR de 200 MHz número 2 na direção x para a área 3 ....................... 126

Anexo C 3 - Perfil GPR de 200 MHz número 3 na direção x para a área 3 ...................... 126

Anexo C 4 - Perfil GPR de 200 MHz número 4 na direção x para a área 3 ....................... 127

Anexo C 5 - Perfil GPR de 200 MHz número 5 na direção x para a área 3 ....................... 127

Anexo C 6 - Perfil GPR de 200 MHz número 6 na direção x para a área 3 ....................... 127

Anexo C 7 - Perfil GPR de 200 MHz número 7 na direção x para a área 3 ...................... 128

Anexo C 8 - Perfil GPR de $200 \mathrm{MHz}$ número 8 na direção x para a área 3 ....................... 128

Anexo C 9 - Perfil GPR de 200 MHz número 9 na direção x para a área 3 ....................... 128

Anexo C 10 - Perfil GPR de 200 MHz número 10 na direção x para a área 3 ................... 129

Anexo C 11 - Perfil GPR de 200 MHz número 11 na direção x para a área 3 ................... 129

Anexo C 12 - Perfil GPR de 200 MHz número 13 na direção x para a área 3 ................... 129

Anexo C 13 - Perfil GPR de 200 MHz número 14 na direção x para a área 3 ................... 130

Anexo C 14 Perfil GPR de 200 MHz número 15 na direção x para a área 3 ...................... 130

Anexo C 15 - Perfil GPR de 200 MHz número 16 na direção x para a área 3 .................. 130

Anexo C 16 - Perfil GPR de 200 MHz número 17 na direção x para a área 3 .................. 131

Anexo C 17 - Perfil GPR de $200 \mathrm{MHz}$ número 18 na direção x para a área 3 ................... 131

Anexo C 18 - Perfil GPR de $200 \mathrm{MHz}$ número 19 na direção x para a área 3 ................... 131

Anexo C 19 - Perfil GPR de 200 MHz número 20 na direção x para a área 3 ................... 132

Anexo C 20 - Perfil GPR de 200 MHz número 21 na direção x para a área 3 ................... 132 
Anexo C 21 - Depth-slice GPR de $200 \mathrm{MHz}$ para a área 3 (profundidade 0,1 m) 132

Anexo C 22 - Depth-slice GPR de $200 \mathrm{MHz}$ para a área 3 (profundidade 0,2 m) 133

Anexo C 23 - Depth-slice GPR de $200 \mathrm{MHz}$ para a área 3 (profundidade 0,3 m) 133

Anexo C 24 - Depth-slice GPR de $200 \mathrm{MHz}$ para a área 3 (profundidade 0,4 m) 133

Anexo C 25 - Depth-slice GPR de $200 \mathrm{MHz}$ para a área 3 (profundidade 0,5 m) 134

Anexo C 26 - Depth-slice GPR de $200 \mathrm{MHz}$ para a área 3 (profundidade 0,6 m) 134

Anexo C 27 - Depth-slice GPR de $200 \mathrm{MHz}$ para a área 3 (profundidade 0,7 m) 134

Anexo C 28 - Depth-slice GPR de $200 \mathrm{MHz}$ para a área 3 (profundidade 0,8 m) 135

Anexo C 29 - Depth-slice GPR de $200 \mathrm{MHz}$ para a área 3 (profundidade 0,9 m) 135

Anexo C 30 - Depth-slice GPR de $200 \mathrm{MHz}$ para a área 3 (profundidade 1,0 m) 135

Anexo C 31 - Depth-slice GPR de $200 \mathrm{MHz}$ para a área 3 (profundidade 1,2 m) 136

Anexo C 32 - Depth-slice GPR de $200 \mathrm{MHz}$ para a área 3 (profundidade 1,3 m) 136

Anexo C 33 - Depth-slice GPR de $200 \mathrm{MHz}$ para a área 3 (profundidade 1,4 m) 136

Anexo C 34 - Depth-slice GPR de $200 \mathrm{MHz}$ para a área 3 (profundidade 1,5 m) 137

Anexo C 35 - Depth-slice GPR de $200 \mathrm{MHz}$ para a área 3 (profundidade 1,6 m) 137

Anexo C 36 - Depth-slice GPR de $200 \mathrm{MHz}$ para a área 3 (profundidade 1,7 m) 137

Anexo C 37 - Depth-slice GPR de $200 \mathrm{MHz}$ para a área 3 (profundidade 1,8 m) 138

Anexo C 38 - Depth-slice GPR de $200 \mathrm{MHz}$ para a área 3 (profundidade 1,9 m) 138

Anexo C 39 - Depth-slice GPR de $200 \mathrm{MHz}$ para a área 3 (profundidade 2,0 m) 138

Anexo C 40 - Depth-slice GPR de $200 \mathrm{MHz}$ para a área 3 (profundidade 2,1 m) 139

Anexo C 41 - Depth-slice GPR de $200 \mathrm{MHz}$ para a área 3 (profundidade 2,2 m) 139

Anexo C 42 - Depth-slice GPR de $200 \mathrm{MHz}$ para a área 3 (profundidade 2,3 m) 139 Anexo C 43 - Depth-slice GPR de $200 \mathrm{MHz}$ para a área 3 (profundidade 2,4 m) 140 Anexo C 44 - Depth-slice GPR de $200 \mathrm{MHz}$ para a área 3 (profundidade 2,5 m) 140 


\section{RESUMO}

Fernandes, I., Investigações GPR em apoio à arqueologia pré-histórica na área de influência do aproveitamento hidrelétrico de Dardanelos, MT. 2014. Dissertação (Mestrado) Instituto de Astronomia, Geofísica e Ciências Atmosféricas, Universidade De São Paulo, SP.

Nesta pesquisa, o método GPR foi empregado para localizar e mapear urnas funerárias enterradas, visando orientar as escavações arqueológicas e auxiliar nas medidas de proteção de sítios arqueológicos na região de influência direta do aproveitamento hidrelétrico de Dardanelos, próximo à Aripuanã, MT. Um estudo arqueológico prévio seria necessário para verificar a presença de sítios arqueológicos, pois a região seria submersa, afetando todo e qualquer possível artefato presente no sítio. $\mathrm{Na}$ área de influência da usina de hidrelétrica já havia um sítio conhecido, o sítio de Dardanelos, sendo este o objeto da presente pesquisa. Dados GPR obtidos com a antena blindada de $200 \mathrm{MHz}$ foram processados e analisados, e os resultados apresentados na forma de perfis 2D e em 3D na forma de depth-slices. Após a aquisição e processamento dos dados foram identificadas as anomalias GPR e interpretadas a fim de identificar os alvos de interesse arqueológico e raízes de árvores, evitando assim, que haja ambiguidade na caracterização dos alvos de interesse. A análise 3D gerada a partir dos perfis de reflexão 2D permitiu diferenciar com clareza os alvos de interesse das raízes de árvores, uma vez que nela podemos visualizar um padrão mais alongado ao invés de pontual, como é apresentado quando temos um artefato arqueológico. Ainda, através da conversão do tempo de percurso da onda eletromagnética em profundidade, podemos identificar a profundidade dos alvos. Esta conversão também ajuda a esclarecer as ambiguidades, uma vez que as raízes são mais rasas e os artefatos mais profundos.

Palavras Chaves: GPR - Ground Penetrating Radar; Arqueologia pré-histórica; Dardanelos. 


\begin{abstract}
Fernandes, I., GPR investigations in support of prehistoric archeology in the area of influence of the hydroelectric Dardanelos, MT. In 2014. Thesis (Master) Institute of Astronomy, Geophysics and Atmospheric Sciences, University Of Sao Paulo, SP.

In this research, GPR method was used to locate and map buried indigenous urns, aiming to guide and assist the archaeological excavations in order to guide protections acts of archaeological sites in the region directly affected by the hydroelectric of Dardanelos, near to Aripuanã, MT. A preliminary archaeological study would be necessary to investigate the presence of archaeological sites, because the area would go underwater, affecting any possible artifact present on the site. In the area of influence of the hydroelectric plant there was already a known site, the site of the Dardanelos, which is the subject of this research. The GPR data obtained with shielded antenna $200 \mathrm{MHz}$ were processed and analyzed, and the results presented as $2 \mathrm{D}$ and $3 \mathrm{D}$ profiles in the form of depth-slices. After processing the GPR data anomalies were identified and interpreted to identify the targets of archeological interest and roots of trees, thus avoiding ambiguity in the characterization of targets of interest. The 3D analysis generated from the $2 \mathrm{D}$ reflection profiles allowed to differentiate clearly the targets of interest from the roots of trees, since they can display a more elongated pattern rather than punctual, as shown when we have an archaeological artifact. Further, by converting the travel time of the electromagnetic wave in depth, we can identify the depth of targets. This conversion also helps to clarify the ambiguities, since the roots are shallower and the artifacts are deeper.
\end{abstract}

Key Words: GPR - Ground Penetrating Radar; prehistoric archeology; Dardanelos. 


\section{CAPÍTULO 1}

\section{INTRODUÇÃO E OBJETIVOS}

Esta pesquisa faz parte do projeto de Arqueologia Preventiva na Área de Influência Direta do Aproveitamento Hidrelétrico Dardanelos e visa atender as exigências da legislação de proteção ao patrimônio arqueológico nacional (Lei 3.924/1961 e Portaria IPHAN 230/2002) visto que o empreendimento situa-se em uma área particularmente rica arqueologicamente. Para tanto, devido às evidências arqueológicas que já foram registradas na região do município de Aripuanã, e no alto potencial arqueológico, foi crucial o desenvolvimento de trabalhos arqueológicos na Área de Influência Direta para que o empreendimento tenha obtido a Licença de Implementação (SCIENTIA, 2009).

O Governo Federal através de um dos projetos do PAC (Programa de Aceleração do Crescimento) e autorizada pela ANEEL (Agência Nacional de Energia Elétrica) planejou a construção da Usina Hidrelétrica de Dardanelos, localizada no município de Aripuanã-MT, por onde passa o rio Aripuanã (DIÁRIO OFICIAL DA UNIÃO, PORTARIA N ${ }^{\circ}$ 128, DE 11 DE ABRIL DE 2007). Devido ao déficit de energia para a região, a capacidade da usina seria prevista para $261 \mathrm{MW}$ e com um investimento de $\mathrm{R} \$ 758$ milhões (PAC/OBRA1482). Pela importância do projeto e valor do investimento, antes de iniciar as obras de implementação da hidrelétrica, seria necessário fazer um estudo arqueológico prévio para verificar a presença de sítios arqueológicos, pois a região seria submersa, afetando todo e qualquer artefato presente no sítio. Na área de influência da usina de hidrelétrica já havia um sítio conhecido, o sítio de Dardanelos, sendo este o objeto da presente pesquisa. 


\section{Introdução e Objetivos}

O sítio de Dardanelos está localizado na área de transição da floresta tropical e do cerrado, sendo uma região com elevado potencial para a localização de artefatos que evidenciem e esclareçam a presença de povos naquela região. Deste modo, encontrar os artefatos arqueológicos remanescentes seria a solução para o problema, uma vez que os artefatos seriam resgatados e incorporados à memória nacional.

A exploração geofísica e, mais especificamente para este caso, o método GPR, é uma ferramenta muito útil para atingir tal objetivo, pois esta metodologia já foi amplamente usada e com resultados excelentes como podem ser encontrados em RODRIGUES, 2004, RODRIGUES et al., 2009; RODRIGUES, 2009; PORSANI et al., 2010 e PORSANI et al., 2012. A metodologia GPR é capaz de fornecer informações sobre o local, a profundidade e um tamanho aproximado do artefato, de modo que essas informações são completamente relevantes para investigações arqueológicas não invasivas, direcionando assim, as escavações, diminuindo custos elevados e tempo de trabalho.

O método GPR possui as etapas de investigação de aquisição dos dados, processamento dos dados $2 \mathrm{D}$ e processamento 3D. Neste trabalho, foram utilizados as etapas de processamento 2D e 3D. Na etapa 2D, são analisados os perfis individuais e é feita uma análise prévia de alguma anomalia presente. $\mathrm{Na}$ etapa $3 \mathrm{D}$, os perfis $2 \mathrm{D}$ são concatenados para que se obtenha um cubo com informações mais precisas e, espacialmente, mais bem localizadas a respeito do alvo.

O método GPR é um método geofísico eletromagnético que possui boa resposta e resolução em um limite definido. Portanto, é um método que possui algumas limitações e fornece informações, muitas vezes, com ambiguidades (PORSANI, 1999). Um exemplo disso são as raízes de árvores mapeadas como alvos de real interesse. Nos perfis $2 \mathrm{D}$, tanto alvos de interesse como raízes de árvores podem ser observados como hipérboles. No entando, quando os perfis 2D são concatenados e geram a visualização 3D da área com uma varredura completa de toda a profundidade da área, pode-se identificar um padrão geométrico do alvo; raízes de árvores são mais rasas, com aspecto mais alongado e que serpenteiam ao longo da área, já os alvos de interesse arqueológico são mais profundos, compactos e de forma mais rotunda. Deste modo, as análises 2D e 3D são complementares, sendo o processamento 2D estritamente necessário para iniciar-se o processamento 3D. 


\section{Introdução e Objetivos}

Nesta pesquisa, o objetivo específico de empregar o método GPR foi de localizar e mapear urnas funerárias enterradas, como qualquer outro material de interesse arqueológico, a exemplo, paleofogueiras e concentração de materiais líticos e cerâmicos, visando orientar as escavações arqueológicas e auxiliar as medidas de proteção de sítios arqueológicos na região em questão. Para alcançar este objetivo foram analisados uma série de dados GPR de 200MHz obtidos com o equipamento SIR 3000 da empresa americana GSSI (Geophysical Survey System, Inc.). Portanto, através do método GPR e do processamento dos dados, este trabalho tem por objetivo contribuir para o mapeamento de artefatos arqueológicos preservando, assim, uma parte da pré-histórica. 


\section{CAPÍTULO 2}

\section{ÁREA DE ESTUDO}

\subsection{LOCALIZAÇÃO}

Localizado na margem esquerda do rio Aripuanã, ao lado do município de Aripuanã encontra-se a noroeste do Estado do Mato Grosso, situado a $700 \mathrm{~km}$ da cidade de Cuiabá no Mato Grosso, e a $510 \mathrm{~km}$ da cidade de Porto Velho em Rondônia. O município de Aripuanã localiza-se a uma latitude de $10^{\circ} 10^{\prime} 00^{\prime \prime}$ sul e a uma longitude $59^{\circ} 27^{\prime} 34^{\prime \prime}$ oeste, dentro da Amazônia. A Figura 2.1 mostra sua localização.

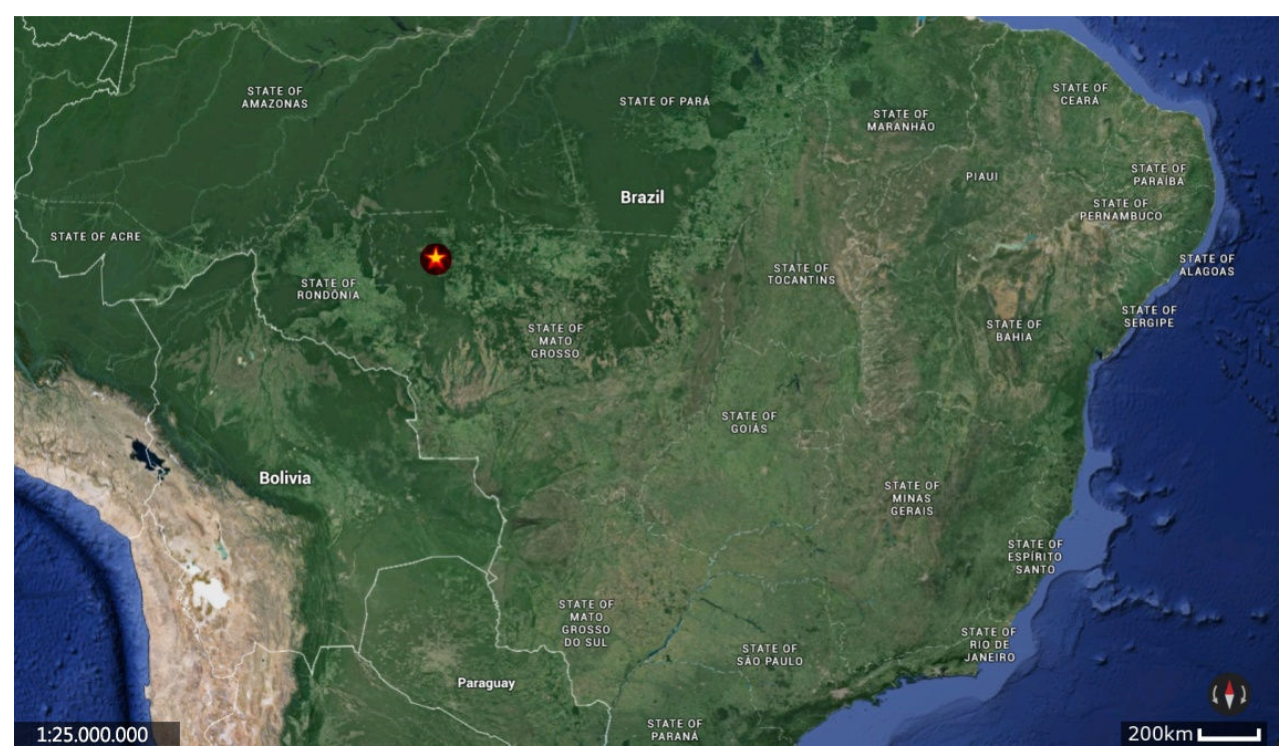

Figura 2. 1. Localização da área de estudo no mapa do Brasil. (Fonte: Google Maps)

Foram escolhidas três áreas de estudo nos sítios arqueológicos localizadas com vértices 


\section{Área de Estudo}

de coordenadas definidas a seguir e mostradas na figura 2.2:

- $\quad$ Área 1

○ Vértice SW : - $10^{\circ} 09^{\prime} 38.3$ ", $-059^{\circ} 27^{\prime}$ 57.4"

○ Vértice NW: $-10^{\circ} 09^{\prime} 37.9^{\prime \prime},-059^{\circ} 27^{\prime}$ 57.5"

○ Vértice NE: $-10^{\circ} 09^{\prime} 37.9^{\prime \prime},-059^{\circ} 27^{\prime} 57.1$ "

○ Vértice SE: $-10^{\circ} 09^{\prime} 38.0^{\prime \prime},-059^{\circ} 27^{\prime} 57.0^{\prime \prime}$

- $\quad$ Área 2

○ Vértice SW: $-10^{\circ} 09^{\prime} 38.0^{\prime \prime},-059^{\circ} 27^{\prime} 53.7^{\prime \prime}$

○ Vértice NW: $-10^{\circ} 09^{\prime} 37.6^{\prime \prime},-059^{\circ} 27^{\prime} 53.8^{\prime \prime}$

○ Vértice NE: $-10^{\circ} 09^{\prime} 37.5^{\prime \prime},-059^{\circ} 27^{\prime} 53.5^{\prime \prime}$

○ Vértice SE: $-10^{\circ} 09^{\prime} 37.8^{\prime \prime},-059^{\circ} 27^{\prime}$ 53.4”

- Área 3

○ Vértice NW: $-10^{\circ} 09^{\prime} 36.6^{\prime \prime},-059^{\circ} 27^{\prime} 52.5^{\prime \prime}$

○ Vértice NE: $-10^{\circ} 09^{\prime} 36.7^{\prime \prime},-059^{\circ} 27^{\prime} 52.4^{\prime \prime}$

○ Vértice SW: $-10^{\circ} 09^{\prime} 37.2^{\prime \prime},-059^{\circ} 27^{\prime} 52.6^{\prime \prime}$

○ Vértice SE: $-10^{\circ} 09^{\prime} 37.5^{\prime \prime},-059^{\circ} 27^{\prime} 52.3^{\prime \prime}$ 


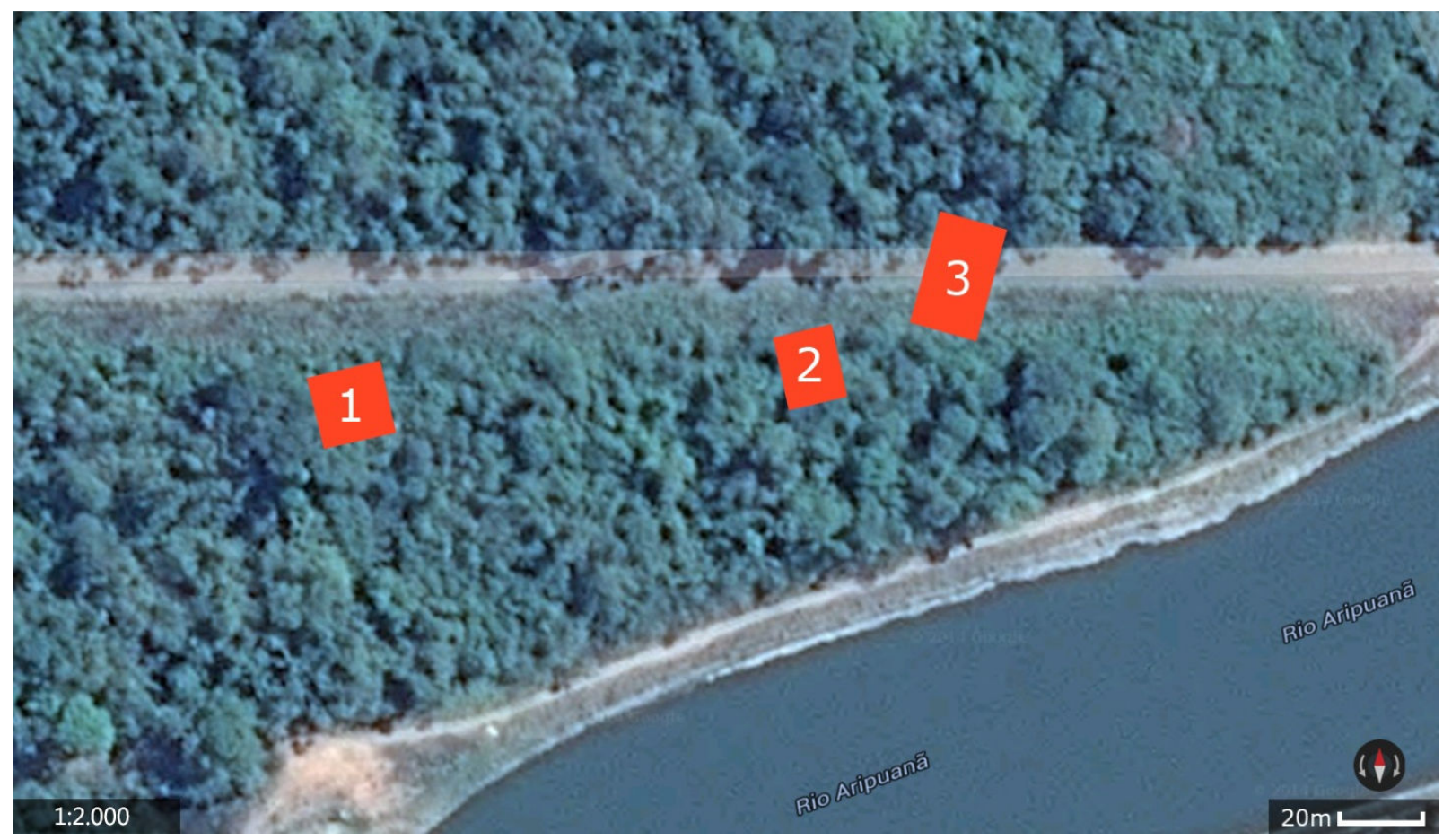

Figura 2. 2 - Localização geográfica das áreas. (Fonte: Google Maps)

\subsection{CARACTERÍSTICAS FISIOGRÁFICAS DA ÁREA DE ESTUDO}

A área do Aproveitamento Hidrelétrico Dardanelos situa-se em uma região de clima tropical quente e úmido, caracterizada por uma grande diversidade ambiental que resulta por estar em uma área de transição da Chapada de Dardanelos e da Depressão da Amazônia. A bacia do rio Aripuanã situa-se em uma região de transição entre os domínios das florestas Amazônicas e dos cerrados, presentes no Planalto Central (SCIENTIA 2007).

A hidrografia da área está representada pela bacia do rio Aripuanã localizada na porção oeste e com fluxo de sul para o norte (ALBUQUERQUE \& OLIVEIRA, 2007). Encontram-se, na interface entre a Chapada de Dardanelos e a Depressão, duas grandes cachoeiras, o Salto de Dardanelos e o Salto das Andorinhas (Figura 2.3). Ao sul das cachoeiras situa-se a zona urbana do município de Aripuanã. 

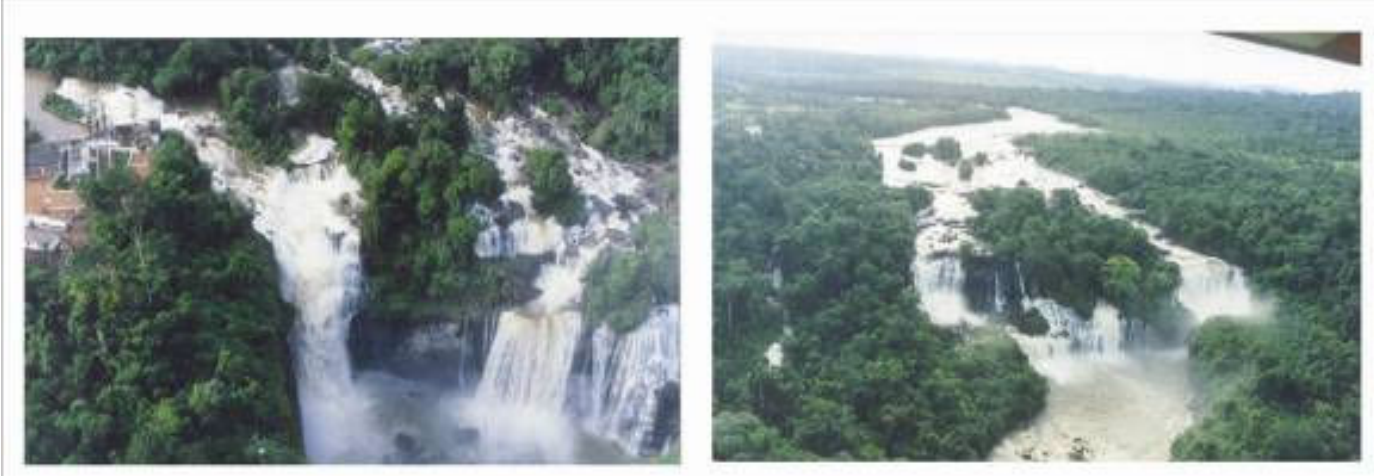

Figura 2. 3 - Salto de Dardanelos (esquerda) e Salto das Andorinhas (direita) (Fonte: SCIENTIA, 2009).

O rio Aripuanã nasce na encosta da serra dos Caiabis no Estado do Mato Grosso elevado aproximadamente a 500 metros acima do nível do mar. Ele percorre desde o Bioma do Cerrado até $22 \mathrm{~m}$ acima do nível do mar no Bioma Amazônia uma extensão de $1.100 \mathrm{~km}$ de norte a sul, desaguando no rio Madeira (SCIENTIA, 2007).

A cobertura vegetal dominante nas áreas dissecadas da Chapada de Dardanelos (IBGE, 2007) é de contato entre Floresta Ombrófila densa que representam 60\% da ocupação. Esta vegetação é sempre verde, caracterizada por mogno, cedro e ipê. Os demais $40 \%$ são compreendidos pelo platô da serra de Dardanelos. Neste mosaico de ambientes florestais e abertos, vive uma fauna rica e diversificada, típica da região amazônica, com alguns elementos característicos do cerrado, com a presença de várias espécies de répteis, anfíbios e mamíferos (Figura 2.4). 

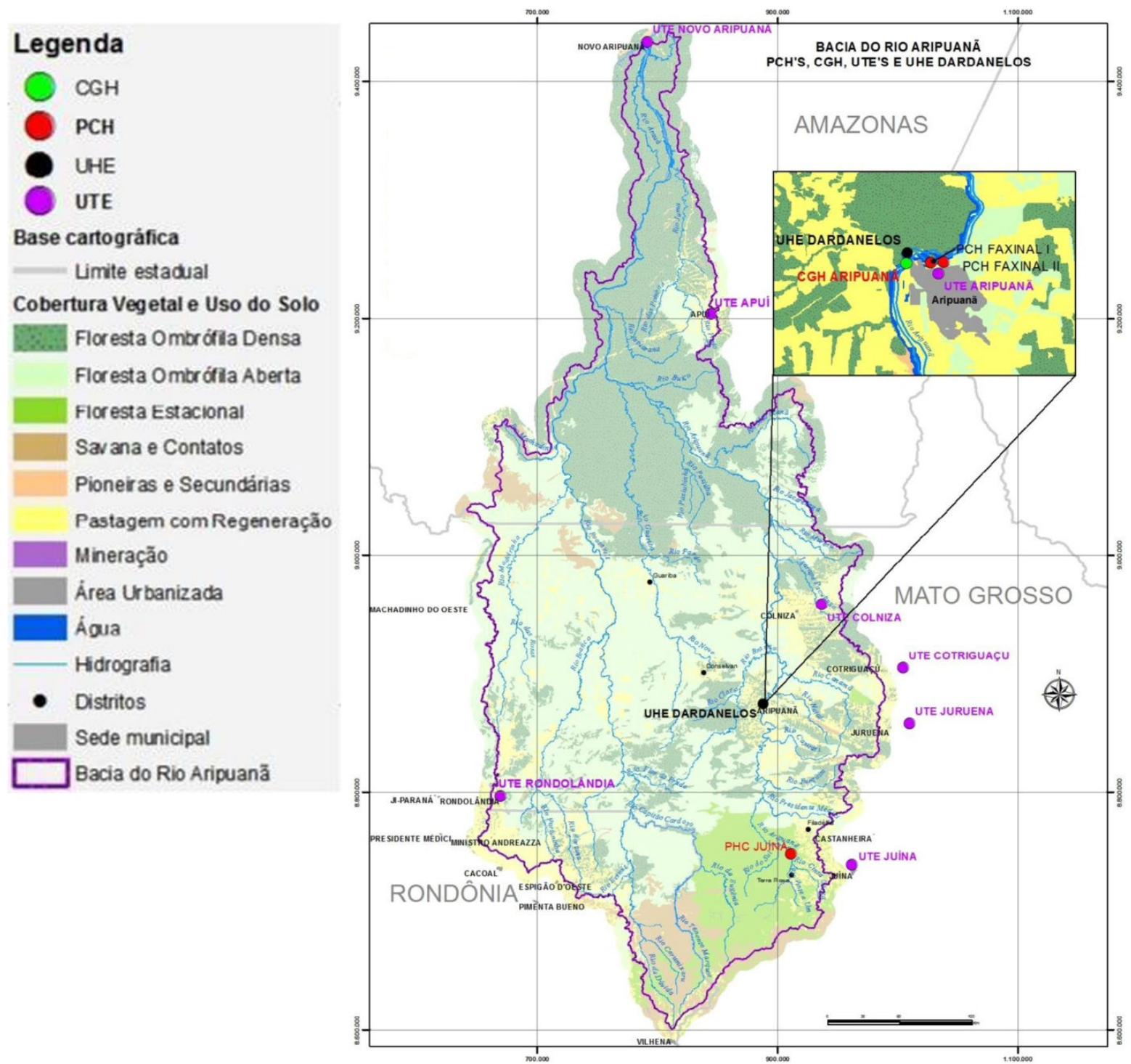

Figura 2. 4 - Mapa da cobertura vegetal e uso do solo na bacia do rio Aripuanã (Fonte:

\section{THEMAG Engenharia, 2011 - Bacia Hidrográfica do Rio Aripuanã).}

Como descrito por Boaventura (1974) e Mello \& Franco (1978) existem três domínios geomorfológicos distintos na folha, ou seja, o Planalto Residual do Norte de Mato Grosso, Planalto Dissecado Sul da Amazônia e a Depressão Interplanáltica da Amazônia Meridional.

Este domínio, chamado de Roosevelt-Aripuanã (1.790-1.740 Ma), é um segmento 


\section{Área de Estudo}

crustal do Paleoproterozóico exposto e consiste de rochas de embasamento, suítes de rochas graníticas cálcio-alcalinas, grupos de rochas vulcânicas e vulcano-sedimentares, granitos anorogênicos e bacias sedimentares (PAYOLA et al., 2002; SANTOS, 2003).

Do ponto de vista geomorfológico o vale do rio Aripuanã, próximo à área do empreendimento, se desenvolve sobre a Chapada de Dardanelos, uma extensa região aplainada, constituída por rochas antigas (cristalinas), recobertas por rochas sedimentares vulcânicas. Na área do empreendimento predominam sedimentos depositados sobre uma sequência de rochas vulcânicas composta de riolitos (rocha granítica de textura fina). Sobre as rochas e formações superficiais da chapada ocorrem solos profundos (RIMA - AHE Dardanelos, 2004). 


\section{Área de Estudo}

\section{Legenda}
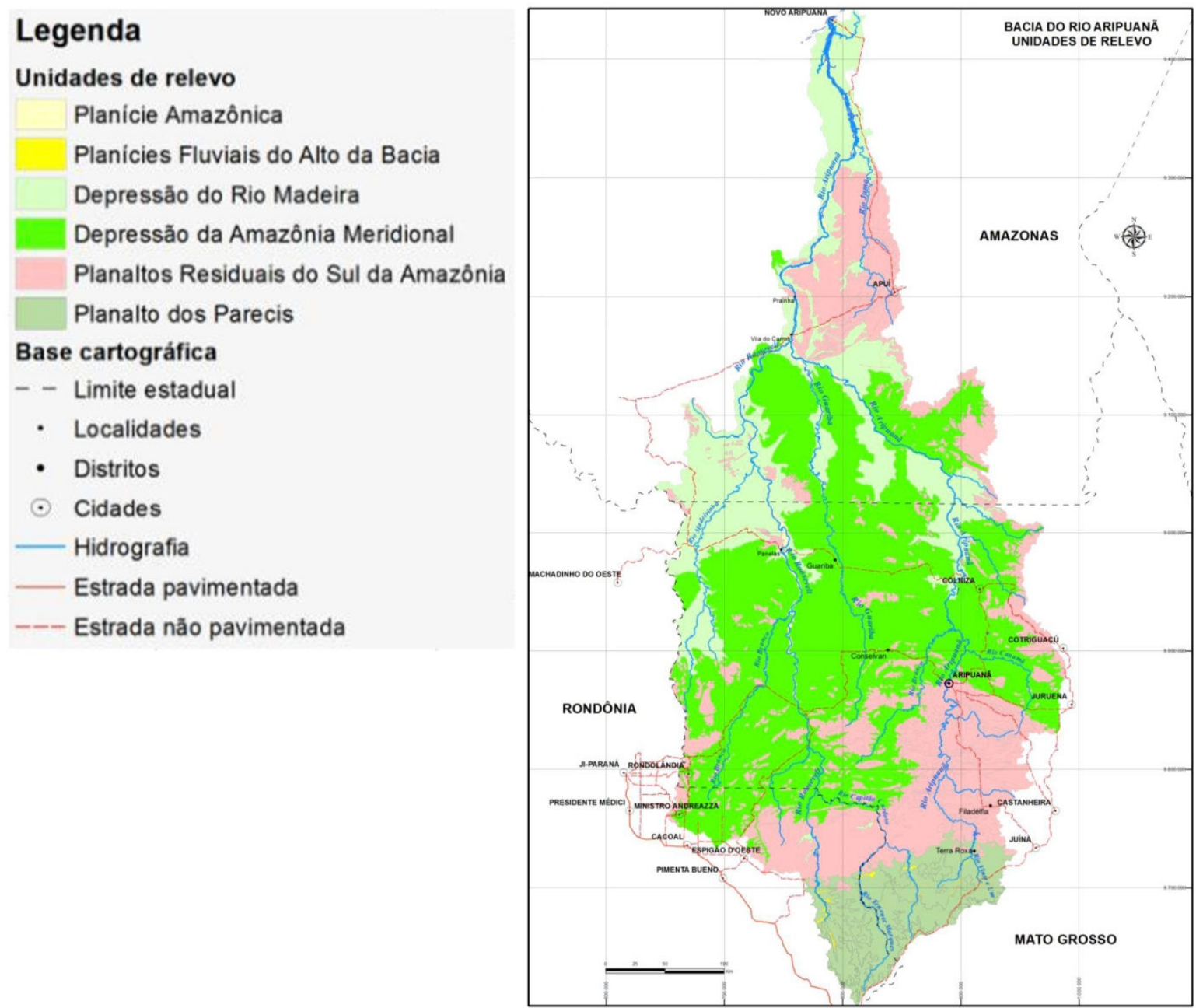

Figura 2. 5 - Mapa das unidades de relevo na bacia do rio Aripuanã (Fonte: THEMAG Engenharia, 2011 - Bacia Hidrográfica do Rio Aripuanã).

Os dados ambientais da área do AHE Dardanelos, resumidos acima na Figura 2.5, sugerem um alto potencial arqueológico para a região. Por um lado, a beleza cênica das cachoeiras, a localização estratégica em uma região de transição de domínios florestais caracterizado por uma rica diversidade florística e faunística, a presença de matéria-prima para indústrias líticas, a presença de relevos de formas suaves, e presença de abrigos, devem ter sido fatores extremamente atrativos para assentamentos de sociedades antigas (Figura 2.6). 


\section{Legenda}

$\check{\sim}+$ Limite da Bacia

Áreas prioritárias para conservação

$\square$ Extremamente alta

Insuficientemente conhecida

Muito alta

Base cartográfica

- - Limite estadual

- Distritos

- Localidades

$\odot$ Cidades

- Estrada pavimentada

Estrada năo pavimentada

Terras indigenas

$\square$ Terras indigenas

Unidades de conservação

Proteçăo integral

Uso sustentável

Hidrografía

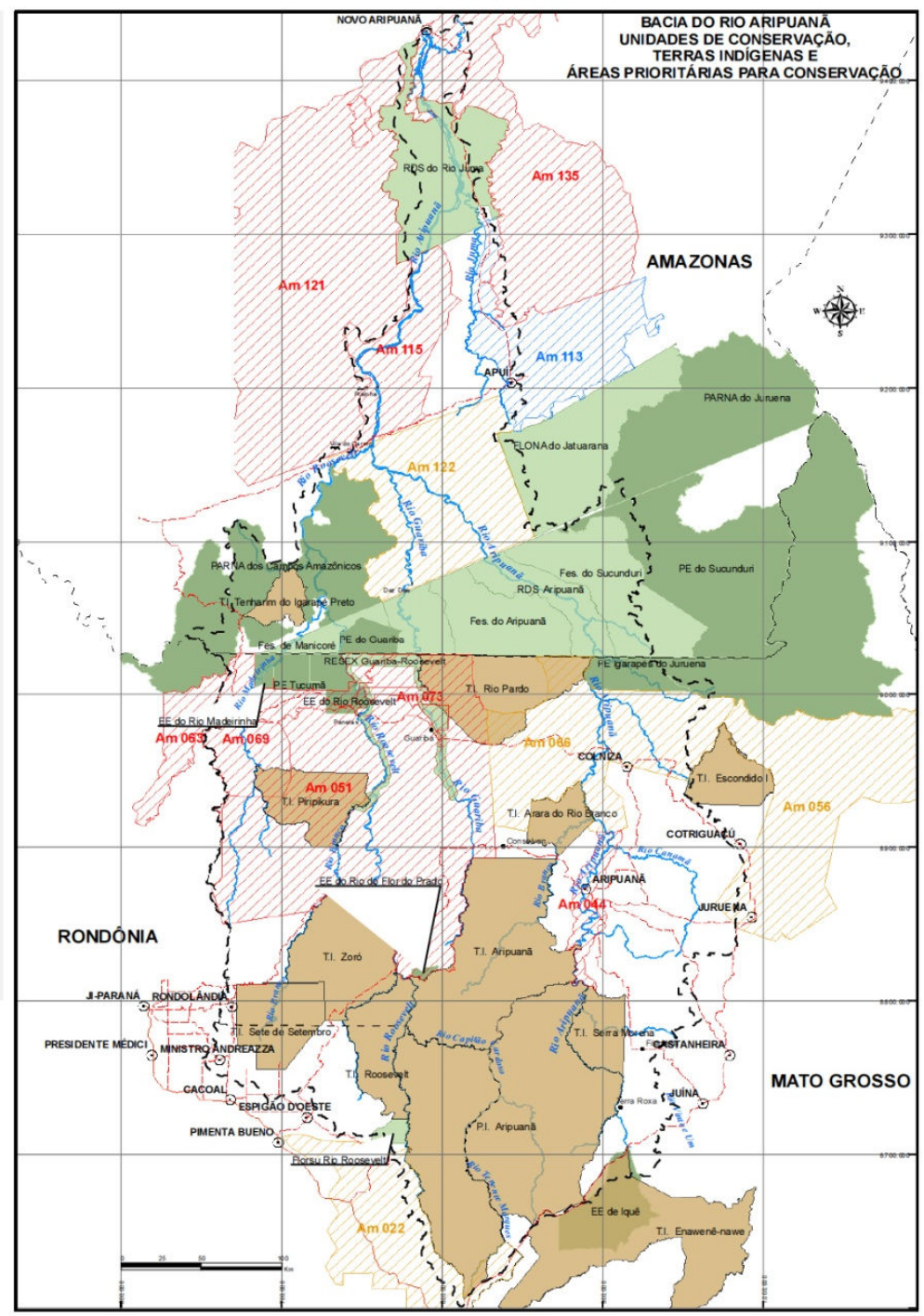

Figura 2. 6 - Mapa das unidades de conservação e terras indígenas na bacia do rio

Aripuanã (Fonte: THEMAG Engenharia, 2011 - Bacia Hidrográfica do Rio Aripuanã). 


\section{Área de Estudo}

\subsection{OCORRÊNCIAS ARQUEOLÓGICAS NA REGIÃO}

Estima-se que a ocupação humana no Centro Oeste do Brasil tenha sido iniciada entre o Pleistoceno Tardio e o Holoceno Inicial. Apesar de existirem datas mais antigas as mais aceitas remetem a uma colonização com início por volta de 12.000 AP (AP-antes do presente) (KIPNIS, 1998). Ainda nesta região, segundo Oliveira e Viana (2000), a presença de grupos agricultores e ceramistas é definida por seis diferentes tradições; Una, Aratu, Uru, Tupiguarani, Bororo e Inciso Ponteada.

A região do alto rio Madeira apesar de ser arqueologicamente pouco conhecida, apresenta indícios de ocupações antigas, que datam do início do Holoceno, por volta de 9.000 anos antes do presente e inclui o que parecem ser os sítios mais antigos de terras pretas em toda a Amazônia (MILLER, 1992). Esse pode ser também o centro inicial de dispersão de povos falantes de línguas do tronco Tupi. (NEVES, 2006).

As ocupações pré-coloniais mais antigas no Mato Grosso e Rondônia dominaram a região ao menos por 8.000 anos (entre 12.000 anos AP e 4.000 anos AP), havendo datas, ainda muito contraditórias, que sugerem inclusive uma maior antiguidade (MILLER, 1987; VILHENA-VIALOU e VIALOU, 1994; VILHENA-VIALOU et al, 1995).

Em um sítio-habitação $(4.780 \pm 90$ AP a $2.640 \pm 60$ AP) MILLER (1987) evidenciou um solo antropogênico (Figura 2.7) juntamente com artefatos líticos de processamento de produtos agrícolas, evidências essas que sugerem a ocorrência de atividade agrícola precoce entre grupos pré-cerâmicos. 


\section{Área de Estudo}

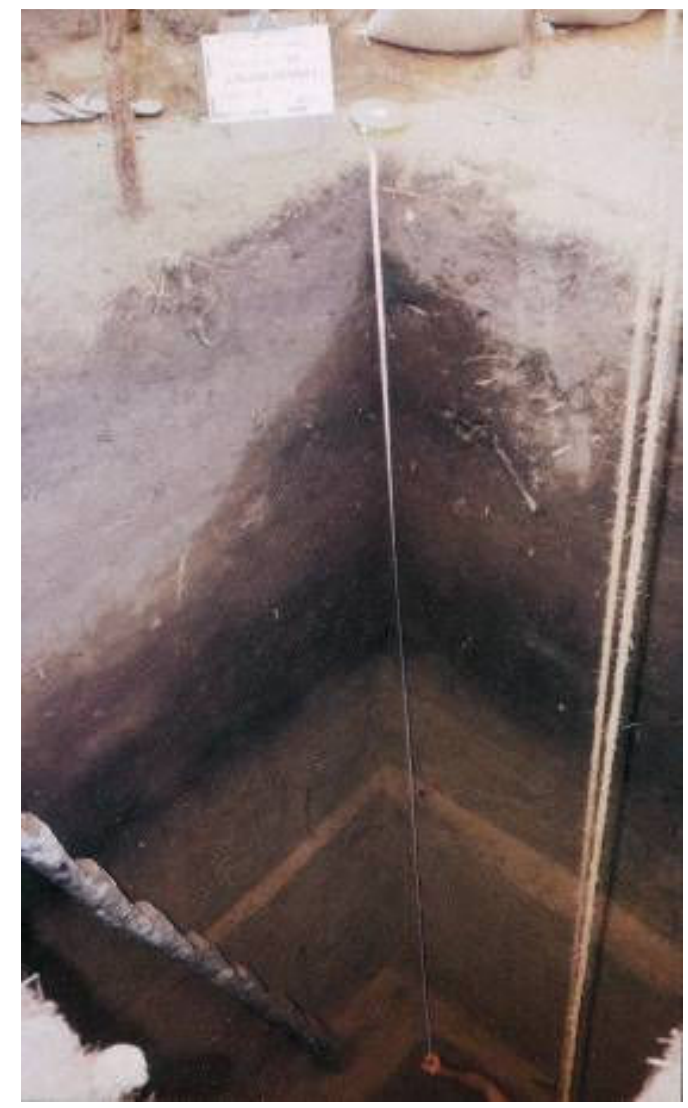

Figura 2. 7 - Perfil estratigráfico ilustrando um paleosolo antrópico (terra preta) (Fonte: MILLER, 1992).

No Mato Grosso o sítio Santa Elina (VIALOU, 2005), a $650 \mathrm{~km}$ ao sul da cidade de Aripuanã em linha reta, apresenta evidências arqueológicas de ocupações por sociedades de caçadores-coletores no final do período Pleistocênico e início do Holoceno, por volta de 12.000 a 4.000 anos antes do presente (SCHMITZ, 1984, 1987). Um pouco mais ao sul, na "Cidade de Pedra" a uma distância de $850 \mathrm{~km}$ em linha reta da cidade de Aripuanã, um conjunto de sítios arqueológicos apresenta evidências de ocupações de sociedades de caçadores- coletores com várias datações do Holoceno médio (4.000 AP), e um sítio (Caverna do Cipó) apresenta evidências arqueológicas de ocupações em torno de 7.000 AP. (VIALOU, 2006). Na região de Rondonópolis, próximo da "Cidade de Pedra", WÜST e VAZ (1998) apresentam uma datação de 10.000 


\section{Área de Estudo}

AP para o sítio Morro da Janela.

Olhando para norte, para uma região um pouco mais próximo da região do empreendimento de Dardanelos, a $450 \mathrm{~km}$ em linha reta em direção noroeste de Aripuanã, na região da Usina Hidroelétrica Samuel, rio Jamari em Rondônia, Eurico Miller (MILLER et al, 1992) descreve um horizonte arqueológico pré-cerâmico com datações entre $8.320 \pm 100$ e $2.640 \pm 60$ para ocupações de povos caçadores- coletores da região.

$\mathrm{Na}$ figura 2.8 é exibida a região próxima à Aripuanã em que são evidenciadas as ocorrências arqueológicas.

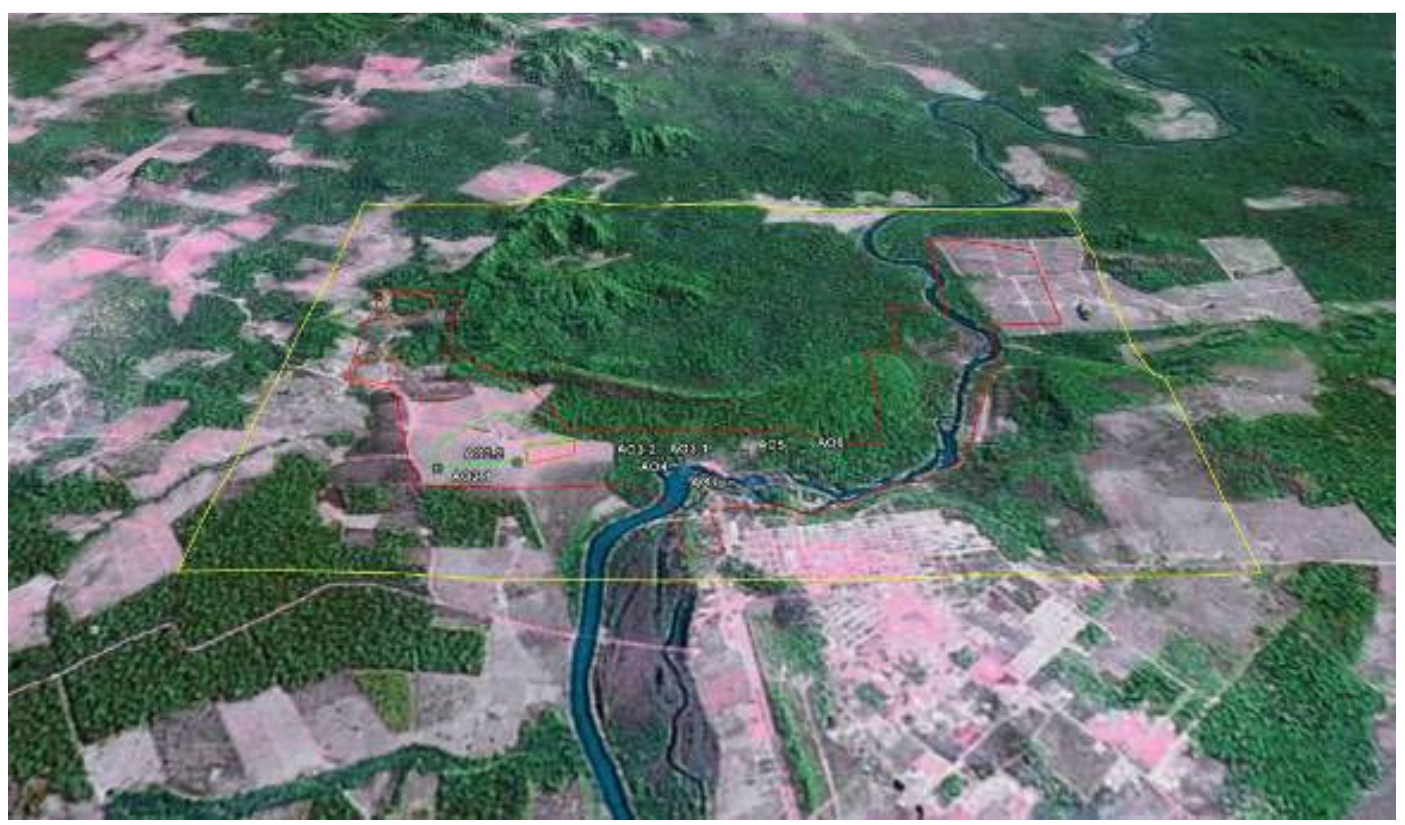

Figura 2.8 - Área de influência direta da hidroelétrica de Dardanelos (polígono vermelho) indicando ocorrências arqueológicas. (Fonte: SCIENTIA, 2009). 


\section{CAPÍTULO 3}

\section{MÉTODO GEOFÍSICO}

\subsection{GEOFÍSICA APLICADA À ARQUEOLOGIA}

Os levantamentos geofísicos em arqueologia continuam a evoluir. Segundo OLHOEFT (1996) o conceito de ondas de rádio para investigar a estrutura interna do solo teve início por volta da década de 1920, como afirma DANIELS (1996), esta metodologia foi desenvolvida na Alemanha em 1929. Na década de 70 o GPR foi usado por CLARCK (1975). A partir de 1980 os métodos geofísicos foram aplicados em arqueologia, sendo a primeira aplicação no Brasil em 1983, segundo ROOSEVELT (1991), na Ilha de Marajó em pesquisas de cerâmicas, mas foi na década de 90 e nos anos 2000 que o método geofísico de alta resolução se tornou largamente utilizado em aplicações em arqueologia no país com vários autores como BARRADAS et al. (1999), PORSANI (1999), MARQUES (2004), PEREIRA et al (2004), ARAGÃO (2006), RODRIGUES et al. (2009) entre outros.

As técnicas geofísicas também estão encontrando um papel crescente na apresentação e interpretação dos sítios arqueológicos, na contribuição para a pesquisa arqueológica e forense (PYE e CROFT, 2004), e para monitorar poços e lençóis freáticos em áreas de mata permanente (MARCELINO et al, 2005).

Apesar da crescente familiaridade com métodos e técnicas, e um número crescente de praticantes, o levantamento geofísico pode ser um assunto muito técnico, bem como uma área fértil para a inovação contínua, a exploração comercial e integração com outras disciplinas de prospecção (SALA et al, 2012).

Segundo Conyers e Goodman. (1997), o uso de levantamentos geofísicos ajudou a delimitar, descrever ou mapear vestígios culturais a um custo baixo e de forma nãodestrutiva, permitindo conceber projetos arqueológicos de uma maneira diferente. Os 


\section{Método Geofísico}

geofísicos melhoraram drasticamente o espaço real coberto por um único projeto, ajudando arqueólogos a explorar grandes áreas e a compreender os locais em pontos de vista mais amplos, e não só pelos objetos materiais ou vestígios arqueológicos. Por outro lado, as informações obtidas em um único levantamento permite que os arqueólogos selecionem o local de sua escavação com informações anteriores que ajudem a otimizar seus recursos e aumentar a eficácia das escavações (GOODMAN e PIRO, 2013)

Para RODRIGUES (2009) a geofísica aplicada à arqueologia envolve a medição de propriedades físicas próximas à superfície da terra - em contextos arqueológicos refere-se de 1 a $2 \mathrm{~m}$ - a fim de detectar e caracterizar possíveis alvos arqueológicos enterrados.

Alguns métodos de levantamento geofísico são mais sensíveis à morfologia de objetos como GPR ou resistividade que são usados em escalas menores. Utilizando sensores e metodologias especificamente pensados para a construção e indústria de engenharia, segundo Gaffney e Gafer (2003) os geofísicos têm aplicado estas técnicas para resolver problemas relacionados com a arquitetura de restauração e obter imagens de objetos arqueológicos específicos.

SALA et al (2012) cita que a capacidade de alta frequência do GPR é comumente usada como uma ferramenta de diagnóstico na arquitetura de restauração, uma vez que o uso da análise 3D pode ajudar a obter informações de objetos acessíveis ocultos ou não e estruturas de um edifício histórico.

Usando antenas de $200 \mathrm{MHz}$ a $2.2 \mathrm{GHz}$, o GPR pode ser usado para a mapear estruturas ocultas de um edifício, detectar rachaduras em blocos de rocha ou detectar pequenas cavidades ou espaços vazios. Outras aplicações avançadas usam emissores e receptores separados para obter resoluções mais altas. Aplicações de alta resolução de resistividade foram utilizadas por GOODMAN et. al (1995) com sucesso para detectar ou delimitar fissuras, ou para testar a integridade dos materiais de construção, também com configurações 3D de pequena dimensão.

Uma única anomalia geofísica em um determinado espaço, não importa se é magnético, eletromagnético ou elétrico, poderia ter uma longa lista de interpretações plausíveis. Isto é porque o subsolo é um meio muito heterogêneo e há uma longa série de 


\section{Método Geofísico}

outros fatores envolvidos na medição de grandezas geofísicas que usamos para caracterizar o conteúdo do solo como afirma HECKMAN (2005).

Mesmo a geofísica aplicada à arqueologia sendo uma disciplina científica, é importante ressaltar que um conjunto de dados obtidos a partir de uma pesquisa precisa ser processado e interpretado para ter um uso real. Como sugere GOODMAN (1994) geofísicos gerenciam informações objetivas (dados) e devem interpretá-los para trazer informações arqueológicas relevantes. Levando-se em mente que as anomalias podem ter mais de uma explicação, as interpretações variam com certo grau de incerteza que deve ser apontado a partir de uma perspectiva arqueológica.

No cenário brasileiro, em estudos conduzidos por RODRIGUES et al. (2009), o método GPR foi usado para estudar importantes sítios arqueológicos no litoral sul que são ainda muito pouco explorados e conhecidos. Nestes sítios encontram-se sambaquis, formados por conchas carbonáticas, que evidenciam a ocupação humana na região no período pré-colonial entre 7,5 e 1,3 mil anos.

Na região central do Brasil, o método GPR foi aplicado por PORSANI et al. (2010) e conduziu escavações em abrigos de rochas onde foram encontradas evidências antropogênicas como a presença de terra-preta e artefatos de madeira e sanou possíveis ambiguidades tais como raízes de árvores e corpos rochosos. Tais resultados mostraram a eficiência do método GPR na identificação dos potenciais alvos arqueológicos enterrados em sítios dentro de uma área cárstica e, orientando as escavações de maneira eficaz, reduziu os custos da investigação e aumentou a probabilidade de encontrar alvos de interesse arqueológico ainda nos estágios iniciais do projeto.

Graças ao trabalho de gerações têm-se descrições detalhadas de uma grande quantidade de vestígios culturais, estudos sobre suas características, materiais de construção e, finalmente, uma bibliografia crescente de geofísica e arqueologia com centenas de estudos de caso. Levando em conta todo esse conhecimento quando interpretamos, é o que faz a diferença entre geofísica e geofísica aplicada à arqueologia (NAJJAR, et al, 2010). 


\section{Método Geofísico}

\subsection{O MÉTODO GPR - GROUND PENETRATING RADAR}

O método GPR é amplamente versátil podendo ser utilizado nas mais diferentes situações e ambientes diversos. Segundo Porsani (1999), o método GPR pode ser comparado à técnica de reflexão sísmica e à técnica de sonar, pois, as técnicas da metodologia de aquisição de campo, bem como os princípios físicos da propagação de ondas, são semelhantes. Eles apenas diferem no fato de que o GPR baseia-se na reflexão de ondas eletromagnéticas.

O radar de penetração no solo (GPR) é um método geofísico que se utiliza de pulsos de radar para mapear a subsuperfície. Este método não destrutivo utiliza radiação eletromagnética na faixa de micro-ondas do espectro de radiofrequências, como frequências UHF/VHF, e detecta os sinais refletidos de estruturas do subsolo. O GPR pode ser utilizado em uma gama variada de diferentes meios físicos, incluindo rocha, solo, água, gelo fresco, pavimentos, entre outras estruturas. Entre os alvos que podem ser detectados podemos destacar objetos, mudanças no material, mudanças na geologia do solo, espaços ocos e rachaduras (DANIELS, 1996).

Para obterem-se os dados GPR, as antenas transmissora e receptora são movidas ao longo de um perfil através de incrementos espaciais constantes, resultando assim, em uma imagem baseada nas variações laterais das propriedades físicas dos materiais em subsuperfície em função do tempo de percurso da onda eletromagnética. Atualmente, os geocientistas têm utilizado o método GPR em vários campos de aplicações, tais como, estudos de sítios arqueológicos, contaminação ambiental, mapeamento de interferências em áreas de testes controlados, estudos hidrogeológicos, estudos sedimentológicos, estudos de rios e lagos, exploração mineral, dentre outras.

O GPR utiliza ondas de rádio e transmite alta frequência (normalmente polarizada) no solo. Quando a onda atinge um objeto enterrado ou uma barreira com diferentes constantes dielétricas, a antena receptora registra variações no sinal do retorno refletido. Os princípios envolvidos são semelhantes à reflexão sísmica, salvo que a energia eletromagnética é usada em vez de energia acústica, e de as reflexões aparecerem devido aos contrastes nas constantes dielétricas diferentes, em vez de impedâncias acústicas 


\section{Método Geofísico}

(DANIELS, 1996).

Mais especificamente, o GPR funciona transmitindo energia eletromagnética de frequência muito alta (pulsos de rádio) no solo e medindo a quantidade de energia que é refletida de volta e o tempo que leva para chegar à superfície (CONYERS e GOODMAN 1997; BEVAN, 1998; KVAMME, 2001, GAFFNEY e GATER 2003). Os solos, rochas e objetos enterrados diferem no grau com o qual absorvem ou refletem a energia. Pulsos de radar são refletidos de volta para a superfície mais rapidamente a partir de objetos rasos do que daqueles que são mais profundos. O tempo necessário para refletância pode ser usado para estimar a profundidade de objetos, superfícies ou até mesmo mudança de geologia, por isto que esta técnica tem grandes benefícios para a arqueologia.

O GPR é, de certo modo, um método para medir a permissividade dielétrica. Os sensores GPR medem o tempo de viagem e a intensidade da energia eletromagnética que é refletida por materiais de subsuperfície e objetos (BURGER, et al 2006; WITTEN, 2006). A velocidade da onda é inversamente proporcional à permissividade dielétrica relativa que é controlada pela presença de umidade (CONYERS, 2004).

As reflexões são criadas nas interfaces entre materiais em que há uma alteração na permissividade dielétrica relativa e, portanto, na velocidade da onda. Ondas de radar que viajam através de areia seca, por exemplo, ficará mais lento quando se deparam com uma camada de areia molhada. Nessa interface, uma parte da energia é refletida, enquanto que a restante é transmitida mais para dentro do solo onde ela pode ser refletida nas interfaces mais profundas (CONYERS, 2004).

Algumas das ondas transmitidas também são refratadas, à medida que passam através da interface muito semelhante ao comportamento da luz quando entra na água. $\mathrm{O}$ índice de reflexão, bem como o ângulo de refração pode ser calculada usando as equações simples (CONYERS, 2004; WITTEN, 2006). A amplitude de reflexão é governada pelo contraste de materiais acima e abaixo da interface. As reflexões mais fortes são geradas a partir de interfaces em que existe uma maior diferença de permissividade dielétrica entre as duas camadas. Isto significa que, se a mudança é muito sutil, reflexões serão fracas e quase imperceptíveis. Com alto contraste, as reflexões são muito fortes. A situação ideal é, portanto, um contraste moderado, porque as reflexões serão fortes o suficiente para detectar 


\section{Método Geofísico}

interfaces de materiais, mas não tão fortes que eles refletem a maior parte da transmissão de energia e bloqueiam para profundidades maiores (ERNENWEIN et al, 2009).

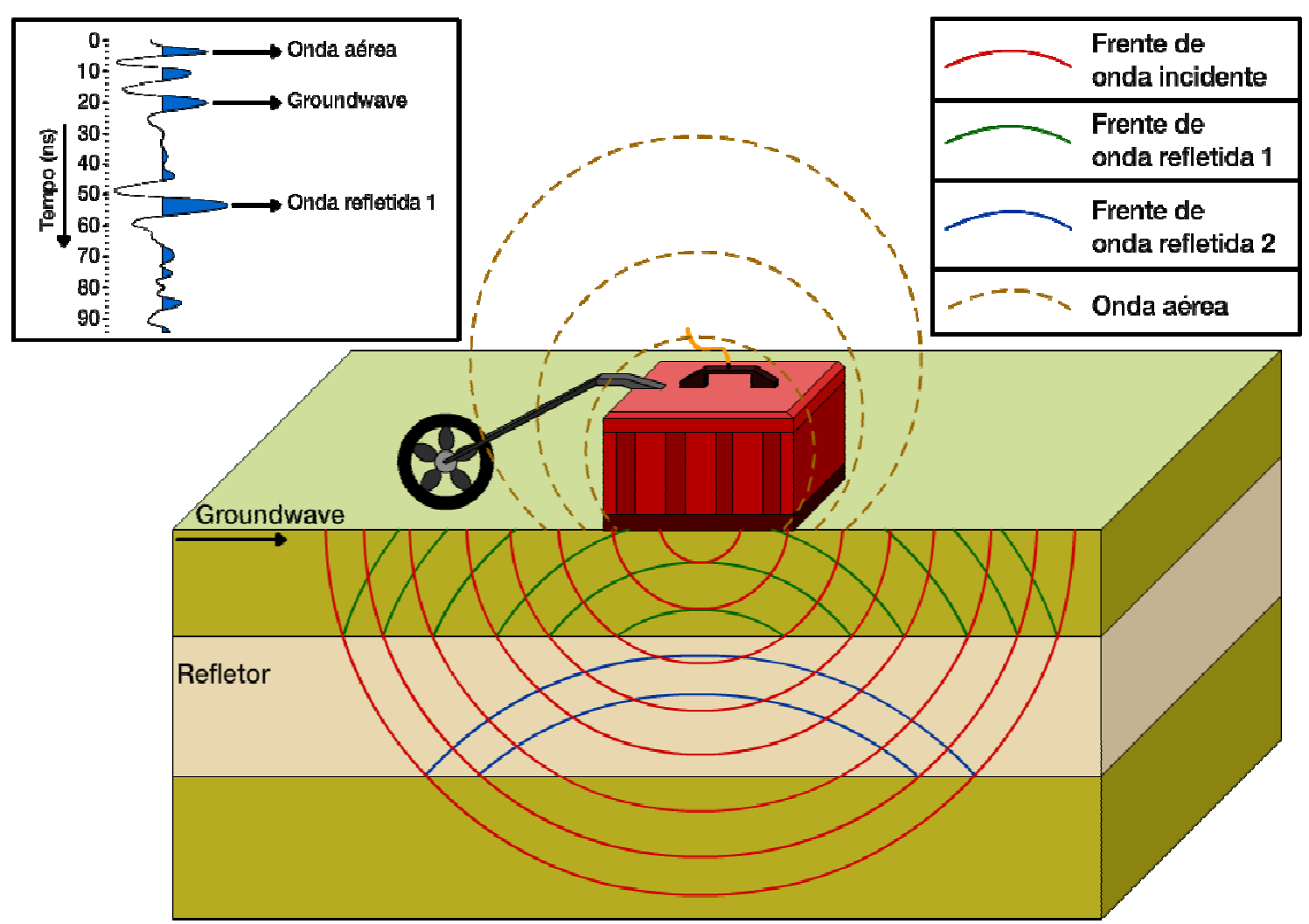

Figura 3. 1 - Esquema de transmissão GPR (Adaptado de SANTOS, 2009).

O intervalo de profundidade do GPR é limitado pela condutividade elétrica do solo, a frequência média transmitida e a potência irradiada. Com o aumento da condutividade, a profundidade de penetração diminui. Isso ocorre devido a energia eletromagnética ser mais rapidamente dissipada em forma de calor, causando uma perda de potência do sinal com a profundidade. Frequências mais altas não penetram tanto quanto as frequências mais baixas, mas permitem uma melhor resolução. A profundidade de penetração depende da frequência da antena, do tipo de material por onde a onda GPR se propaga e da condutividade dos materiais. De maneira geral, obtém-se a profundidade 


\section{Método Geofísico}

máxima em solos arenosos e granitos, pois são materiais altamente resistivos onde a profundidade de penetração pode alcançar até cerca de 40 a 50 metros. Antenas GPR estão geralmente em contato com o solo para a obtenção de um sinal mais forte, no entanto, podem-se usar antenas aéreas, acima do solo.

\subsection{FUNDAMENTOS TEÓRICOS}

Os princípios físicos e matemáticos dos métodos eletromagnéticos são primordialmente fundamentados pelas equações de Maxwell (JACKSON, 1998):

I. $\quad$ Lei de Gauss (Eq. 3.1);

II. Lei de Gauss para o magnetismo (Eq. 3.2);

III. Lei da indução de Faraday (Eq.3.3),

IV. Lei de Ampère com a correção de Maxwell (Eq.3.4)

São elas:

$$
\begin{gathered}
\vec{\nabla} \cdot \vec{E}=\frac{\rho}{\varepsilon_{0}} \\
\vec{\nabla} \cdot \vec{B}=0 \\
\vec{\nabla} \times \vec{E}=-\frac{\partial \vec{B}}{\partial t} \\
\vec{\nabla} \times \vec{B}=\mu_{0} \vec{j}+\mu_{0} \varepsilon_{0} \frac{\partial \vec{E}}{\partial t}
\end{gathered}
$$

Sendo os campos vetoriais: E é a intensidade de campo elétrico $(\mathrm{V} / \mathrm{m})$, B é a indução magnética ou densidade de fluxo magnético ( $\mathrm{Wb} / \mathrm{m}^{2}$ ou tesla) e $\mathbf{E}$ é o campo elétrico ou intensidade de campo elétrico (N/C). E sendo as fontes: J é densidade de corrente elétrica $\left(\mathrm{A} / \mathrm{m}^{2}\right)$, $\rho$ é densidade de carga elétrica, $\mu_{0}$ a permeabilidade magnética do 


\section{Método Geofísico}

vácuo $\left(\mathrm{N} / \mathrm{A}^{2}\right)$ e $\varepsilon_{0}$ permissividade elétrica do vácuo ou constante dielétrica $(\mathrm{F} / \mathrm{m})$.

$\mathrm{Na}$ lei de Gauss (3.1), linhas de campo elétrico divergem entre si na presença de carga elétrica, a carga é a fonte do campo elétrico. Sem a presença da carga $\rho$, a equação se iguala a zero.

Na lei de Gauss para o magnetismo (3.2), Linhas de campo magnético não divergem, o campo da densidade de fluxo magnético é livre de fontes; não há monopolos magnéticos.

Na lei da indução de Faraday (3.3), as alterações na densidade do fluxo magnético levam a um vórtice do campo elétrico. O sinal de menos se reflete na lei de Lenz.

$\mathrm{Na}$ lei de Ampère com correção de Maxwell (3.4), as correntes elétricas, incluindo a corrente de deslocamento, implicam a um vórtice do campo magnético.

Os campos J, B e D são constitutivos do meio e são representadas por propriedades físicas dos materiais como condutividade elétrica, permissividade dielétrica e permeabilidade magnética.

A primeira relação constitutiva do meio, em uma análise detalhada, a lei de Ohm é descrita pela relação linear entre o campo densidade de corrente $\mathbf{J}$ e o vetor campo elétrico E, com $\sigma$ sendo condutividade elétrica como o fator de proporcionalidade. A condutividade indica a facilidade com que um material apresenta para conduzir corrente elétrica, quando submetido a uma diferença de potencial:

$$
\vec{J}=\sigma \vec{E} \quad \text { Eq. } 3.5
$$

Para a segunda relação constitutiva do meio, temos a seguinte situação. Em uma constante excitação do campo elétrico $\mathbf{D}$ e valores crescentes de $\varepsilon$, a intensidade do campo elétrico $\mathbf{E}$ diminui. Desta forma, o efeito de enfraquecimento do campo elétrico na mesma excitação é detectado, isto é, de uma dada densidade de fluxo elétrico ou uma carga elétrica predeterminada. Sob a influência de uma tensão aplicada às placas do capacitor de tensão fixada em $U$ e o campo elétrico $\mathbf{E}=\mathrm{U} / \mathrm{d}$ (onde d é o espaçamento entre as placas), nos fornece os resultados de excitação elétrica $\mathbf{D}$ com a permissividade elétrica $\varepsilon$. A susceptibilidade é uma medida da densidade do transportador ligado a um material isolante, 


\section{Método Geofísico}

com base na densidade de portadores de carga livre. Em eletrodinâmica e também em eletrostática, a permissividade é utilizada para descrever os fenômenos acima como o fator de proporcionalidade na relação entre a densidade de fluxo elétrico e a intensidade do campo elétrico:

$$
\vec{D}=\varepsilon \vec{E} \quad \text { Eq. } 3.6
$$

$\mathrm{Na}$ terceira relação constitutiva do meio temos o campo de indução magnético $\mathbf{H}$ que representa como um campo magnético $\mathbf{B}$ influencia a organização de dipolos magnéticos em um dado meio, incluindo a migração de dipolo e reorientação dipolo magnético. Sua relação com a permeabilidade magnética é dado por:

$$
\mathbf{B}=\mu \mathbf{H}, \quad \text { Eq. } 3.7
$$

Onde a permeabilidade magnética, $\mu$, é um escalar, se o meio é isotrópico ou um tensor de segunda ordem para um meio anisotrópico.

De posse das três relações constitutivas do meio, vamos aplicar o rotacional na equação da lei de indução de Faraday. Assim, temos:

$$
\vec{\nabla} x(\vec{\nabla} x \vec{E})=-\vec{\nabla} x\left(\frac{\partial B}{\partial t}\right)=-\frac{\partial}{\partial t}(\vec{\nabla} x \vec{B})=-\mu \frac{\partial}{\partial t}(\vec{\nabla} x \vec{H})
$$

Se aplicarmos a identidade vetorial:

$$
\vec{\nabla} x(\vec{\nabla} x \vec{E})=\vec{\nabla}(\vec{\nabla} \cdot \vec{E})-\nabla^{2} \vec{E}
$$

Onde o divergente do campo elétrico é igual a zero, pois o meio é homogêneo e livre de cargas. Isto ocorre, pois as cargas dissipam-se muito rapidamente no ambiente geológico. Obtemos: 


\section{Método Geofísico}

$$
-\nabla^{2} \vec{E}=-\mu \frac{\partial}{\partial t}(\vec{\nabla} x \vec{H})
$$

Se substituirmos nesta equação a lei de Ampère com a correção de Maxwell e a primeira e segunda lei constitutivas temos:

$$
-\nabla^{2} \vec{E}=-\mu \frac{\partial}{\partial t}\left(\sigma \vec{E}+\varepsilon \frac{\partial \vec{E}}{\partial t}\right)
$$

O que nos leva a:

$$
\nabla^{2} \vec{H}=\mu \varepsilon \frac{\partial^{2} \vec{H}}{\partial^{2} t}+\mu \sigma \frac{\partial \vec{H}}{\partial t}
$$

Com procedimento análogo, obtemos a equação para o campo H:

$$
\nabla^{2} \vec{E}=\mu \varepsilon \frac{\partial^{2} \vec{E}}{\partial^{2} t}+\mu \sigma \frac{\partial \vec{E}}{\partial t}
$$

Como os campos elétrico $\mathbf{E}$ e magnético $\mathbf{H}$ comportam-se como ondas, podemos escrevê-los como:

$$
\begin{aligned}
& \vec{E}(z, t)=\vec{E}_{0} e^{i(k z-\omega t)} \quad \text { Eq. } 3.14 \\
& \vec{H}(z, t)=\vec{H}_{0} e^{i(k z-\omega t)}
\end{aligned}
$$

Substituindo os campos nas equações encontradas, teremos: 


\section{Método Geofísico}

$$
\begin{aligned}
& \frac{\partial^{2} \vec{E}}{\partial z^{2}}=\mu \varepsilon \frac{\partial^{2} \vec{E}}{\partial^{2} t}+\mu \sigma \frac{\partial \vec{E}}{\partial t} \\
& \frac{\partial^{2} \vec{H}}{\partial z^{2}}=\mu \varepsilon \frac{\partial^{2} \vec{H}}{\partial^{2} t}+\mu \sigma \frac{\partial \vec{H}}{\partial t}
\end{aligned}
$$

Como z e t são linearmente independentes, podemos resolver a equação da onda separadamente, assumindo o comportamento oscilatório, temos:

$$
\begin{gathered}
\frac{\partial \vec{E}}{\partial z}=i k \vec{E}_{o} e^{i(k z-\omega t)} \\
\frac{\partial^{2} \vec{E}}{\partial z^{2}}=-k^{2} \vec{E}_{o} e^{i(k z-\omega t)}=-k^{2} \vec{E} \\
\frac{\partial \vec{E}}{\partial t}=-i \omega \vec{E}_{o} e^{i(k z-\omega t)}=-i \omega \vec{E} \\
\frac{\partial^{2} \vec{E}}{\partial t^{2}}=-\omega^{2} \vec{E}_{o} e^{i(k z-\omega t)}=-\omega^{2} \vec{E}
\end{gathered}
$$

Substituindo nas equações de onda para $\mathbf{E}$ e $\mathbf{H}$, temos:

$$
\begin{aligned}
-k^{2} \vec{E} & =-\mu \varepsilon \omega^{2} \vec{E}-i \mu \sigma \omega \vec{E} \\
-k^{2} \vec{H} & =-\mu \varepsilon \omega^{2} \vec{H}-i \mu \sigma \omega \vec{H}
\end{aligned}
$$

$\mathrm{E}$, finalmente, obtemos o número de onda $\mathrm{k}^{2}$ :

\section{Eq. 3.24}

$$
k^{2}=\mu \varepsilon \omega^{2}+i \mu \sigma \omega
$$




\section{Método Geofísico}

Como podemos ver, o número de onda representa um número complexo. E pode ser reescrito em altas frequências por:

$$
\mathrm{k}=\alpha+\mathrm{i} \beta \quad \text { Eq. } 3.25
$$

A parte real $\alpha$ representa a constante de atenuação e a parte imaginária $\beta$ representa a constante de propagação (STRATTON, 1941). Porém, o GPR opera em regime de altas frequências em um meio dielétrico que oferece baixa perda. Portanto, podemos relacionar os termos real e imaginário do número de onda $\mathrm{k}^{2}$ como:

$$
\omega^{2} \mu \varepsilon>i \omega \mu \sigma \quad \text { Eq. } 3.26
$$

Se fizermos a expansão em série de Taylor para o número de onda iremos obter, para coeficientes de segunda ordem, os valores de $\alpha$ e $\beta$ :

$$
\begin{array}{ll}
\alpha=\frac{\sigma}{2} \sqrt{\frac{\mu}{\varepsilon}} & \text { Eq. } 3.27 \\
\beta=\omega \sqrt{\mu \varepsilon} & \text { Eq. } 3.28
\end{array}
$$

Através das equações de onda do campo elétrico e do campo magnético pode-se encontrar a velocidade de propagação da onda eletromagnética que se propaga no meio. $\mathrm{O}$ interesse em encontrar tal parâmetro é sua influência tanto na propagação quanto na atenuação da onda. Que são, obviamente, complementares, ou seja: $\mathrm{A}+\mathrm{P}=1$. Depois da manipulação algébrica, tem-se:

$$
\mathrm{v}=\frac{\mathrm{c}}{\sqrt{\varepsilon_{\mathrm{r}}}}
$$




\section{Método Geofísico}

Onde c é a velocidade da luz no vácuo $(0,3 \mathrm{~m} / \mathrm{ns})$ e $\varepsilon_{\mathrm{r}}$ a permissividade elétrica relativa.

Como sabemos, o comprimento de onda é dado pela relação entre a velocidade e a frequência, ou seja, $\lambda=v / f$. Se substituirmos na expressão da velocidade para a onda eletromagnética obtem-se:

$$
\lambda=\frac{c}{f \sqrt{\varepsilon_{r}}}
$$

Quando o objeto a ser investigado é espesso, terá um topo e uma base. A análise do comprimento de onda pode permitir e diferenciar a base e o topo de objetos de espessura pequena (SHERIFF, 1991). Substituindo a equação 3.30 e manipulando algebricamente, obtem-se a constante de atenuação $\alpha$, expressa como:

$$
\alpha=1,636 \frac{\sigma_{\mathrm{o}}}{\sqrt{\varepsilon_{\mathrm{r}}}}
$$

onde $\alpha$ é expresso em decibéis por metro $(\mathrm{dB} / \mathrm{m})$ e $\sigma_{0}$ é a condutividade elétrica sob corrente contínua medida em $\mathrm{mS} / \mathrm{m}$.

Para obter-se um sinal de um objeto enterrado a ser investigado, a onda eletromagnética precisa encontrar um contraste de dois meios diferentes. Isso significa que as propriedades físicas como permissividade elétrica, condutividade elétrica e permeabilidade magnética devem ser diferentes para o GPR detectá-lo. Considerando, então, um meio com duas camadas, expressamos a amplitude do coeficiente de reflexão $\mathrm{GPR}, \mathrm{r}_{\mathrm{GPR}}$ :

$$
\mathrm{r}_{\mathrm{gpr}}=\frac{\sqrt{\sigma_{1}+\mathrm{i} \omega \varepsilon_{1}}-\sqrt{\sigma_{2}+\mathrm{i} \omega \varepsilon_{2}}}{\sqrt{\sigma_{1}+\mathrm{i} \omega \varepsilon_{1}}+\sqrt{\sigma_{2}+\mathrm{i} \omega \varepsilon_{2}}}
$$




\section{Método Geofísico}

Uma descrição detalhada sobre os procedimentos algébricos envolvidos na dedução das principais equações do método GPR pode ser encontrada em DANIELS (1996), PORSANI (1999), entre outras. 


\section{CAPÍTULO 4}

\section{AQUISIÇÃO E PROCESSAMENTO DOS DADOS}

Neste capítulo, tratar-se-á do processo de aquisição e processamento dos dados GPR adquiridos nas áreas alvos de estudo. As investigações visam identificar e mapear alvos de interesse arqueológico na região. Nos tópicos subsequentes abordar-se-á a descrição sistemática da aquisição e do processamento de campo.

\subsection{AQUISIÇÃO DOS DADOS GPR}

\subsubsection{O SISTEMA}

Os dados foram obtidos com o equipamento SIR 3000 da empresa americana GSSI (Geophysical Survey System, Inc.) do Laboratório de Instrumentação Geofísica pertencente ao IAG/USP. O sistema é composto por antenas blindadas (transmissora-receptora), e uma unidade de controle central. Após a conexão correta e verificação da unidade de controle central com as antenas, é feita a calibração do odômetro (roda).

O sistema que constitui a aparelhagem do GPR é basicamente composto por três módulos:

- Antena blindada transmissora e receptora;

- $\quad$ Unidade de controle central.

- $\quad$ Odômetro;

Cada módulo é conectado por cabos e calibrado com o odômetro antes que se 
possa iniciar a aquisição (Figura 4.1).

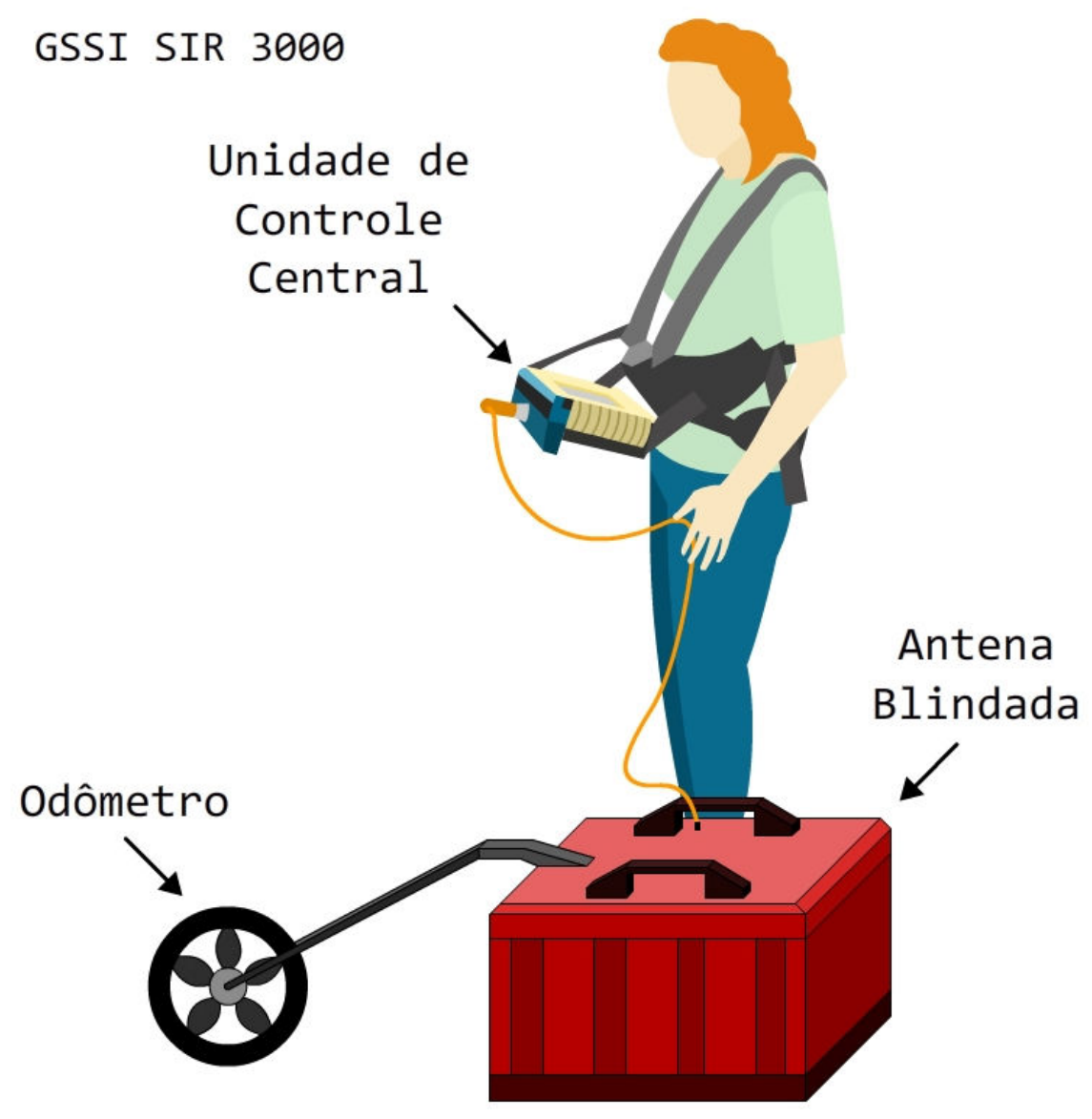

Figura 4. 1- Esquema de funcionamento do GPR.

Foi utilizada a antena blindada de $200 \mathrm{MHz}$ para a aquisição dos dados desta pesquisa. Com esta frequência, é possível investigar o subsolo até cerca de 2 metros de profundidade (PORSANI, 1999).

Segundo MILLER et al (1992), as escavações arqueológicas prévias feitas nos sítios próximos às áreas de estudos, alvos de interesse são encontrados em profundidades menores que 2 metros de profundidade, portanto, a antena de $200 \mathrm{MHz}$ mostra-se adequada aos objetivos propostos. 


\section{Aquisição e Processamento dos Dados}

Houve também uma problemática na logística e organização para que fosse feita a melhor escolha do equipamento que seria utilizado para a obtenção dos dados. O local dos sítios arqueológicos era remoto e somente seria possível levar junto com a equipe uma só antena GPR. O acesso ao local era limitado, sendo possível acessá-lo somente de avião onde o espaço físico era extremamente limitado (Figura 4.2).

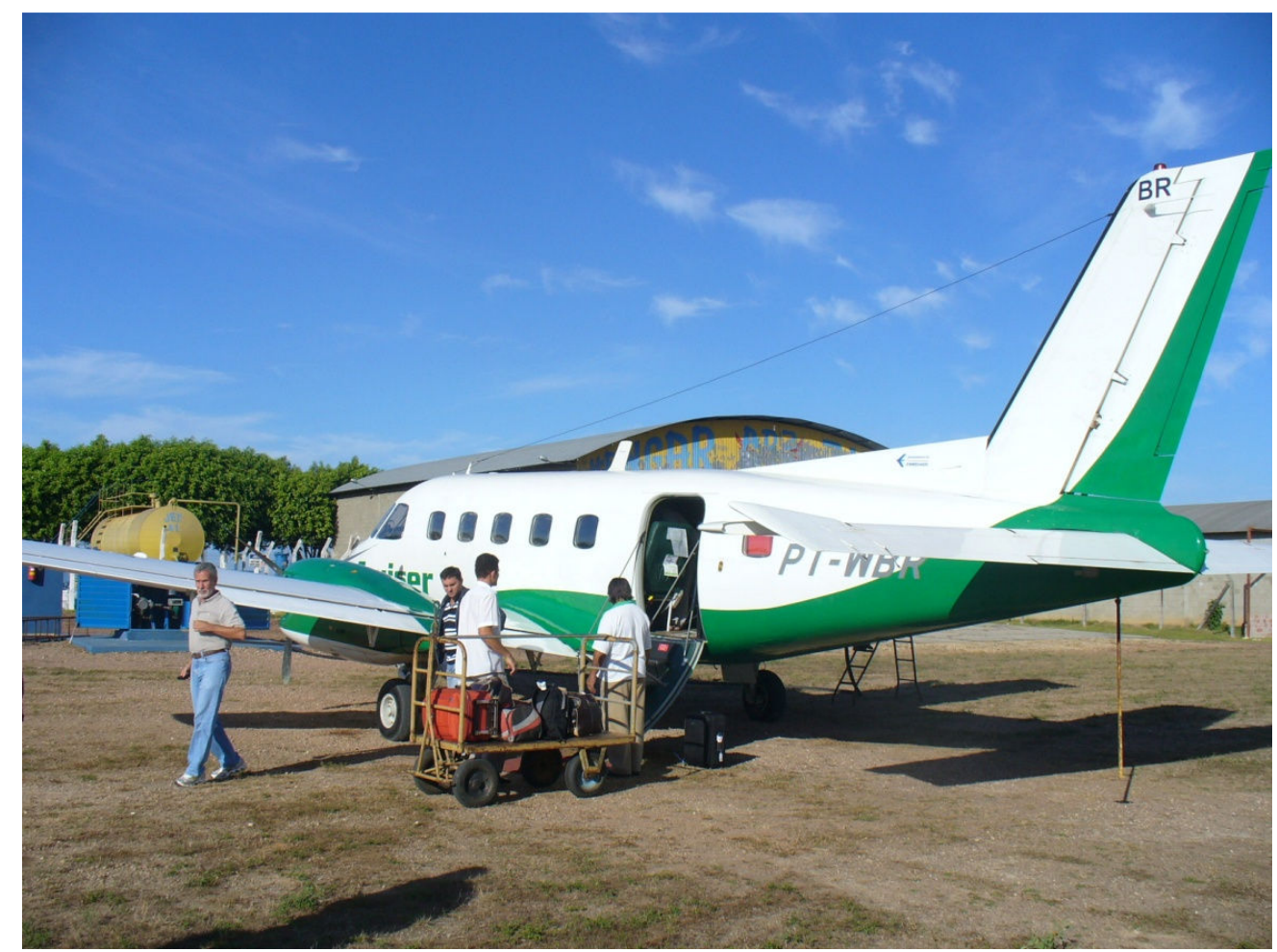

Figura 4. 2 - Equipamento GPR sendo retirado do pequeno avião.

\subsubsection{RECONHECIMENTO DAS ÁREAS DE INTERESSE}

Para que a aquisição fosse iniciada, um reconhecimento regional do campo foi feito previamente para que fosse escolhida a melhor maneira de se estudar os sítios arqueológicos. Para isto, foi feito um reconhecimento aéreo e um terrestre (Figura 4.3). Os sítios arqueológicos foram previamente divididos para um melhor diagnóstico, pois a área 


\section{Aquisição e Processamento dos Dados}

se situava em uma região de amplo potencial arqueológico, baseado em evidências registradas conforme projeto encaminhado ao IPHAN (SCIENTIA 2007).

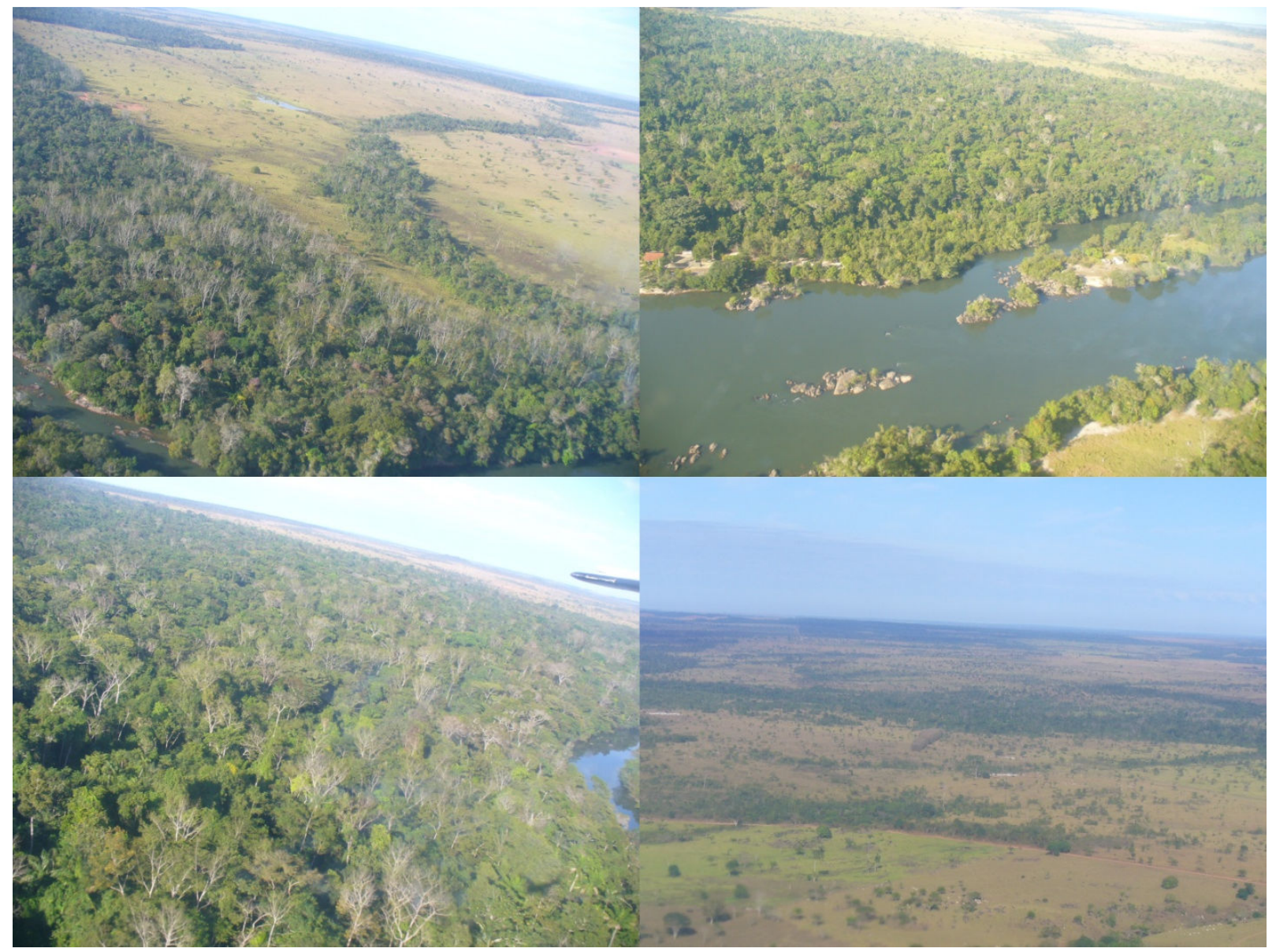

Figura 4.3 - Reconhecimento aéreo da região.

Foram realizados testes preparatórios na área do sítio arqueológico, com 8 perfis 2D antes que fossem feitas as aquisições mais sistemáticas (Figura 4.4). 


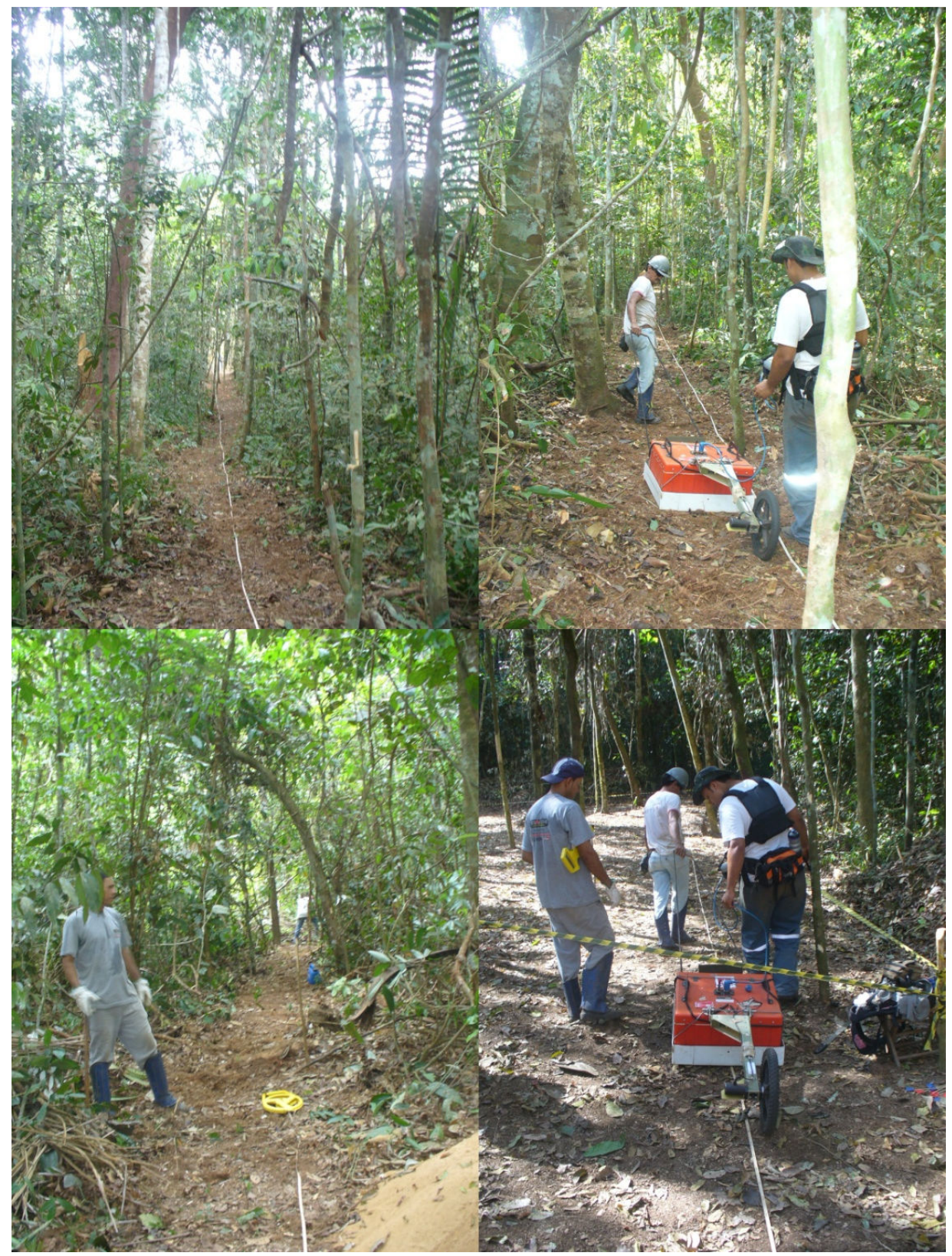

Figura 4.4 - Testes preparatórios na região dos sítios arqueológicos.

\subsubsection{AQUISIÇÃO NAS ÁREAS DE INTERESSE}

Posteriormente ao levantamento de teste preparatório, as regiões foram divididas em três áreas e foram feitos 3 grids 3D. As áreas escolhidas estão mostradas na figura 4.5 e são 


\section{Aquisição e Processamento dos Dados}

mostradas em detalhes na figura 4.6 as quais foram demarcadas no mapa de acordo com levantamento de GPS feito em campo.

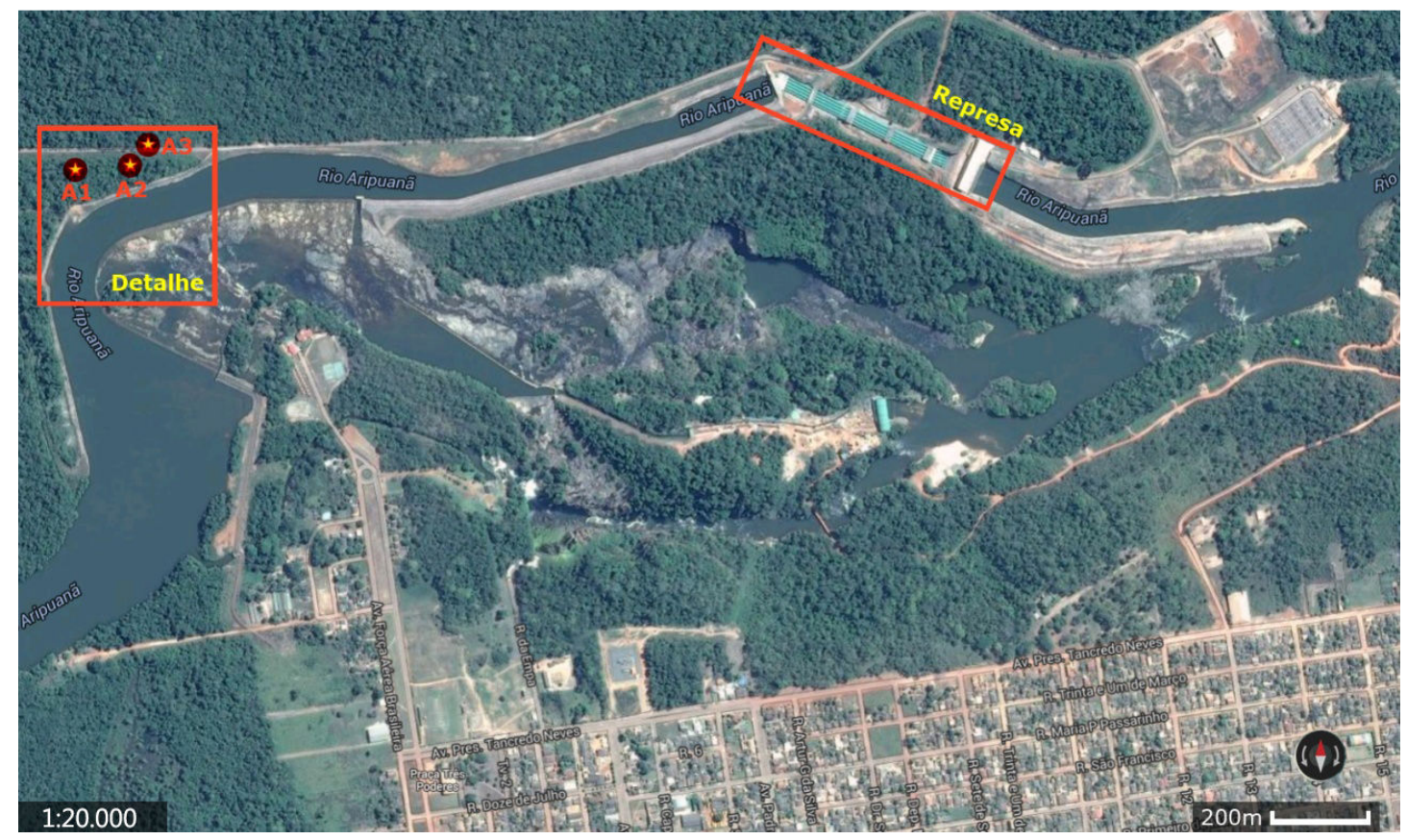

Figura 4.5 - Áreas escolhidas para aquisição dos dados. (Fonte: Google Maps, 2014) 


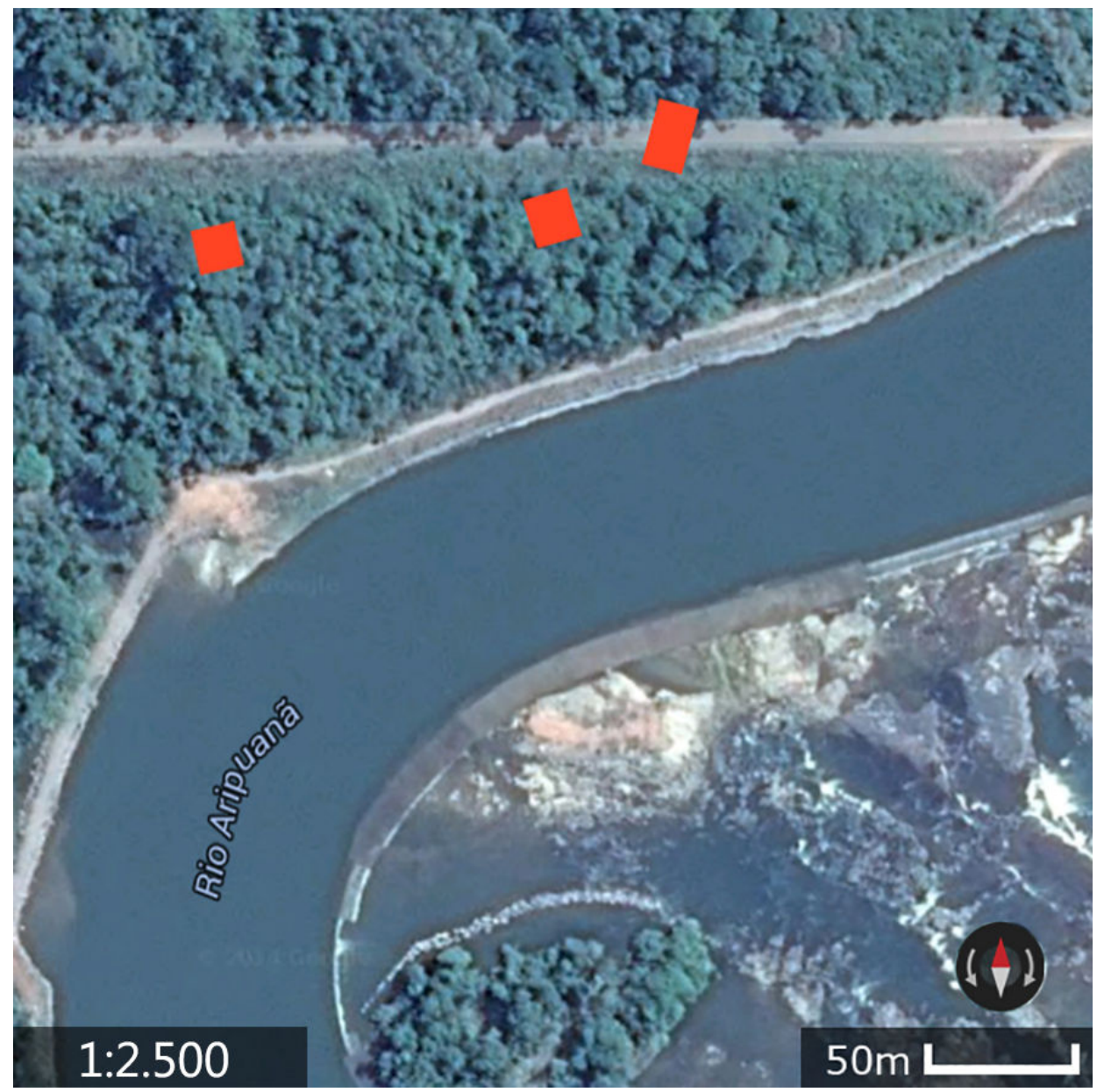

Figura 4.6 - Áreas em maior detalhe escolhidas para a aquisição dos dados. (Fonte:

Google Maps, 2014)

Foram adquiridos perfis GPR 2D e quase-3D com a antena de $200 \mathrm{MHz}$ (Figura 4.7). O levantamento quase-3D consiste em adquirir vários perfis $2 \mathrm{D}$ paralelos que são concatenados e assim gerando um cubo de dados 3D que são estudados em depths-slices. 


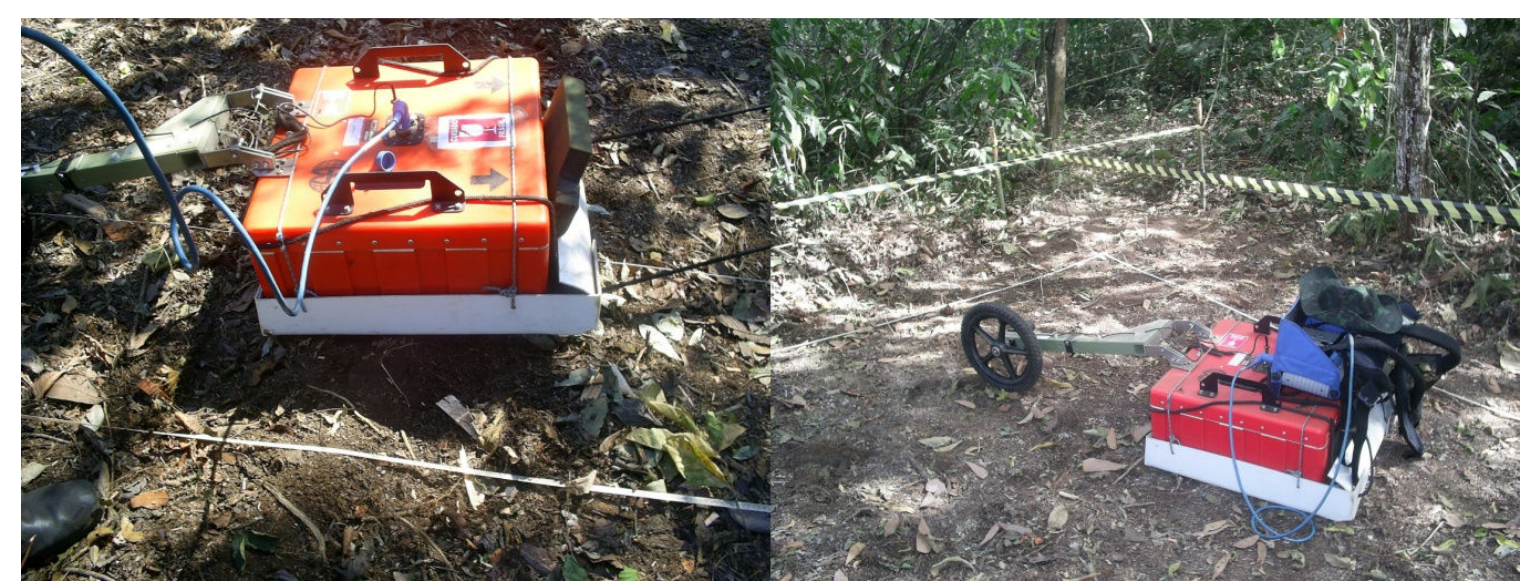

Figura 4.7 - Equipamento GPR utilizado

O modo de operação destes perfis de reflexão paralelo obtido dá-se através do afastamento da antena em valores constantes de incremento. A antena é puxada ao longo de uma linha delimitada, sendo transportada ao longo das linhas sucessoras. Vários perfis 2D sucessivos foram adquiridos para formar um mapa 3D completo (Figura 4.8).

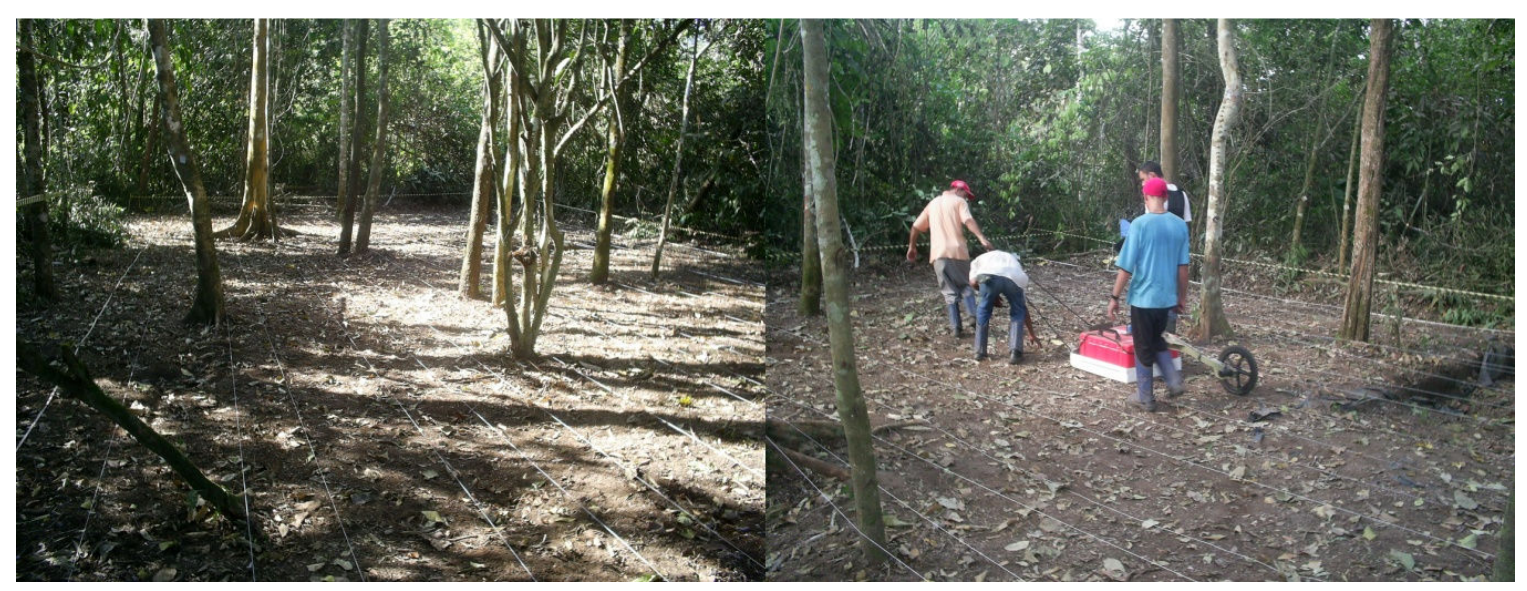

Figura 4.8 - Esquema de montagem para a aquisição dos grids 3D 


\subsection{4. ÁREA 1}

$\mathrm{Na}$ área 1 , de 10 por 15 metros, foram obtidos 31 perfis no eixo x e 21 perfis no eixo y. $\mathrm{O}$ incremento dos perfis foi de $50 \mathrm{~cm}$ em ambos os eixos (Figura 4.9).

\section{Área 1}
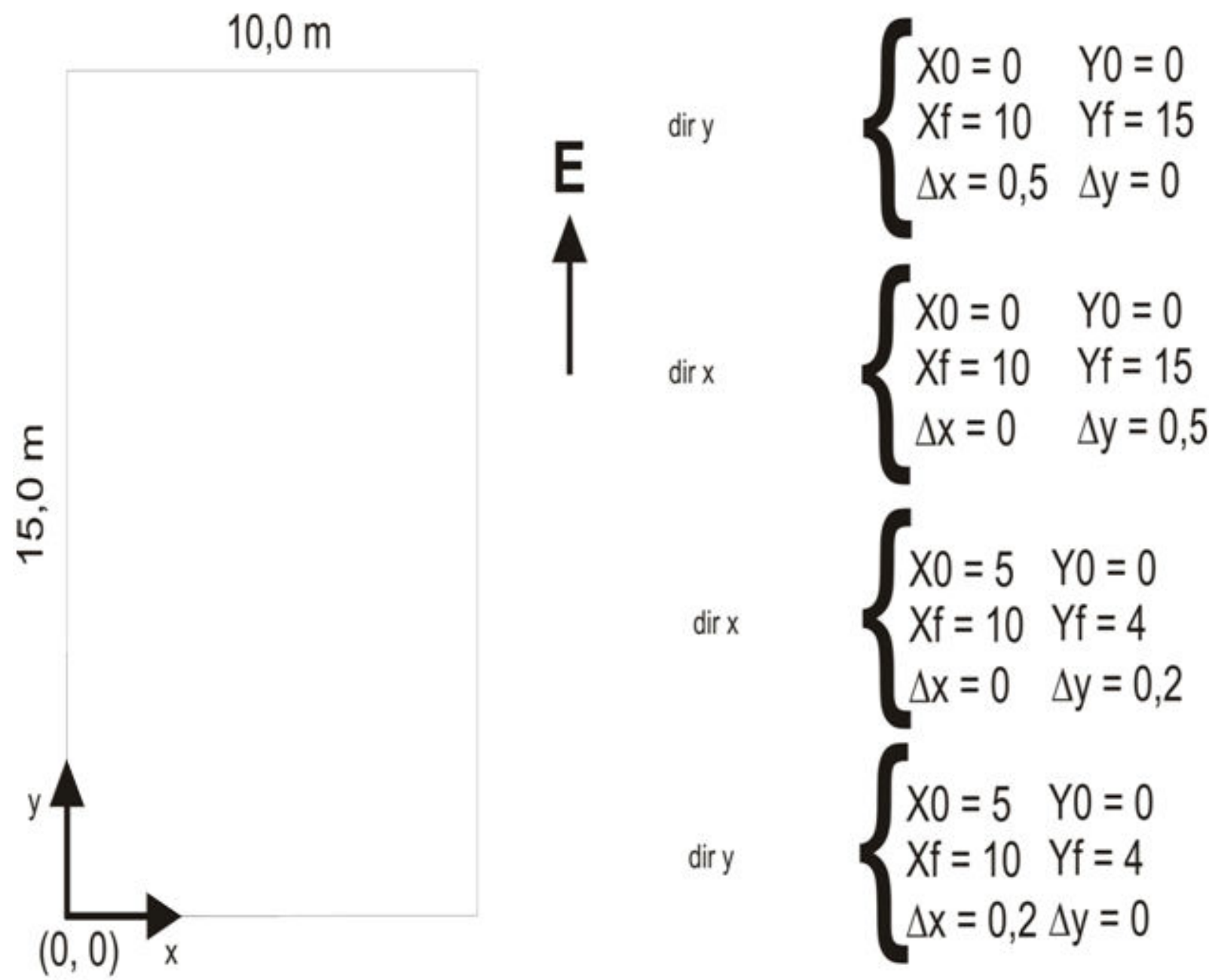

Figura 4.9- Esquema da aquisição da área 1 e seu detalhe 


\subsection{5. ÁREA 2}

$\mathrm{Na}$ área 2, de 12 por 15 metros, foram obtidos 31 perfis no eixo x e 25 perfis no eixo y. Dentro desta área, havia uma antiga escavação arqueológica. O incremento dos perfis foi de $50 \mathrm{~cm}$ em ambos os eixos (Figura 4.10).

\section{Área 2}

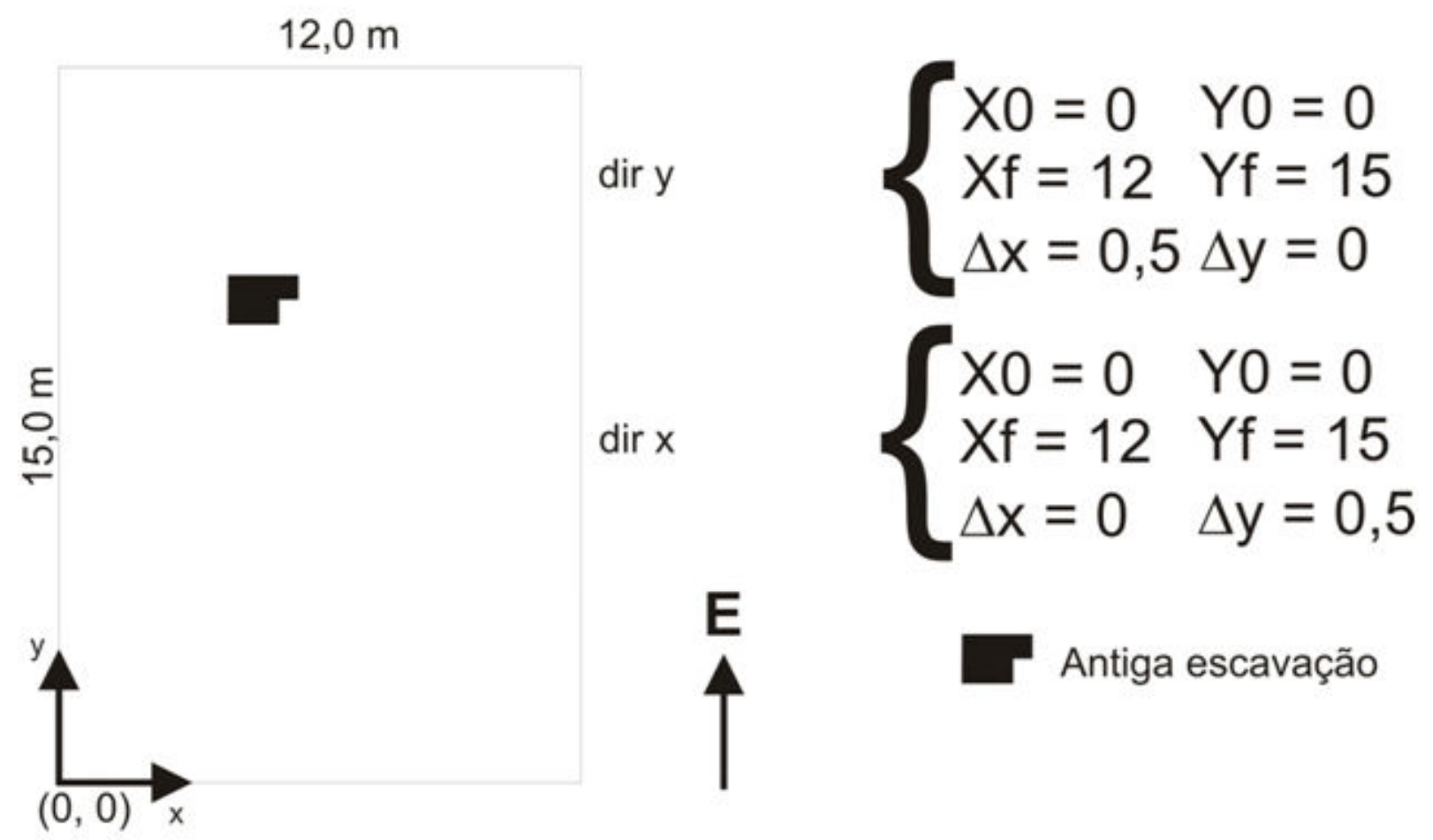

Figura 4. 10 - Esquema da aquisição da área 2 


\subsection{6. ÁREA 3}

$\mathrm{Na}$ área 3, de 24 por 10 metros, foram obtidos 21 perfis no eixo x e 49 perfís no eixo y. $\mathrm{O}$ incremento dos perfis foi de $50 \mathrm{~cm}$ em ambos os eixos (Figura 4.11).

\section{Área 3}

\section{$24,0 \mathrm{~m}$}

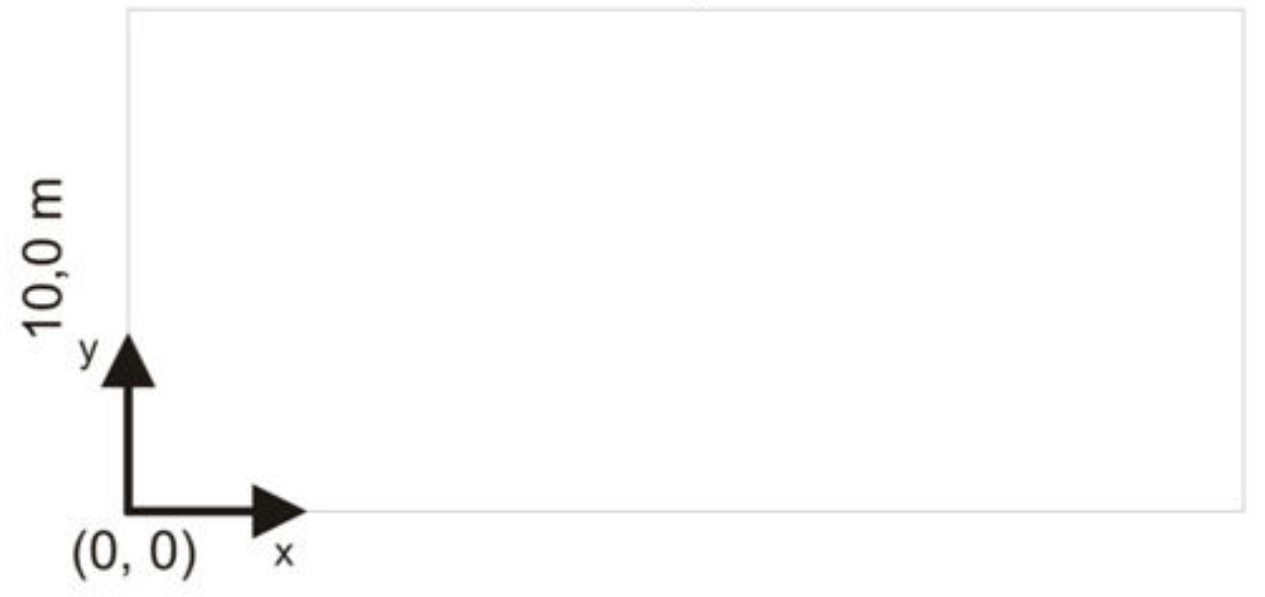

$\operatorname{dir} x$

dir y

$$
\left\{\begin{array} { l l } 
{ X 0 = 0 } & { Y 0 = 0 } \\
{ X f = 2 4 } & { Y f = 1 0 } \\
{ \Delta x = 0 } & { \Delta y = 0 , 5 }
\end{array} \quad \left\{\begin{array}{ll}
X 0=0 & Y 0=0 \\
X f=24 & Y f=10 \\
\Delta x=0,5 & \Delta y=0
\end{array}\right.\right.
$$

Figura 4. 11 - Esquema da aquisição da área 3 
Aquisição e Processamento dos Dados

\subsection{PROCESSAMENTO DOS DADOS GPR}

O processamento dos dados foi feito com o uso do software ${ }^{\circledR}$ Reflexw 7.0 dividido em duas partes, o processamento 2D e o processamento 3D.

\subsubsection{PROCESSAMENTO DOS PERFIS 2D}

Para esta primeira parte, foram utilizadas no processamento dos dados as etapas mostradas a seguir o fluxograma da figura 4.12. 


\section{Aquisição e Processamento dos Dados}

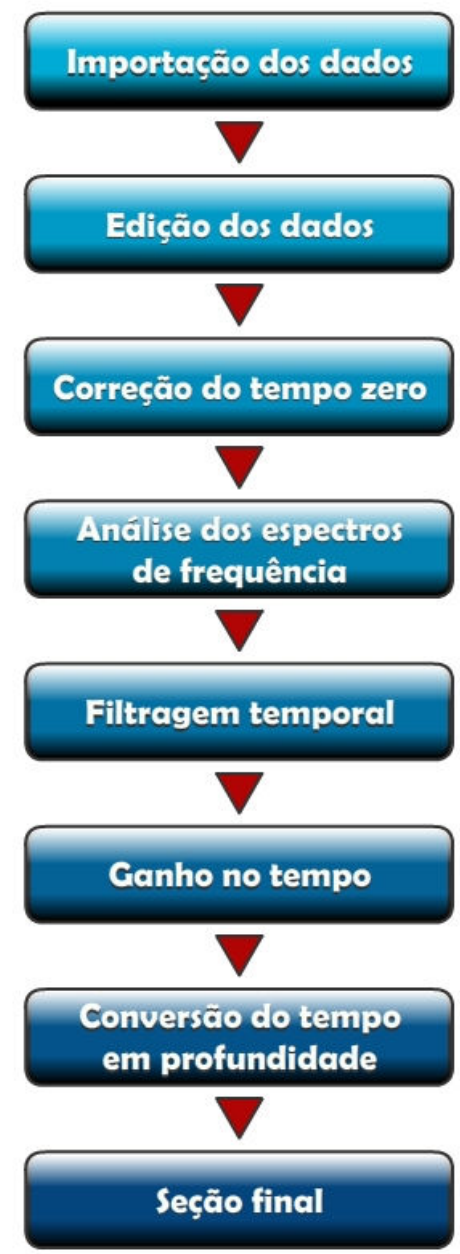

Figura 4. 12 - Fluxograma das etapas de processamento GPR.

Primeiramente, os dados adquiridos nos levantamentos de campo devem ser importados criando, assim, um projeto de leitura dentro do software.

Em sequência, na edição dos dados, são fornecidas informações como a geometria, direção e tamanho dos perfis.

$\mathrm{Na}$ correção do tempo zero, os traços foram ajustados ao tempo de chegada da onda aérea, ou seja, a primeira onda do radargrama.

Em seguida foi feita a analise do espectro de frequências, o que permite determinar, dentro de uma banda limitada de frequência, onde estão contidos os sinais de 


\section{Aquisição e Processamento dos Dados}

maior amplitude. Esta análise permite definir as frequências do filtro passa-banda, o que ajuda a eliminar ruídos de baixa e alta frequência, melhorando significativamente a relação sinal/ruído, contribuindo para facilitar a identificar os alvos.

$\mathrm{Na}$ etapa de ganho temporal, o objetivo de sua aplicação é recuperar os sinais atenuados que ocorrem devidos às perdas por espalhamentos geométricos e dispersão, relacionadas à propagação da onda até ser registrada nos receptores, sendo que foram utilizados ganhos lineares e exponenciais.

$\mathrm{Na}$ conversão dos perfis de tempo em profundidade, a velocidade utilizada foi baseada na conversão do tempo de percurso das ondas refletidas. Calcula-se esse valor utilizando-se a expressão:

$$
v=\frac{2 h}{t}
$$

Esta expressão relaciona os valores reais de profundidades dos alvos e o tempo de percurso das reflexões interpretado no radargrama, ajustando-se as curvas de velocidades aos refletores hiperbólicos. Desta forma, na conversão do tempo em profundidade dos perfis adquiridos, foi ajustada a velocidade de $0,070 \mathrm{~m} / \mathrm{ns}$.

Após o processamento dos perfis 2D, apresenta-se a seção final. Este fluxograma é aplicado a todos os perfis para serem processados sequencialmente e, posteriormente, serem concatenados formando um cubo 3D para toda a área estudada.

\subsubsection{PROCESSAMENTO 3D}

$\mathrm{Na}$ etapa de processamento 3D, também se deve seguir alguns passos para que se possa visualizar toda a área em sua profundidade (depth-slice).

Dentro do software, em um diretório específico para processamento e interpretação 3D, usa-se uma ferramenta para gerar um arquivo de dados concatenando 


\section{Aquisição e Processamento dos Dados}

diversos perfis $2 \mathrm{D}$.

Nesta etapa, é imprescindível informar os parâmetros de aquisição de dados no campo, por exemplo, se os perfis foram adquiridos de maneira equidistantes e qual a distância de incremento entre os perfis.

Após esta etapa, o cubo 3D é gerado e podem-se escolher diversas formas de perspectivas de visualizações, sendo elas em cortes ou fatias pelo eixo x, eixo y, eixo z ou, ainda, pela perspectiva da área de cima, na qual podemos descer em profundidade (depthslices). Este último é o de maior interesse, pois permite uma visualização completa do interior do subsolo, identificando, assim, os alvos de interesses arqueológicos. 


\section{CAPÍTULO 5}

\section{INTERPRETAÇÃO E RESULTADOS}

Neste capítulo serão apresentados a interpretação e os resultados dos perfis GPR obtidos com a antena blindada de $200 \mathrm{MHz}$ que apresentaram feições de interesse arqueológico ou que demonstraram ambiguidade para que fossem interpretadas. Todos os outros resultados dos perfis 2D e dos depth-slice 3D poderão ser encontrados nos anexos A, $\mathrm{B}$ e C, para cada uma das três áreas.

\section{1. ÁREA 1}

Para a área 1 foram processados 31 perfis $2 \mathrm{D}$ no eixo $\mathrm{x}$ e 21 perfis no eixo $\mathrm{y}$. Como esperado, ambos os eixos mostram os mesmos resultados. Alguns dos perfis apresentaram anomalias em formas hiperbólicas, A Figura 5.1 mostra o resultado do perfil GPR de $200 \mathrm{MHz}$ número 18 na direção y, na qual pode-se observar várias reflexões hiperbólicas. 


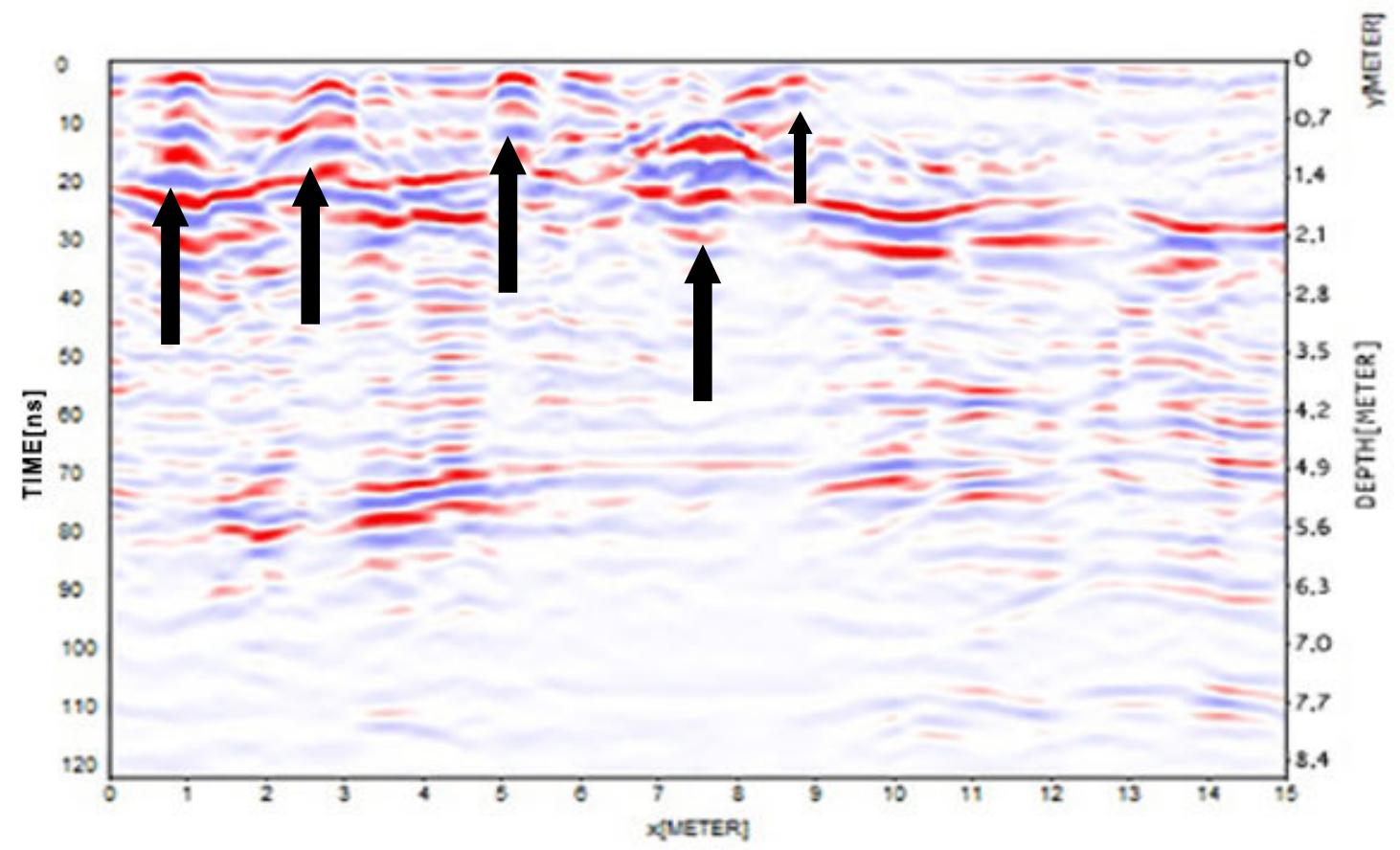

Figura 5. 1 - Perfil GPR de 200 MHz número 18 na direção y para a área 1 indicando algumas anomalias hiperbólicas em tons de vermelho, azul e branco.

Claramente, podem-se observar várias hipérboles mais próximas da superfície. Estas hipérboles, tanto quanto a mais profunda indicada, serão melhor visualizadas na perspectiva 3D em depth-slice. Porém, para que não haja dúvidas de que estas anomalias representadas possam ser algum alvo de interesse arqueológico, é oportuno usar-se o recurso da mudança na escala de cores que, por muitas vezes, auxilia na interpretação e promove melhor julgamento quanto à relevância do alvo identificado (Figura 5.2). 


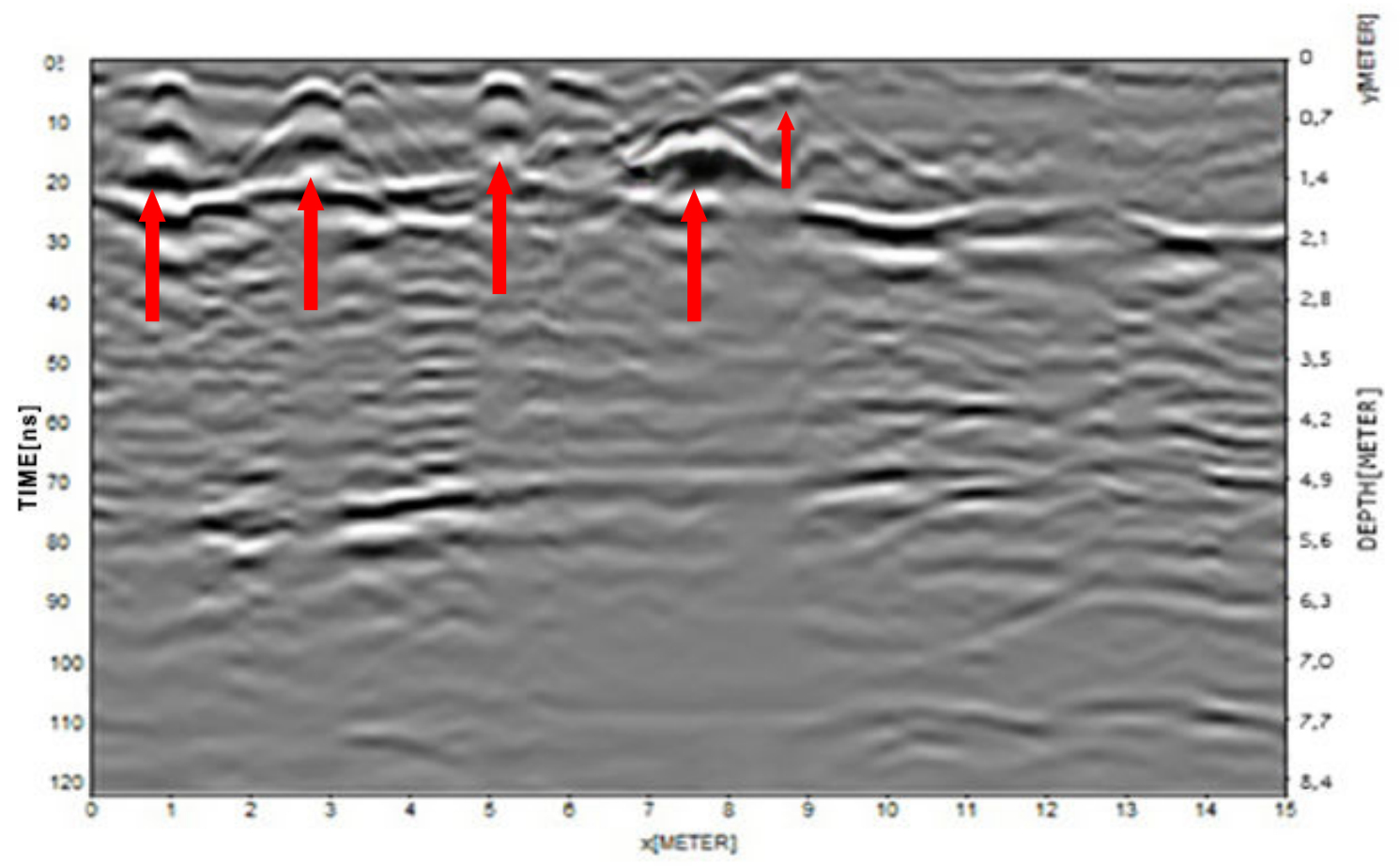

Figura 5. 2 - Perfil GPR de $200 \mathrm{MHz}$ número 18 na direção y para a área 1 indicando algumas anomalias hiperbólicas em tons de cinza.

A seguir, visualizam-se estes perfis sob outro ponto de vista, podendo assim se ter uma clara ideia de como são geradas as perspectivas em profundidade adotadas. A figura 5.3 mostra o perfil GPR de $200 \mathrm{MHz}$ número 18 na direção y, já anteriormente apresentado, dentro do cubo 3D gerado. 


\section{Interpretação e Resultados}

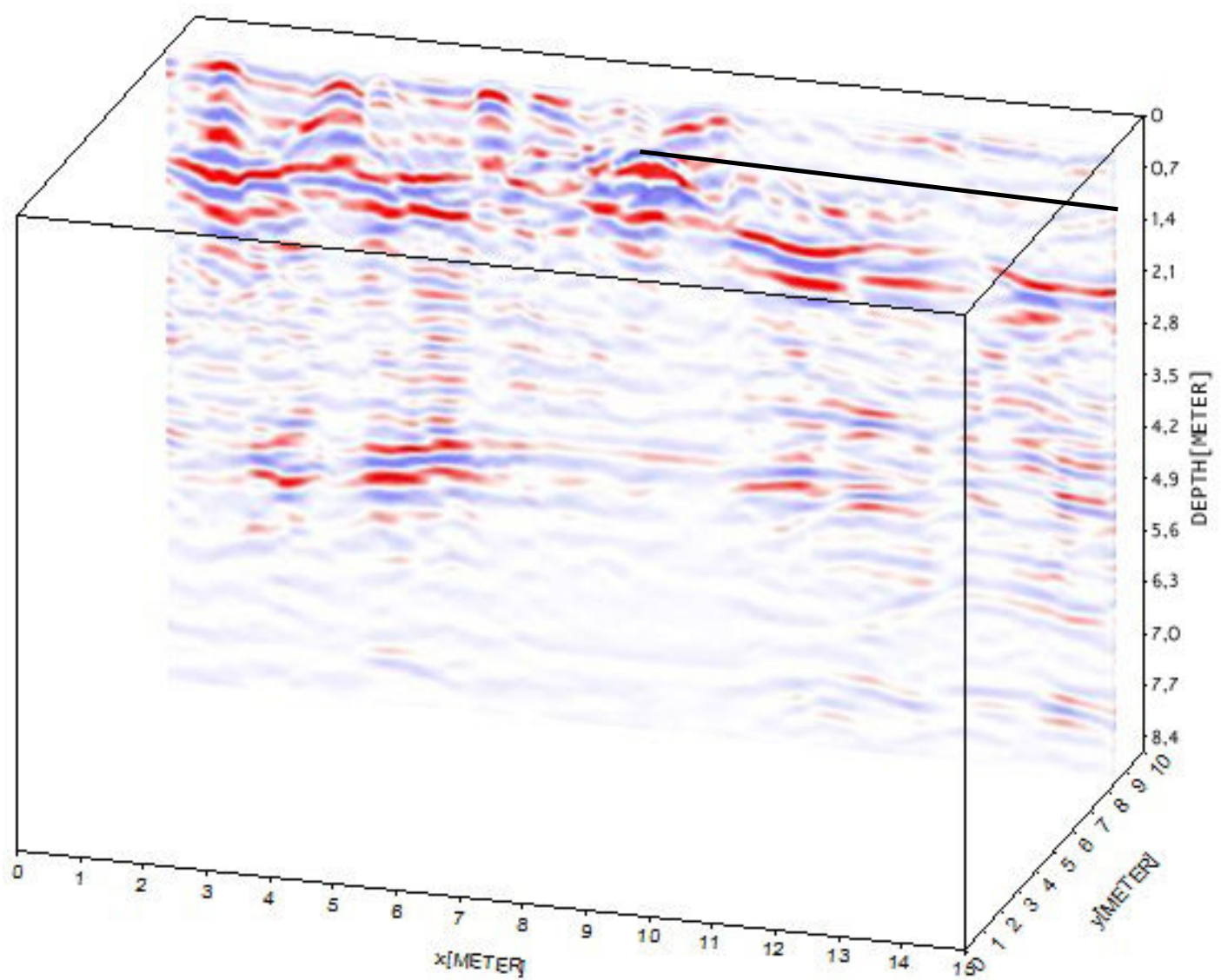

Figura 5. 3 - Perfil GPR de 200 MHz número 18 na direção y para a área 1 dentro do cubo 3D gerado.

Tendo este perfil 2D dentro do cubo gerado, fica facilitada a visualização em profundidade em depth-slice. Na figura 5.4 está contemplada a imagem na forma de depthslice gerada para a superfície, ou seja, profundidade em $0 \mathrm{~m}$. 
Interpretação e Resultados

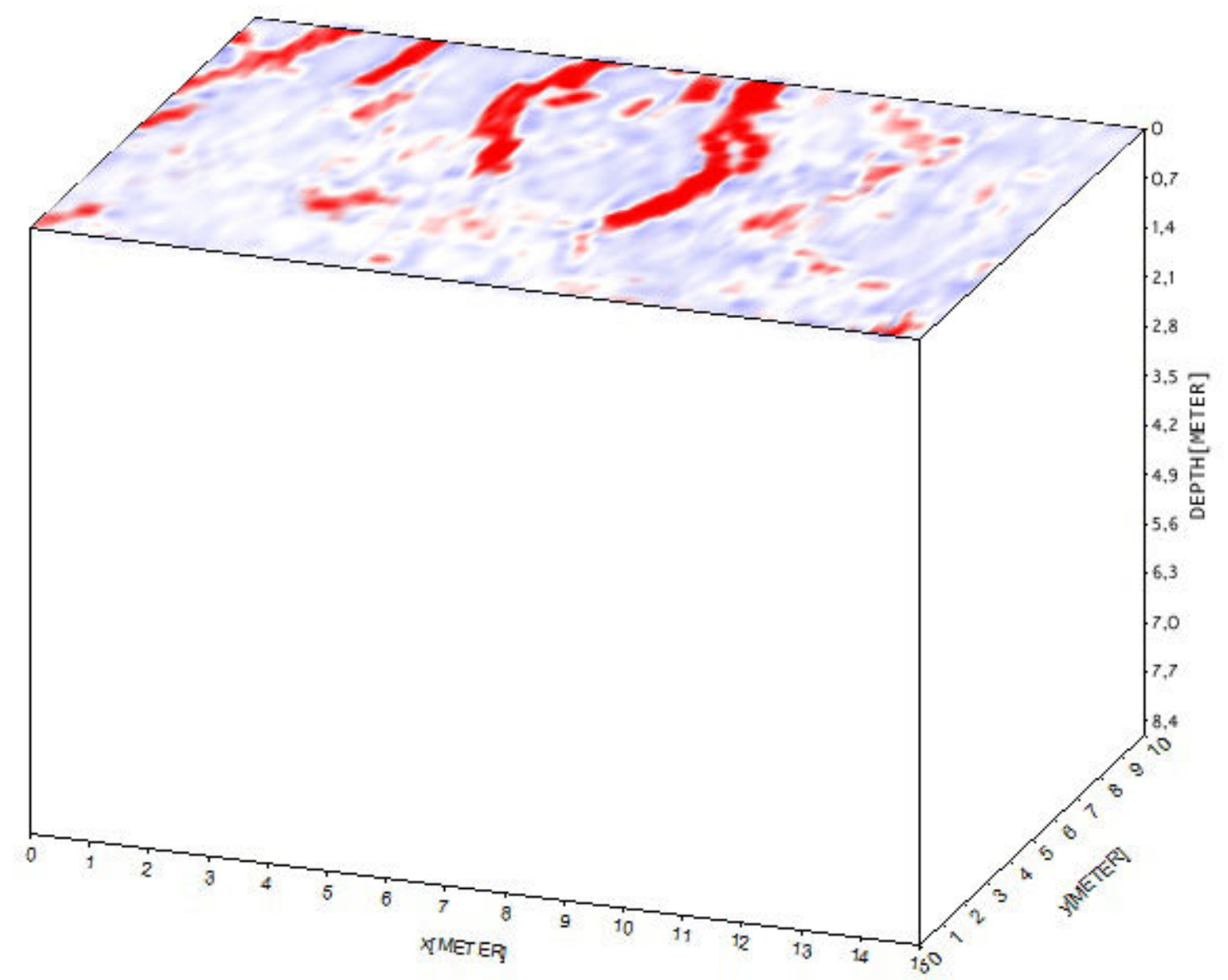

Figura 5. 4 - Depth-slice GPR de 200 MHz para a área 1 (profundidade 0 m). 


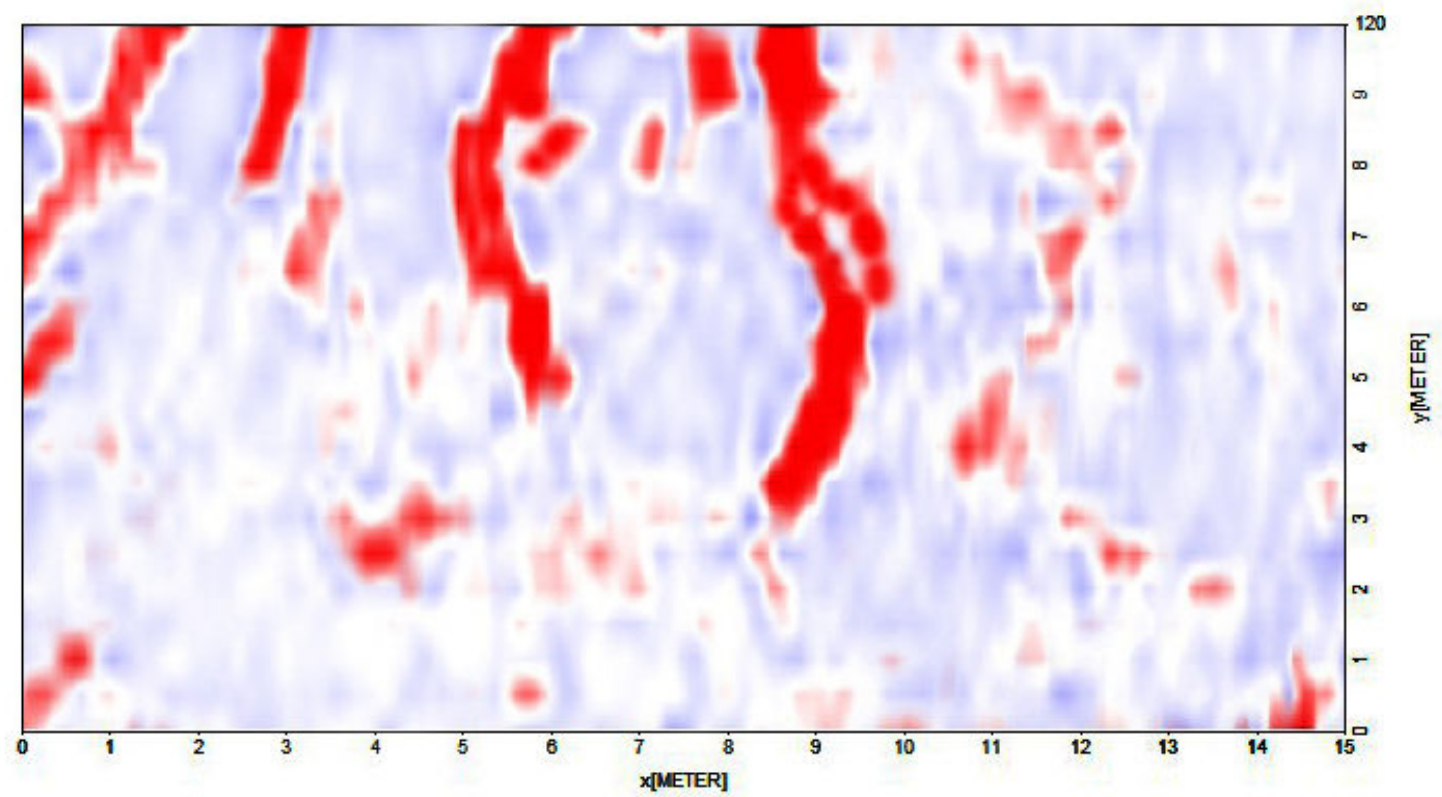

Figura 5. 5 - Depth-slice GPR de $200 \mathrm{MHz}$ para a área 1 (profundidade $0 \mathrm{~m}$ ).

A figura 5.5 mostra o depth-slice para a área 1 para a profundidade de $0 \mathrm{~m}$, no plano $\mathrm{x}-\mathrm{y}$ feições longilíneas que foram formadas através das sucessivas anomalias hiperbólicas dos perfis 2D. Este tipo de feição não representa alvo de interesse arqueológico, pois estão relacionadas com as raízes de árvores, caracterizadas por um feitio longo e próximo à superfície.

No perfil GPR 2D de $200 \mathrm{MHz}$ número 18 na direção y, mostrado anteriormente, foi identificada uma hipérbole não tão próxima à superfície. Observando-a na perspectiva em depth-slice vê-se que está próxima de 1,3 m, como mostra a figura 5.6. 


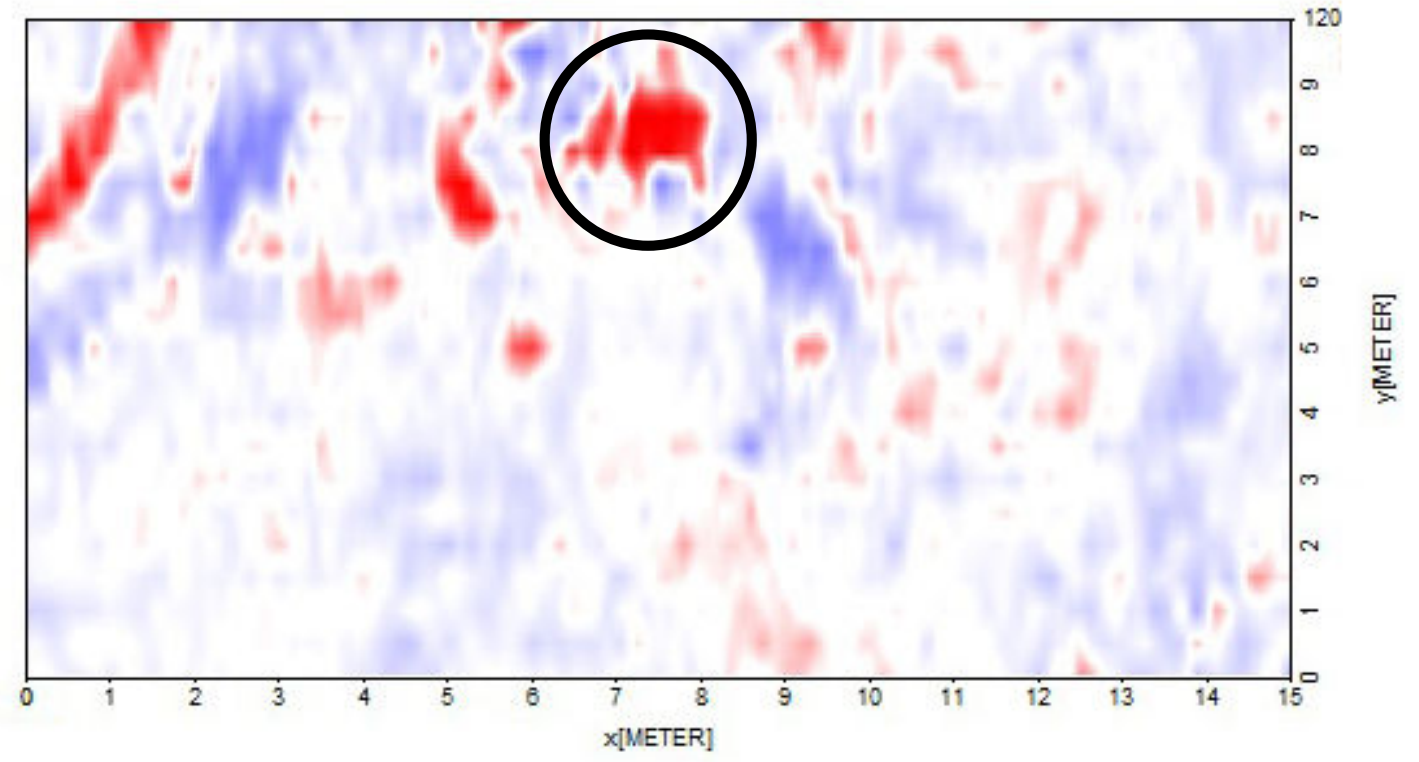

Figura 5. 6 - Depth-slice GPR de $200 \mathrm{MHz}$ para a área 1 (profundidade 1,3 m).

Nesta imagem (figura 5.6), destaca-se um objeto em forma arredondada e descontínua, ou seja, não possui conexões alongadas com seu entorno e de dimensões consideráveis. Este alvo caracteriza um alvo de interesse arqueológico e foi indicado para escavações devido ao grande potencial de ser um artefato.

Portanto, destacam-se as hipérboles de interesse arqueológico e as raízes de árvores, conforme destacadas no depth-slices. A Figura 5.7 mostra o resultado das escavações, onde foram constatadas as raízes de árvores e um bloco de rocha que se caracterizou como um bom exemplo de ambiguidade na interpretação dos perfis GPR. 


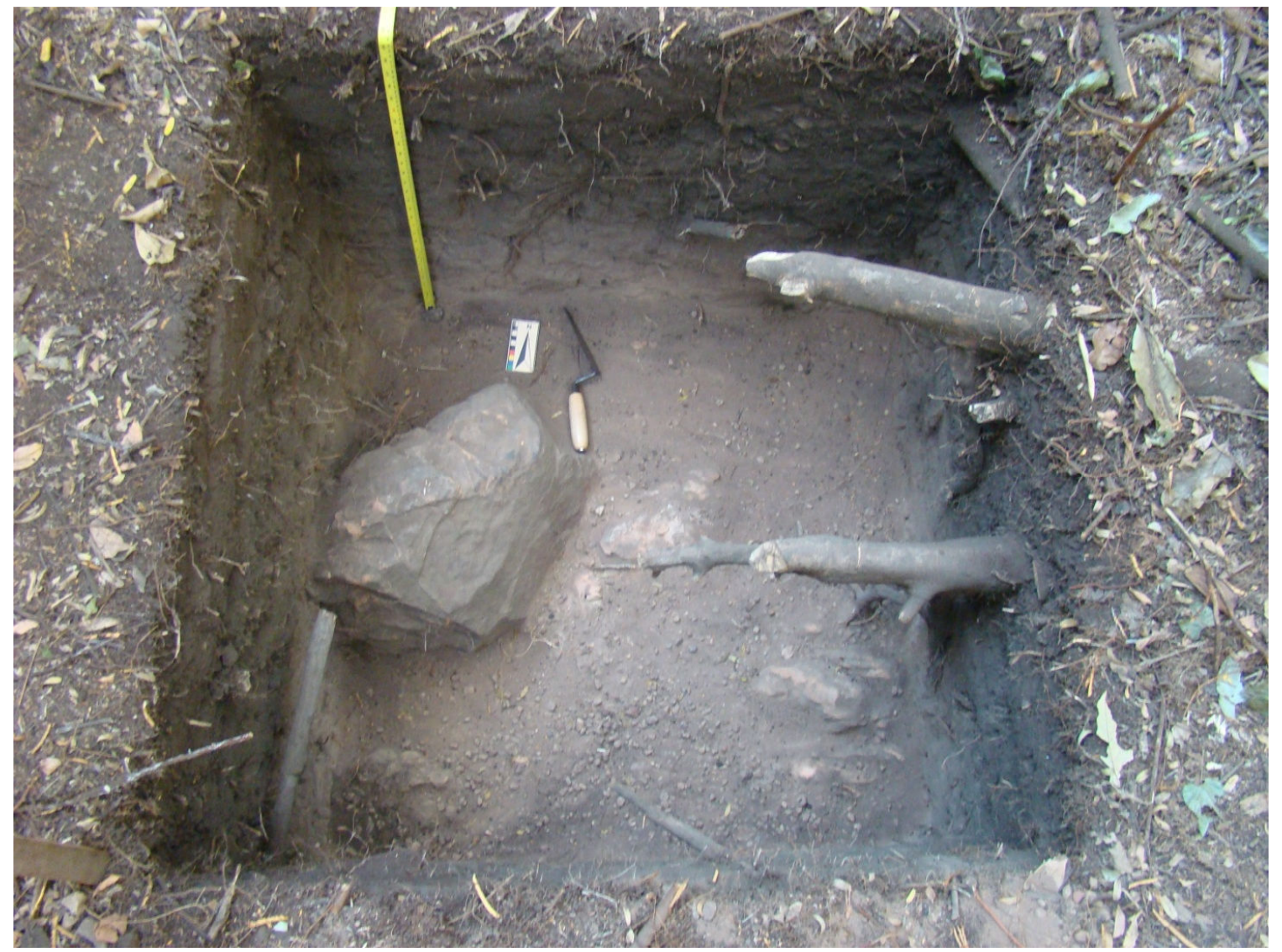

Figura 5. 7 - Resultado das escavações indicadas pelo perfil GPR número 18 na direção $\mathbf{y}$.

Este resultado em específico não é de interesse arqueológico caracterizando, assim, um exemplo de ambiguidade na interpretação GPR. O resultado apresentado tanto pelos perfis 2D quanto pelo depth-slice 3D indicaram claramente uma anomalia, porém, a relevância do resultado só pôde ser constatado após a escavação.

Ainda na mesma área, pode-se observar em outro perfil 2D de número 16 na direção y, uma hipérbole sinuosa a uma profundidade maior, como pode ser observado na figura 5.8. 


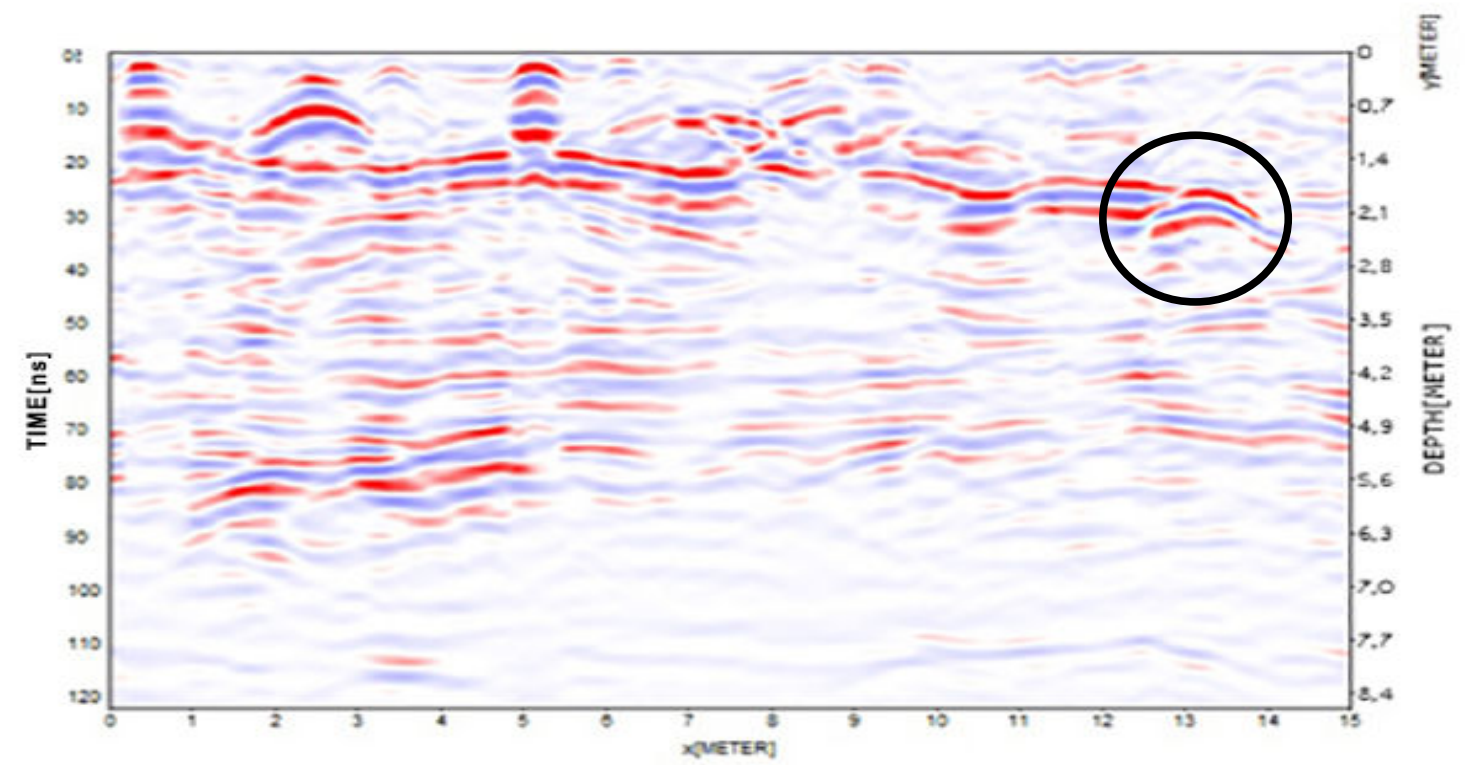

Figura 5. 8 - Perfil GPR de 200 MHz número 16 na direção y para a área 1 indicando uma anomalia hiperbólica em tons de vermelho, azul e branco.

O mesmo perfil pode ser observado em outro esquema de cores para reafirmar com destreza a presença de uma anomalia relevante (Figura 5.9). 


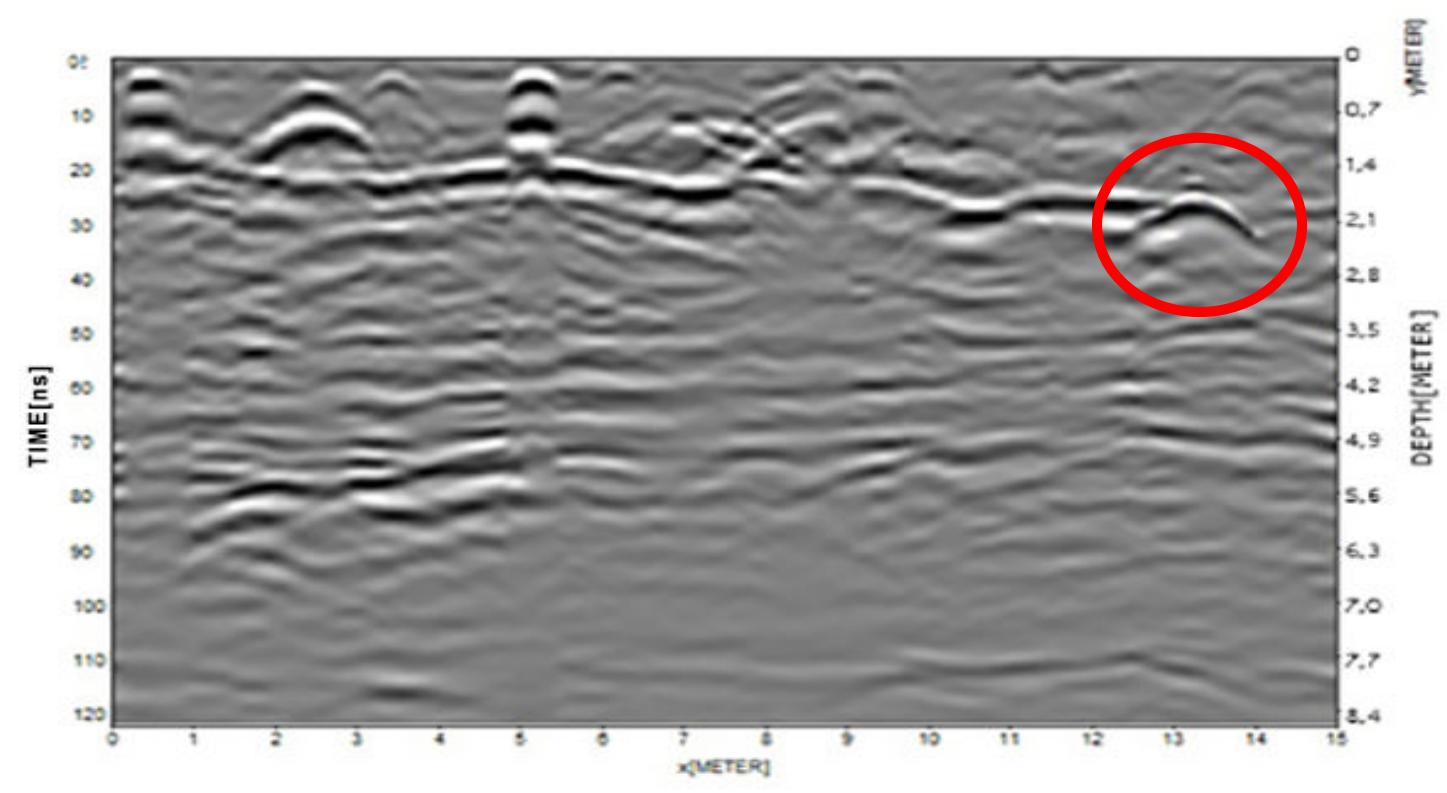

Figura 5. 9 - Perfil GPR de 200 MHz número 16 na direção y para a área 1 indicando uma anomalia hiperbólica em tons de cinza.

Para que se possa ter certeza da natureza geométrica desta anomalia vê-se o depthslice na profundidade indicada de 2,0 m como apresentado na figura 5.10.

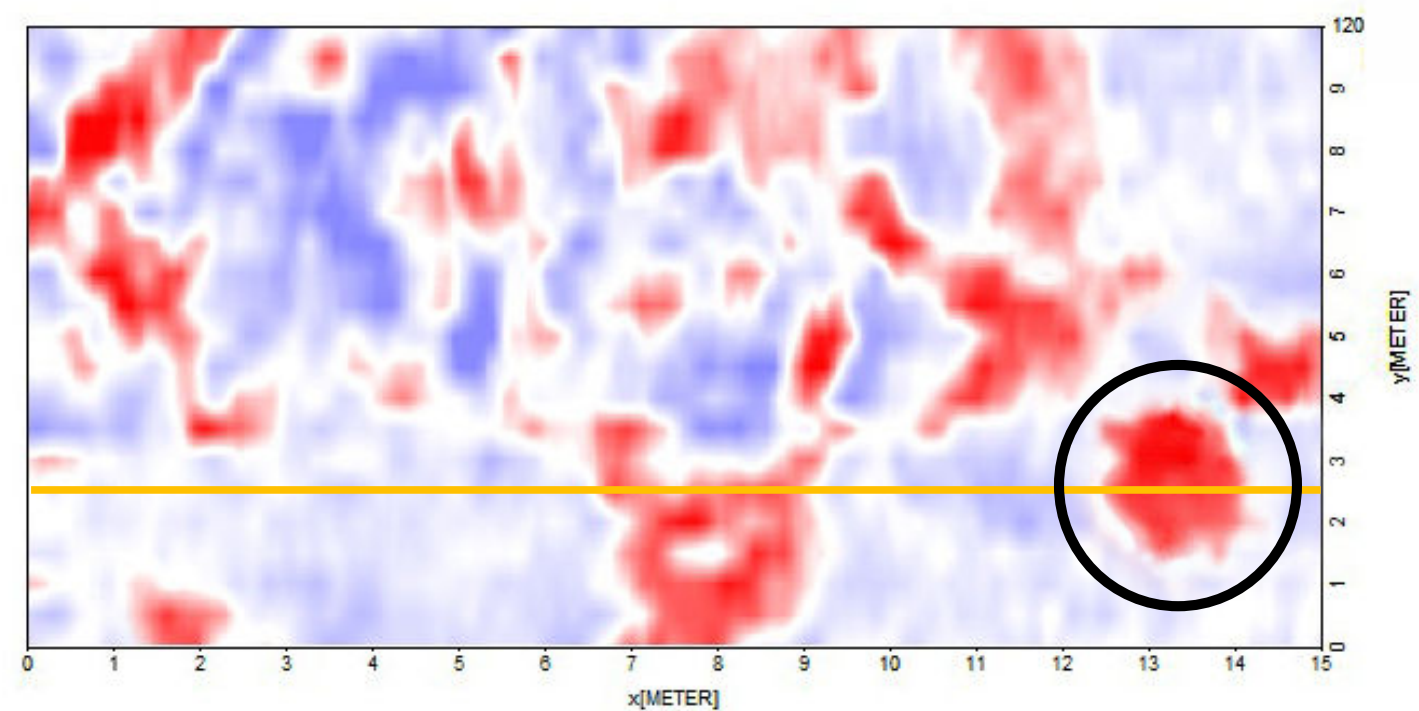

Figura 5. 10 - Depth-slice GPR de $200 \mathrm{MHz}$ para a área 1 (profundidade 2,0 m). 
Interpretação e Resultados

Neste perfil, pode-se observar um objeto circular, sem conexões longilíneas e de dimensões consideráveis. Esta anomalia caracteriza um alvo de interesse arqueológico e foi indicado para escavações. A linha em amarelo representa o perfil 2D mostrado nas figuras 5.8 e 5.9 .

Como resultado das escavações, foi encontrado o objeto mostrado na figura 5.11.

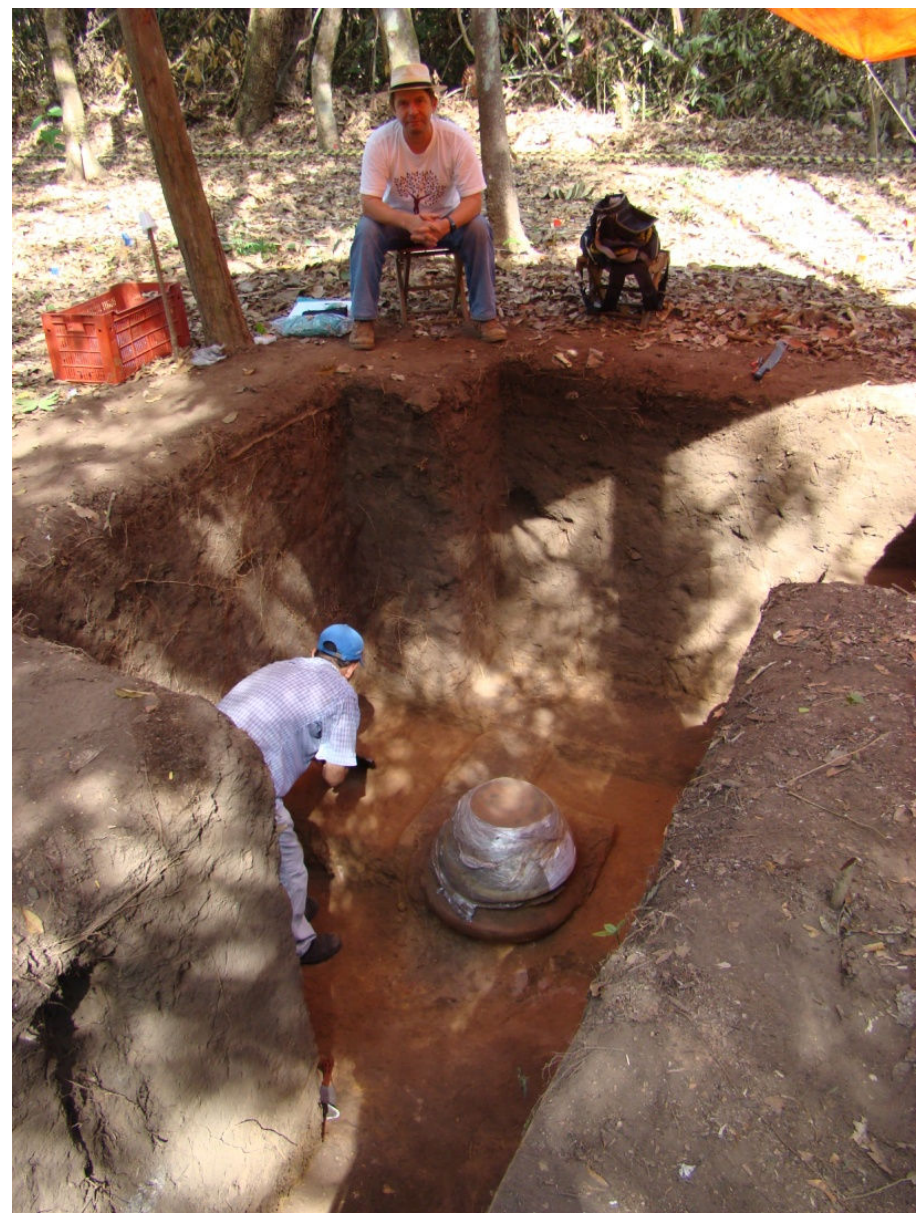

Figura 5.11 - Urna funerária encontrada como resultado indicada pelo perfil GPR número 16 na direção y. 
Esta urna funerária indígena foi encontrada no local o qual havia apresentado uma anomalia nos perfis GPR. Esta urna foi encaminhada para os órgãos competentes para datação e análises.

Todos os outros resultados dos perfis 2D e dos depth-slice 3D estão apresentados no anexo A.

\section{2. ÁREA 2}

$\mathrm{Na}$ área dois foram adquiridos 31 perfis no eixo x e 25 perfis no eixo y. Aqui são apresentados os resultados do processamento no eixo y.

Assim como já apresentado na área 1, foram processados sequencialmente os perfis 2D e gerado o cubo 3D. Na figura 5.12 observa-se um perfil GPR de $200 \mathrm{MHz}$ número 6 na direção y com a presença de algumas anomalias (hipérboles) que aparecem próximas à superfície. É possível também notar um gênero distinto de anomalia. Observase uma forma reta com linhas bem delimitadas. Trata-se de um antigo local de escavação onde foi encontrado um artefato arqueológico, o que só se faz aumentar as possibilidades de se mapear outros alvos que possam estar próximos a esta antiga zona já explorada. 


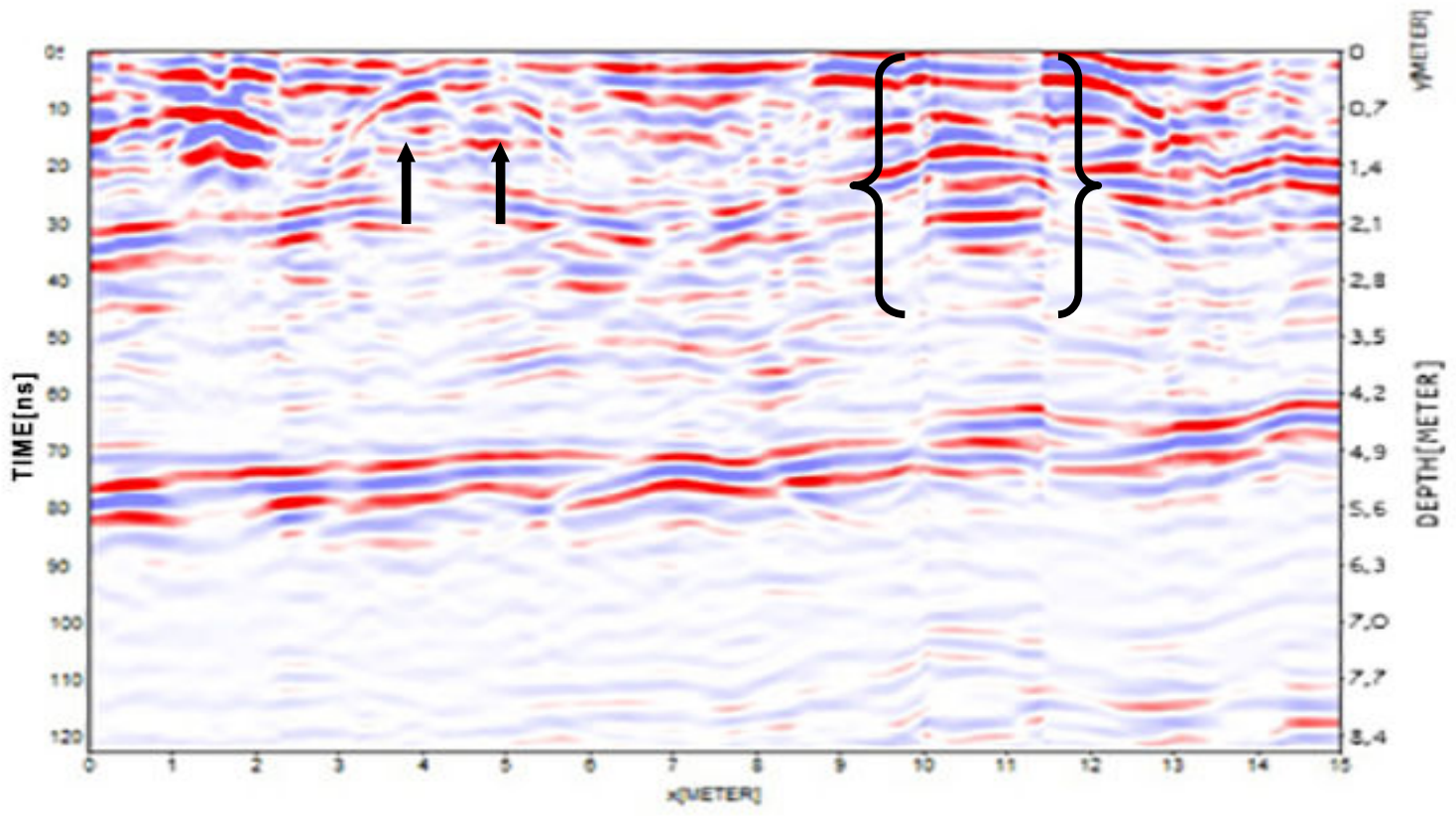

Figura 5. 12 - Perfil GPR de 200 MHz número 6 na direção y para a área 2 indicando uma anomalias hiperbólicas e uma delimitação de uma antiga escavação em tons de vermelho, azul e branco.

Para que se possa observar com clareza a delimitação longitudinal da antiga escavação, observar-se-á o mesmo perfil com a escala de cinzas (figura 5.13). 


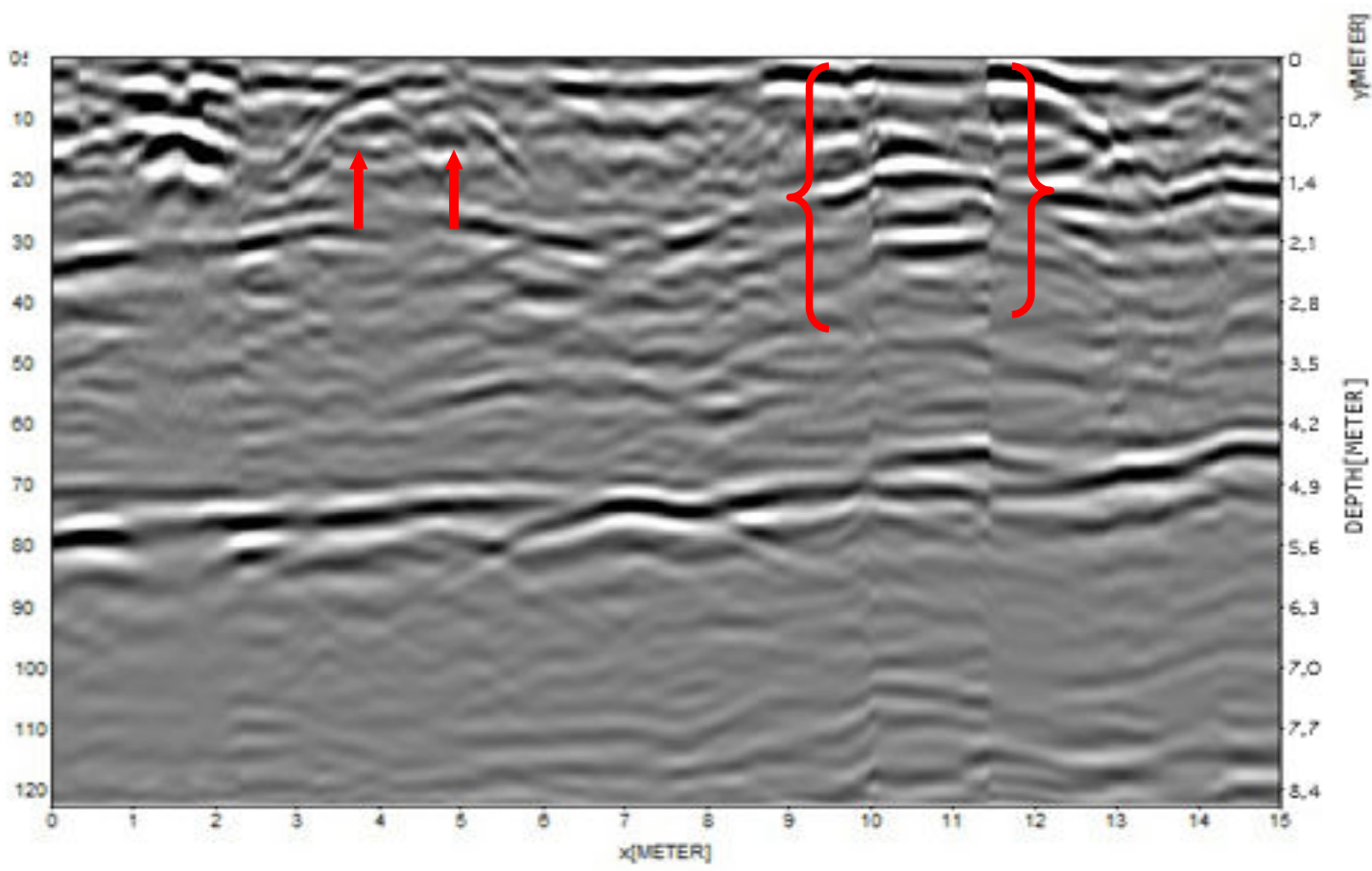

Figura 5. 13 - Perfil GPR de 200 MHz número 6 na direção y para a área 2 indicando uma anomalias hiperbólicas e uma delimitação de uma antiga escavação em tons de cinza.

Nas figuras 5.12 e 5.13 também é possível observar um camada litológica bastante marcante. Por ser um aspecto contínuo, que se apresenta ao longo de todo o perfil e também se mostrou presente em todos os perfis 2D (que poderão ser observados no Anexo B), pode estar relacionada a geologia local, nível d'água ou, ainda, a presença de terra-preta que constitui interesse arqueológico.

O depth-slice 3D foi gerado a fim de se visualizar estas feições. Pode-se observálas na figura 5.14 . 


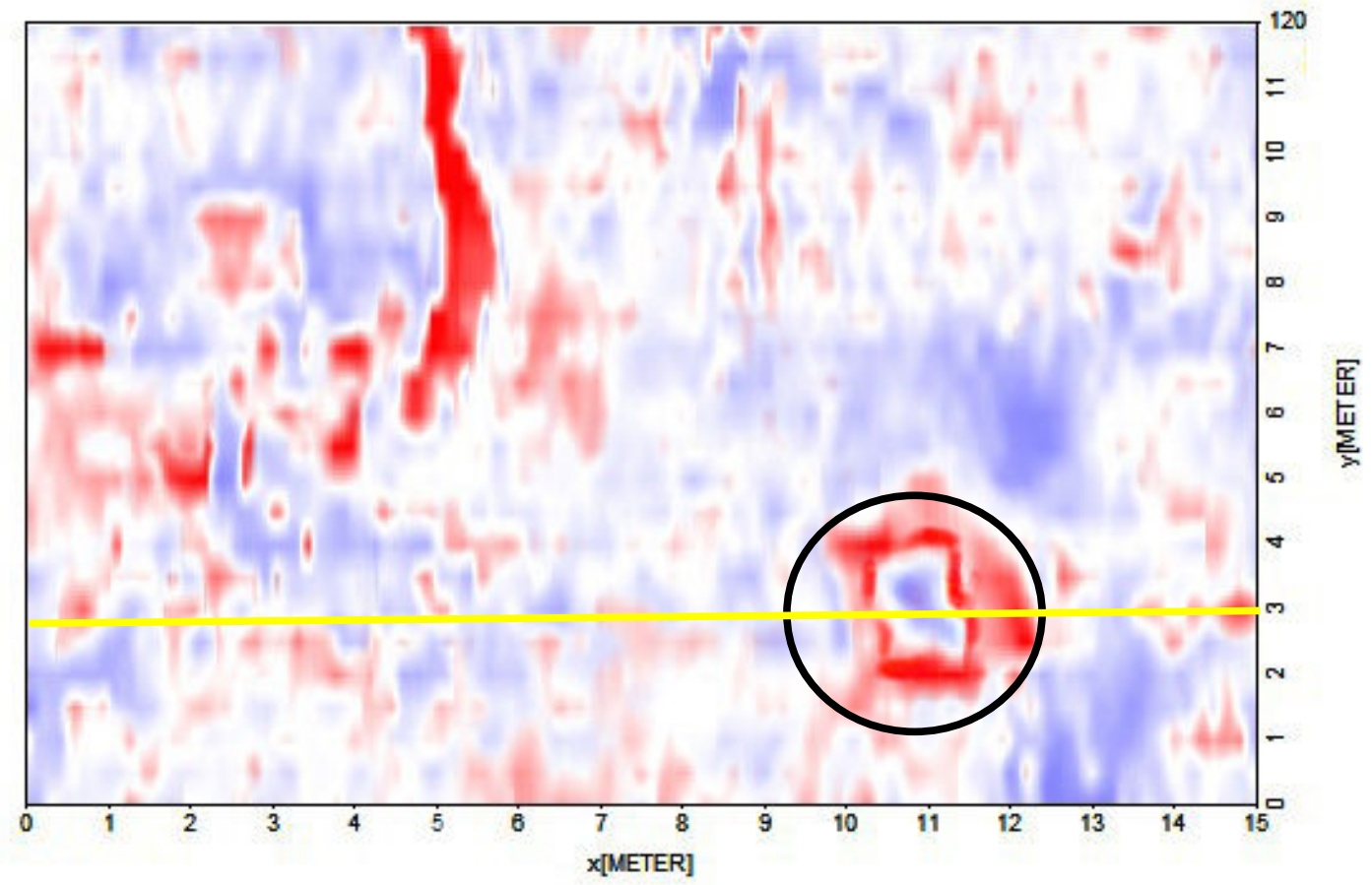

Figura 5. 14 - Depth-slice GPR de 200 MHz para a área 2 (profundidade 0 m).

Com clareza, é observada uma forma quadrangular onde foi o local da antiga escavação. A linha amarela indica a perfil 2D mostrados nas figuras 5.12 e 5.13. Também é vista uma fisionomia alongada e contínua que se mostrou presente na mesma direção em vários dos perfis $2 \mathrm{D}$ (Anexo $\mathrm{B}$ ). Isto representa uma raiz de árvore na qual, para que não houvesse qualquer dúvida, foi escavada. O resultado da escavação é visto na figura 5.15. 


\section{Interpretação e Resultados}

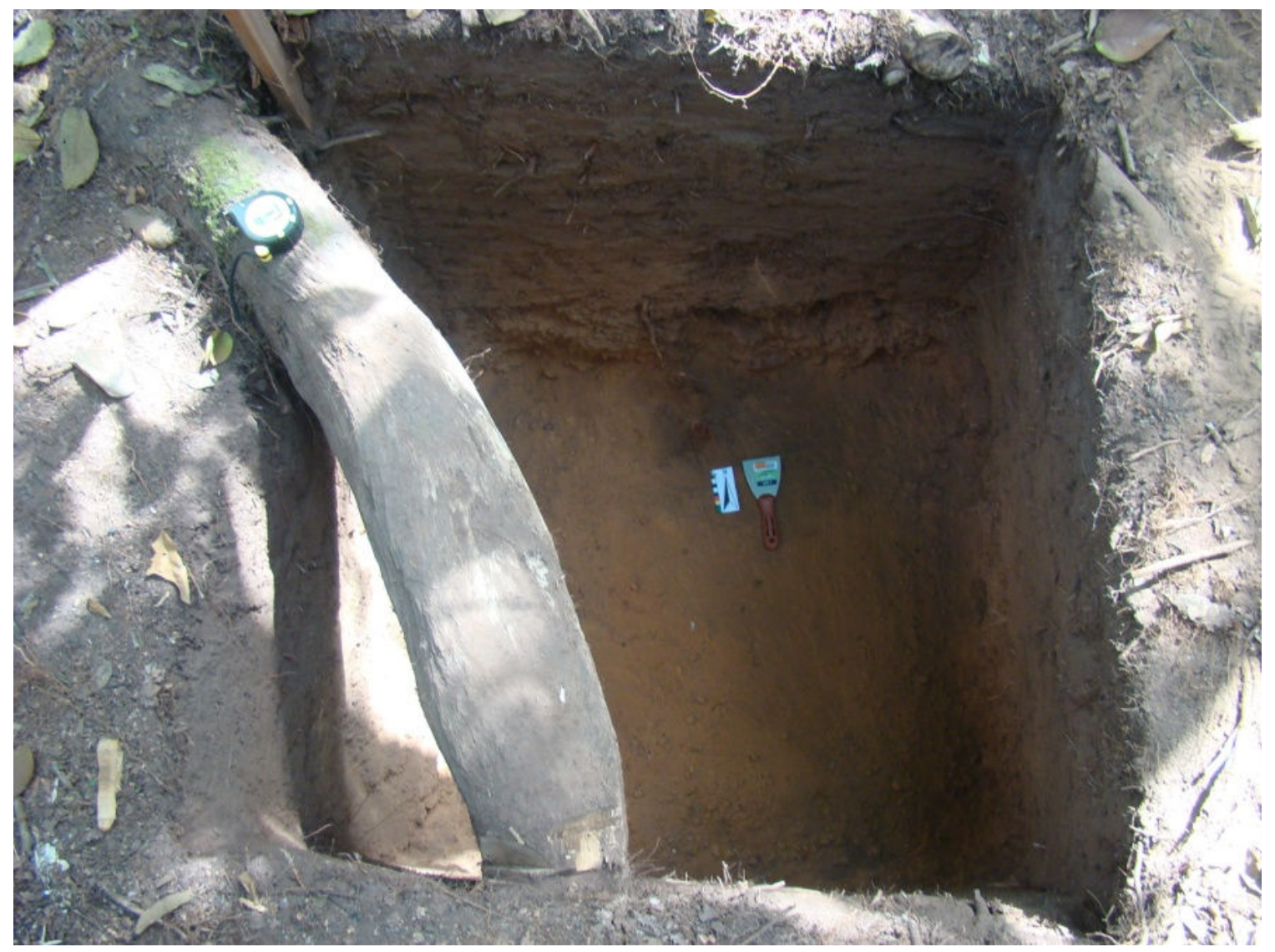

Figura 5. 15 - Raiz de árvore próxima à superfície indicada no depth-slice 3D.

Na figura 5.16 observa-se no perfil GPR 2D número 4 na direção y duas anomalias próximas, porém, com diferentes profundidades. 


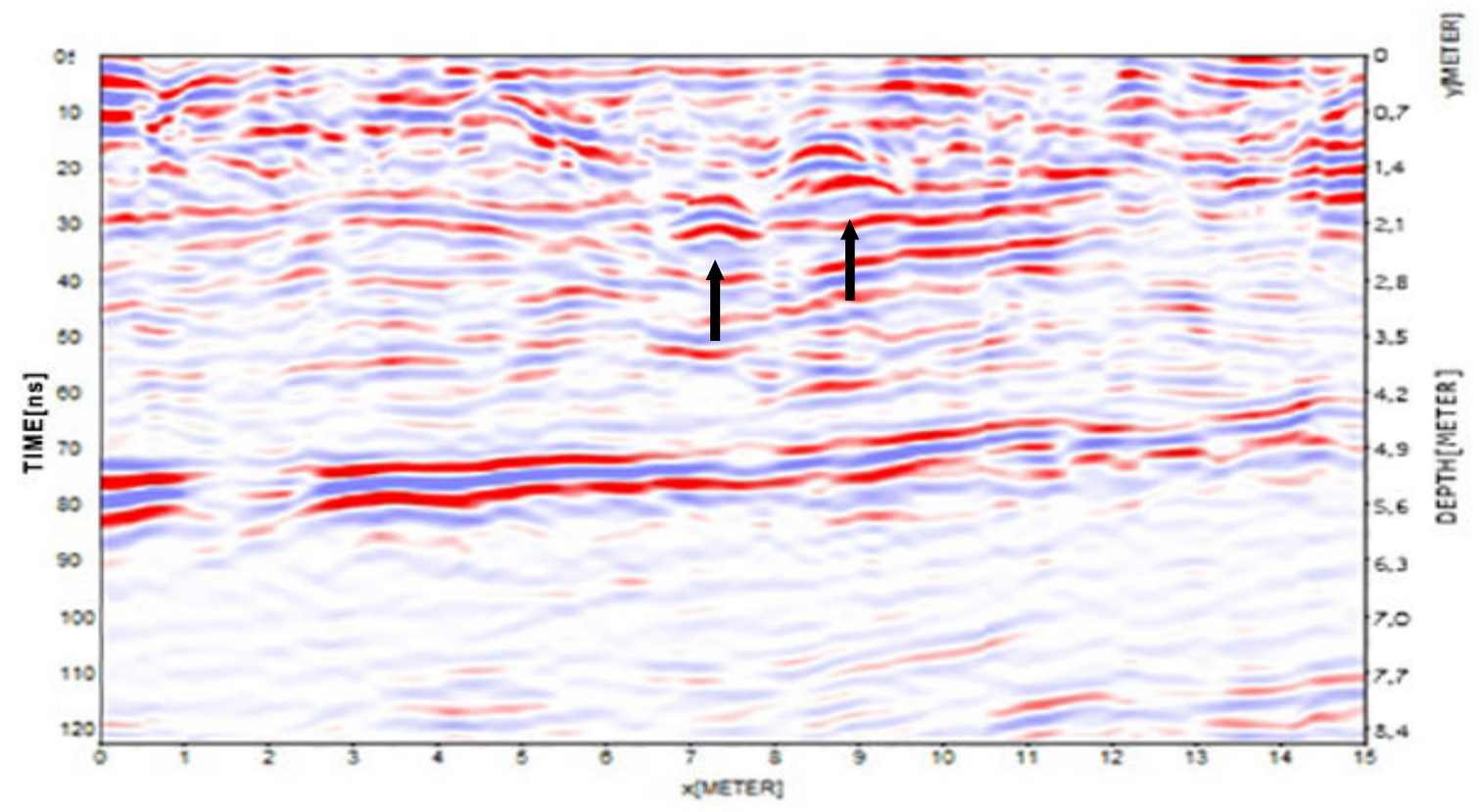

Figura 5. 16 - Perfil GPR de $200 \mathrm{MHz}$ número 4 na direção y para a área 2 indicando duas anomalias hiperbólicas em tons de vermelho, azul e branco.

Para uma observação mais minuciosa, observar-se-á o mesmo perfil GPR 2D número 4 na direção y em escala de cinza na figura 5.17 nas quais as feições hiperbólicas ficaram mais nítidas. 


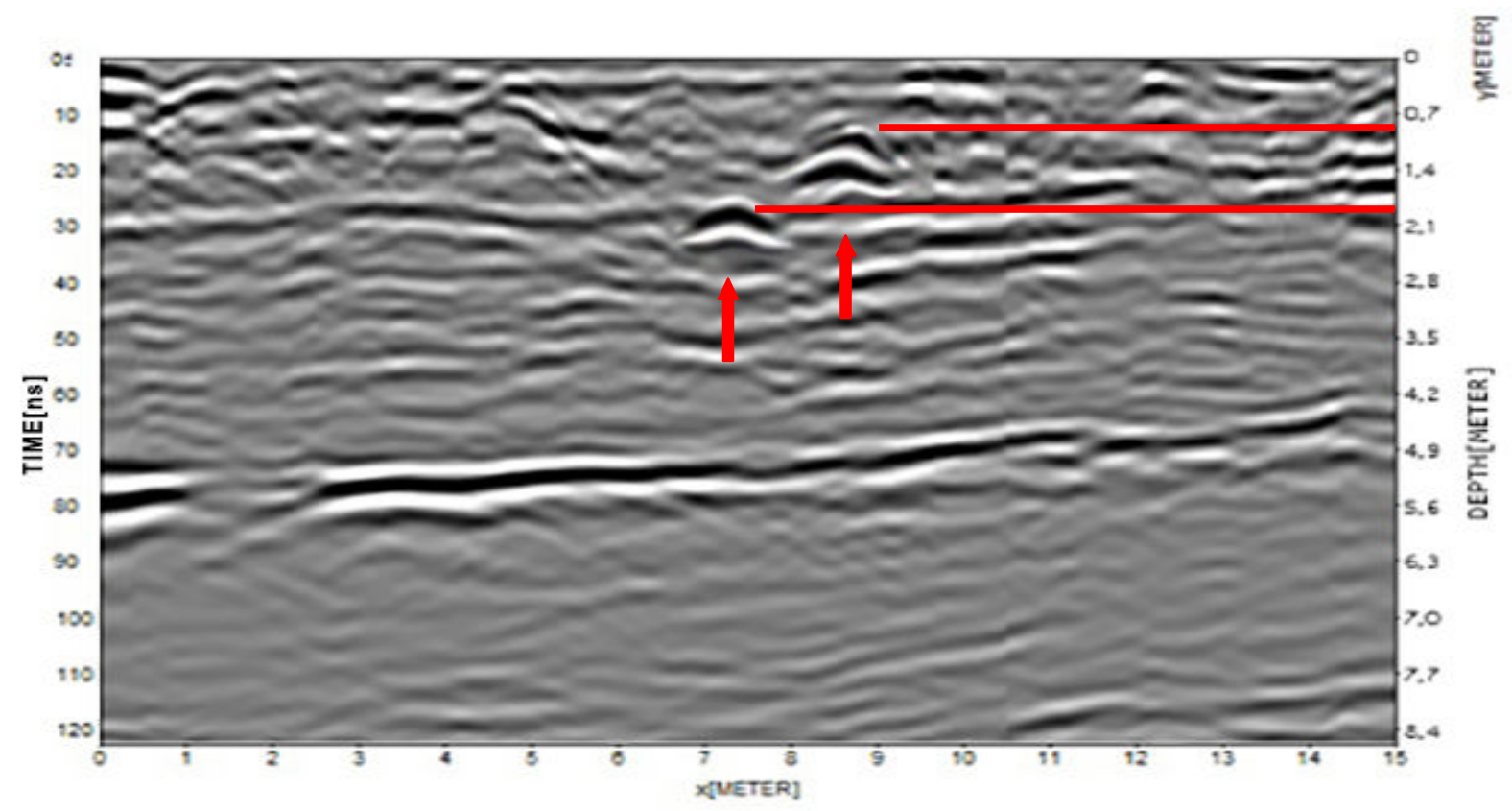

Figura 5. 17 - Perfil GPR de 200 MHz número 4 na direção y para a área 2 indicando duas anomalias hiperbólicas em tons de cinza.

Estas duas anomalias aparecem no mesmo perfil 2D, porém, como apresentam-se em profundidades diferentes, a imagem em depth-slice será apresentada em duas etapas. A primeira, mais rasa, foi observada em profundidade de $0,9 \mathrm{~m}$, mostrada na figura 5.18 . 


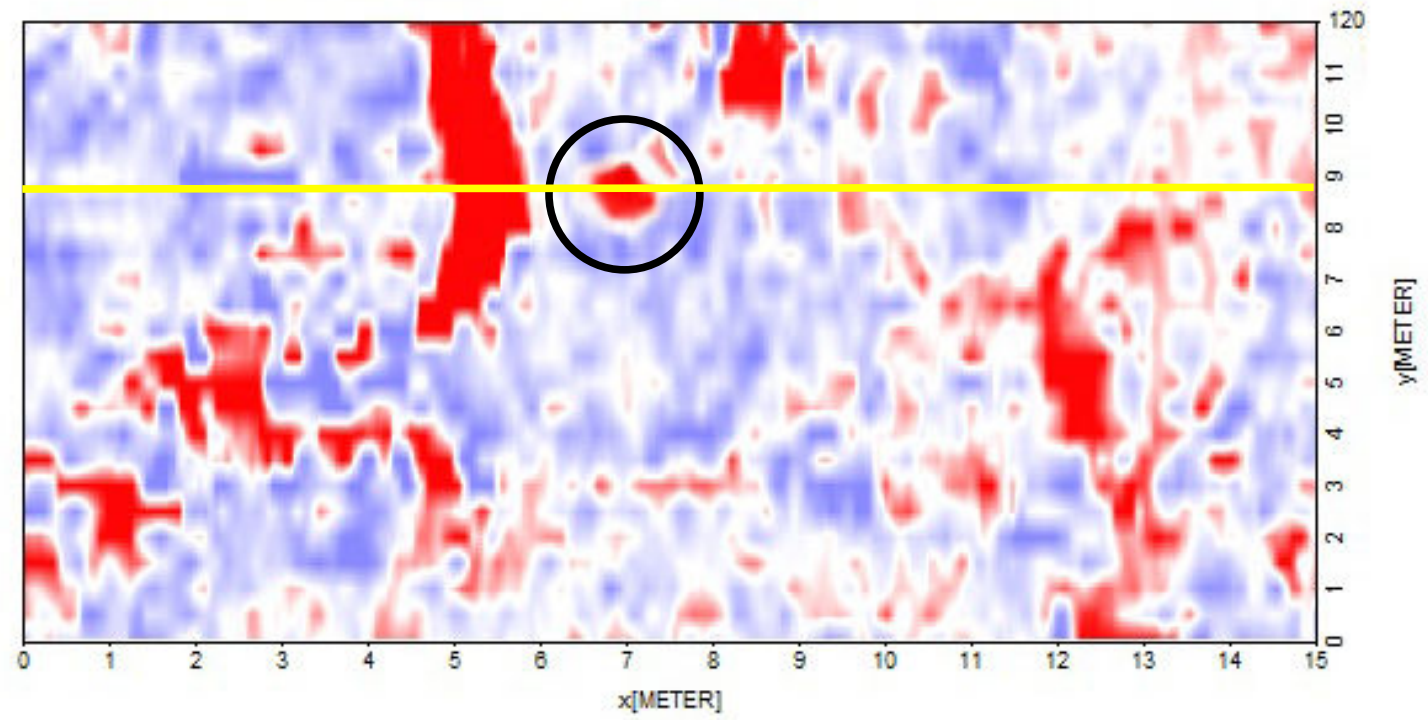

Figura 5. 18 - Depth-slice GPR de 200 MHz para a área 2 (profundidade 0,9 m).

Observa-se um alvo em formato circular e desconectado com as demais feições. Este alvo é o mesmo que aparece como uma anomalia hiperbólica no perfil 2D indicado na figuras 5.16 e 5.17 e aqui representado pela linha amarela. Este alvo constitui um grande potencial arqueológico.

Ainda advindo do mesmo perfil GPR 2D de $200 \mathrm{MHz}$ número 4 na direção y já indicado, a outra anomalia apresentada em maior profundidade pode ser observada no depth-slice 3D da figura 5.19. 


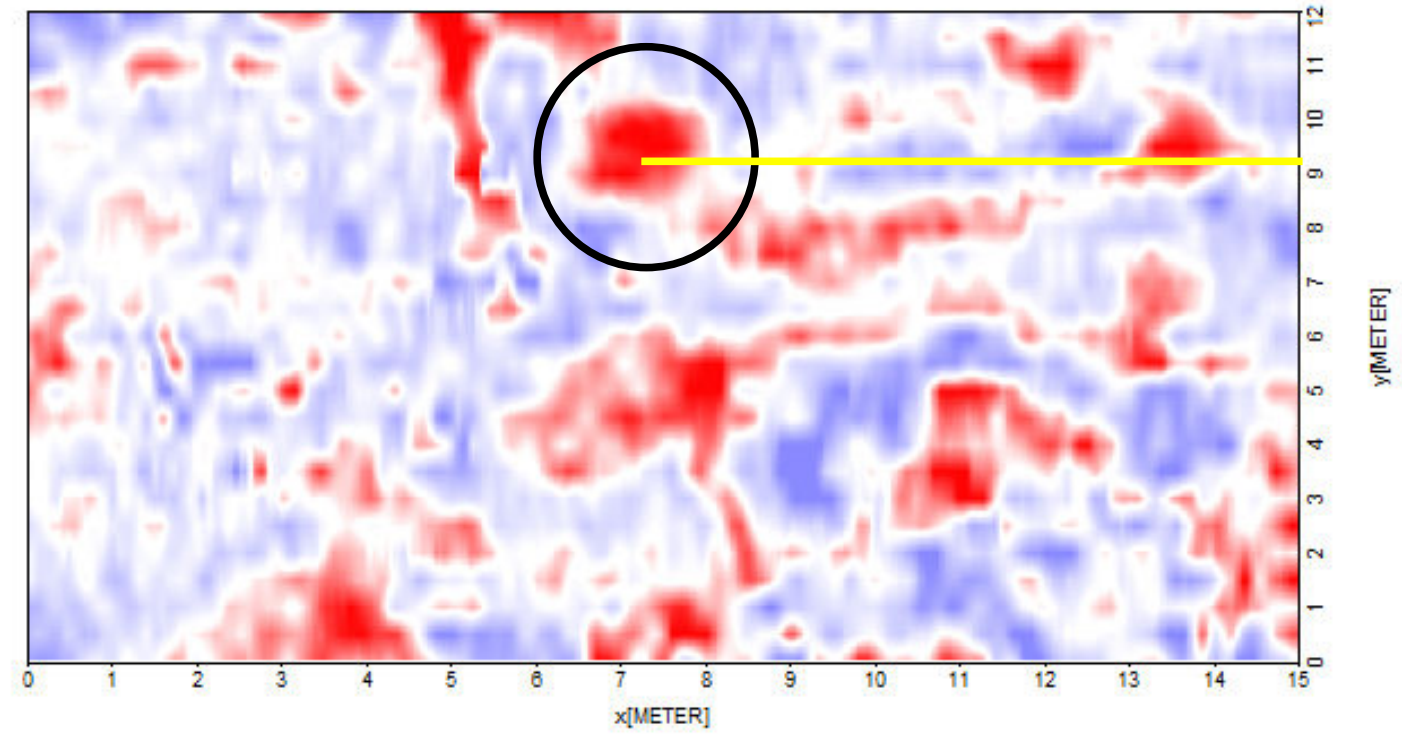

Figura 5. 19 - Depth-slice GPR de 200 MHz para a área 2 (profundidade 2,1 m).

Neste perfil, observa-se a presença de um alvo em formato circular e descontínuo. A região demarcada evidencia a presença de alvo de interesse arqueológico no qual foi indicado para a escavação. Como resultado da escavação, foram encontradas duas urnas funerárias indígenas como mostra a figura 5.20. 


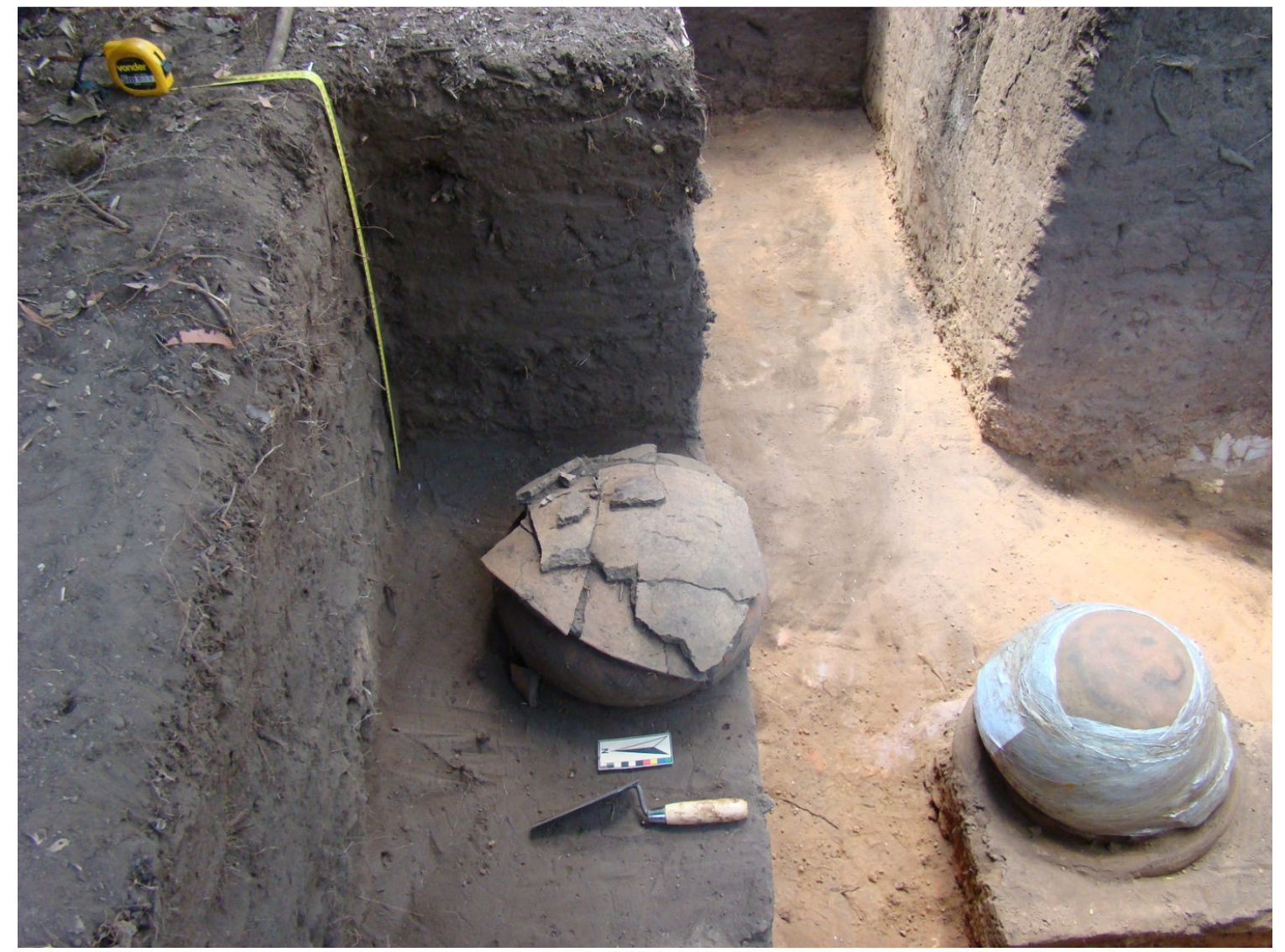

Figura 5. 20 - Resultado da escavação indicada pelos perfis GPR de $200 \mathrm{MHz}$ número 4 na direção y.

Estas urnas funerárias indígenas foram encontradas no local o qual havia apresentado as anomalias nos perfis GPR. Estas, assim como a anterior, foram encaminhadas para os órgãos competentes para datação e análises.

Todos os outros resultados dos perfis 2D e dos depth-slice 3D estão apresentados no anexo B.

\section{3. ÁREA 3}

$\mathrm{Na}$ área 3 foram adquiridos 21 perfis ao longo do eixo x e 49 ao longo do eixo y. 
Os dados aqui apresentados foram processados através do eixo $\mathrm{x}$.

Assim como já apresentado nas áreas 1 e 2, foram processados sequencialmente os perfis $2 \mathrm{D}$ e gerado o cubo 3D. Na figura 5.21 observa-se um perfil GPR 2D de $200 \mathrm{MHz}$ número 12 na direção x com a presença de algumas anomalias (hipérboles) que aparecem próximas à superfície e uma anomalia mais profunda.

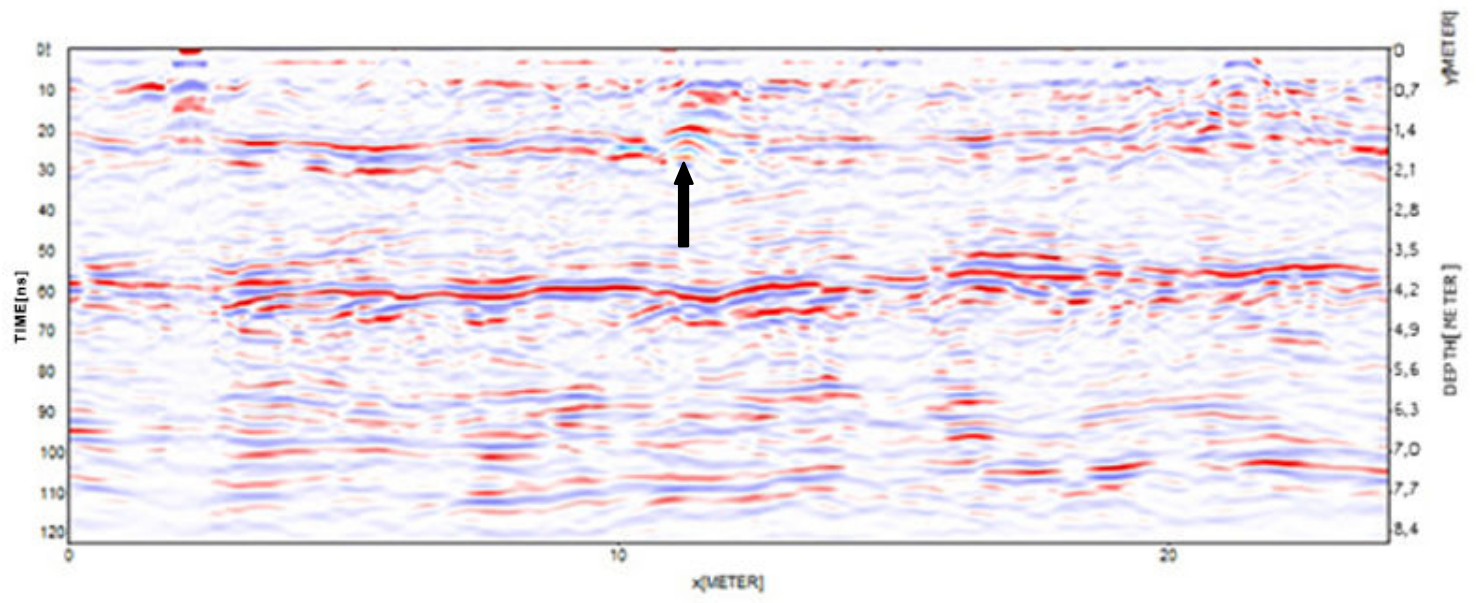

Figura 5. 21 - Perfil GPR de 200 MHz número 12 na direção x para a área 3 indicando uma anomalia hiperbólica em tons de vermelho, azul e branco.

Para que se possam sanar as dúvidas, pode-se visualizar na figura 5.22 o mesmo perfil em escala de cinza, onde nota-se claramente a presença das hipérboles. 


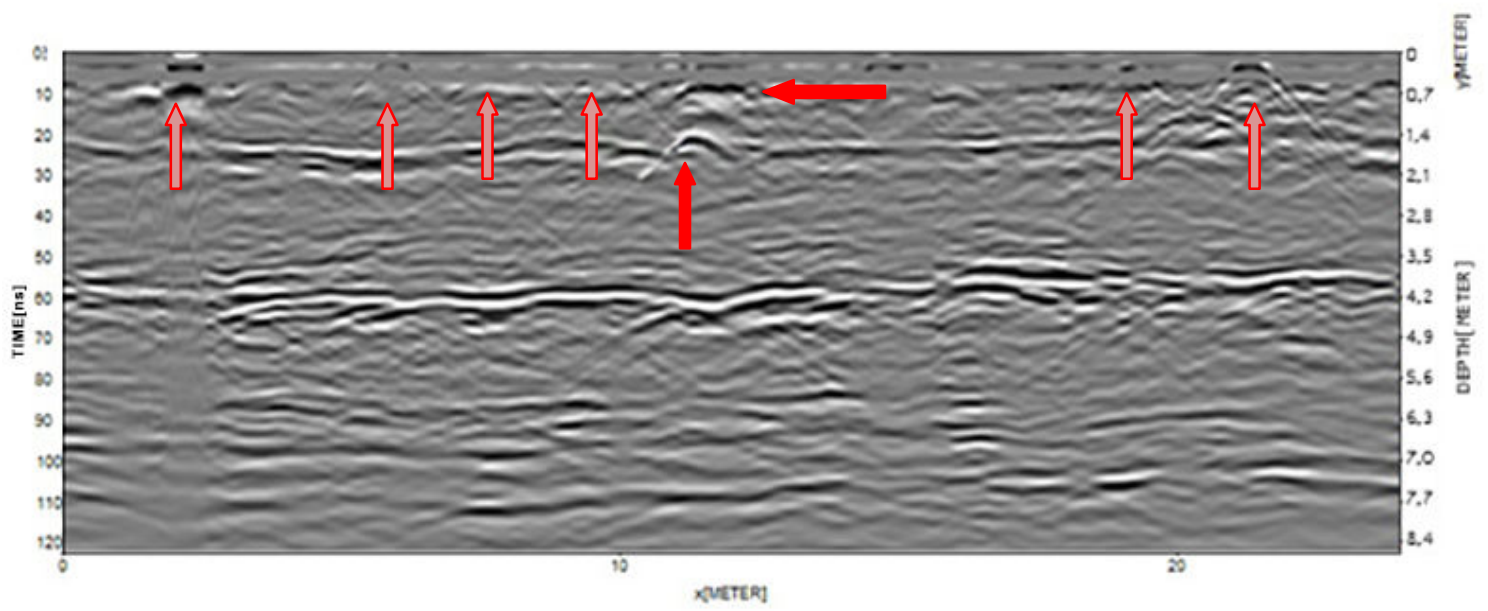

Figura 5. 22 - Perfil GPR de 200 MHz número 12 na direção x para a área 3 indicando anomalias hiperbólicas em tons de cinza.

Como já discutido, as hipérboles próximas à superfície não constituem anomalias de interesse arqueológico, pois indicam raízes de árvores como vista na figura 5.23.

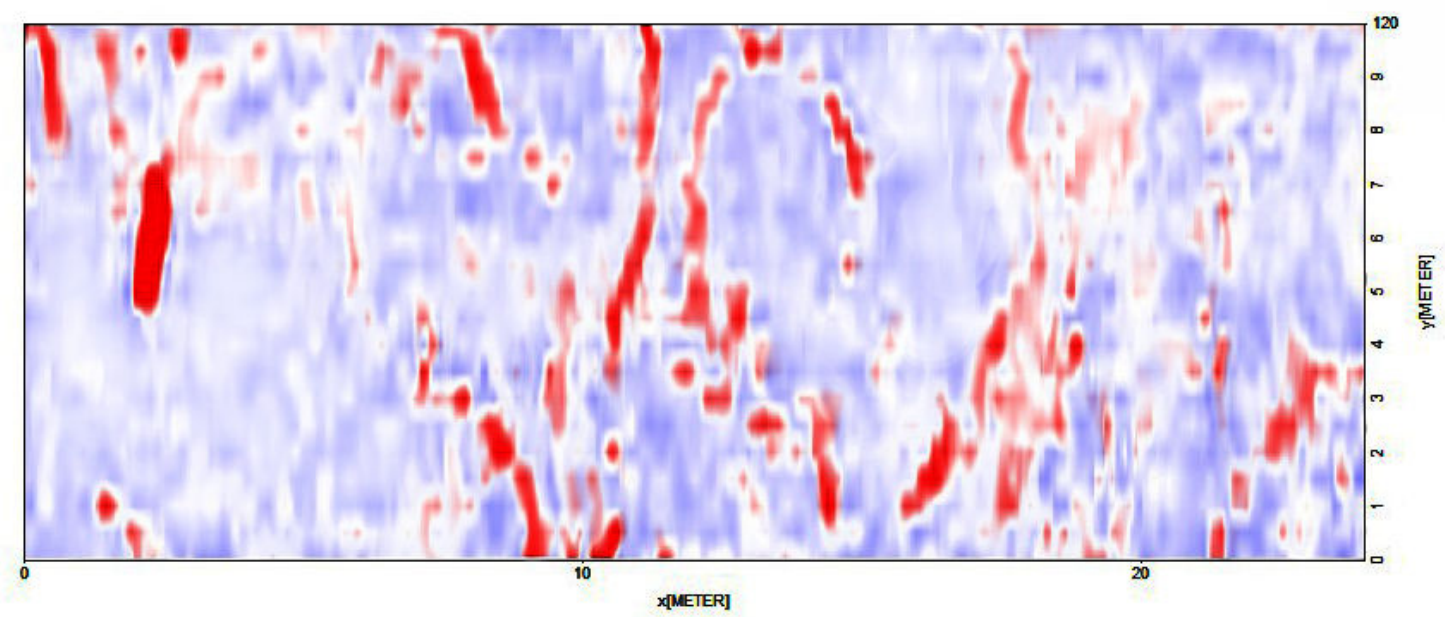

Figura 5. 23 - Depth-slice GPR de 200 MHz para a área 2 (profundidade 0 m). 
Porém, ainda na figura 5.22, é vista uma anomalia indicada mais profundamente que começa na profundidade de $0,7 \mathrm{~m}$ e termina na profundidade de $1,1 \mathrm{~m}$. Esta anomalia pode ser analisada em depth-slice da figura 5.24.

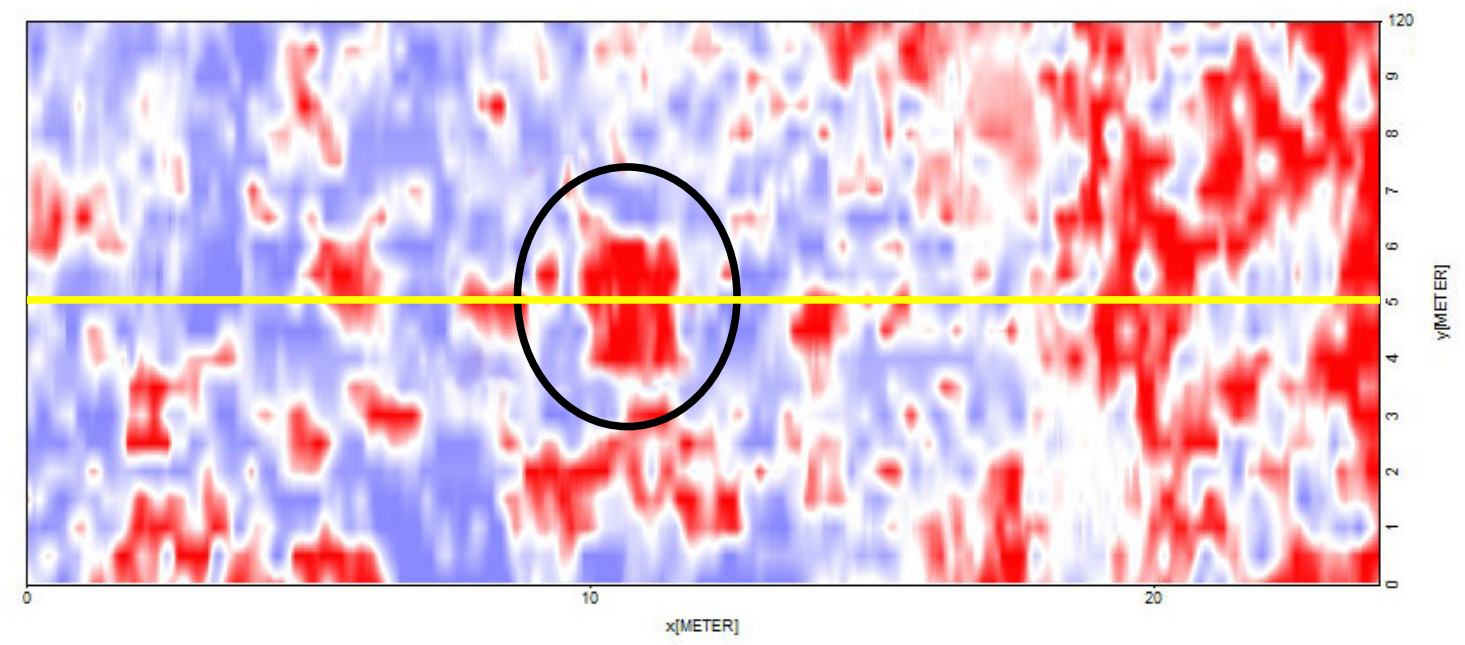

Figura 5. 24 - Depth-slice GPR de 200 MHz para a área 3 (profundidade 1,1 m).

Esta anomalia aqui observada tem uma forma retangular e descontínua. A linha amarela indica o perfil 2D GPR de $200 \mathrm{MHz}$ de número 12 na direção x apresentado nas figuras 5.21 e 5.22. Ela foi indicada para escavação como um possível artefato de interesse arqueológico. O resultado da escavação é visto na figura 5.25. 


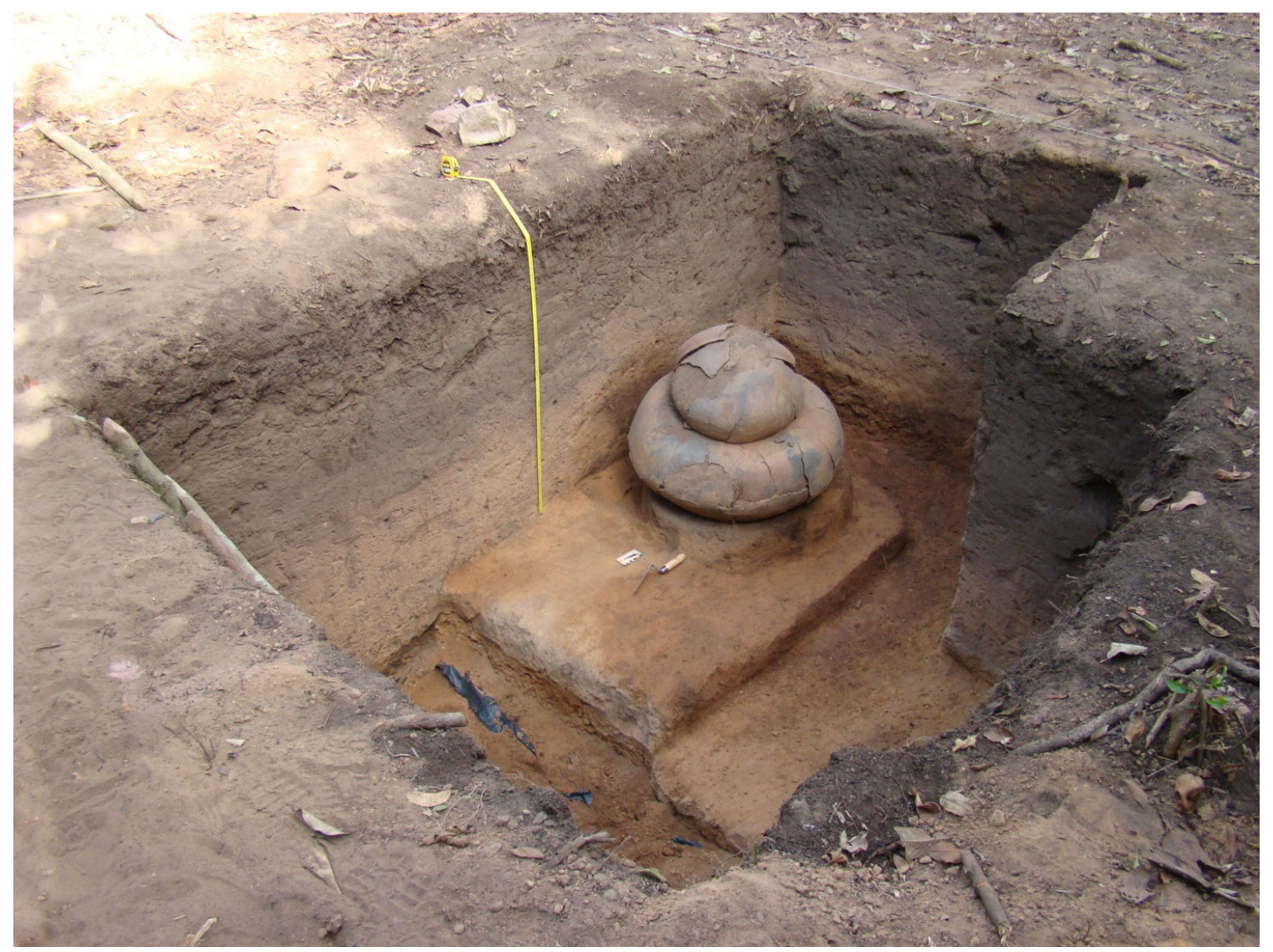

Figura 5. 25 - Resultado da escavação indicada pelo perfil GPR de 200 MHz número 12 na direção $x$.

A escavação resultou em uma urna funerária indígena de forma circular, mas que estava sob uma base retangular de material diferenciado do solo em que a enterrava. Isto explica as duas anomalias hiperbólicas sobrepostas no perfil GPR 2D de $200 \mathrm{MHz}$ número 12 na direção x e a visualização da base retangular no em depth-slice.

Todos os outros resultados dos perfis 2D e dos depth-slice 3D estão apresentados no anexo C. 


\subsection{OUTRAS ANÁLISES DOS PERFIS 2D}

Depois de ter-se analisado as três áreas, pôde-se observar em todos os perfis GPR 2D de $200 \mathrm{MHz}$ a presença de uma descontinuidade longilínea em grande profundidade. Os resultados e análises GPR não podem afirmar de maneira conclusiva qual a natureza real desta feição, porém, por elas aparecerem em todos os perfis e em todas as áreas, abrem-se tais perspectivas para análise: esta descontinuidade pode ser uma mudança estratigráfica da geologia natural da região, uma mudança litológica, presença de lençol de água subterrâneo ou, até mesmo, a presença de terra-preta na qual representa grande interesse arqueológico.

As escavações resultantes das indicações fornecidas pelo GPR não foram profundas para que tivessem ultrapassado o local onde ocorreram as reflexões. Porém, escavações de análise indicaram que ela possa ser responsável pela presença de arenito (figura 5.26). 


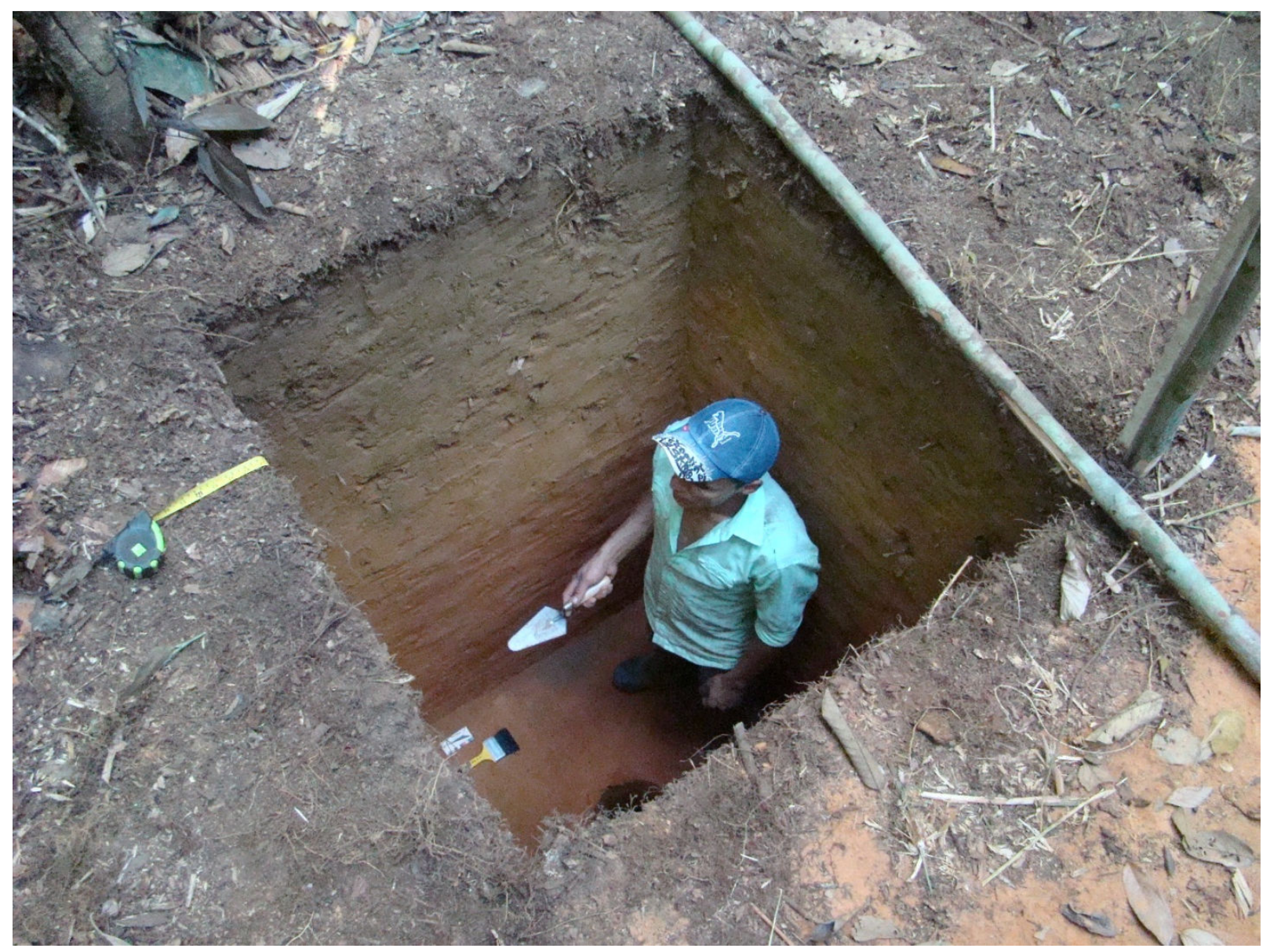

Figura 5. 26 - Escavação para análise estratigráfica. 


\section{CAPÍTULO 6}

\section{CONCLUSÕES E RECOMENDAÇÕES}

\subsection{CONCLUSÕES}

Neste trabalho de pesquisa, foram obtidos resultados significativos na identificação e mapeamento de todas as áreas estudadas. Eles forneceram indícios dos alvos arqueológicos e local de escavações, principais objetivos do projeto. $\mathrm{O}$ mapeamento 3D através da concatenação das sondagens $2 \mathrm{D}$ foi de fundamental representatividade para a conclusão e resultados desta pesquisa pois, pela natureza dos alvos em questão, arqueológicos, ele pôde fornecer dados e imagens mais precisos sobre a forma e geometria dos artefatos. Contudo, o método GPR foi capaz de mapear e sondar estas áreas de influência arqueológica com clareza. Feito isto, foi possível ainda identificar quais foram os alvos indicados que, de fato, tiveram um resultado significativo após as escavações, bem como aqueles que não se mostraram importantes do ponto de vista arqueológico, mas que mostraram a natureza ambígua do método apesar da grande capacidade de identificação do GPR.

$\mathrm{Na}$ área 1 foi indicada e escavada uma raiz de árvore e logo abaixo um bloco de rocha de grande porte, evidenciando uma ambiguidade na interpretação, que mostrava algo em contraste com a geologia local mas que não representou interesse arqueológico. Também foi sanada de forma conclusiva que várias anomalias que apareciam lado a lado nos perfis $2 \mathrm{D}$ e de aspecto serpenteado no depth-slice eram, de fato, raízes de árvores.

$\mathrm{Na}$ área 2, além de identificar duas urnas funerárias indígenas lado a lado, mas em profundidades diferentes, pôde-se notar como é a natureza do sinal obtido na presença de uma antiga escavação.

$\mathrm{Na}$ área 3, encontrou-se, além da urna funerária indígena, a presença de uma base onde, provavelmente, foi usada no ritual no qual ela foi enterrada. 


\section{Conclusões e Recomendações}

\subsection{RECOMENDAÇÕES}

Diante da experiência obtida com este trabalho de pesquisa, algumas recomendações podem ser feitas.

A interpretação conjunta do processamento dos dados dos perfis $2 \mathrm{D}$ e depth-slice 3D foi de fundamental importância para que se tenha êxito nas escavações arqueológicas de maneira a minimizar as ambiguidades na interpretação dos resultados.

Ainda, para estudos no campo da arqueologia o uso do método GPR mostra-se extremamente eficiente, pois o mapeamento de grandes áreas é rápido eficaz o que possibilita melhor análise em ambas as direções.

Em apoio complementar a este trabalho de pesquisa, poderão ser desenvolvidas análises e interpretações geológicas tais como estratigráfica, litológica e mineralógica a fim de contribuir com as interpretações e, assim, melhor explicar as fortes reflexões de altas amplitudes do GPR. 


\section{REFERÊNCIAS BIBLIOGRÁFICAS}

AlBUQUERQUE, M.C. \& OLIVEIRA, C.C., Programa Geologia do Brasil - Projeto Noroeste de Mato Grosso, 2007.

ARAGÃO, R. C. Metodologia Geofísica aplicada à pesquisa de salvamento arqueológico nos Sítios Bittencourt, Jambuaçu e Jaburu, Estado do Pará. 2006. 60 f. Dissertação (Mestrado em Geofísica) - Universidade Federal do Pará, Belém, 2006.

BARRADAS, J. A.; SCHAAN, D. P.; LUIZ, J.G. Magnetic and GPR Survey to Identify Archaeological Features on Cacoal Site, Anajás River, Marajó Island, Pará, Brazil. In: CONGRESSO INTERNACIONAL DA SOCIEDADE BRASILEIRA DE GEOFÍSICA, 6., Rio de Janeiro, 1999.

BEVAN, B. W., Geophysical Exploration for Archaeology: An Introduction to Geophysical Exploration. Midwest Archaeological Center Report No. 1. U.S. Department of the Interior, National Park Service, Midwest Archaeological Center, Lincoln, Nebraska. 1998.

BOAVENTURA, R.S. Geomorfologia de parte da Folha SC.21 - Juruena. Belém, Projeto RADAM, 48p. (Relatório Interno RADAM, 2-GM), 1974.

BURGER, H. R., SHEEHAN, A. F. e JONES, C. H., Introduction to Applied Geophysics: Exploring the Shallow Subsurface. W. W. Norton \& Company, New York. 2006.

CLARK, A., Archaeological prospecting: A progress report. Journal of Archaeological Science, vol. 2, issue 4, pp. 297-314. 1975. 
CONYERS, L. B. e GOODMAN, D., Ground-Penetrating Radar: An Introduction for Archaeologists. AltaMira Press, Walnut Creek, California, p232, 1997.

CONYERS, L. B., Ground-penetrating Radar for Archaeology. AltaMira Press, Walnut Creek, California, pp. 246-250, 2004.

DANIELS, J. J., Surface Penetrating Radar. The Institution of Eletrical Engineers, London, United Kingdon, 300p., 1996.

DIÁRIO OFICIAL DA UNIÃO, PORTARIA Nº 128, DE 11 DE ABRIL DE 2007

ERNENWEIN, E. G., HARGRAVE, M. L., Archaeological Geophysics for DoD Field Use: a Guide for New and Novice Users, pp. 10-41, 2009.

GAFFNEY, C. e GATER, J., Revealing the Buried Past, Geophysics for Archaeologists. Tempus Publishing, Ltd., Gloucestershire, UK. 2003.

GOODMAN, D. Ground-penetrating radar simulation in engineering and archaeology, vol. 59: 224, 1994.

GOODMAN, D., NISHIMURA, Y. e ROGERS, J. D., GPR time-slices in archaeological prospection. Archaeological Prospection. 2:85-89, 1995.

GOODMAN, D.; PIRO, S. GPR Remote Sensing in Archaeology. Springer Science \& Business Media, 2013.

Google Maps, 2014. Imagens (C2014 Landsat, Data SIO, NOAA, U.S. Navy, NGA, GEBCO, Dados do mapa C2014 Google.

HECKMAN, E., Geophysical methodologies and test site for battlefield archaeology. Unpublished Master's thesis, University of Arkansas. 2005. 
IBGE. Instituto Brasileiro de Geografia E Estatística. Estatística Século XX. Memória Institucional Geociências. Servidor de Mapas. Mapas Interativo. 2007.

JACKSON, John David, Classical Electrodynamics. Hoboken, NJ: John Wiley \& Sons, Inc., 3rd edition, p.2. 1998.

KIPNIS, R. Early hunter-gatherers in the Americas: perspectives from central Brazil. Antiquity 72(277):581-592. 1998.

KVAMME, K. L., Current Practices in Archaeogeophysics: Magnetics, Resistivity, Conductivity, and Ground Penetrating Radar. In Earth Sciences and Archaeology, edited by P. Goldberg, V. T. Holliday and C. R. Ferring, pp. 353-384. Kluwer Academic / Plenum Publishers, New York. 2001.

Lei 3.924/1961 e Portaria IPHAN 230/2002.

MARCELINO, T. H.; SHIRAIWA, S.; BORGES, W. R.; FILHO, N. P.; RAITER, F. GPR para a verificação do nível d'água subterrânea em transição Floresta Amazônica e Cerrado. Acta Amazônica. Vol. 35(3), p. 367-374, 2005.

MARQUES, F. L. T. Modelo da Agroindústria Canavieira Colonial no Estuário Amazônico: Estudo Arqueológico de Engenhos dos Séculos XVIII e XIX. 2004. 193 f. Tese (Doutorado em História) - Pontifícia Universidade do Rio Grande do Sul, Porto Alegre, 2004.

MELO, D.P. \& FRANCO, M.S.M. Geomorfologia. In: BRASIL. Departamento Nacional da Produção Mineral. Projeto RADAMBRASIL. Folha SC.21 - Juruena. Rio de Janeiro: Radambrasil, (Levantamento de Recursos Naturais, 20). p.117-164. 1978.

MILLER, E.T. Arqueologia nos empreendimentos hidrelétricos da Eletronorte; resultados preliminares. Brasilia, DF, Eletronorte, 1992. 
MILLER, E.T. Pesquisas arqueológicas paleoindígenas no Brasil Ociendetal. Estudios Atacameños. 8:9-15, 1987.

NAJJAR, R. Arqueologia no Pelourinho. IPHAN / Programa Monumenta, Brasília, DF, pp. 118-119, 2010.

NEVES, E.G. Arqueologia da Amazônia. Rio de Janeiro, Jorge Zahar Editor, 2006.

OLHOEFT, G.R., Application of ground penetrating radar. In: International Conference on Ground Penetration Radar, 6th, 1996, pp.1-3, Sendai, Japan. 1996.

OLIVEIRA, J.E. \& S.B. VIANA O centro-oeste antes de Cabral. Revista USP. 44:142189,2000

PAYOLLA, B.L.; BETTENCOURT, J.S.; KOZUCH, M.; LEITE Jr., W.B.; VAN SCHMUS, W.R. Geological evolution of the basement rocks in the east-central part of the Rondônia Tin Province, SW Amazonian Craton, Brazil: U-Pb and Sm-Nd isotopic constraints. Precambrian research, 2002.

PEREIRA, E.; GUAPINDAIA, V.; LUIZ, J. G. Levantamento Arqueológico na Área da Sub-Estação Santa Rita, Macapá (AP). Relatório Técnico, Museu Paraense Emílio Goeldi, Coordenação de Ciências Humanas., 28p. 2004.

PORSANI, J.L., Ground penetrating radar (GPR): Proposta metodológica de emprego em estudos geológico-geotécnicos nas regiões de Rio Claro e Descalvado - SP. Tese (Doutorado), Instituto de Geociências e Ciências Exatas, UNESP, Campus de Rio Claro - SP, 145p., 1999.

PORSANI, J.L., JANGELME, G.M., KIPNIS, R., 2010. GPR survey at Lapa do Santo archaeological site, Lagoa Santa karstic region, Minas Gerais state, Brazil. Journal of Archaeological Science, v.37, p.1141 - 1148. 
PORSANI, J.L.; JANGELME, G.M.; KIPNIS. R.; 2012. Use of ground-penetrating radar to map subsurface features at the Lapa do Santo archaeological site (Brazil). Near Surface Geophysics (Online), v.10, p.141 - 144.

PYE, K. \& CROFT, D. J.; Forensic Geoscience: Principles, Techniques and Applications. Geological Society, London, Special Publications, 232, 1-5. _9 The Geological Society of London, 2004.

RIMA - AHE Dardanelos. Relatório de Impacto Ambiental do Aproveitamento Hidrelétrico Dardanelos, Rio Aripuanã / Município de Aripuanã - MT, 2004.

RODRIGUES, S.I., Caracterização GPR de Tambores Metálicos e Plásticos: Estudo sobre o Sítio Controlado do IAG/USP. Dissertação (Mestrado). Instituto de Astronomia, Geofísica e Ciências Atmosféricas, Departamento de Geofísica, 2004.

RODRIGUES, S.I., Contribuições dos métodos GPR e Eletromagnético Indutivo em estudos de sítios arqueológicos de sambaquis costeiros no Estado de Santa Catarina Tese (Doutorado), Instituto de Astronomia, Geofísica e Ciências Atmosféricas, Departamento de Geofísica, 2009.

RODRIGUES, S.I., PORSANI, J.L., SANTOS, V.R.N., DE BLASIS, P.A.D., GIANINI, P.C.F., 2009. GPR and Inductive Electromagnetic Surveys Applied in Three Coastal Sambaqui (Shell Mounds) Archaeological Sites in Santa Catarina State, South Brazil. Journal of Archaeological Science, v.36, p.2081 - 2088.

ROOSEVELT, A.C. - Moundbuilders of the Amazon: Geophysical archaeology on Marajo Island, Brazil. Academic Press. 495 p., 1991.

SALA, R., GARCIA, E. e TAMBA, R., Archaeological Geophysics - From Basics to New Perspectives. SOT Prospecció Arqueològica, ERAAUB, Spain, pp.133-142, 2012. 
SANTOS, J.O.S. Geotectônica dos escudos das Guianas e Brasil-Central. In.: BIZZI, L. A.; SCHOBBEnHAUS, Carlos; VIDOTTI, R. M.; GONÇALVES, J. H. (eds.). Geologia, Tectônica e Recursos Minerais do Brasil. Rio de Janeiro: CPRM, p. 169-226, 2003.

SANTOS, V.R.N., Emprego dos Métodos Eletromagnético Indutivo e GPR no Mapeamento de Redes de Interferências Instaladas no Sítio Controlado de Geofísica Rasa do IAG/USP. Dissertaçao (Mestrado). Instituto de Astronomia, Geofísica e Ciências Atmosféricas, Departamento de Geofísica, p.42, 2009.

SCHMITZ, P.I. Caçadores e Coletores da Pré-história do Brasil. Instituto Achietano de Pesquisas/UNISINOS, São Leopoldo, Rio Grande do Sul, 1984.

SCHMITZ, P.I. Prehistoric Hunters and Gatherers of Brazil. Journal of World Prehistory, 1(1):53-125, 1987.

SCIENTIA. Projeto de Arqueologia Preventiva na Área de Influência Direta do Aproveitamento Hidrelétrico Dardanelos, MT. São Paulo: Scientia Consultoria Científica, 2007.

SCIENTIA Projeto de Arqueologia Preventiva na Área de Influência Direta do Aproveitamento Hidrelétrico Dardanelos, MT. São Paulo: Scientia Consultoria Científica, 2009.

SHERIFF, R.E., Encyclopedic dicitionary of exploration geophysics. 3 ed. Tulsa: Society of Exploration Geophysicists, 376p., 1991.

STRATTON, J. A., Electromagnetic Theory. McGraw Hill Book Company, New York, 615p., 1941. 
THEMAG ENGENHARIA, Estudos de Inventário Hidrelétrico da Bacia do Rio Aripuanã, Relatório Final. Apêndice F - Avaliação Ambiental Integrada Tomo 1 Texto. Volume I, pp. 59-184, 2011.

VIALOU, A.V. Pré-história do Mato Grosso, Volume 1, Santa Elina. São Paulo, EDUSP, 2005.

VIALOU, A.V. Pré-história do Mato Grosso, Volume 2, Cidade de Pedra, São Paulo, EDUSP, 2006.

VILHENA-VIALOU, A. \& VIALOU, D., Les premiers peuplement préhistorique du Mato Grosso. Bulletin de la Société Préhistorique Française, 91(45):257-263, 1994.

VILHENA-VIALOU, A. Découverte de Mylodontinae dans un habitat préhistorique daté du Mato Grosso (Brésil): l'abri rupestre Santa Elina. Compte Rendus de l'Académie des Sciences, 230(2):655-661, 1995.

WITTEN, A. J., Handbook of Geophysics and Archaeology. Equinox Publishing, London, 2006.

WÜST, I. \& L.J. de M. Vaz, Grafismos de ação no alto São Francisco, sudeste do Mato Grosso. Revista do Museu Antropológico, 2(1):47-88, 1998. 


\section{ANEXO A: ÁREA 1}

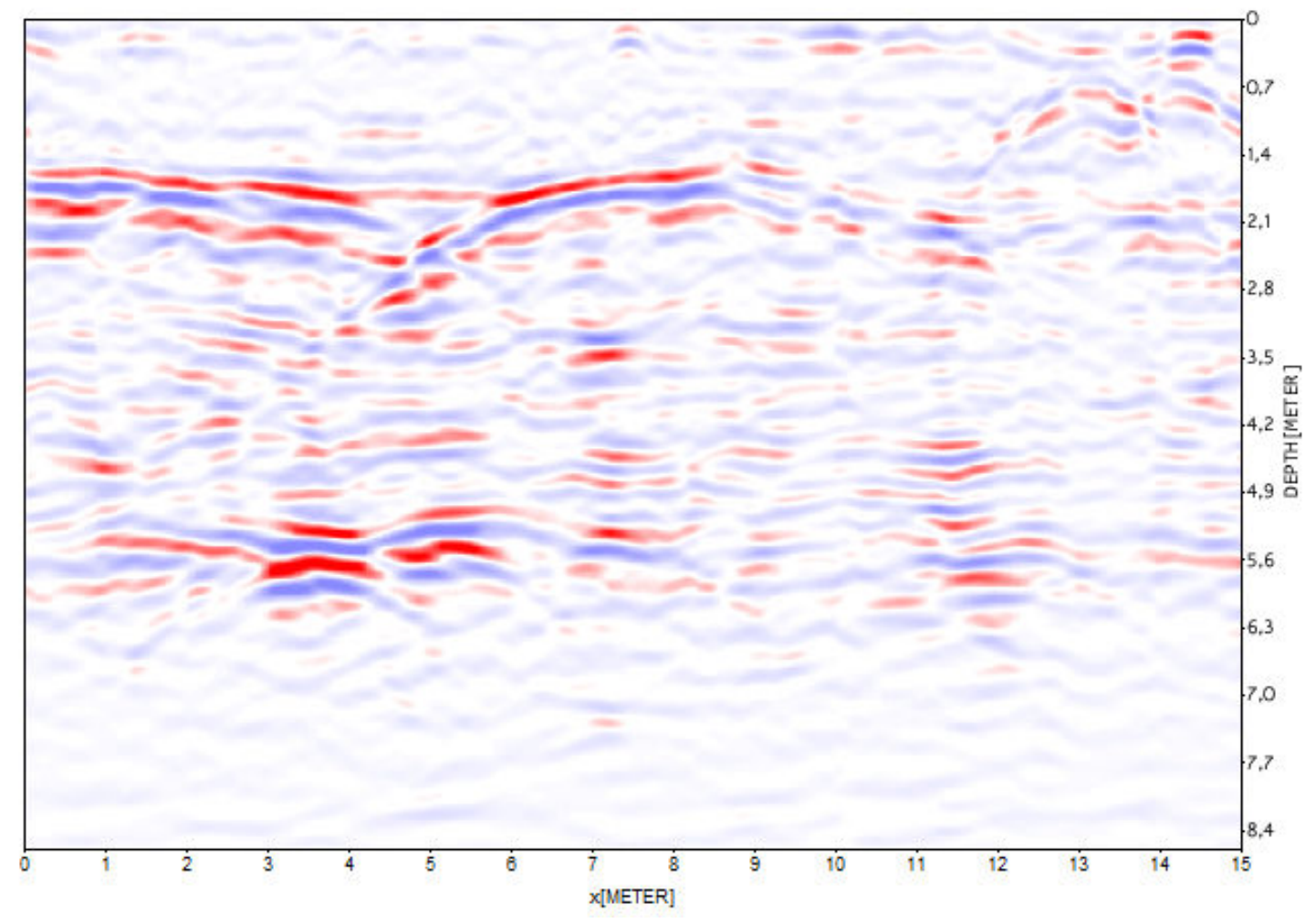

Anexo A 1 - Perfil GPR de 200 MHz número 1 na direção y para a área 1 


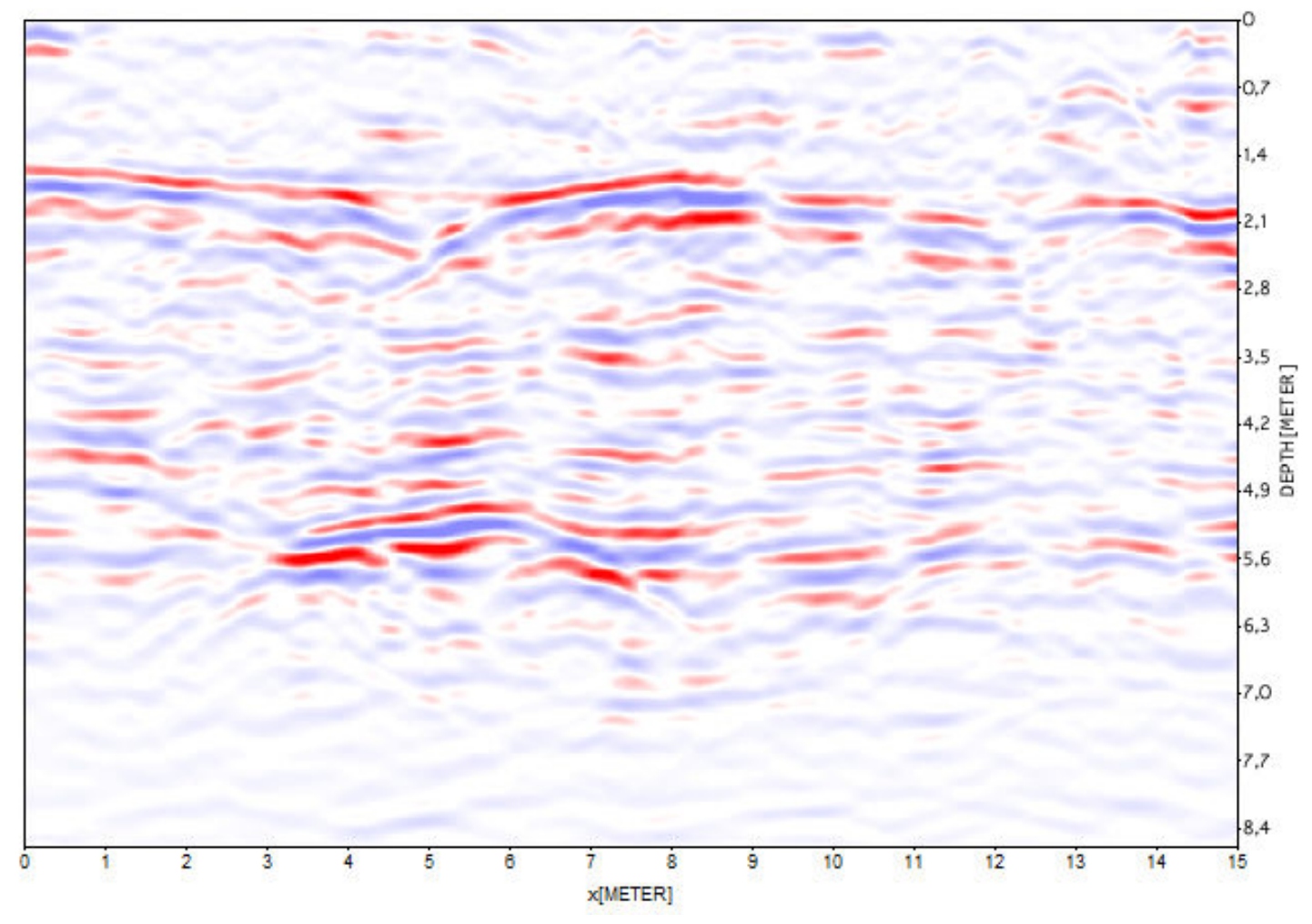

Anexo A 2 - Perfil GPR de 200 MHz número 2 na direção y para a área 1

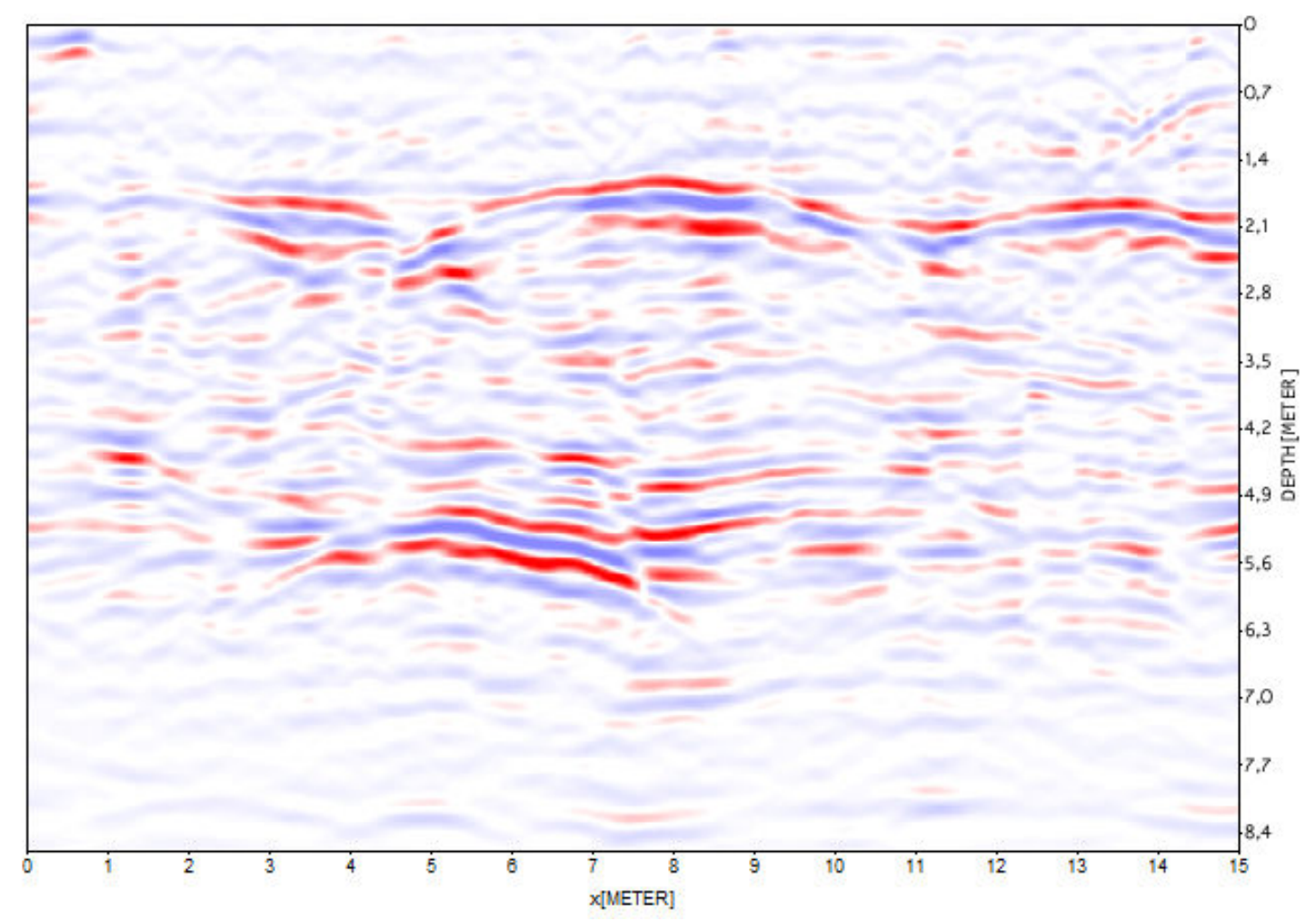

Anexo A 3 - Perfil GPR de 200 MHz número 3 na direção y para a área 


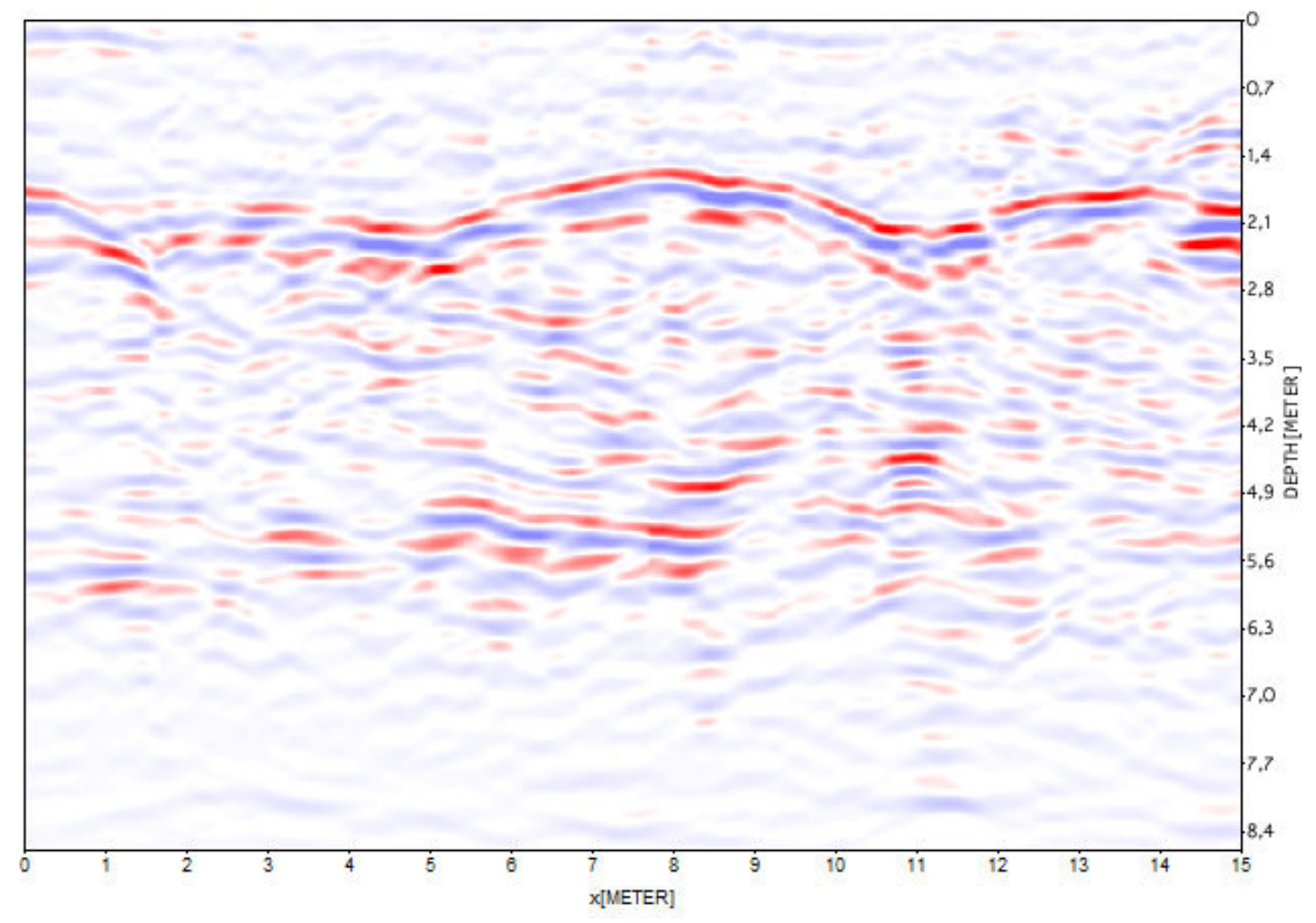

Anexo A 4 - Perfil GPR de 200 MHz número 4 na direção y para a área 1

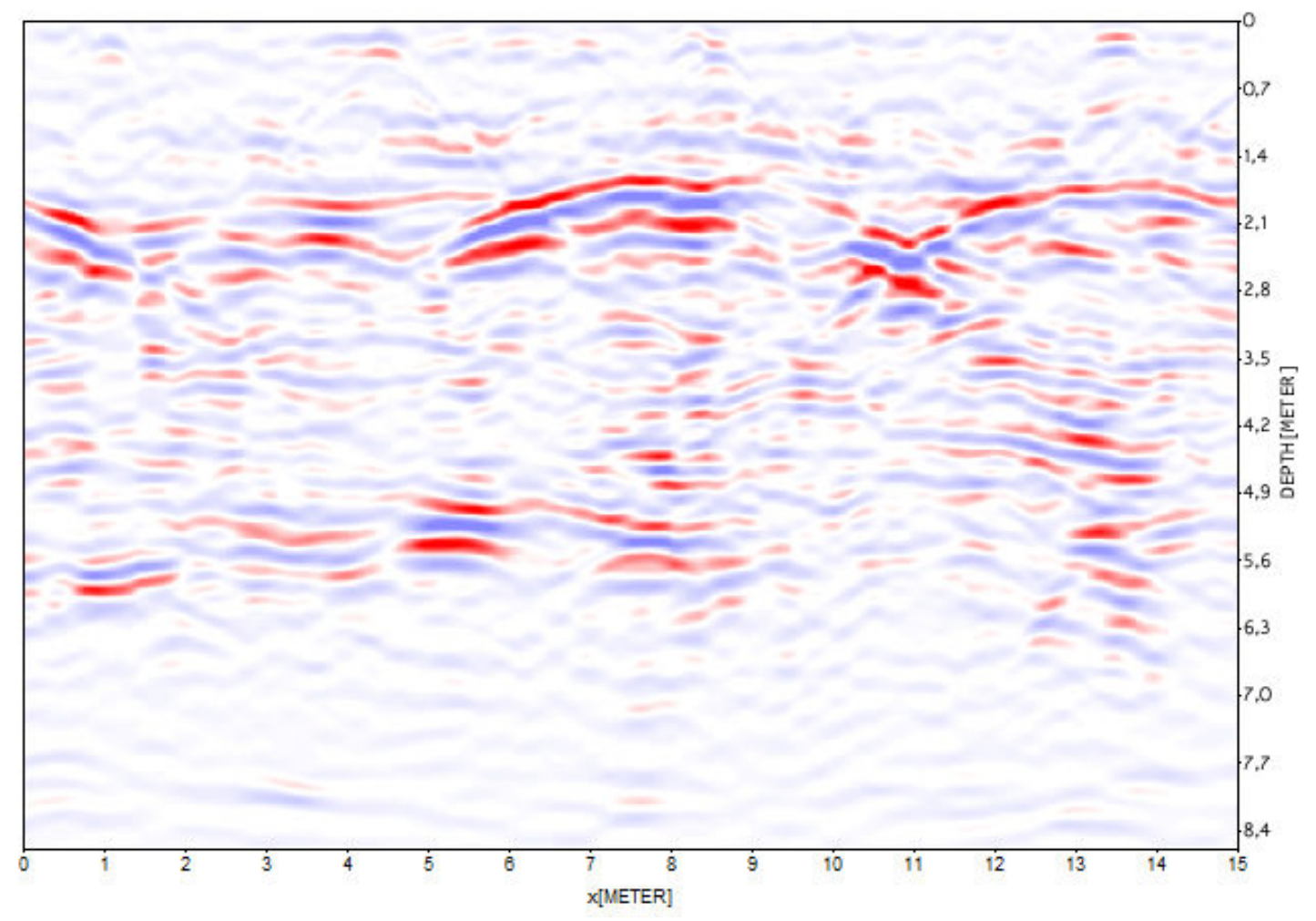

Anexo A 5 - Perfil GPR de 200 MHz número 5 na direção y para a área 1 


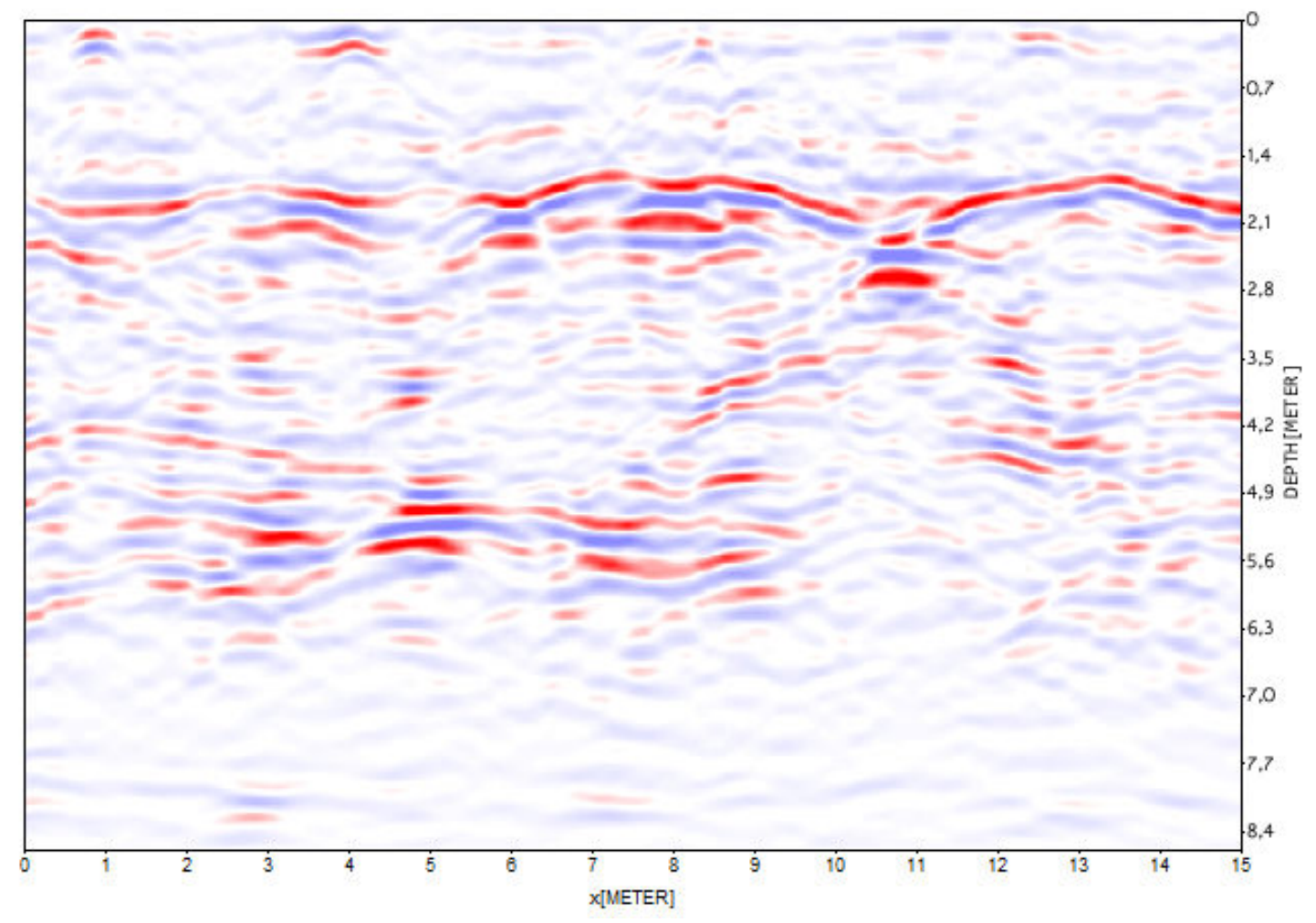

Anexo A 6 - Perfil GPR de 200 MHz número 6 na direção y para a área 1

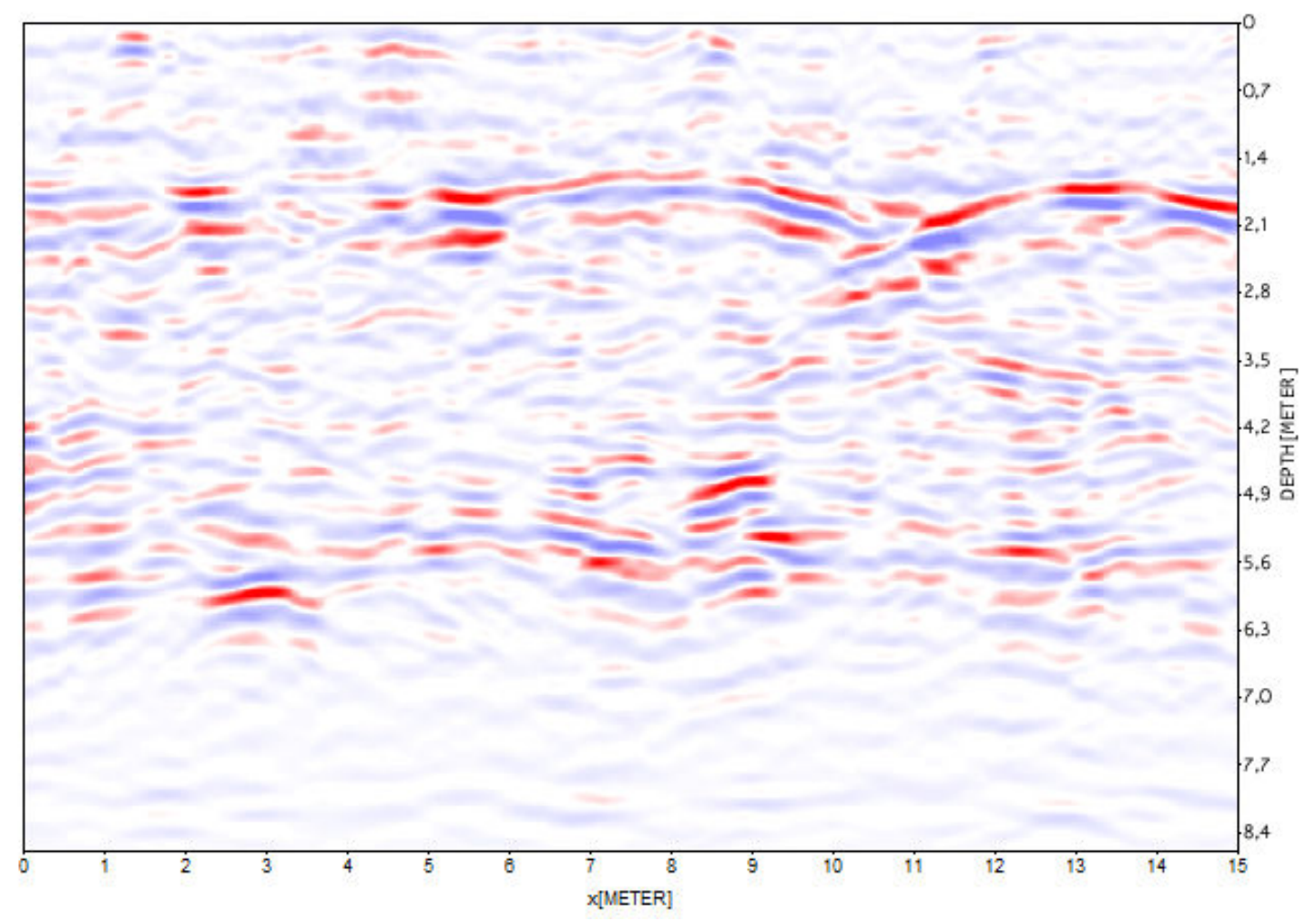

Anexo A 7 - Perfil GPR de 200 MHz número 7 na direção y para a área 1 


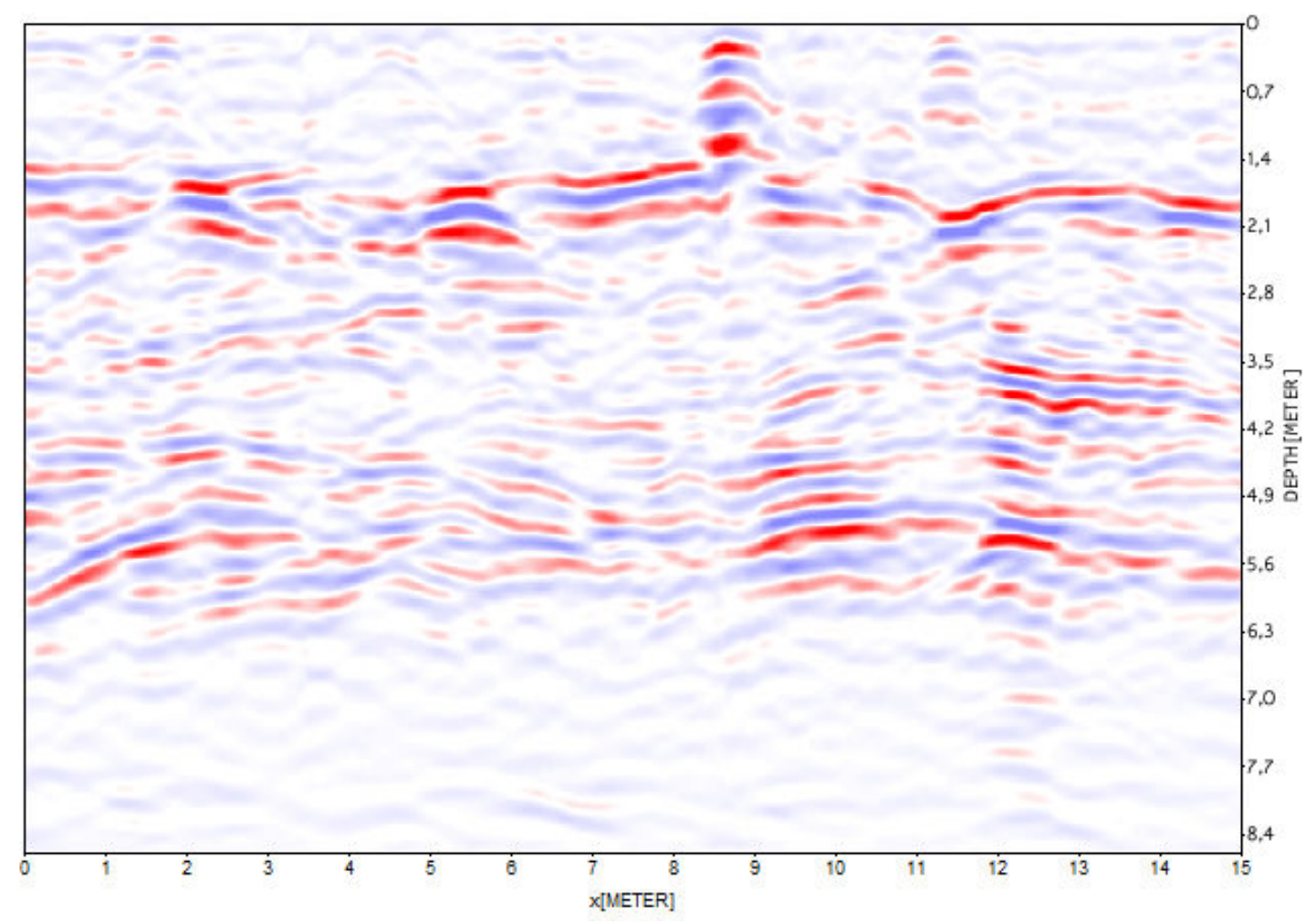

Anexo A 8 - Perfil GPR de 200 MHz número 8 na direção y para a área 1

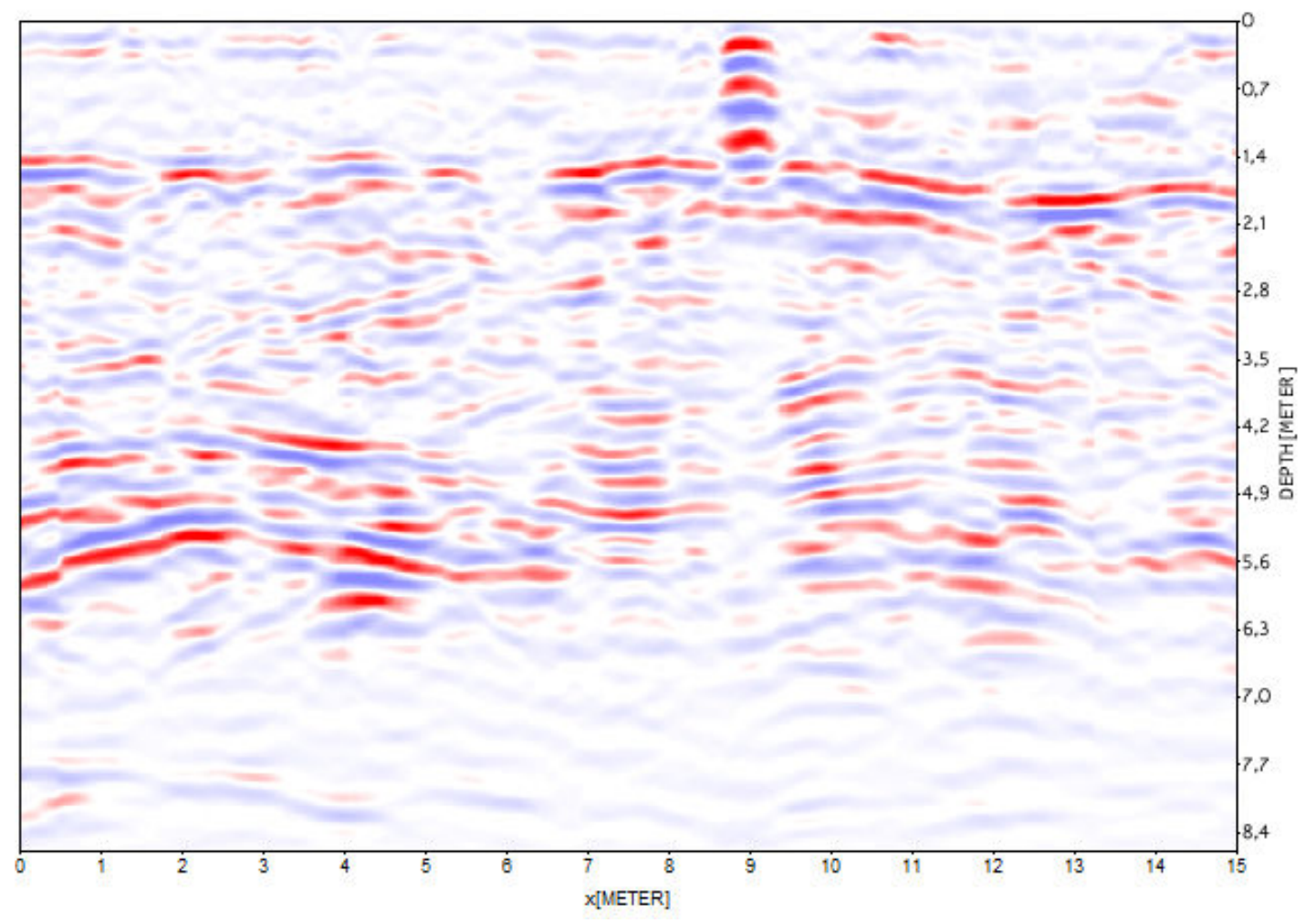

Anexo A 9 - Perfil GPR de 200 MHz número 9 na direção y para a área 1 


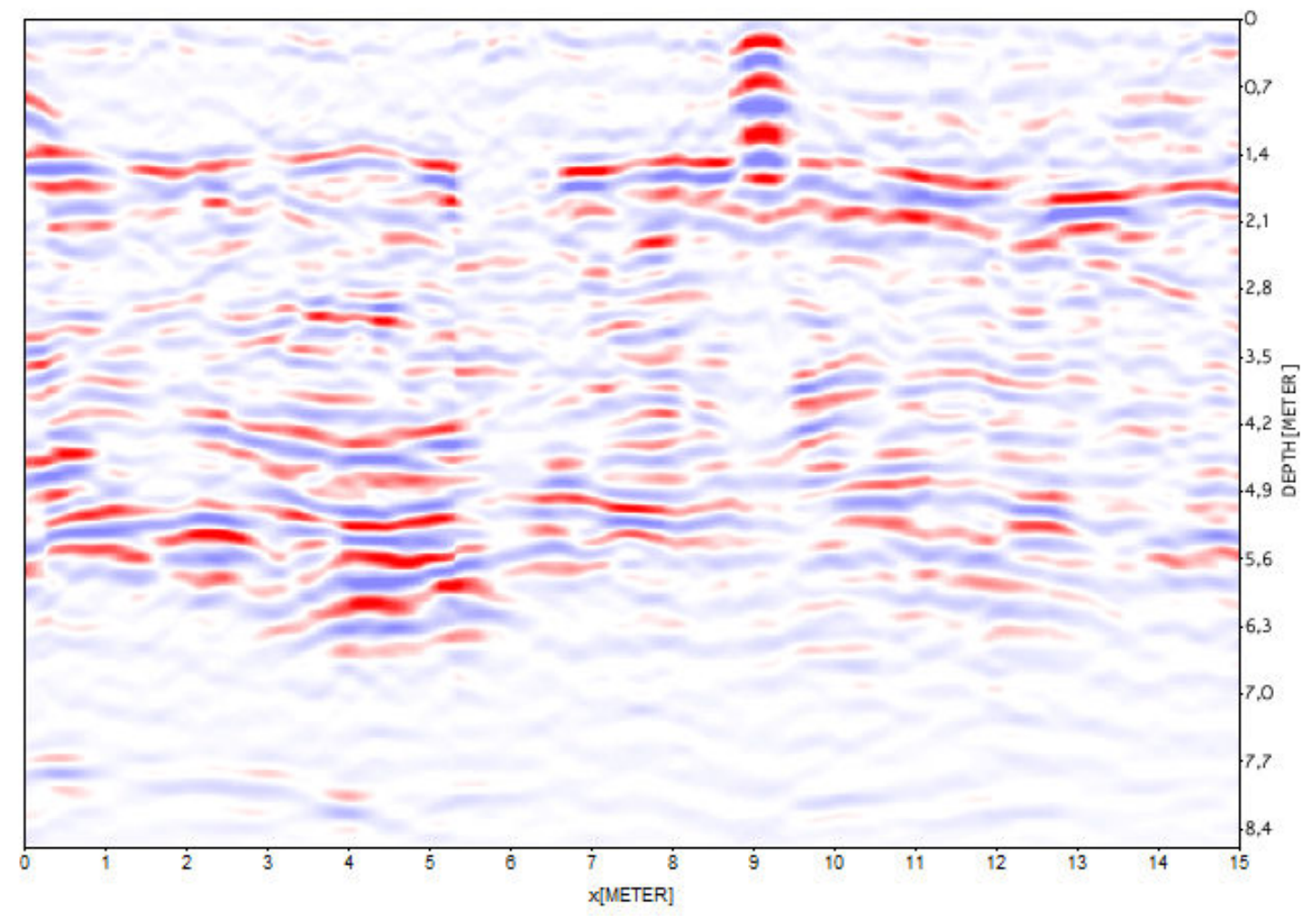

Anexo A 10 - Perfil GPR de 200 MHz número 10 na direção y para a área 1

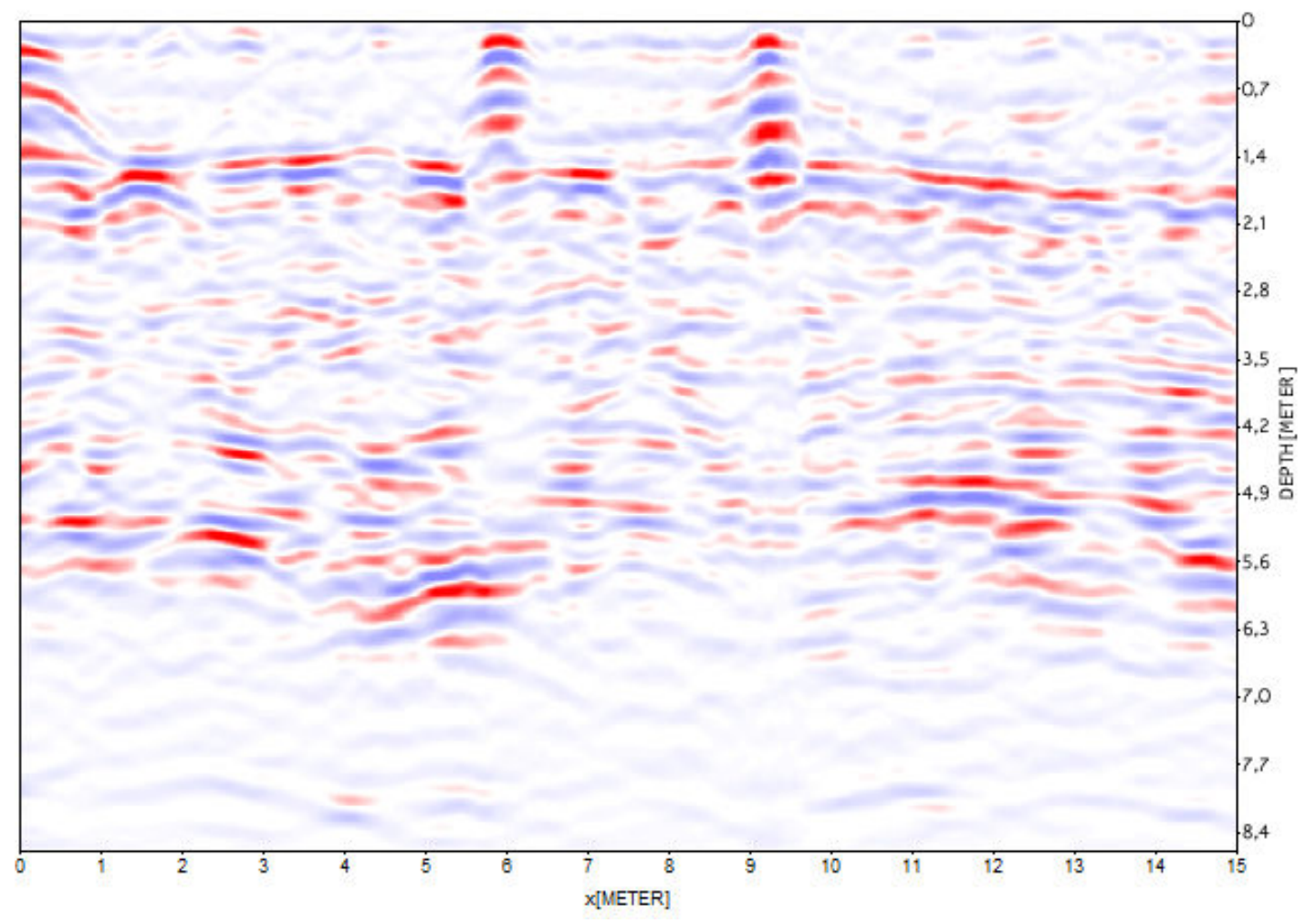

Anexo A 11 - Perfil GPR de 200 MHz número 11 na direção y para a área 1 


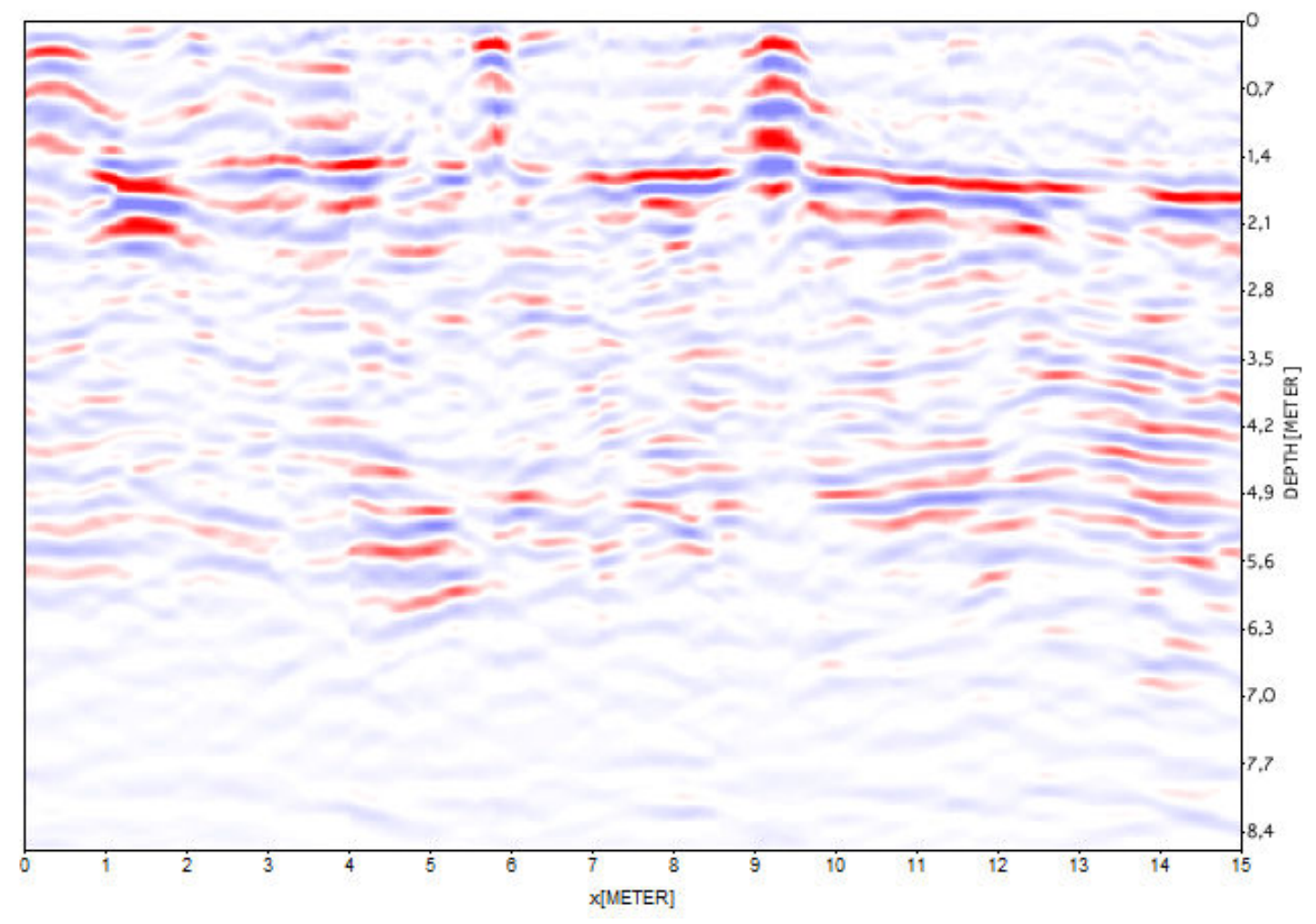

Anexo A 12 - Perfil GPR de 200 MHz número 12 na direção y para a área 1

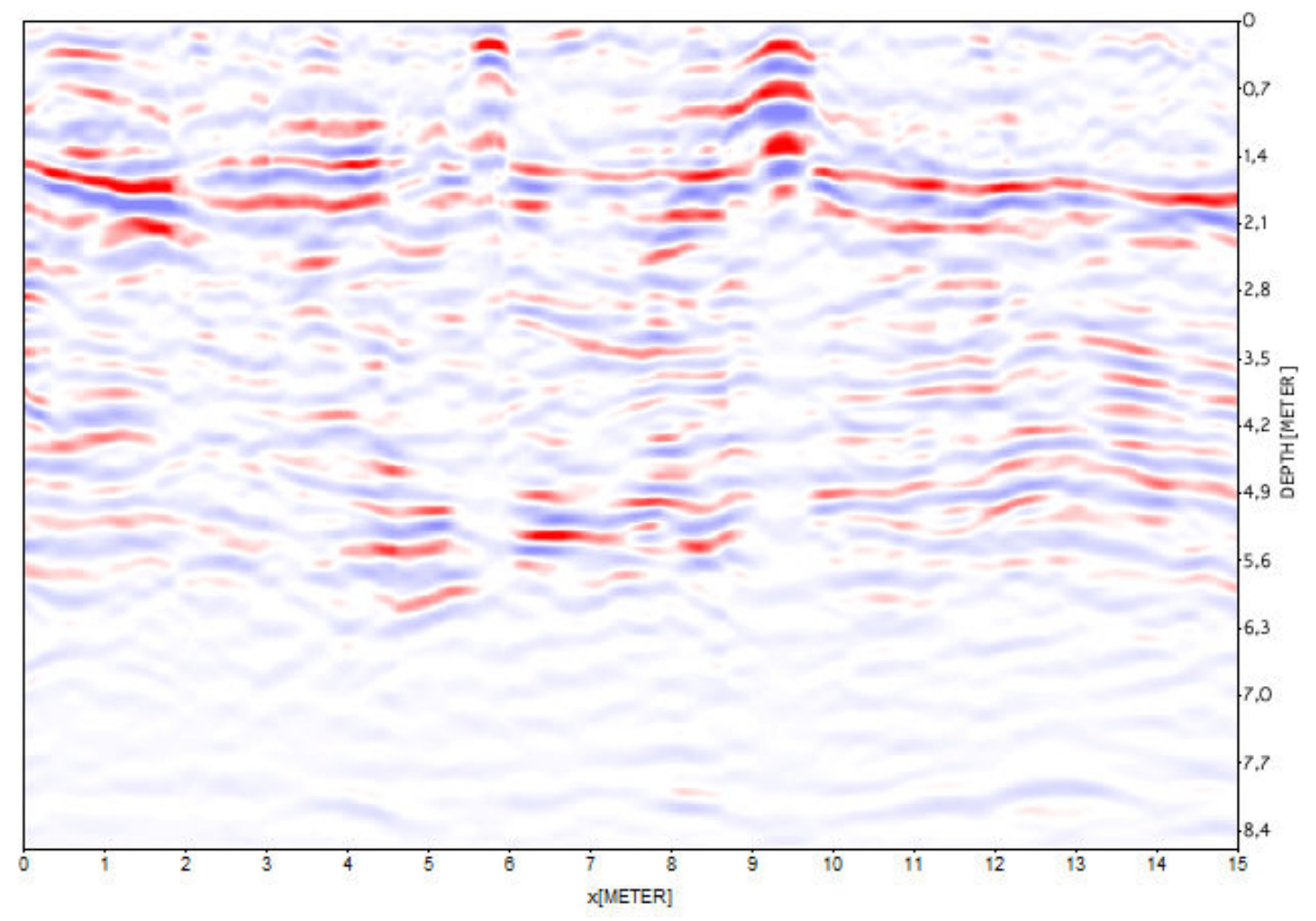

Anexo A 13 - Perfil GPR de 200 MHz número 13 na direção y para a área 1 


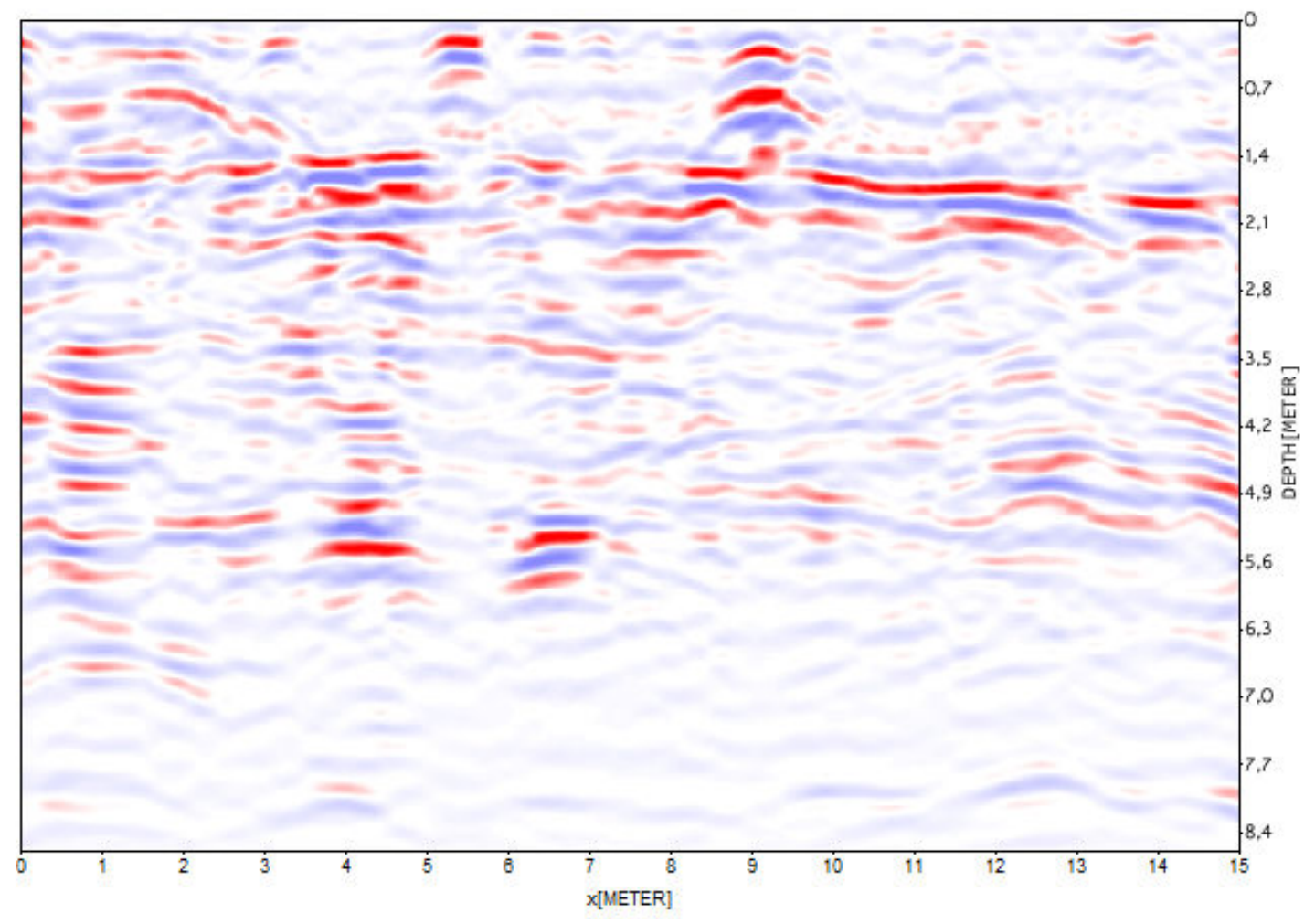

Anexo A 14 - Perfil GPR de 200 MHz número 14 na direção y para a área 1

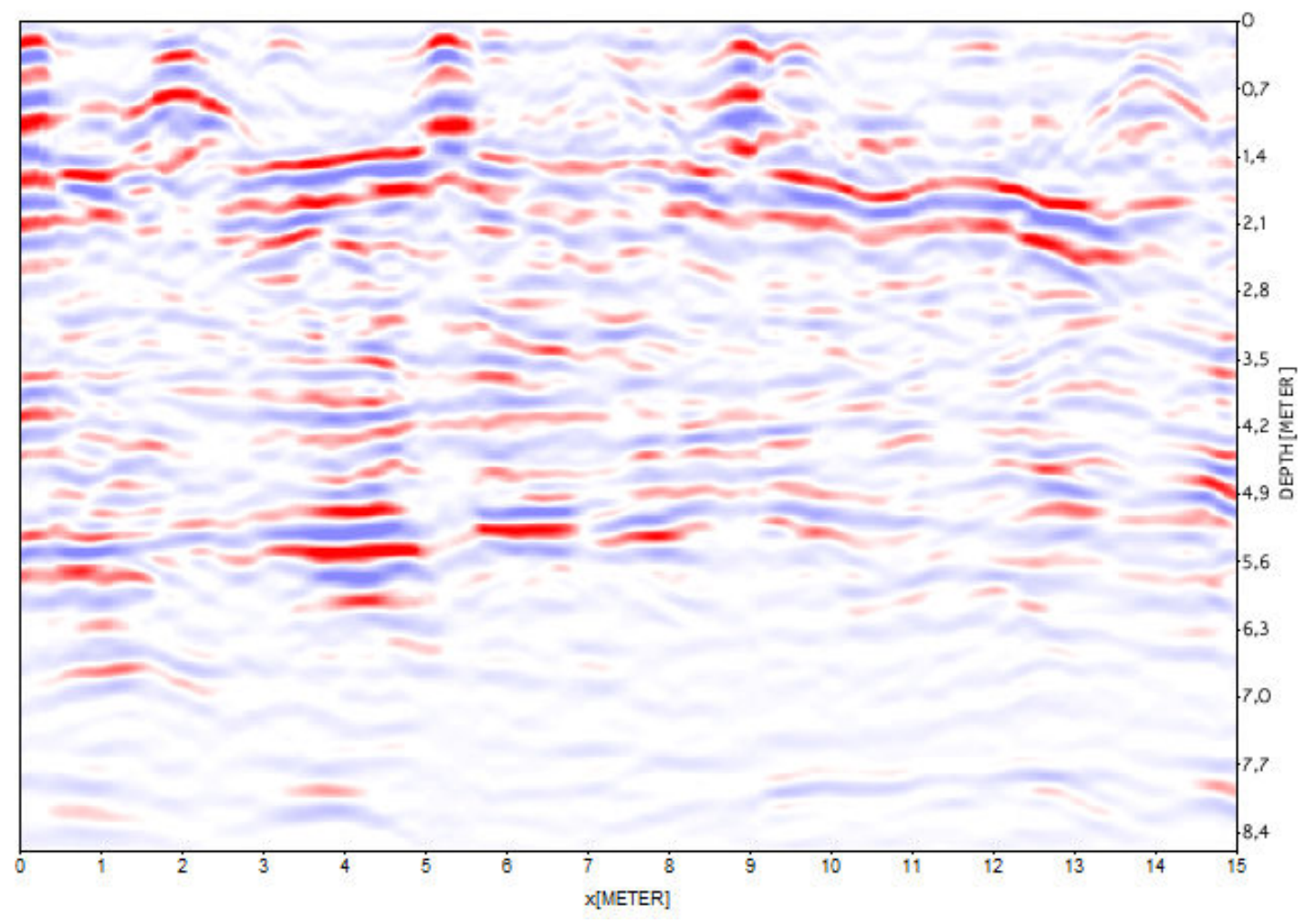

Anexo A 15 - Perfil GPR de 200 MHz número 15 na direção y para a área 1 


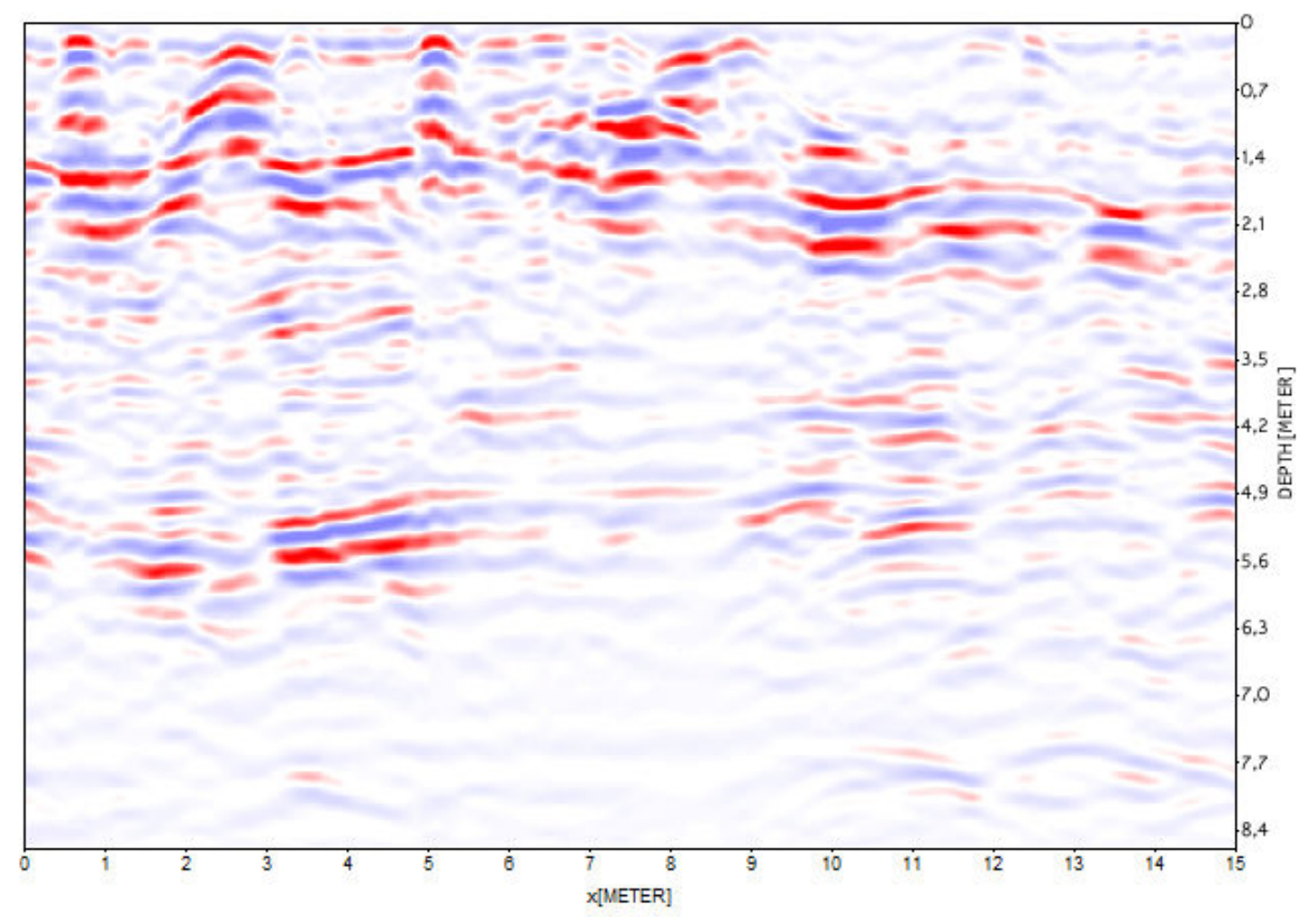

Anexo A 16 - Perfil GPR de 200 MHz número 17 na direção y para a área 1

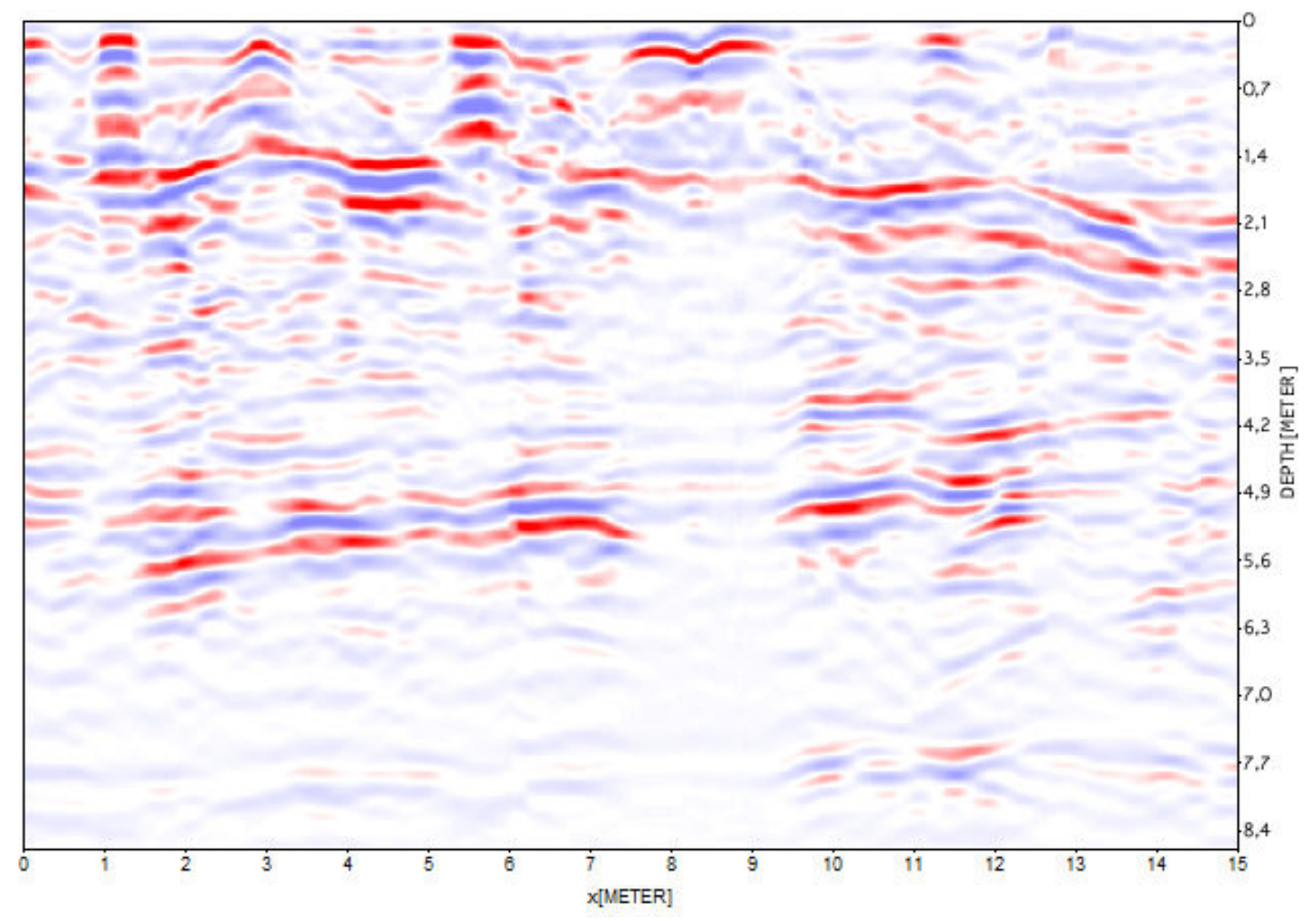

Anexo A 17 - Perfil GPR de 200 MHz número 19 na direção y para a área 1 


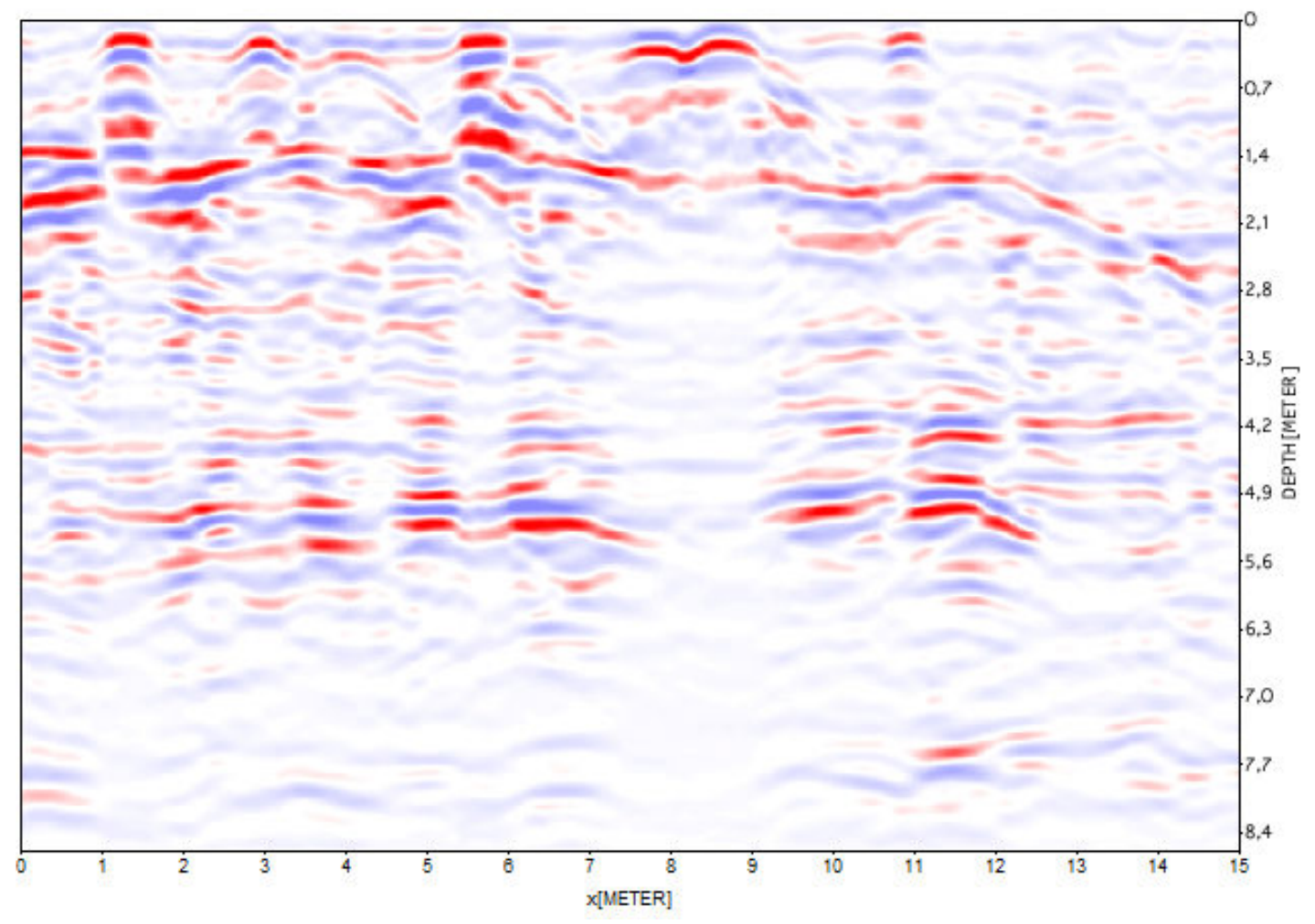

Anexo A 18 - Perfil GPR de 200 MHz número 20 na direção y para a área 1

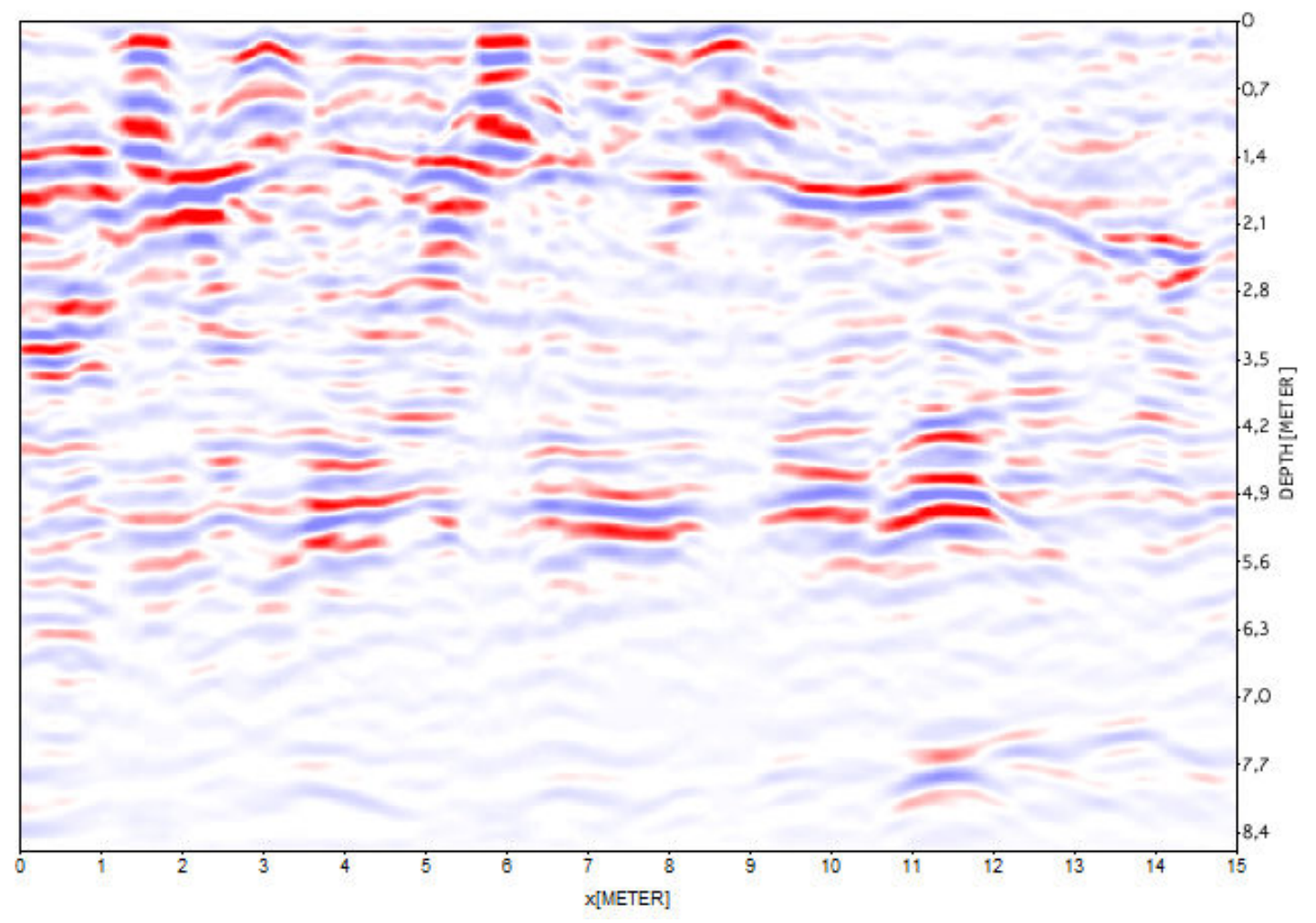

Anexo A 19 - Perfil GPR de 200 MHz número 21 na direção y para a área 1 


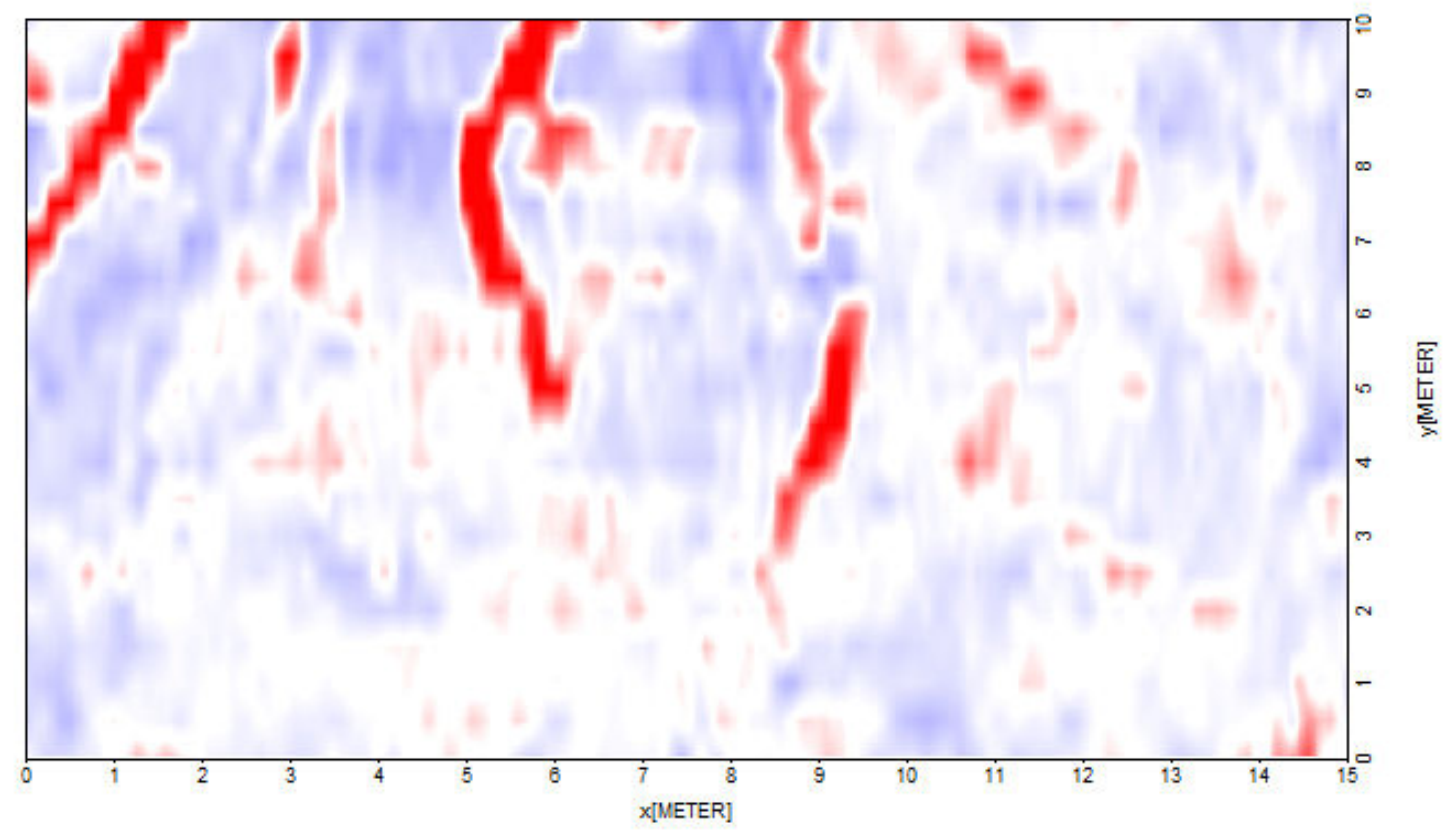

Anexo A 20 - Depth-slice GPR de 200 MHz para a área 1 (profundidade 0,1 m)

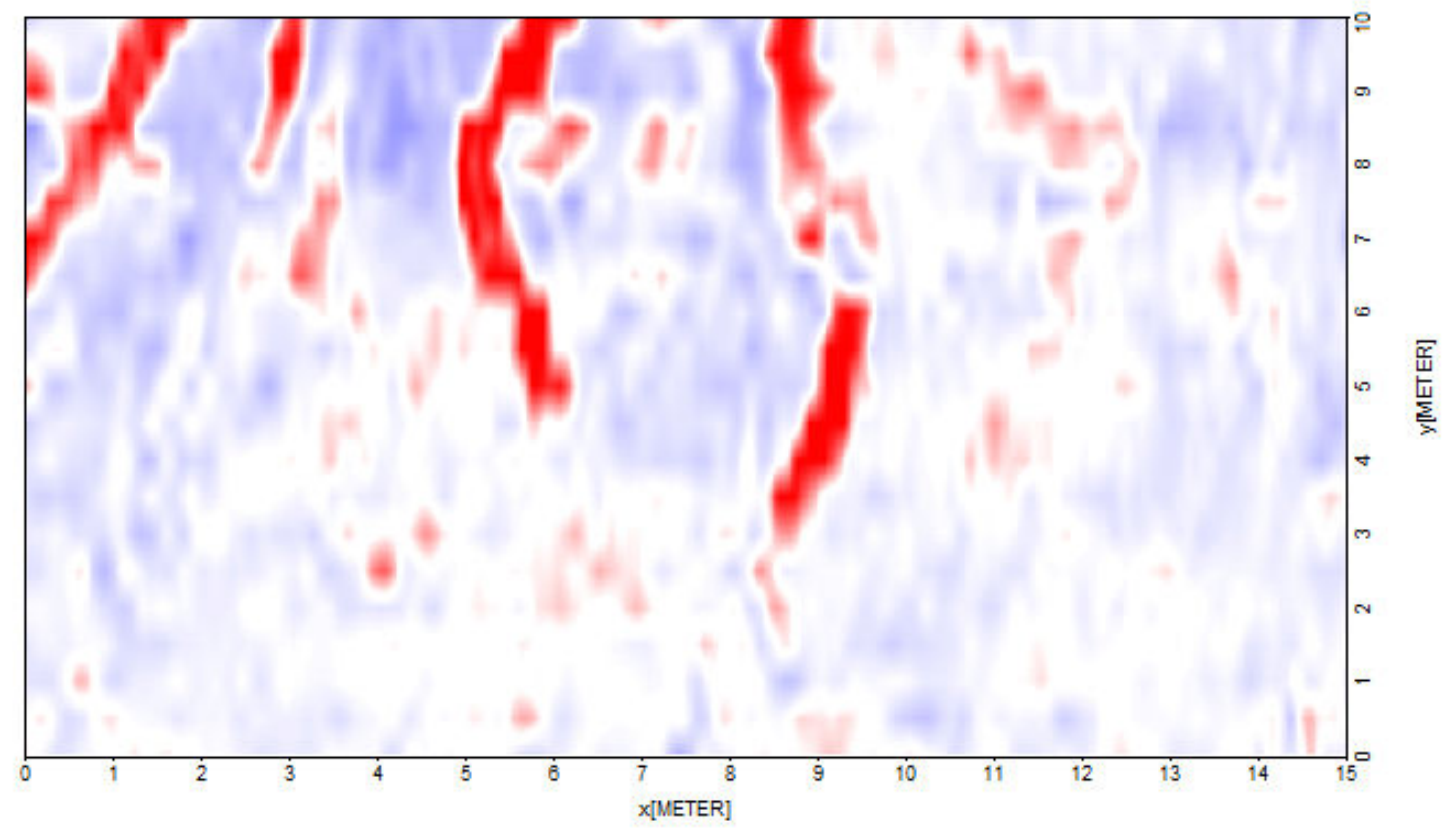

Anexo A 21 - Depth-slice GPR de 200 MHz para a área 1 (profundidade 0,2 m) 


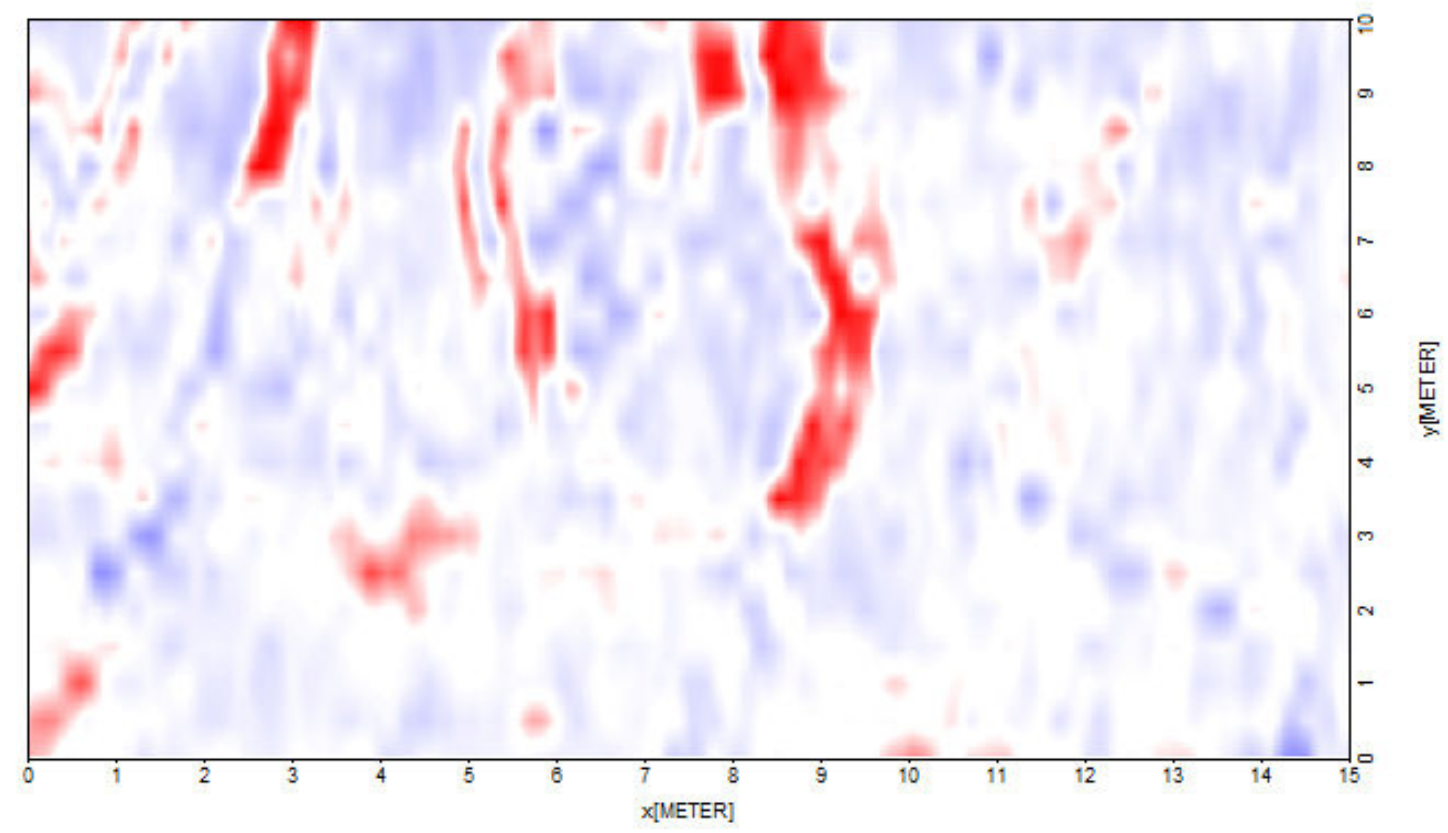

Anexo A 22 - Depth-slice GPR de 200 MHz para a área 1 (profundidade 0,3 m)

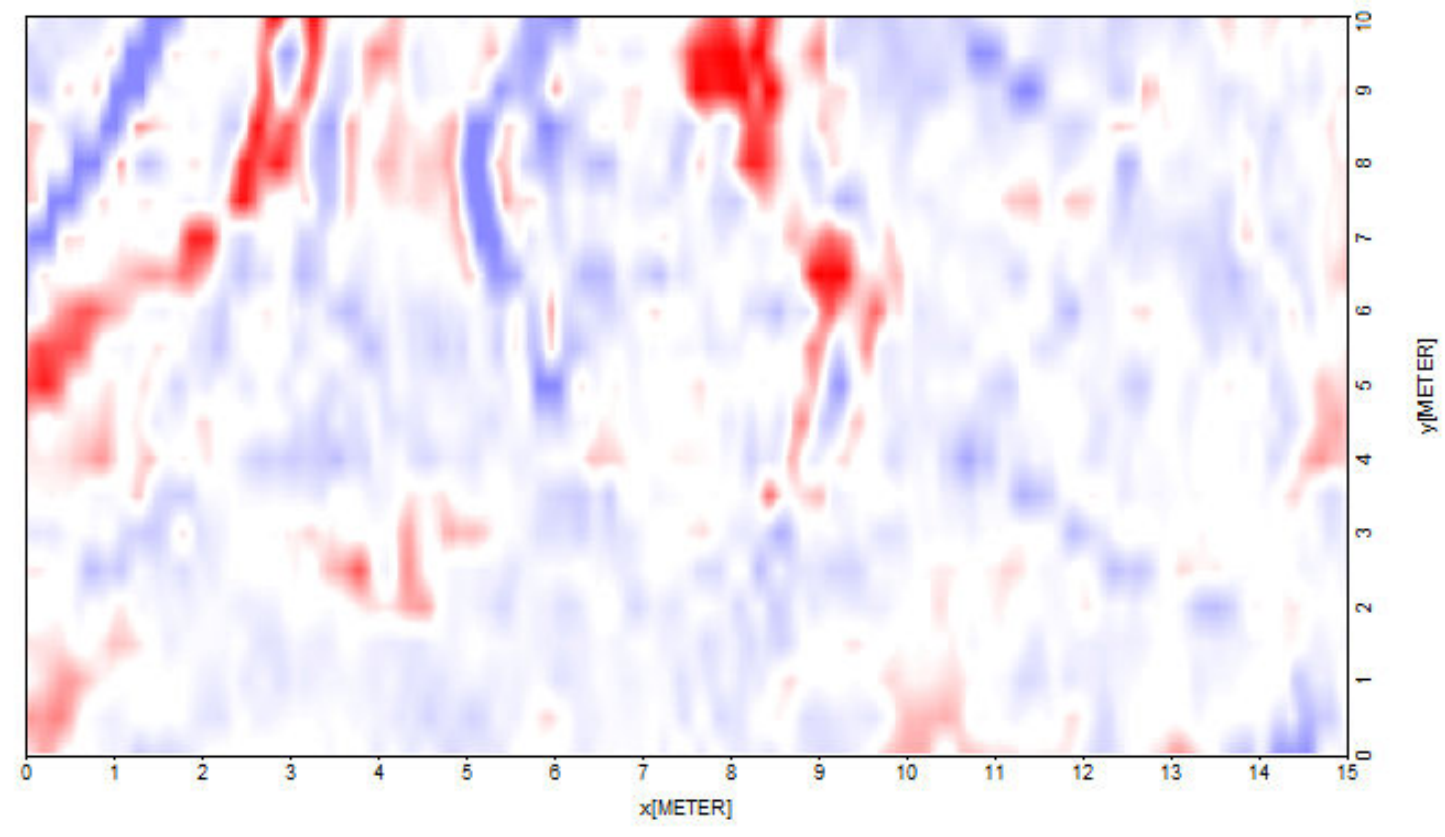

Anexo A 23 - Depth-slice GPR de 200 MHz para a área 1 (profundidade 0,4 m) 


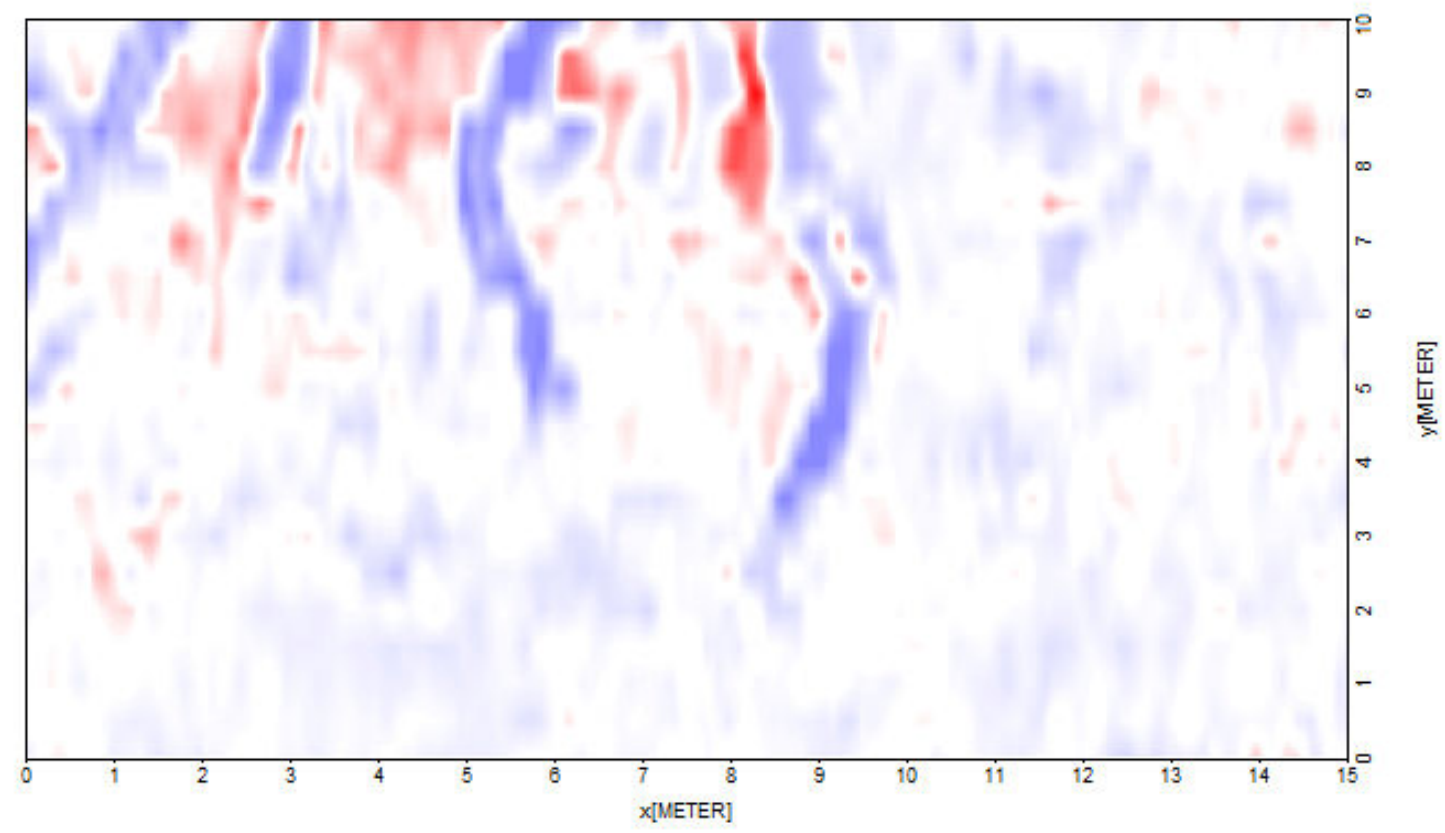

Anexo A 24 - Depth-slice GPR de 200 MHz para a área 1 (profundidade 0,5 m)

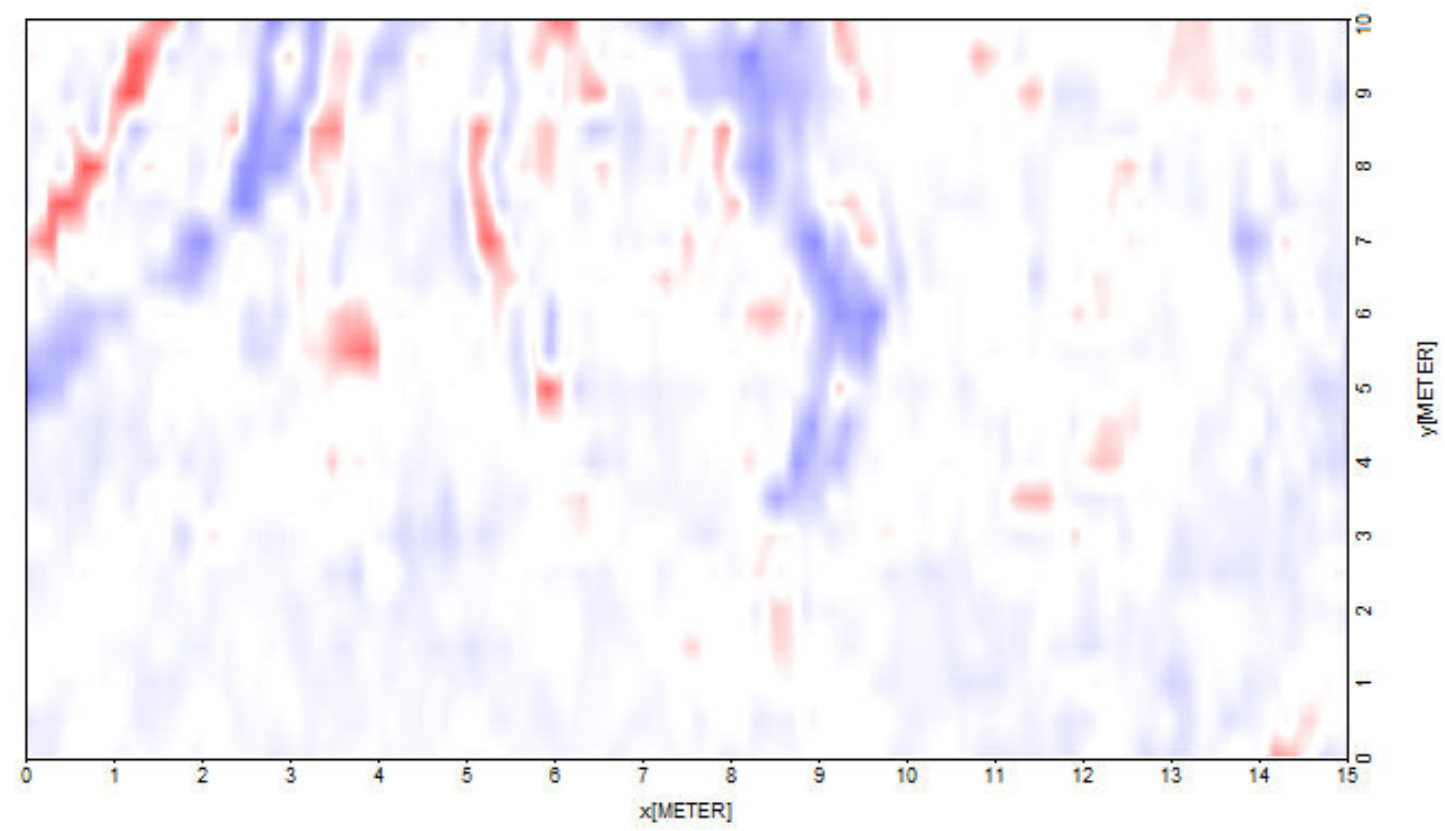

Anexo A 25 - Depth-slice GPR de 200 MHz para a área 1 (profundidade 0,6 m) 


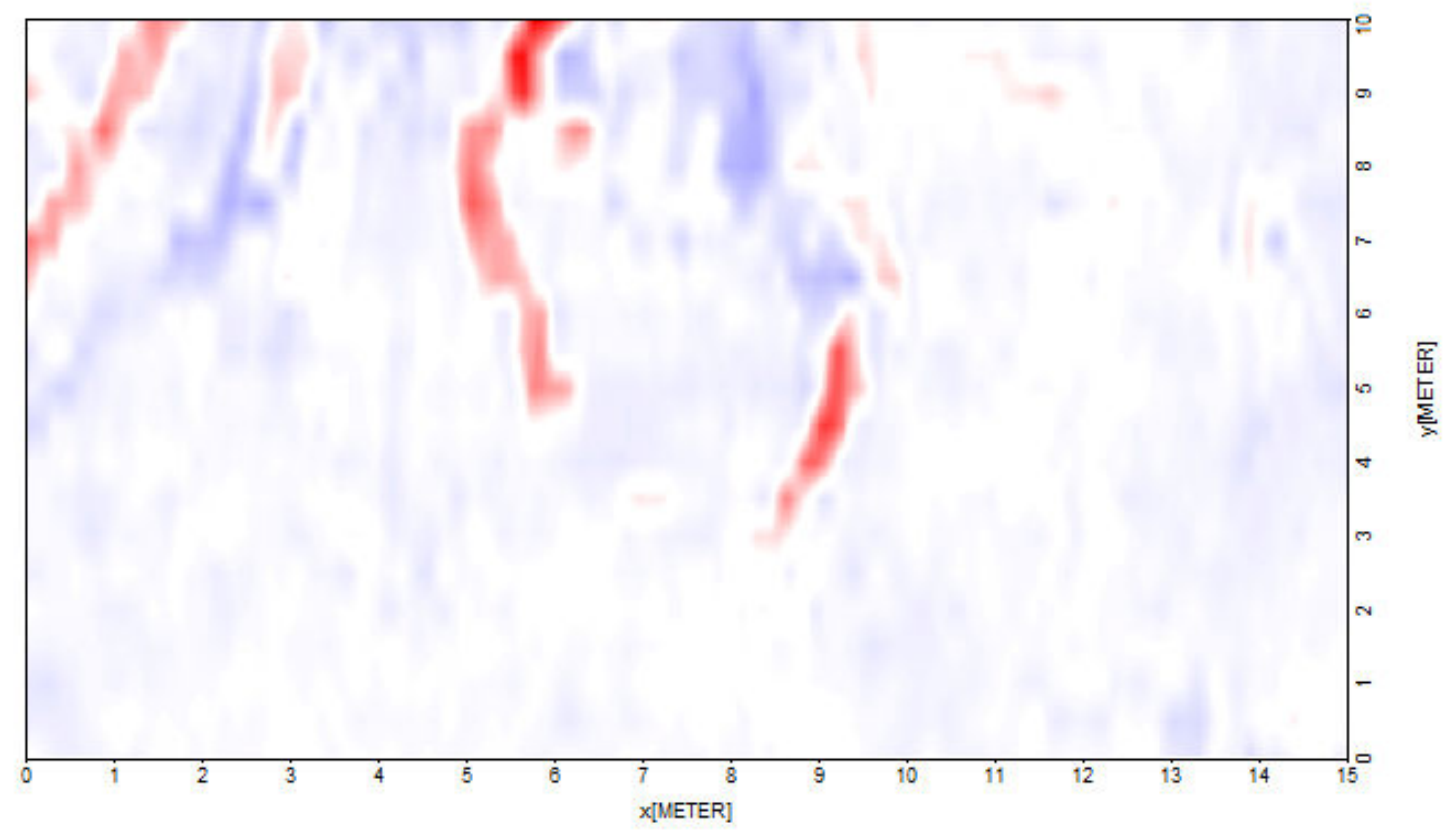

Anexo A 26 - Depth-slice GPR de 200 MHz para a área 1 (profundidade 0,7 m)

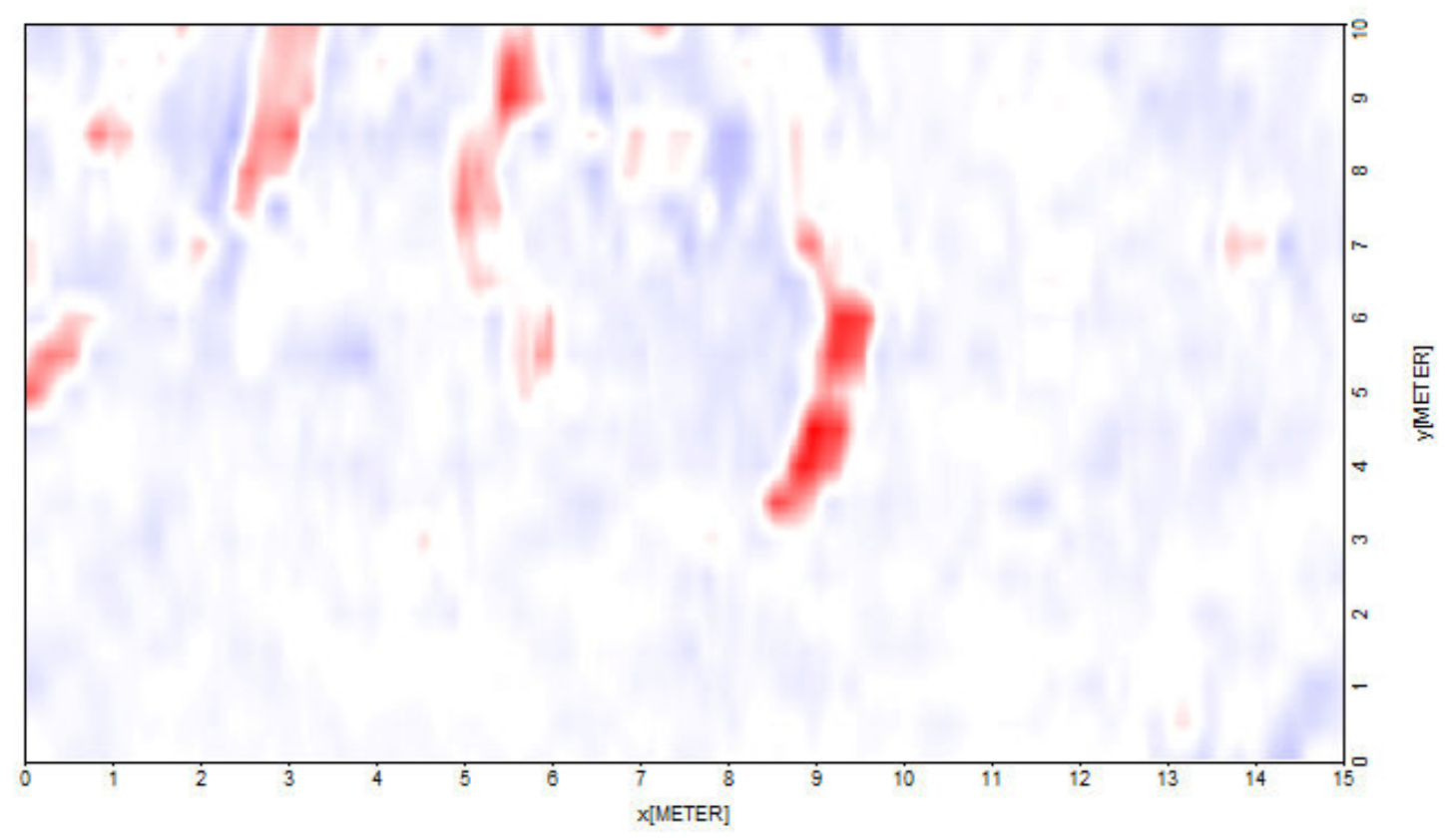

Anexo A 27 - Depth-slice GPR de 200 MHz para a área 1 (profundidade 0,8 m) 


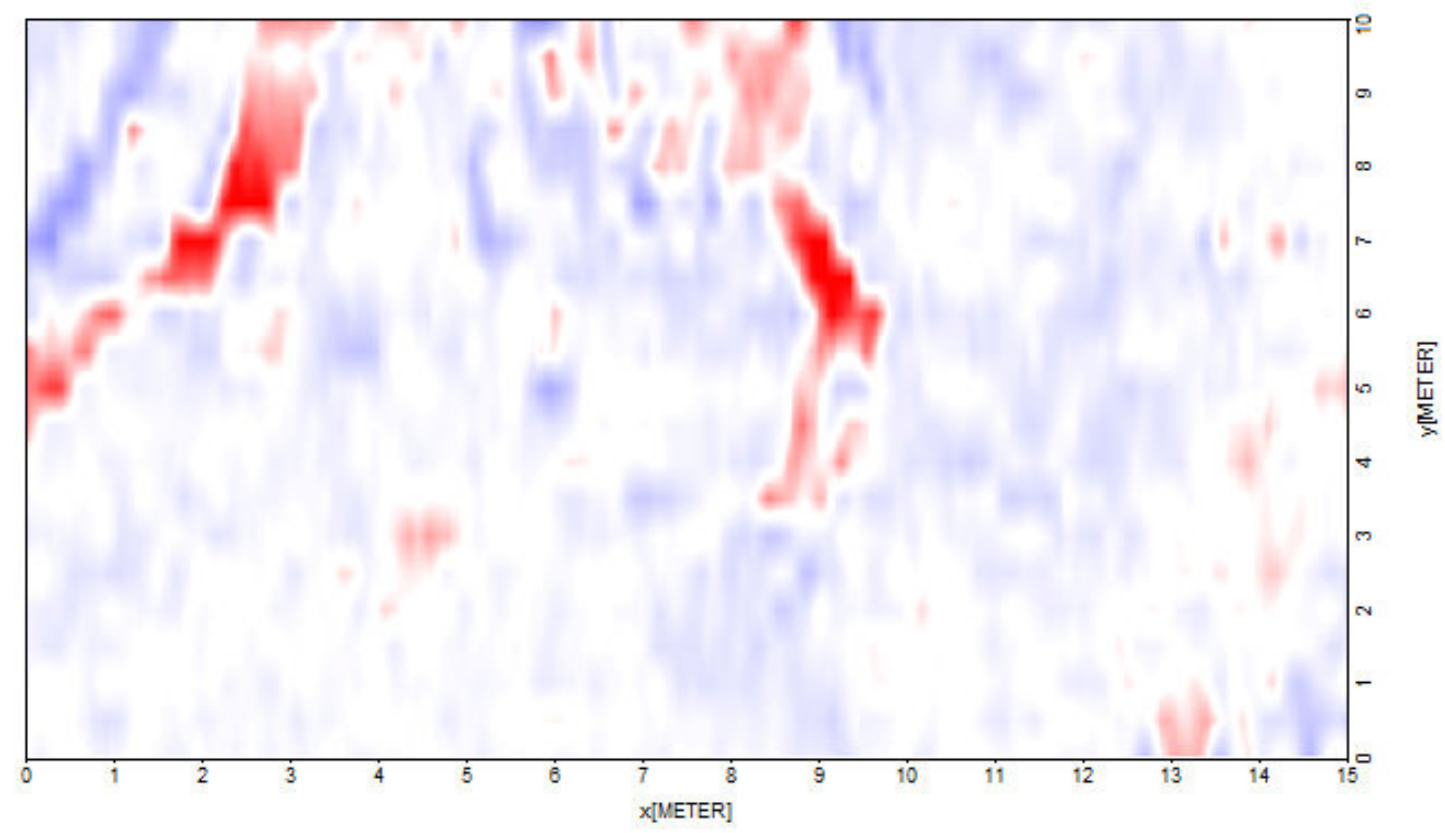

Anexo A 28 - Depth-slice GPR de 200 MHz para a área 1 (profundidade 0,9 m)

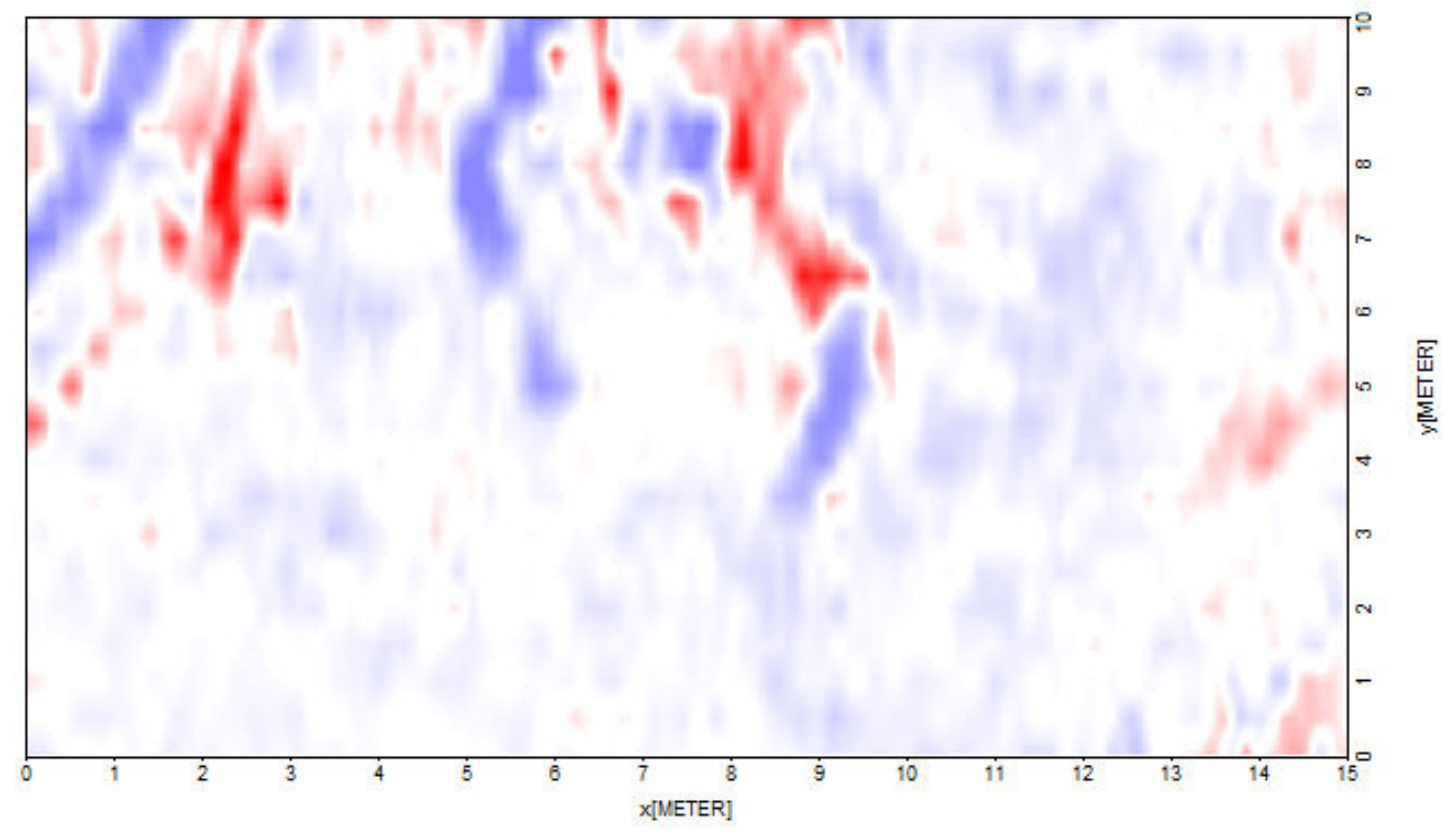

Anexo A 29 - Depth-slice GPR de 200 MHz para a área 1 (profundidade 1,0 m) 


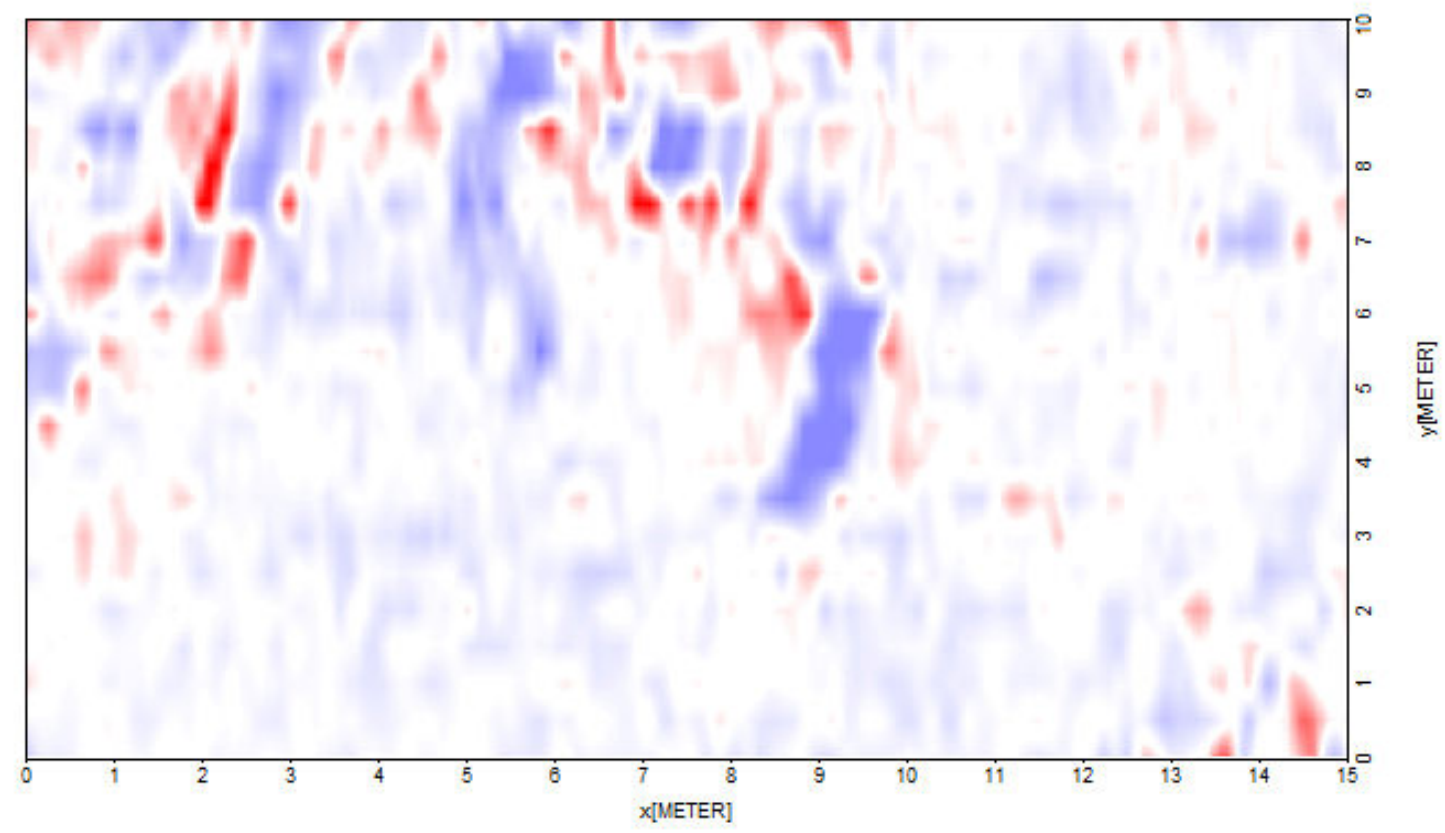

Anexo A 30 - Depth-slice GPR de 200 MHz para a área 1 (profundidade 1,1 m)

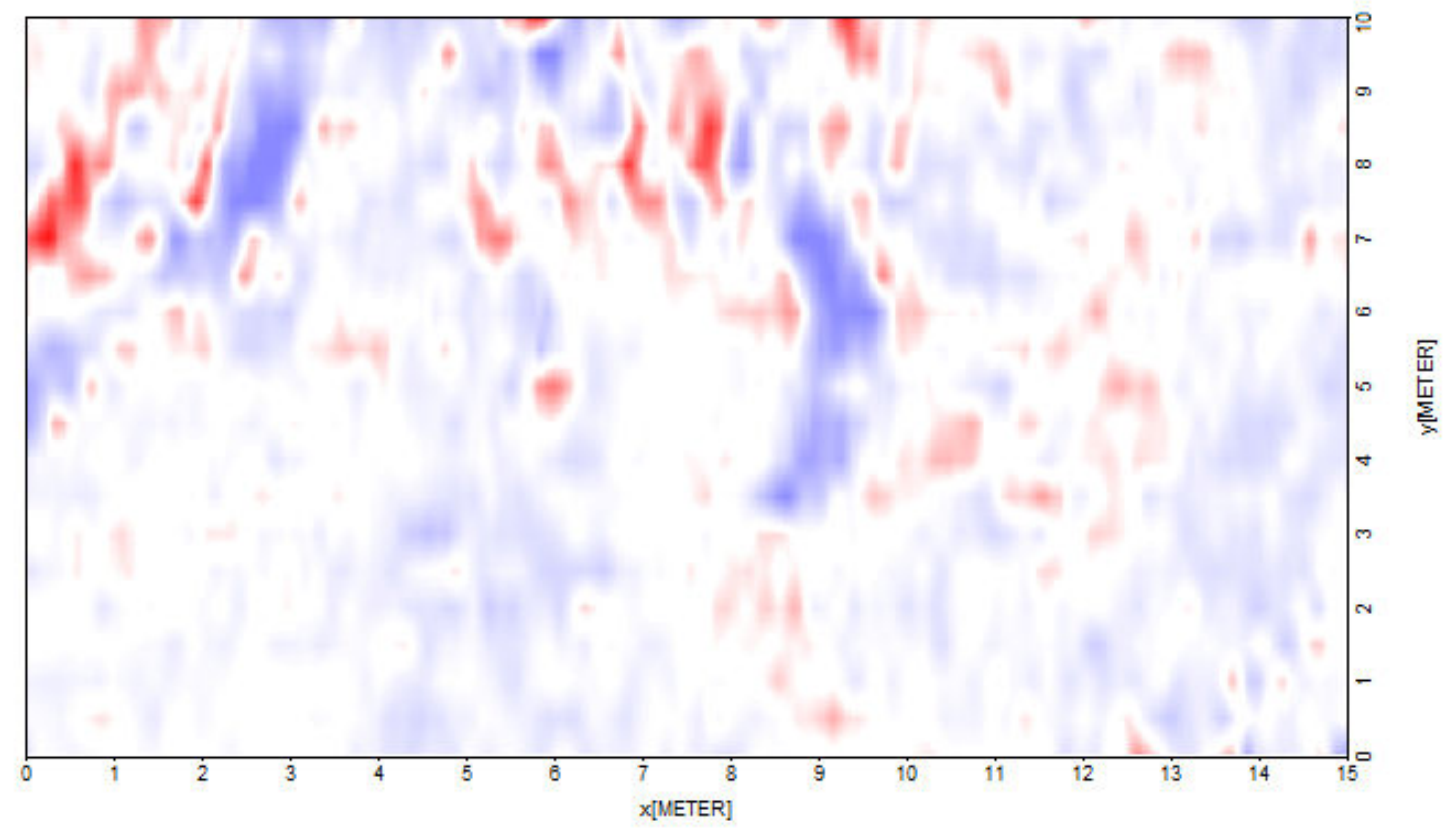

Anexo A 31 - Depth-slice GPR de 200 MHz para a área 1 (profundidade 1,2 m) 


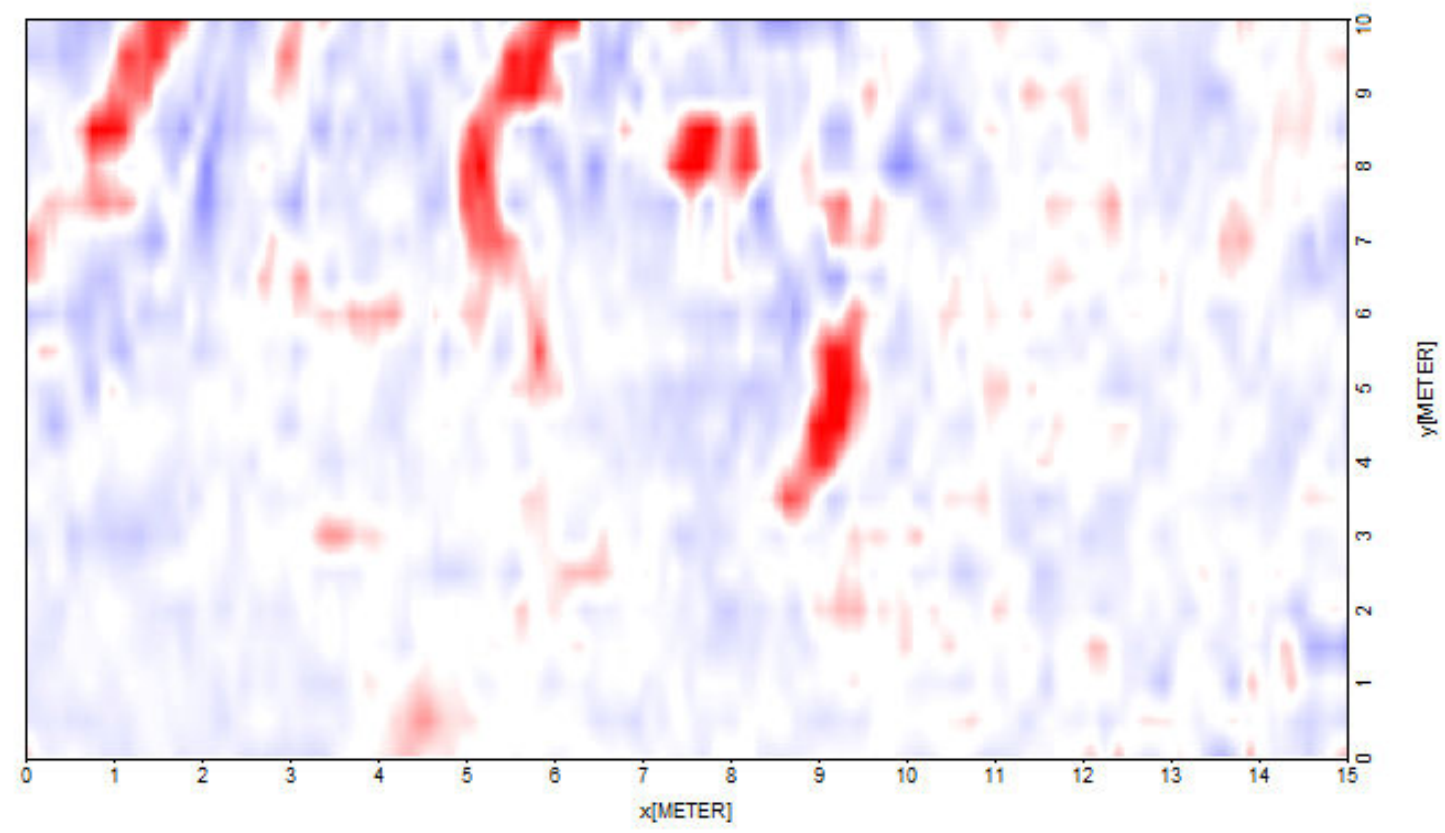

Anexo A 32 - Depth-slice GPR de 200 MHz para a área 1 (profundidade 1,4 m)

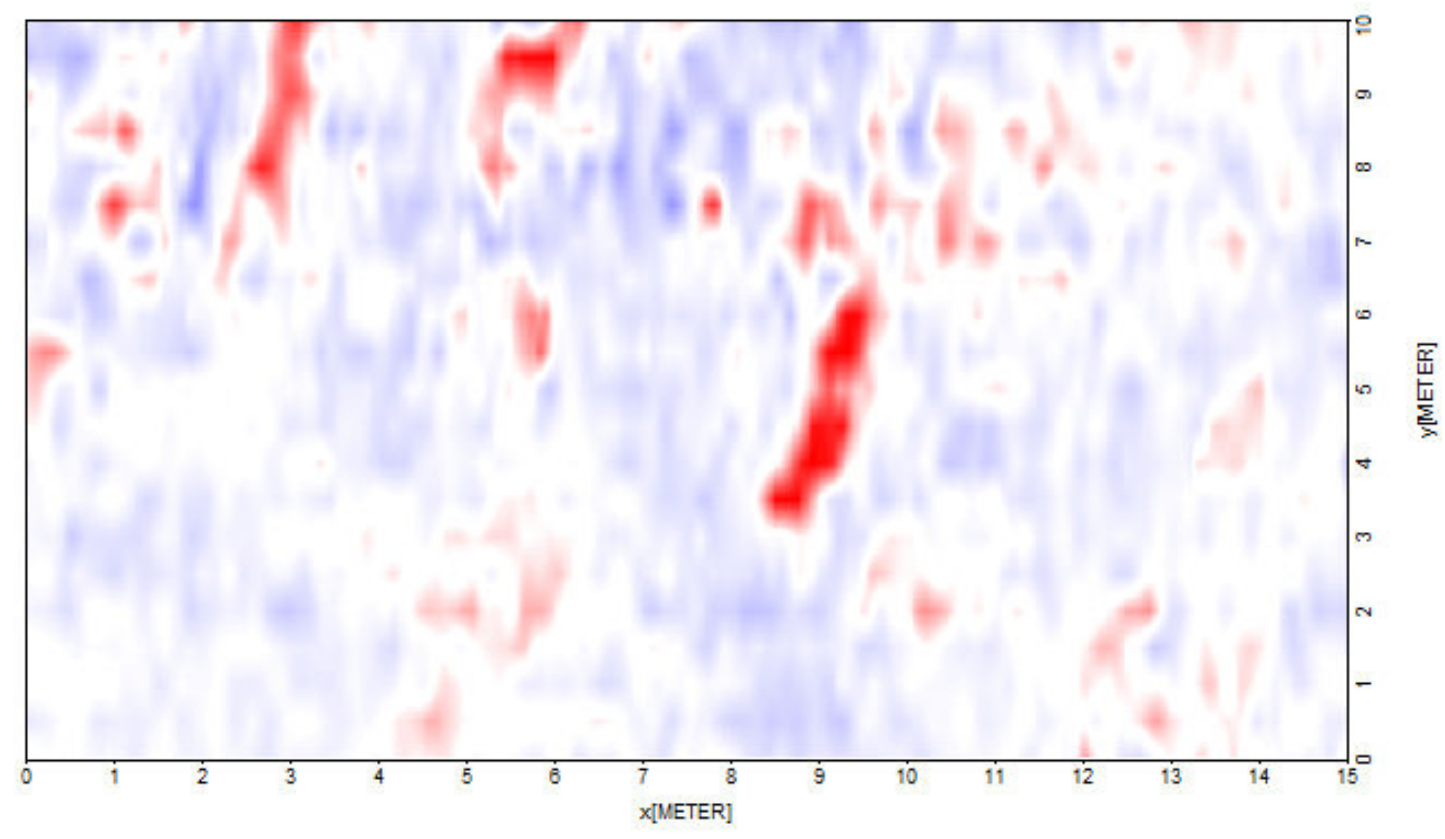

Anexo A 33 - Depth-slice GPR de 200 MHz para a área 1 (profundidade 1,5 m) 


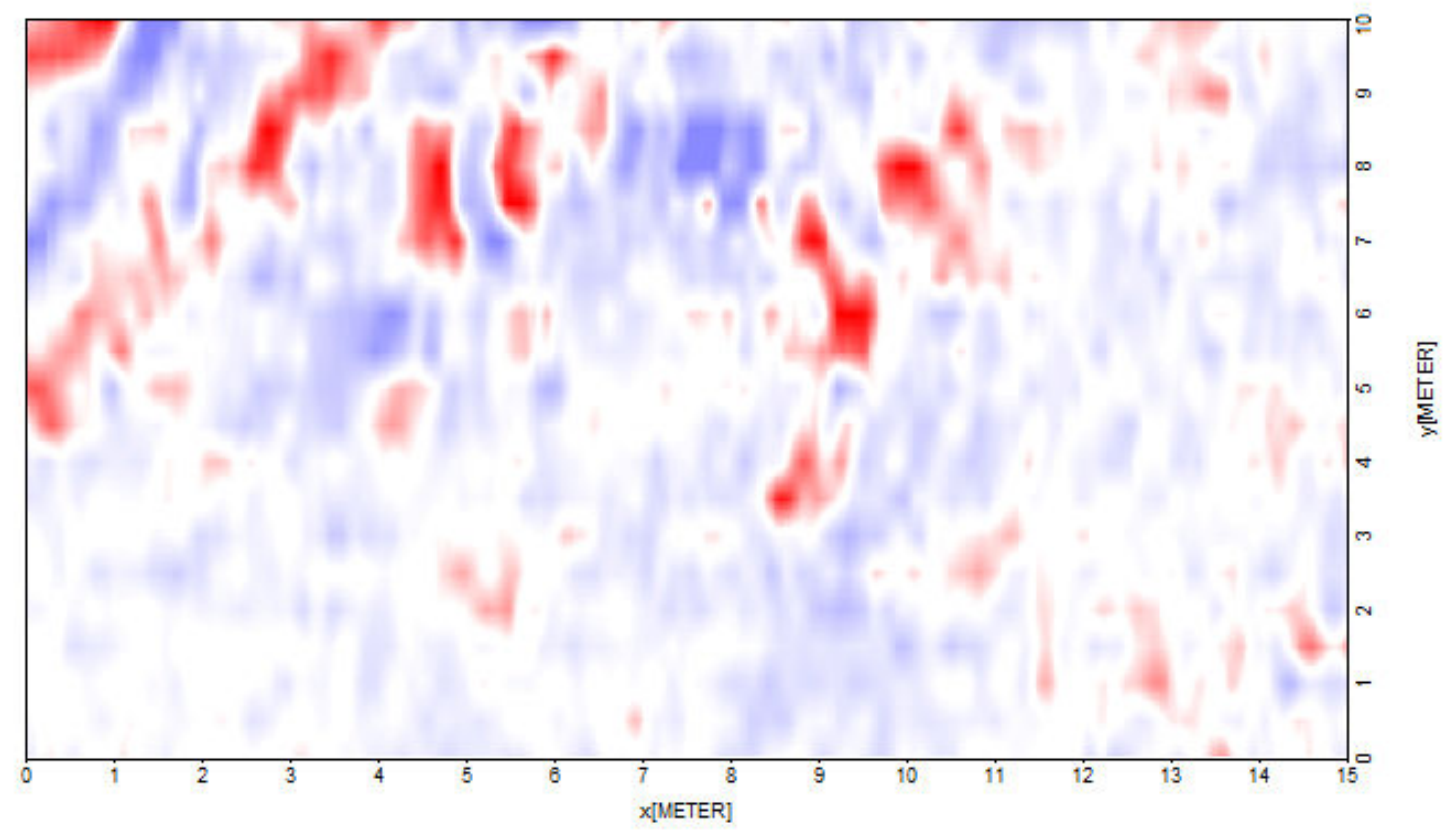

Anexo A 34 - Depth-slice GPR de 200 MHz para a área 1 (profundidade 1,6 m)

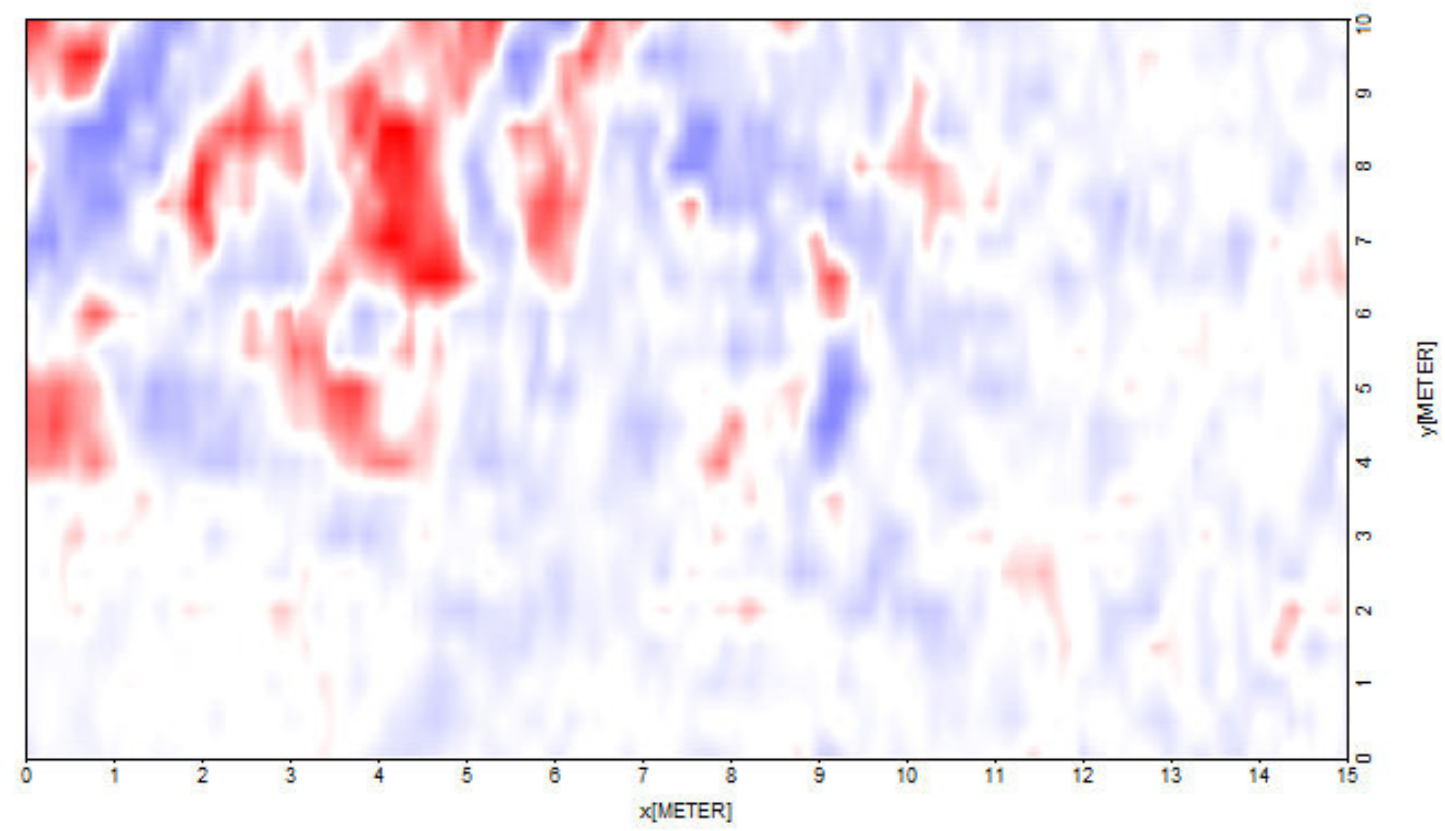

Anexo A 35 - Depth-slice GPR de 200 MHz para a área 1 (profundidade 1,7 m) 


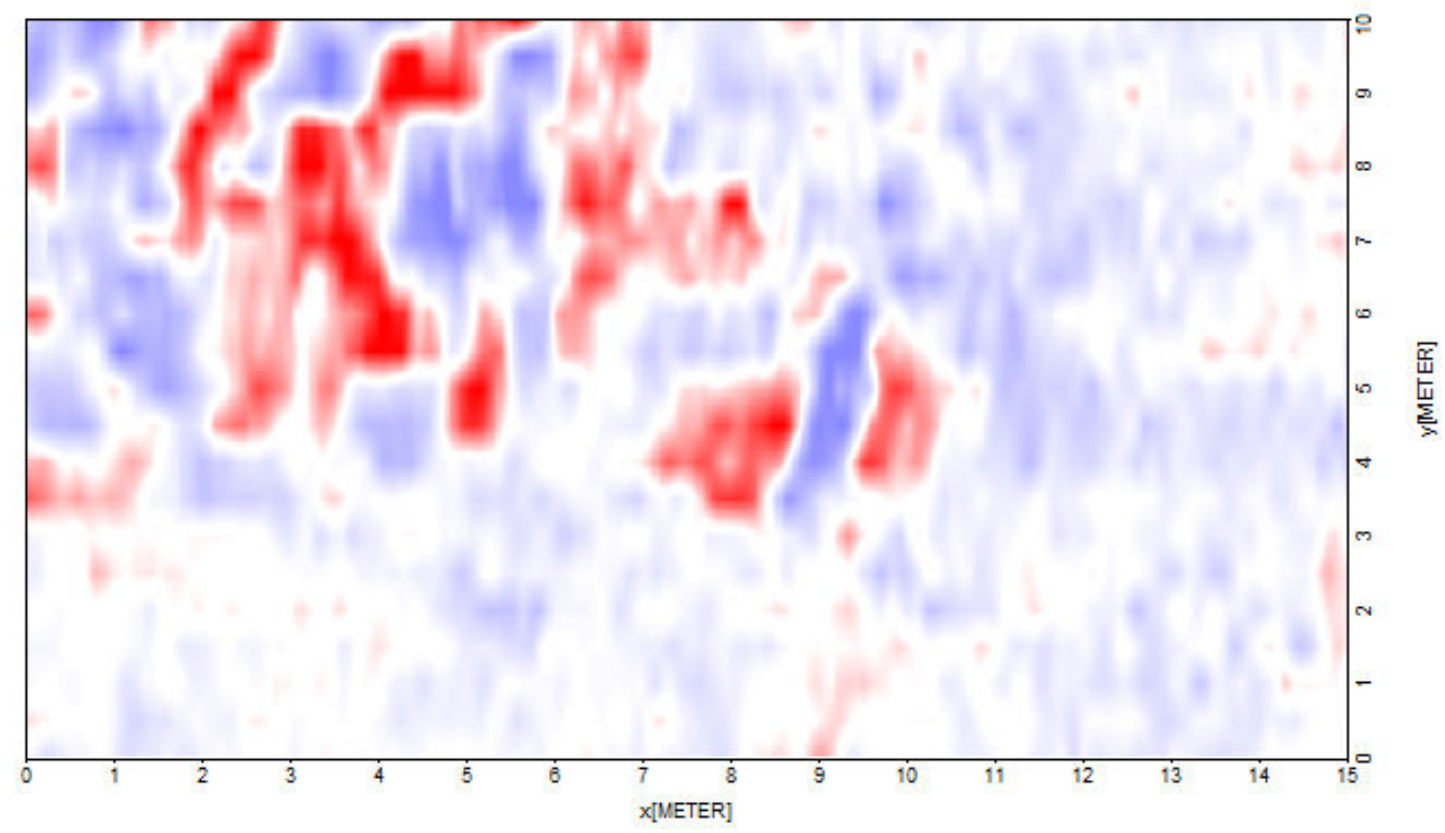

Anexo A 36 - Depth-slice GPR de 200 MHz para a área 1 (profundidade 1,8 m)

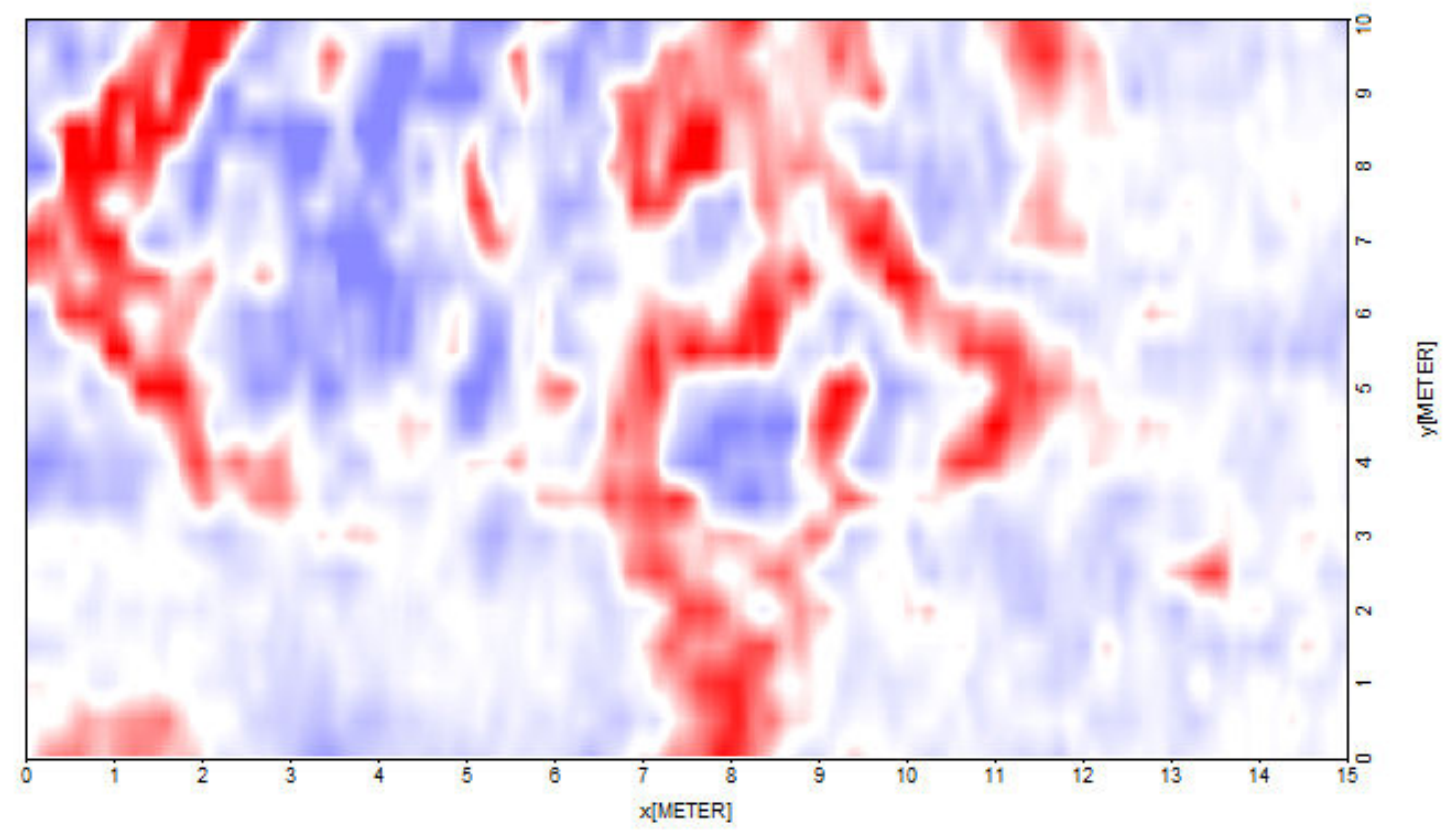

Anexo A 37 - Depth-slice GPR de 200 MHz para a área 1 (profundidade 1,9 m) 


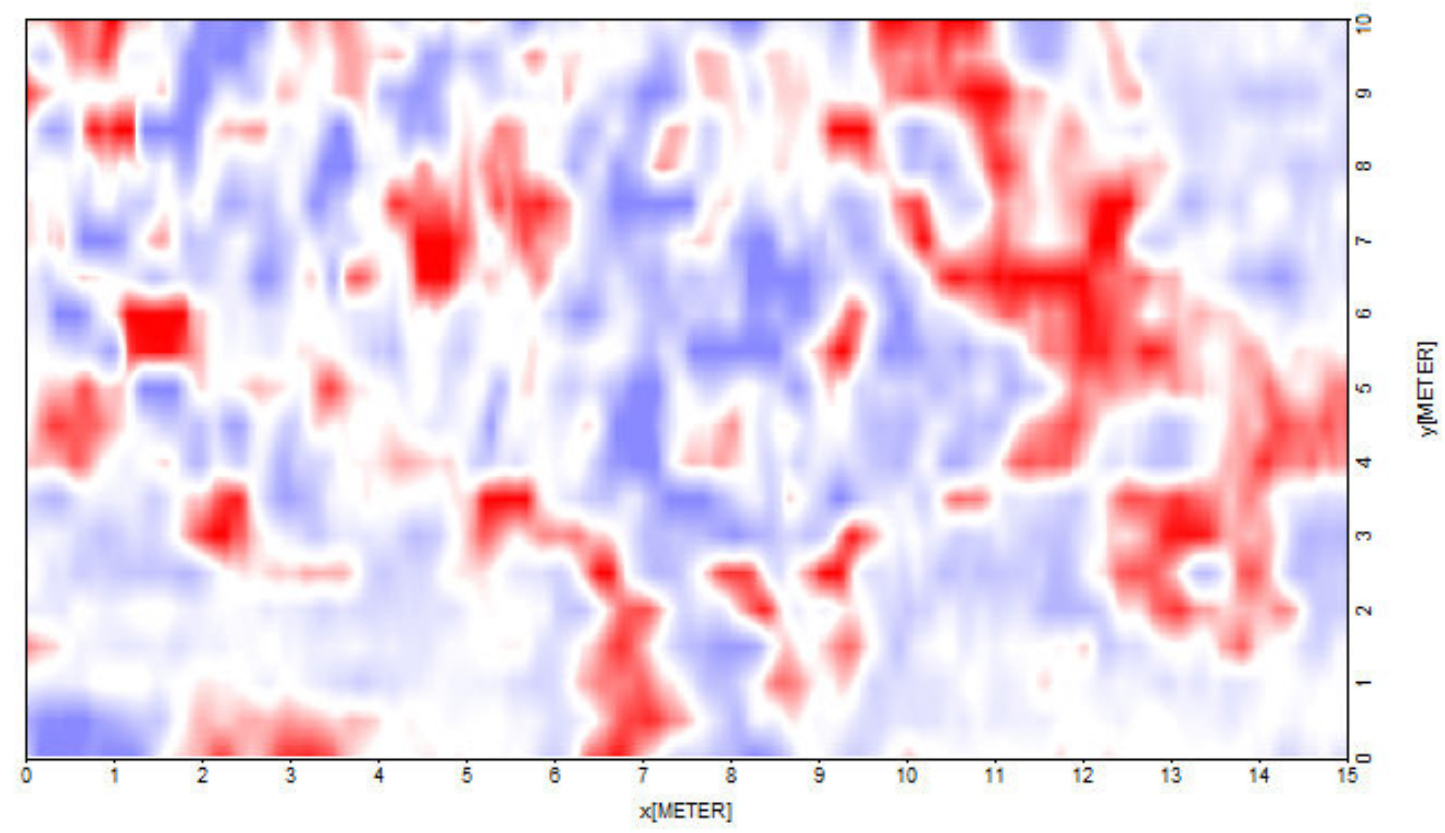

Anexo A 38 - Depth-slice GPR de 200 MHz para a área 1 (profundidade 2,1 m)

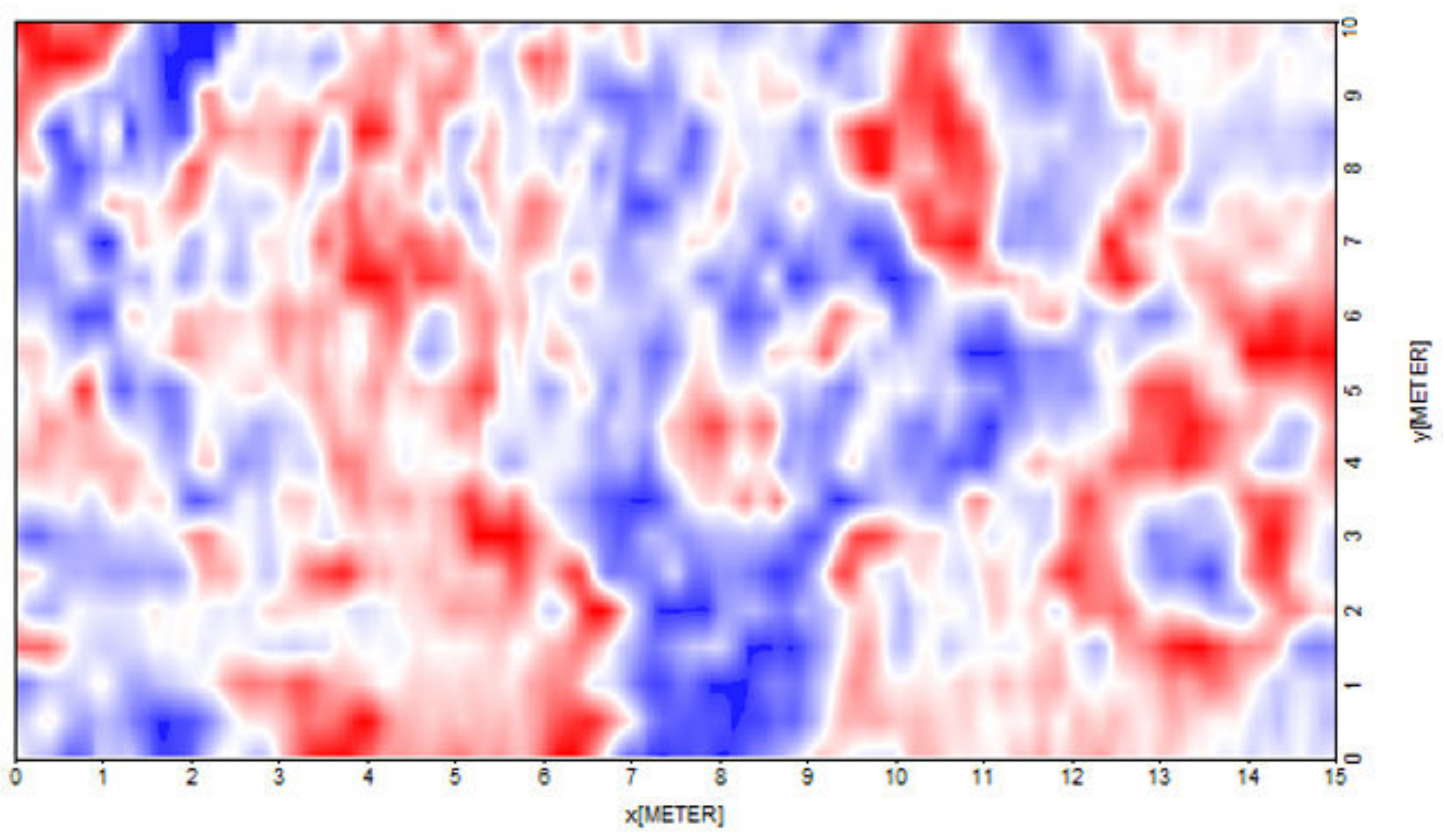

Anexo A 39 - Depth-slice GPR de 200 MHz para a área 1 (profundidade 2,2 m) 


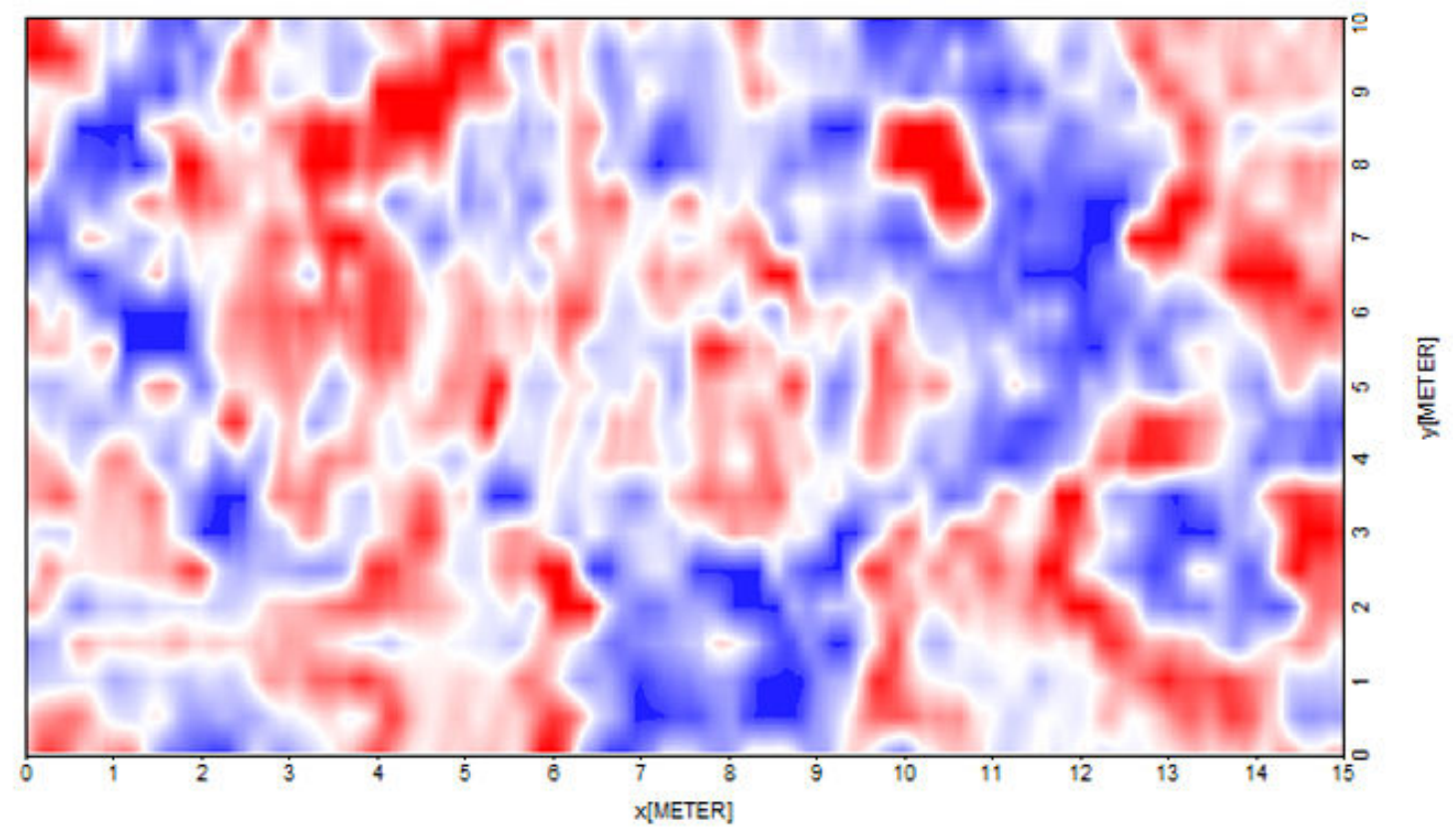

Anexo A 40 - Depth-slice GPR de 200 MHz para a área 1 (profundidade 2,3 m)

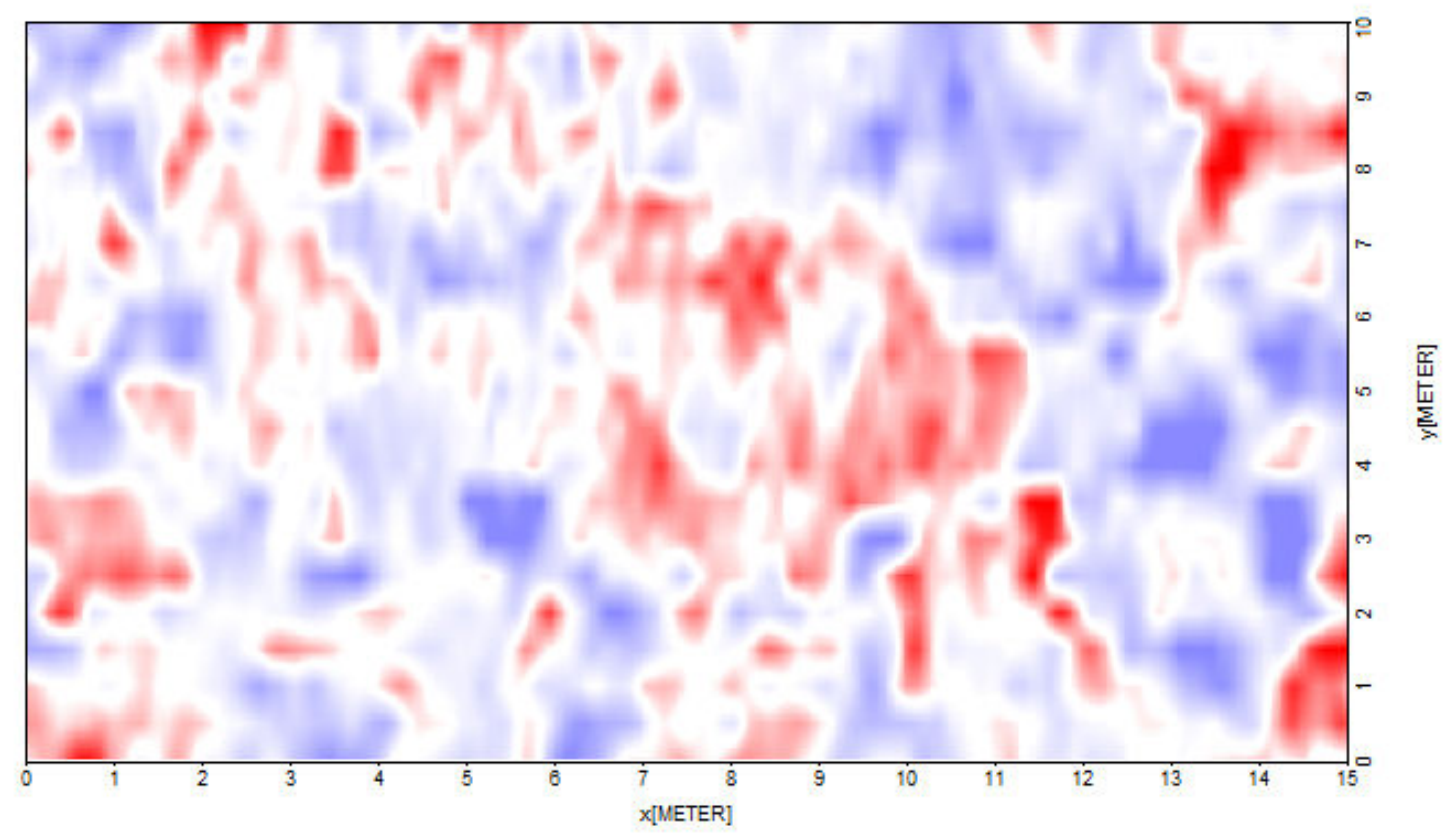

Anexo A 41 - Depth-slice GPR de 200 MHz para a área 1 (profundidade 2,4 m) 


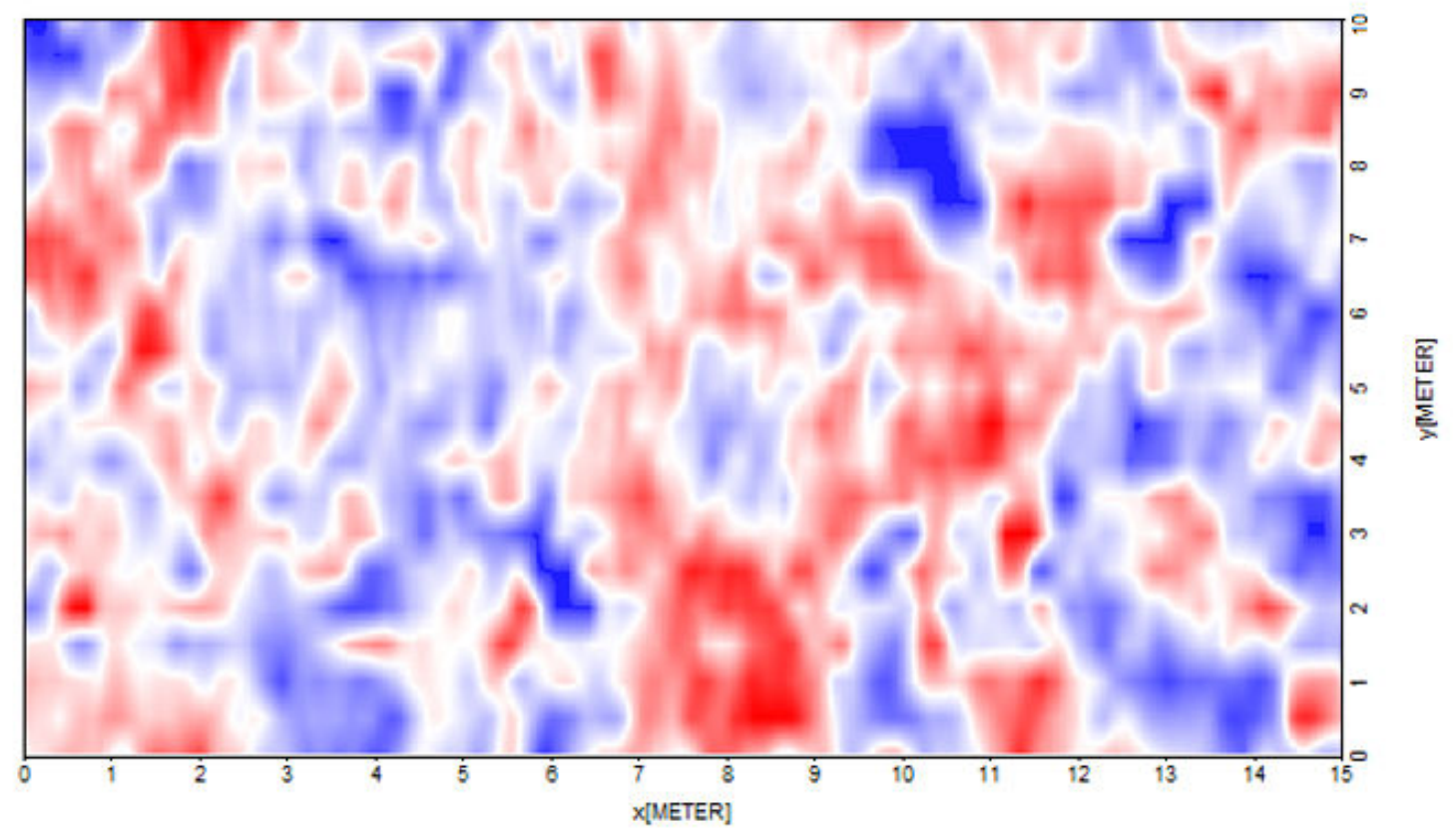

Anexo A 42 - Depth-slice GPR de 200 MHz para a área 1 (profundidade 2,5 m) 


\section{ANEXO B: ÁREA 2}

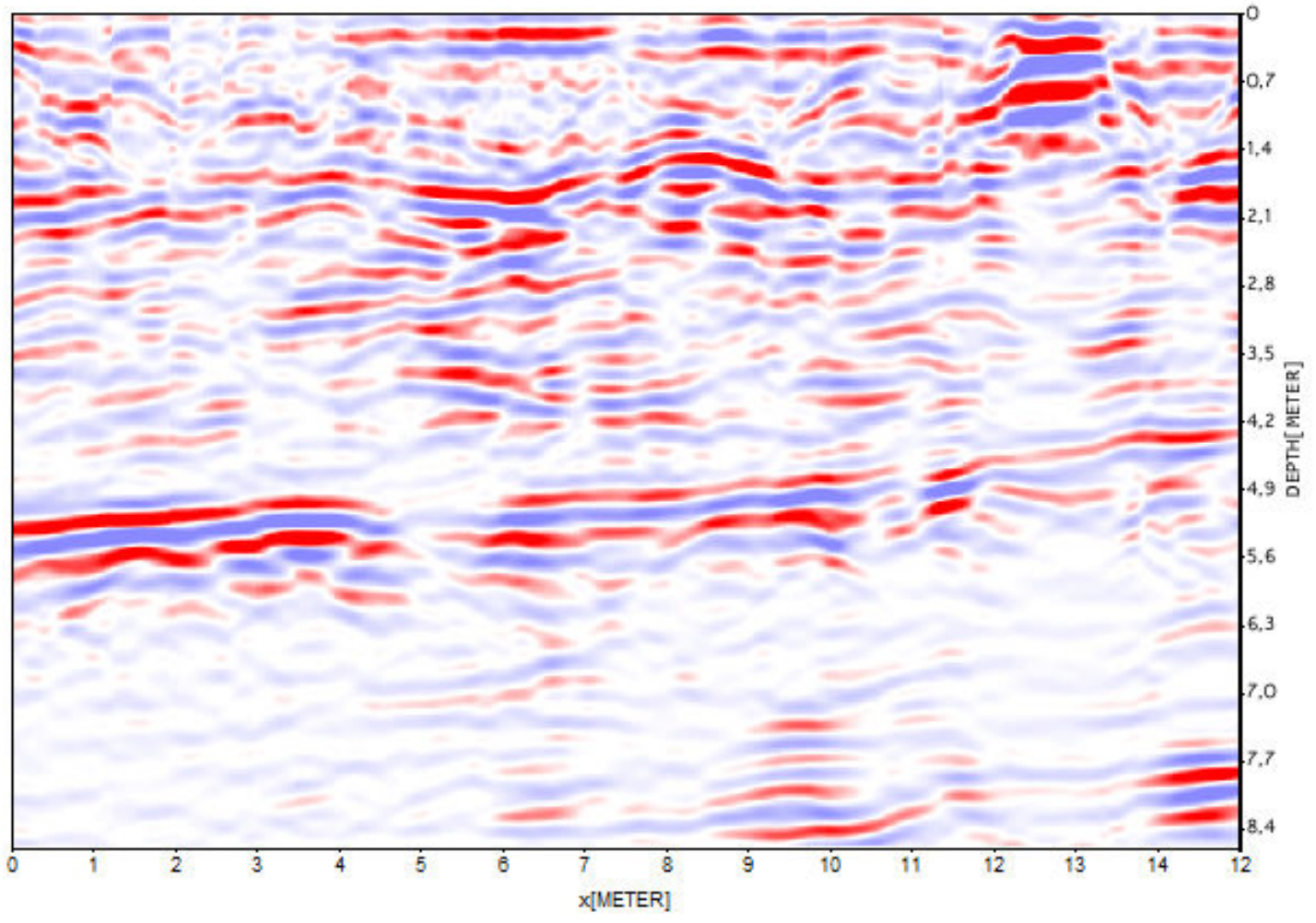

Anexo B 1 - Perfil GPR de 200 MHz número 1 na direção y para a área 2 


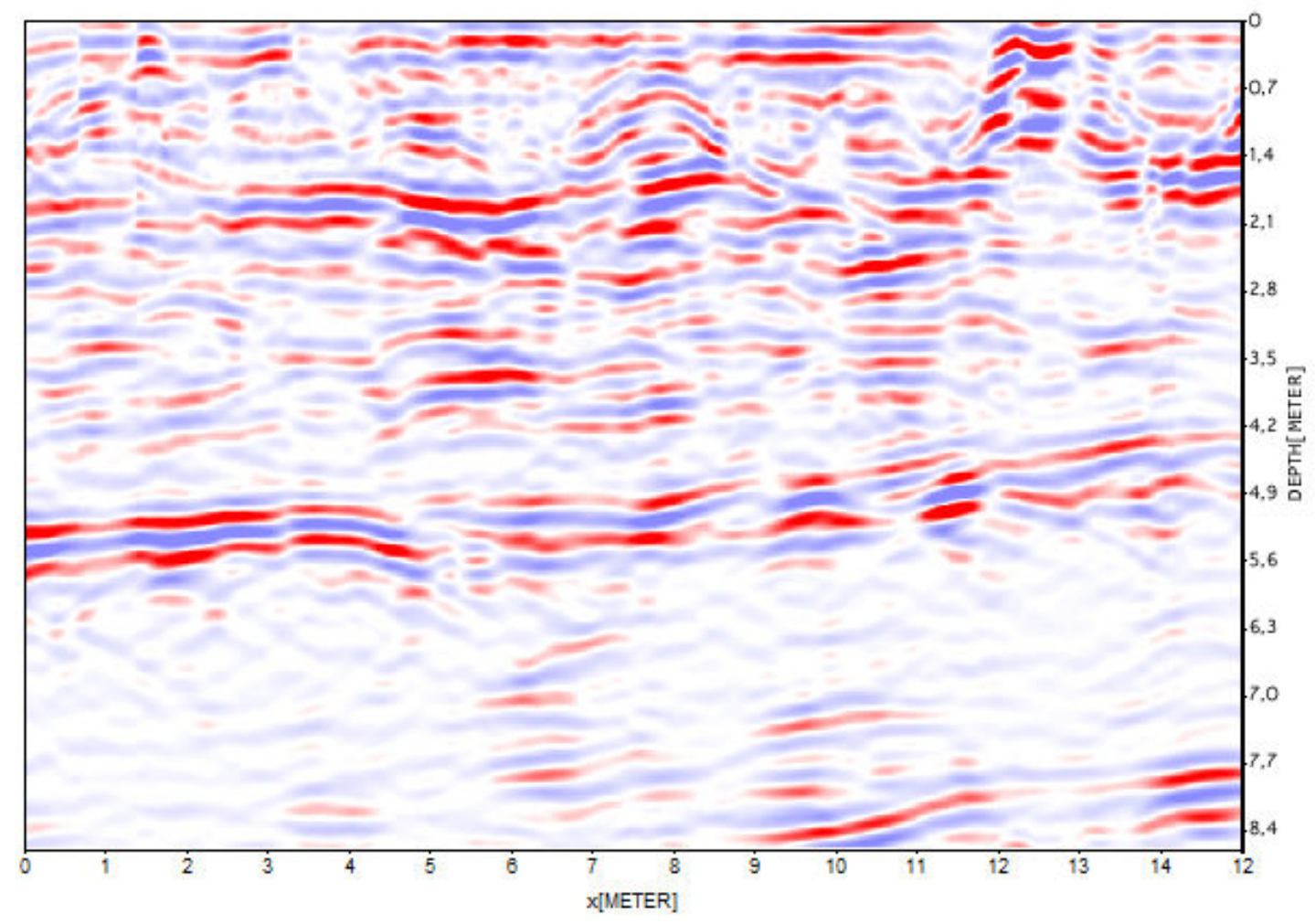

Anexo B 2 - Perfil GPR de 200 MHz número 2 na direção y para a área 2

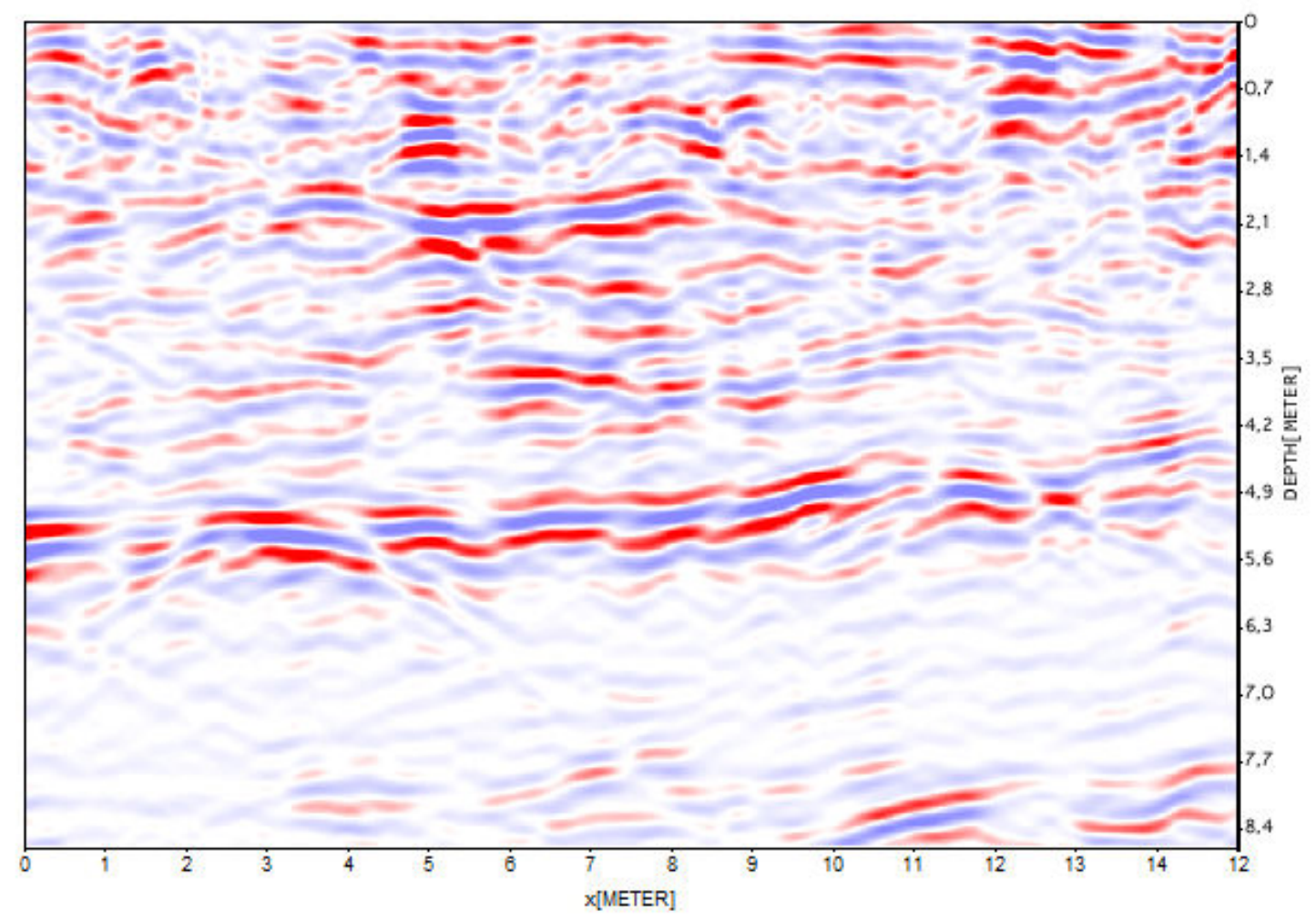

Anexo B 3 - Perfil GPR de 200 MHz número 3 na direção y para a área 2 


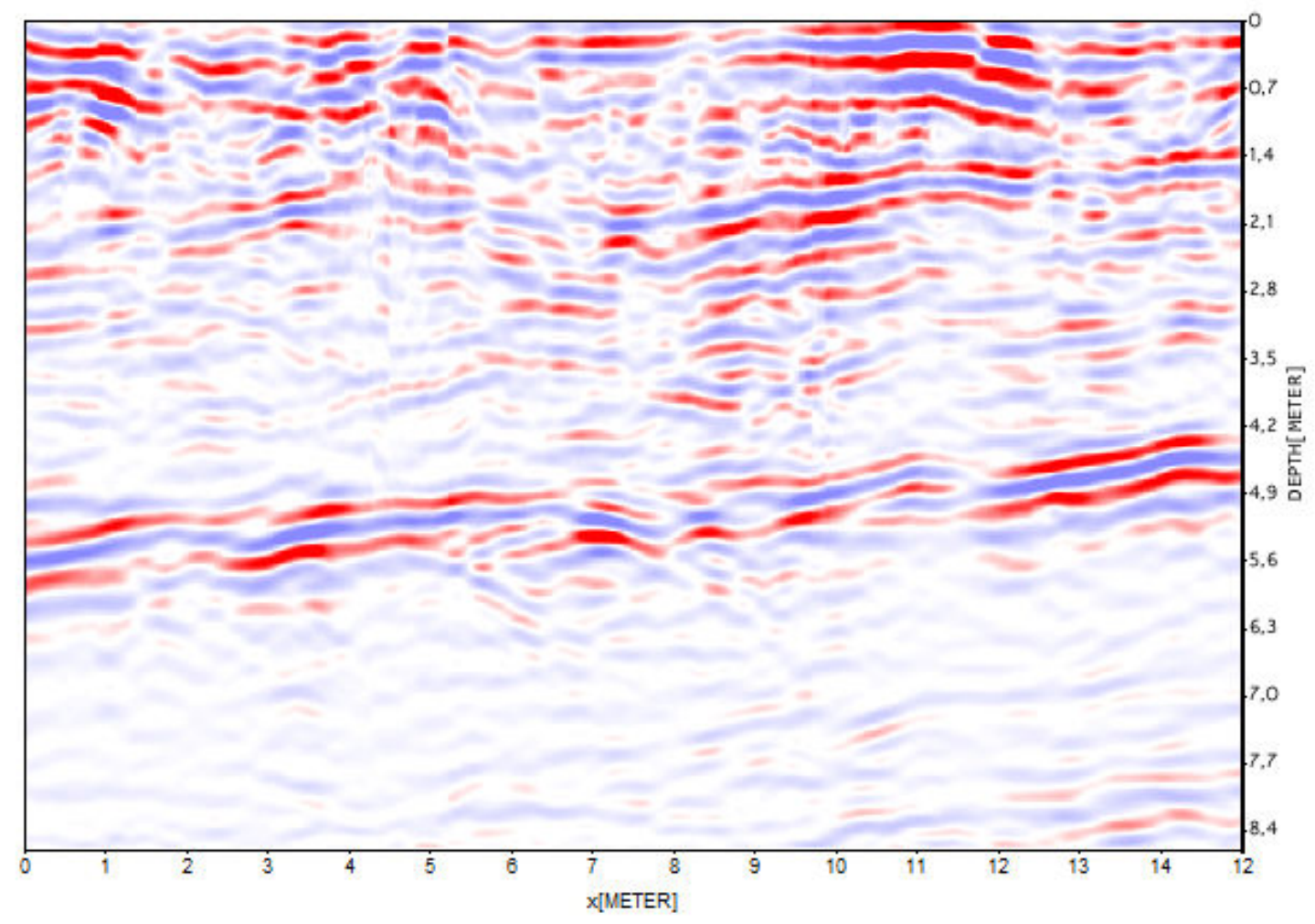

Anexo B 4 - Perfil GPR de 200 MHz número 5 na direção y para a área 2

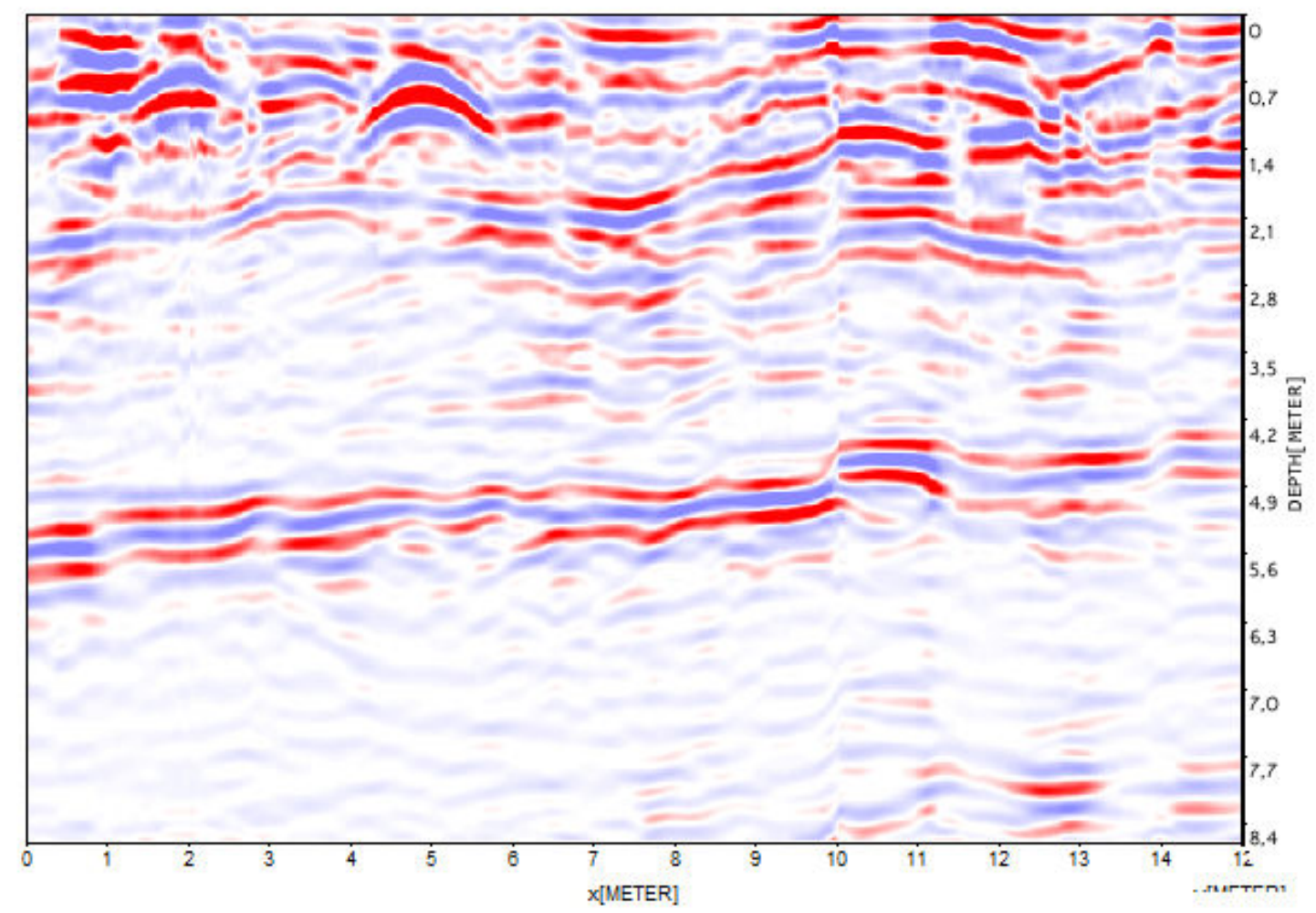

Anexo B 5 - Perfil GPR de 200 MHz número 7 na direção y para a área 2 


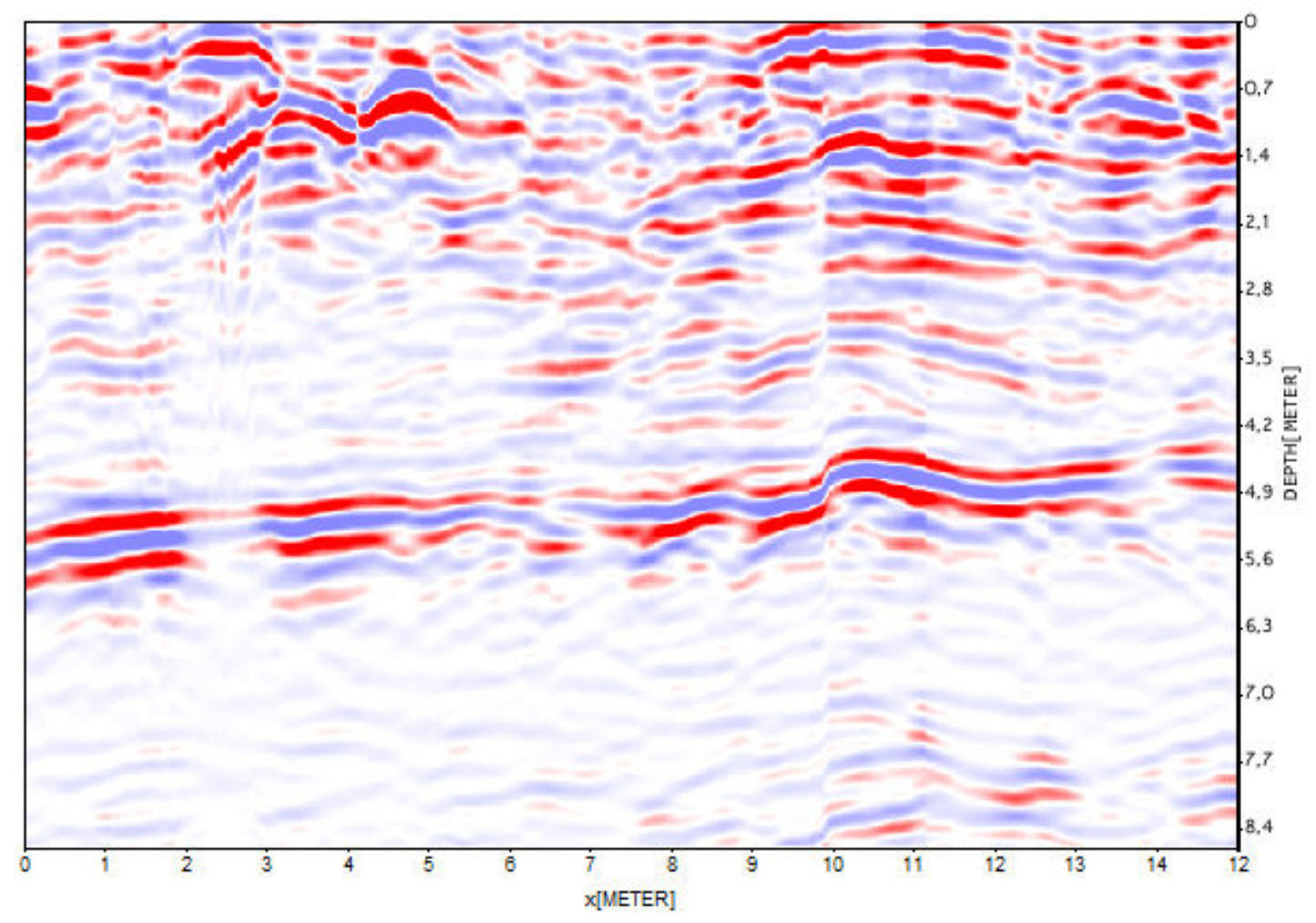

Anexo B 6 - Perfil GPR de 200 MHz número 8 na direção y para a área 2

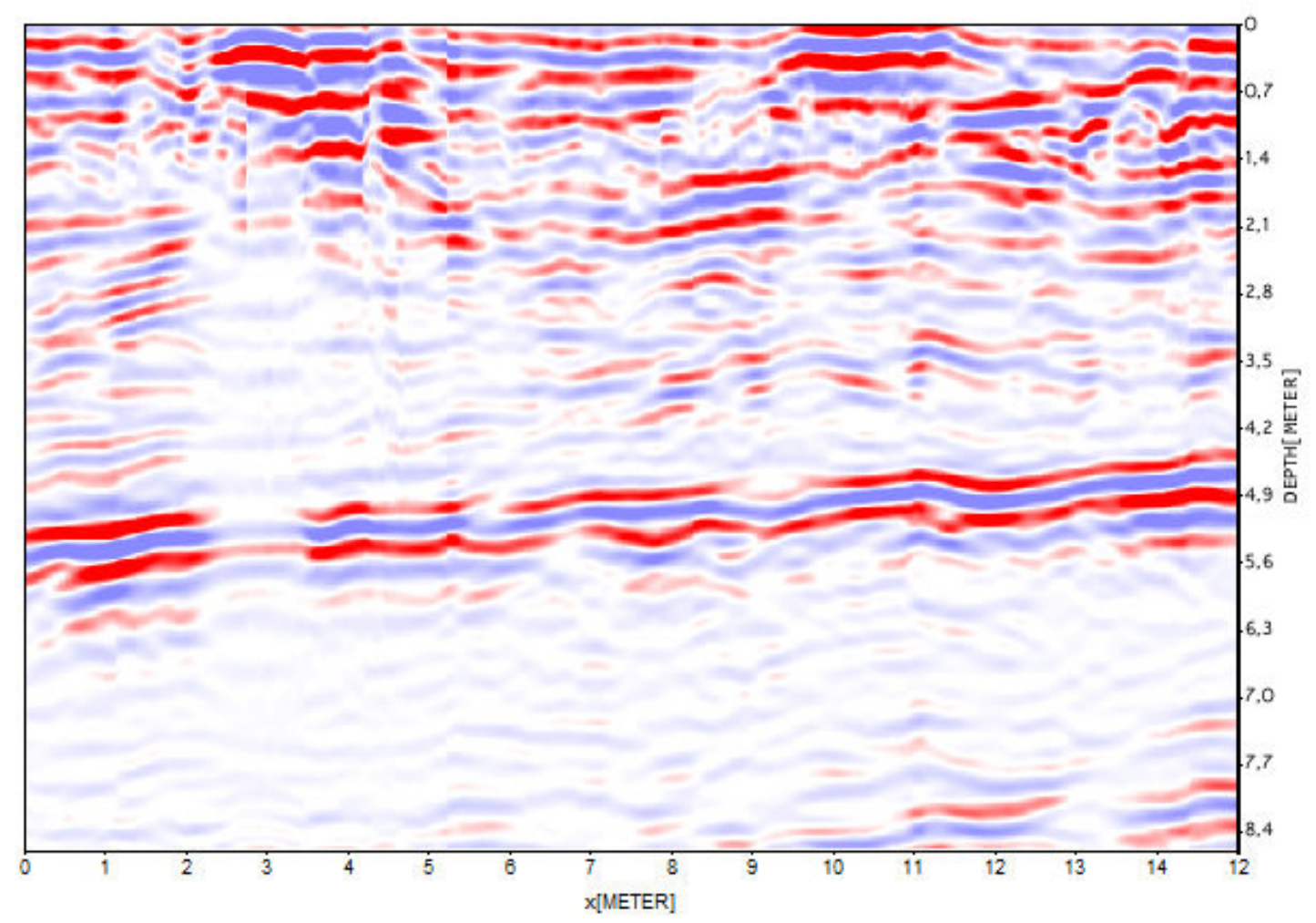

Anexo B 7 - Perfil GPR de 200 MHz número 9 na direção y para a área 2 


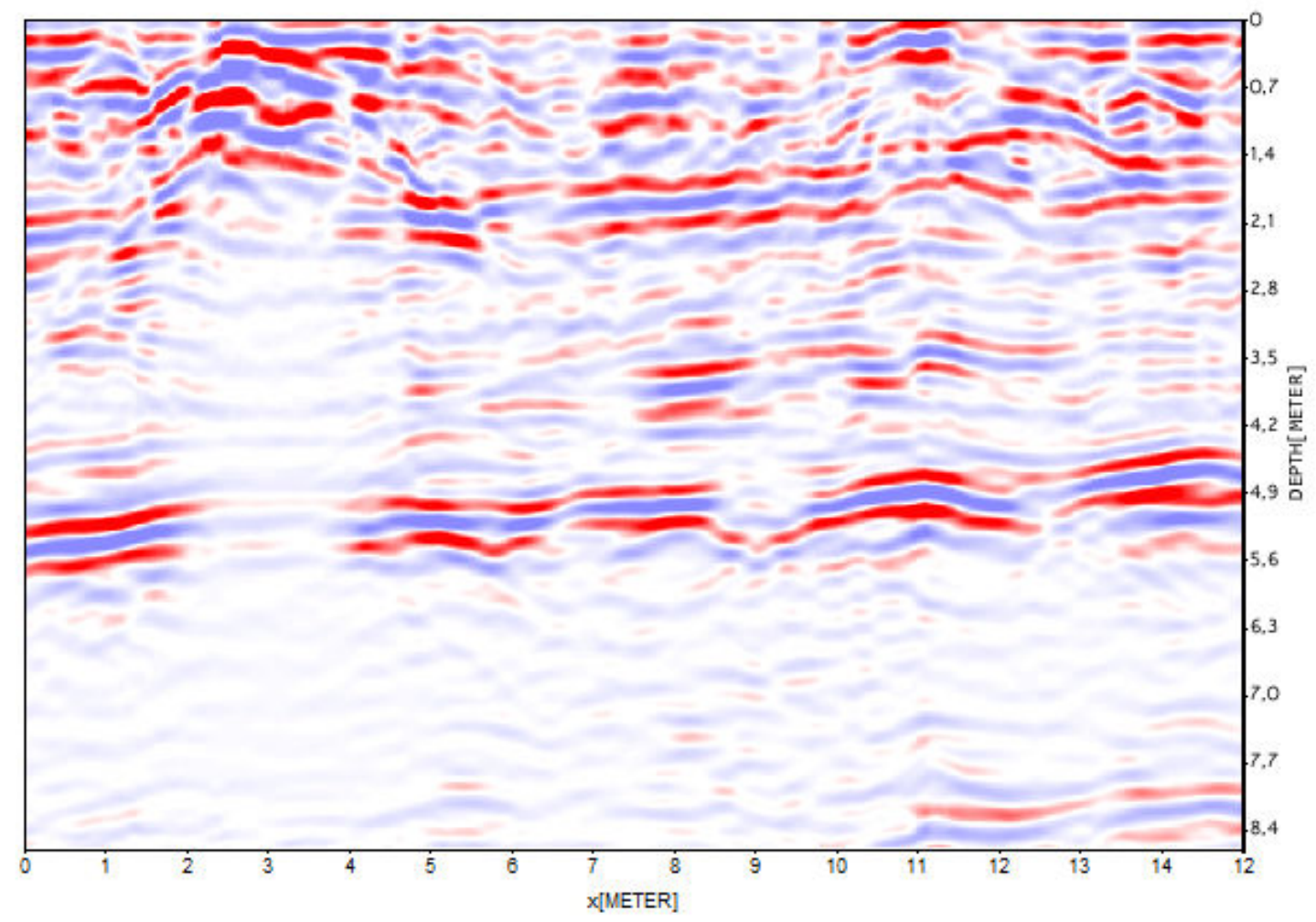

Anexo B 8 - Perfil GPR de 200 MHz número 10 na direção y para a área 2

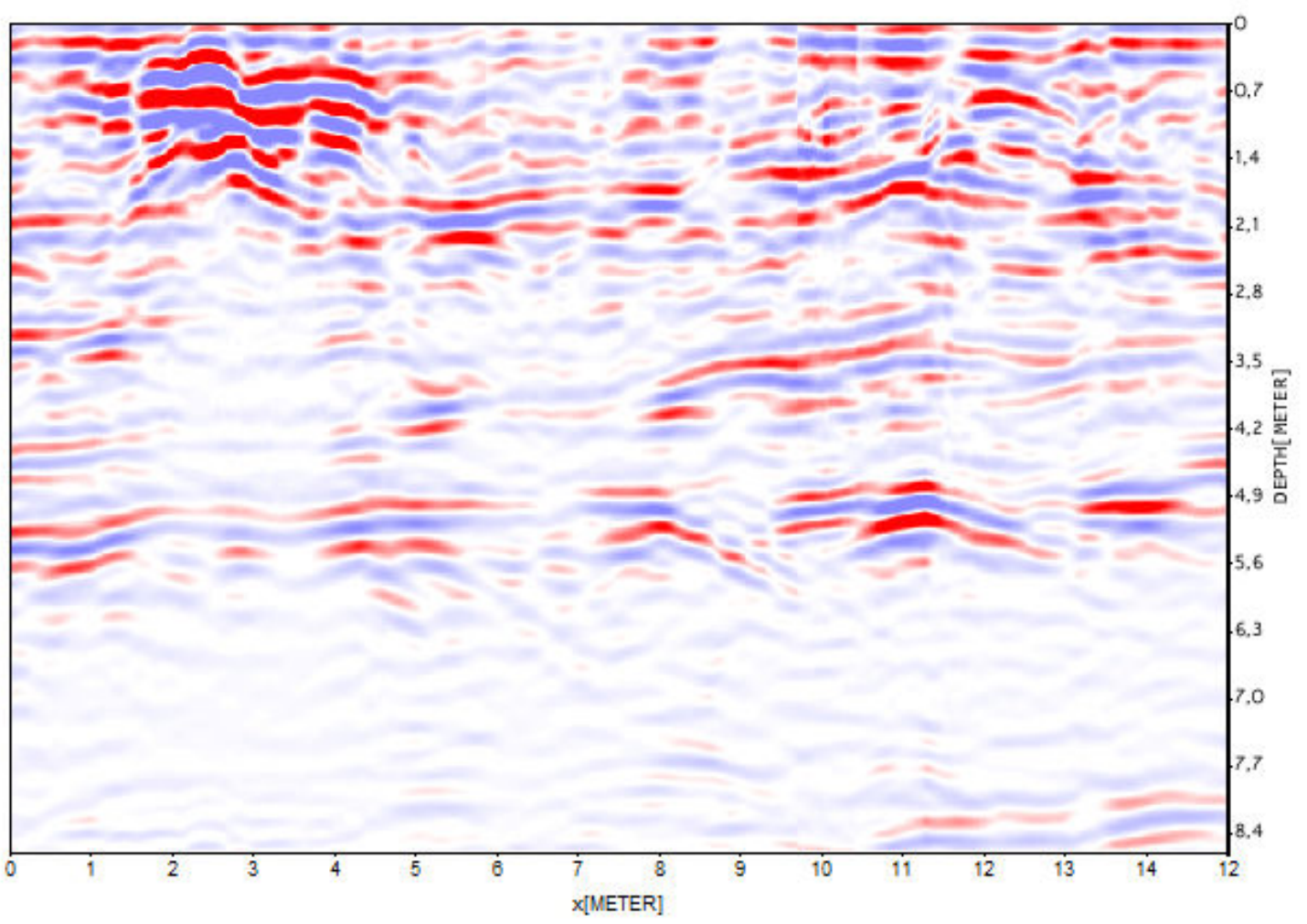

Anexo B 9 - Perfil GPR de 200 MHz número 11 na direção y para a área 2 


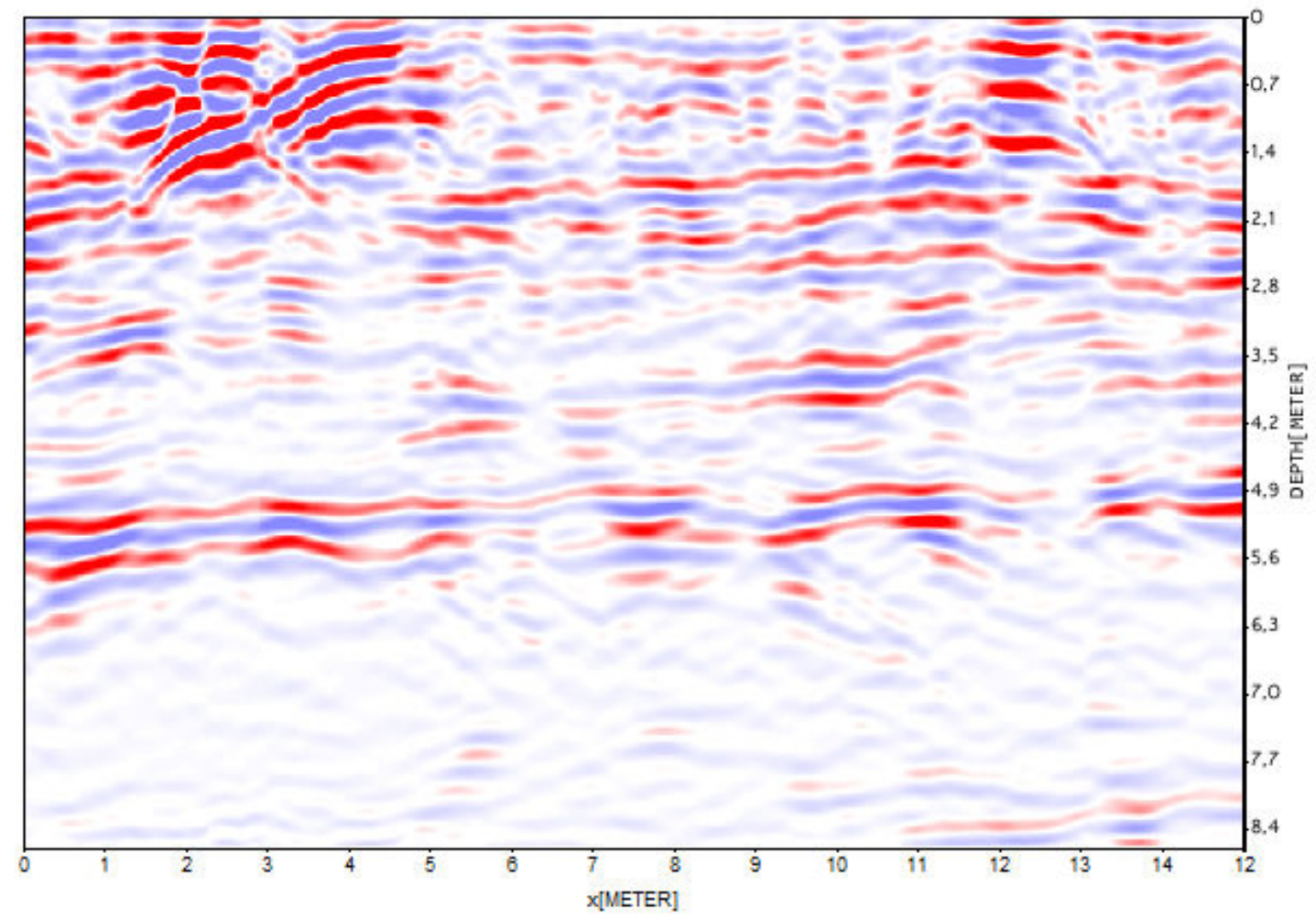

Anexo B 10 - Perfil GPR de 200 MHz número 12 na direção y para a área 2

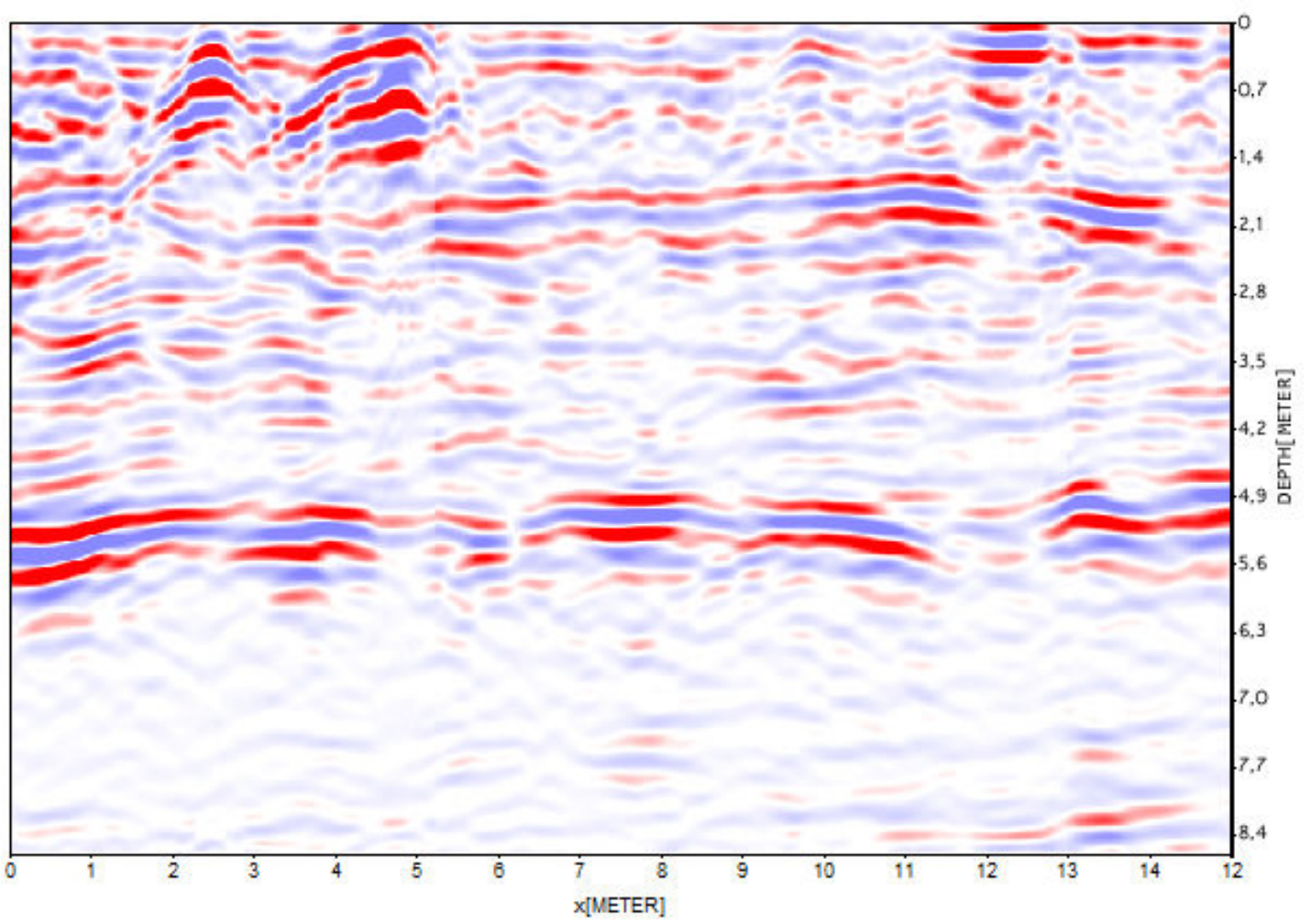

Anexo B 11 - Perfil GPR de 200 MHz número 13 na direção y para a área 2 


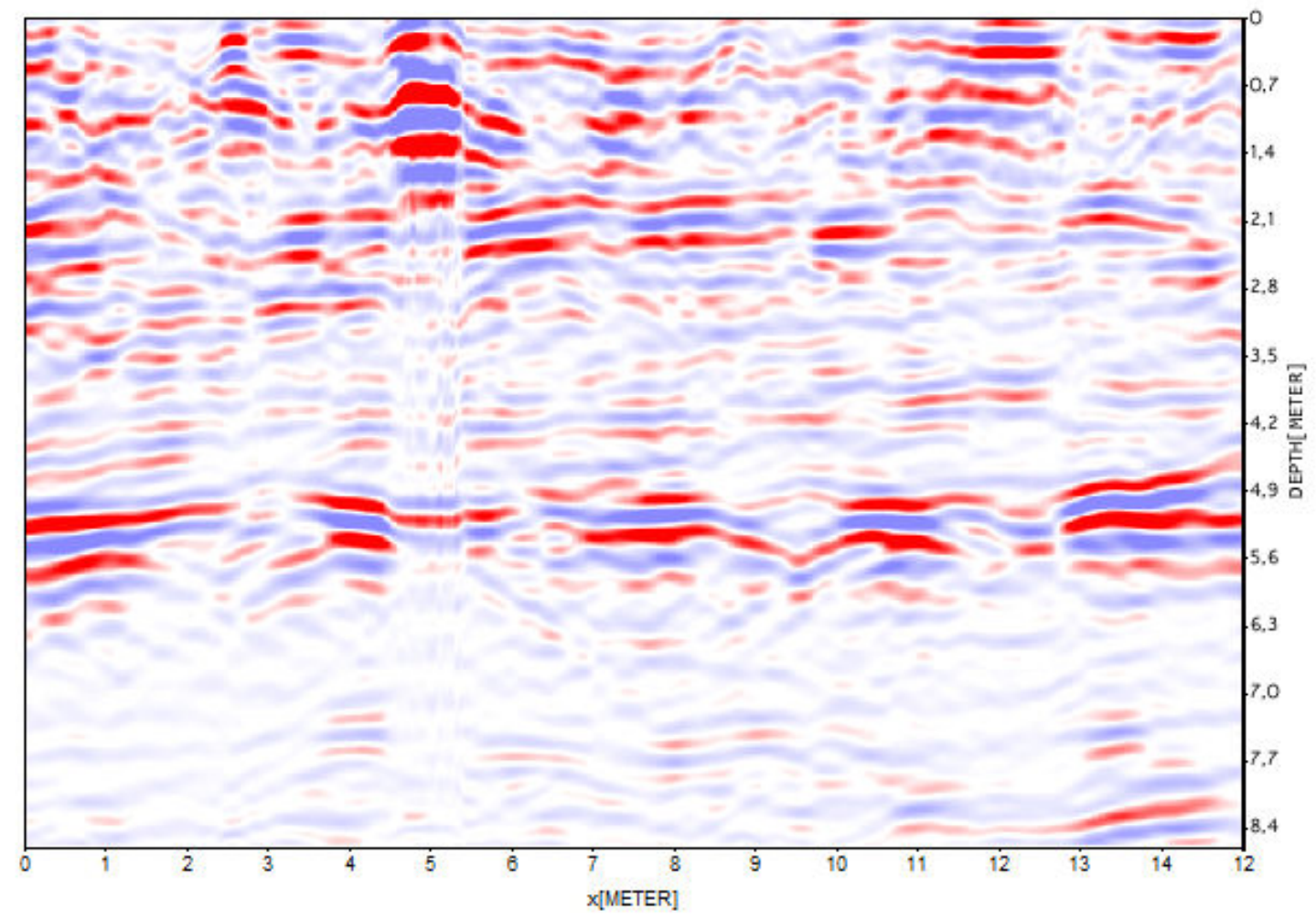

Anexo B 12 - Perfil GPR de 200 MHz número 14 na direção y para a área 2

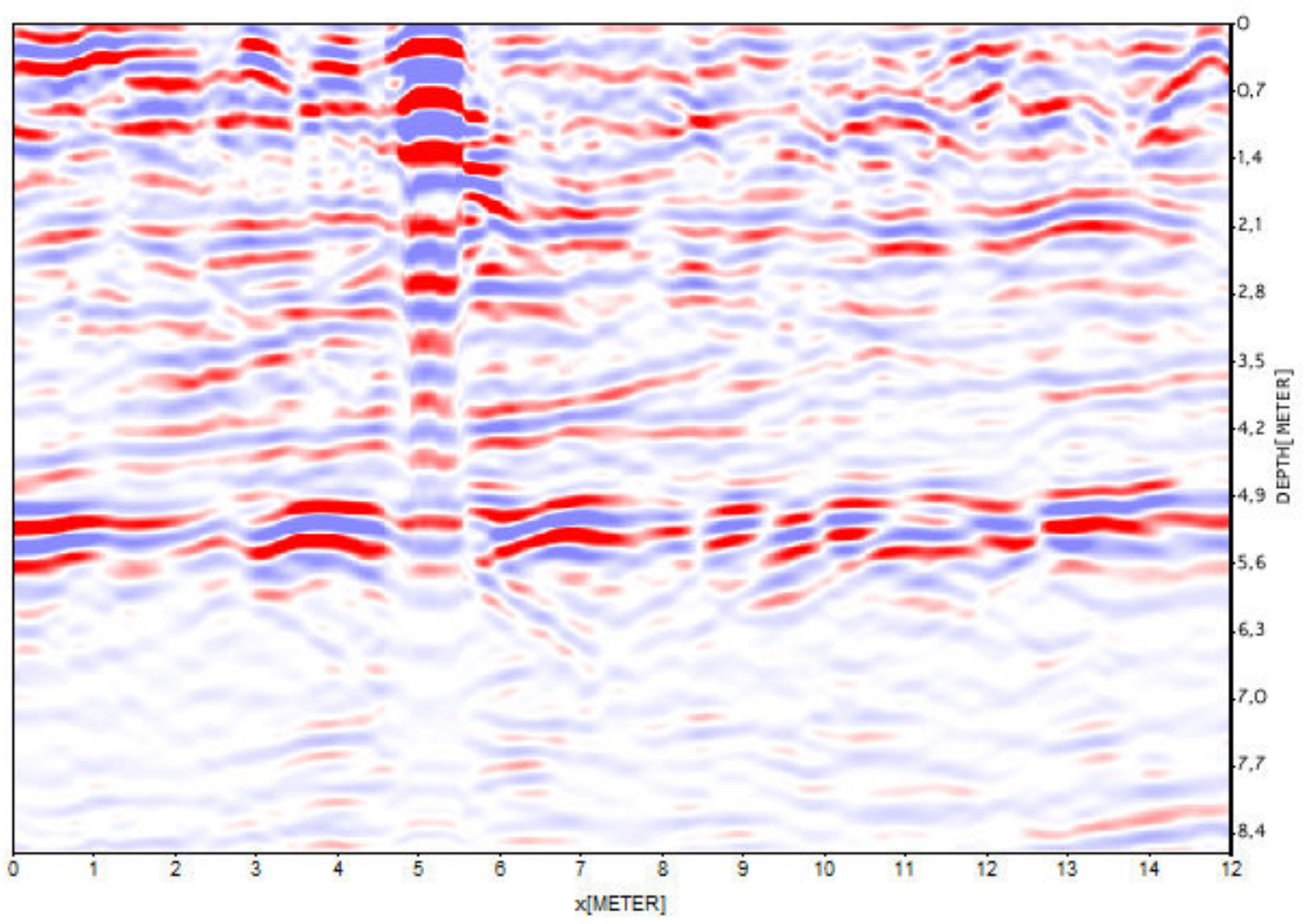

Anexo B 13 - Perfil GPR de 200 MHz número 15 na direção y para a área 2 


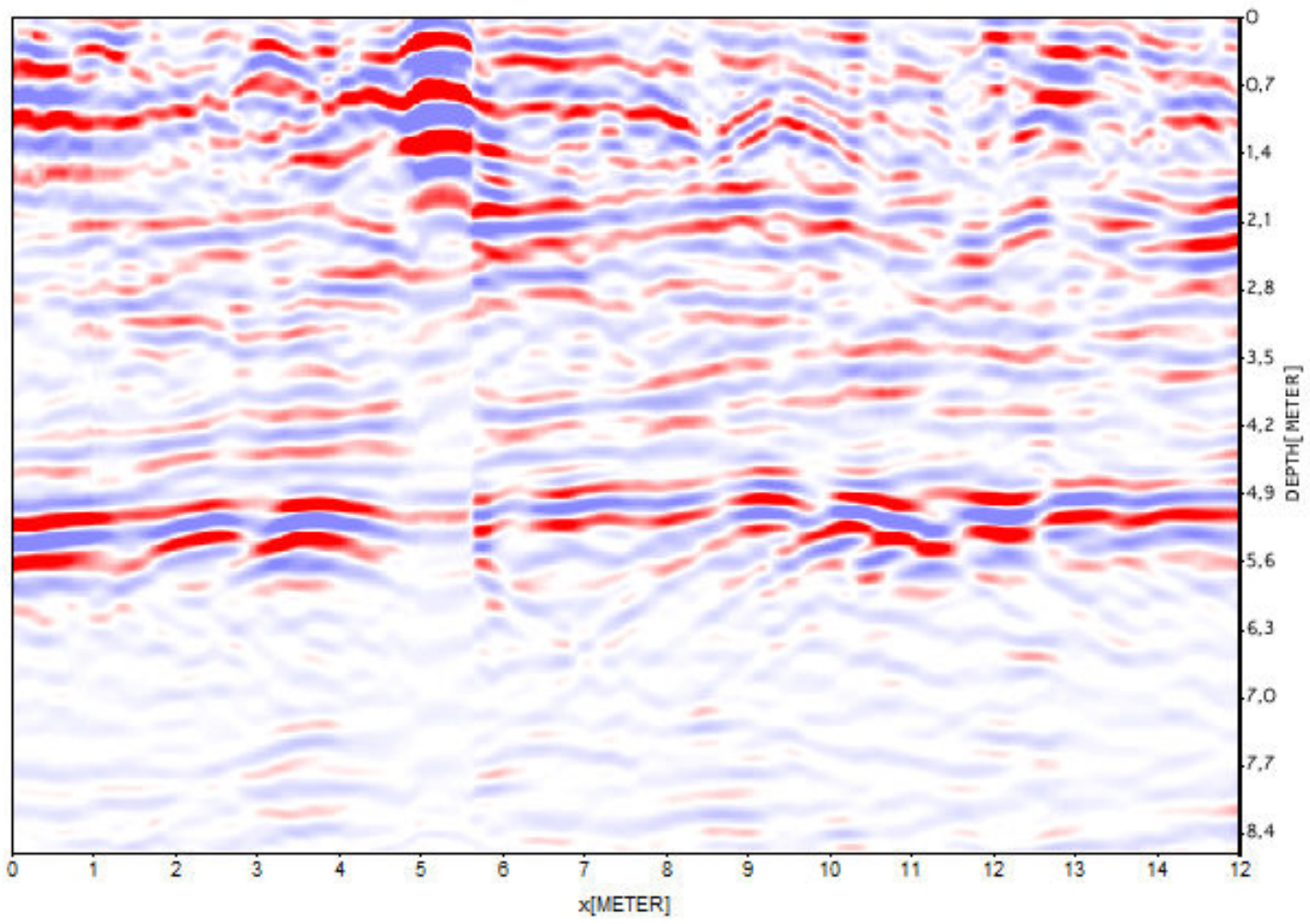

Anexo B 14 - Perfil GPR de 200 MHz número 16 na direção y para a área 2

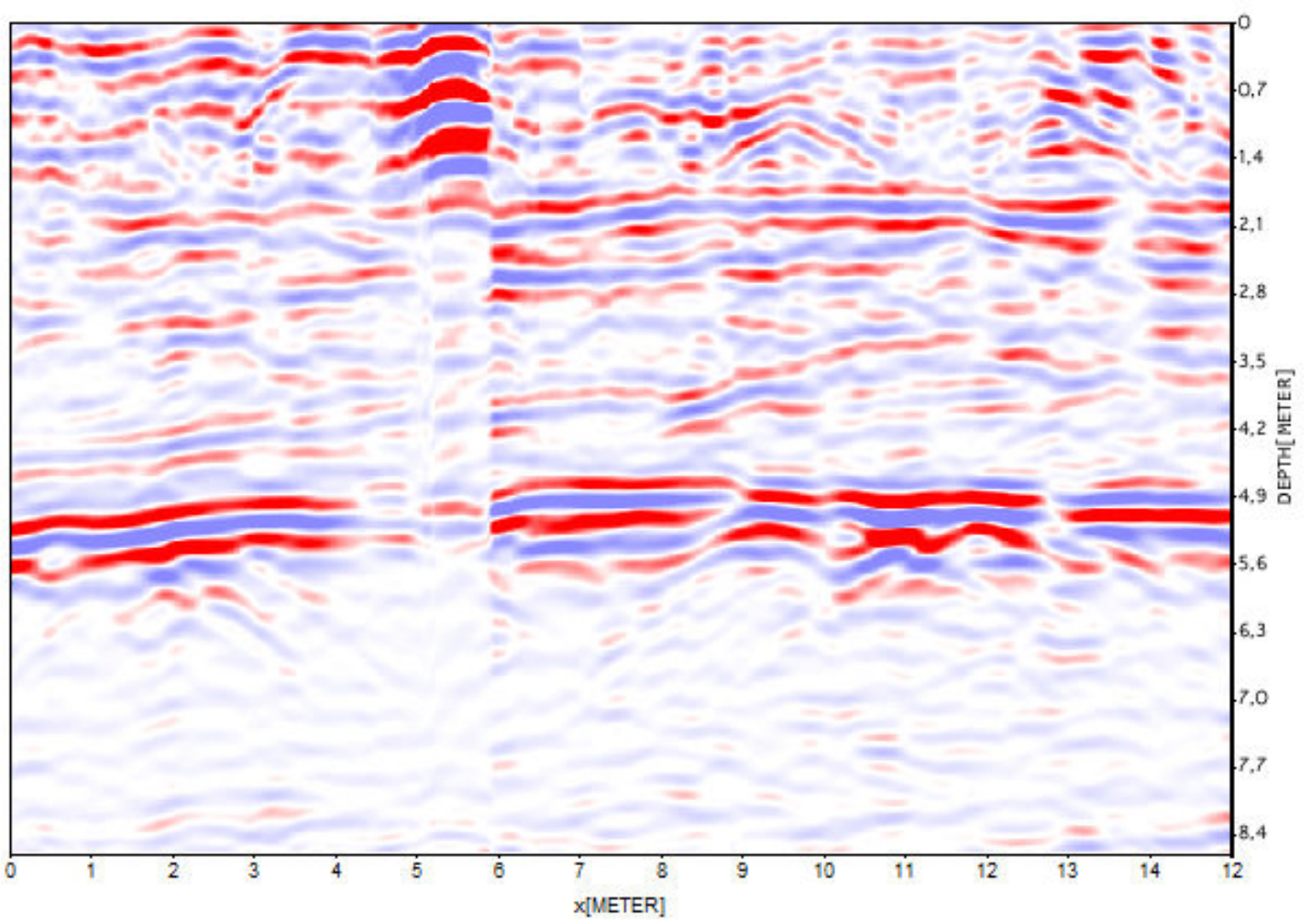

Anexo B 15 - Perfil GPR de 200 MHz número 17 na direção y para a área 2 


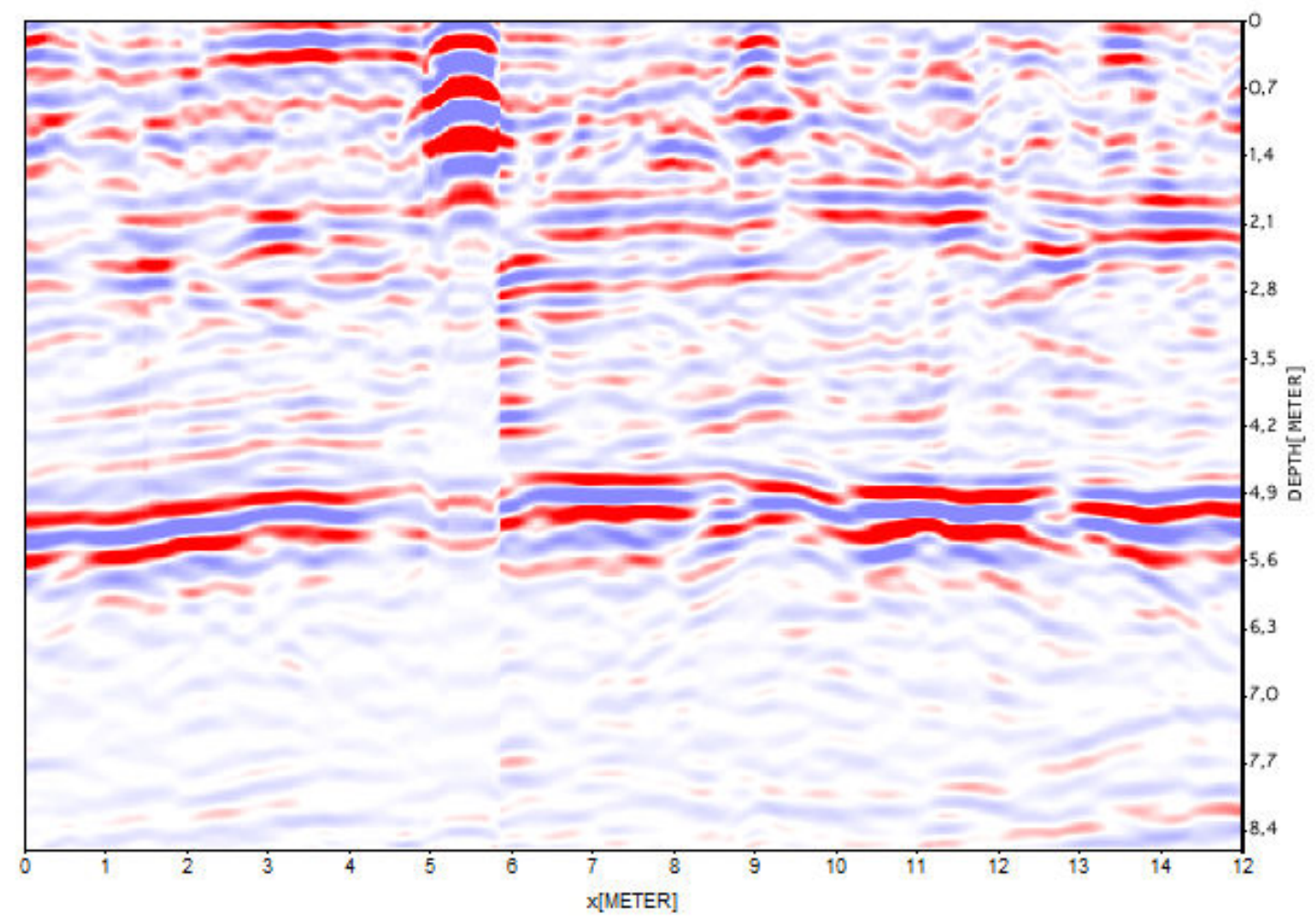

Anexo B 16 - Perfil GPR de 200 MHz número 18 na direção y para a área 2

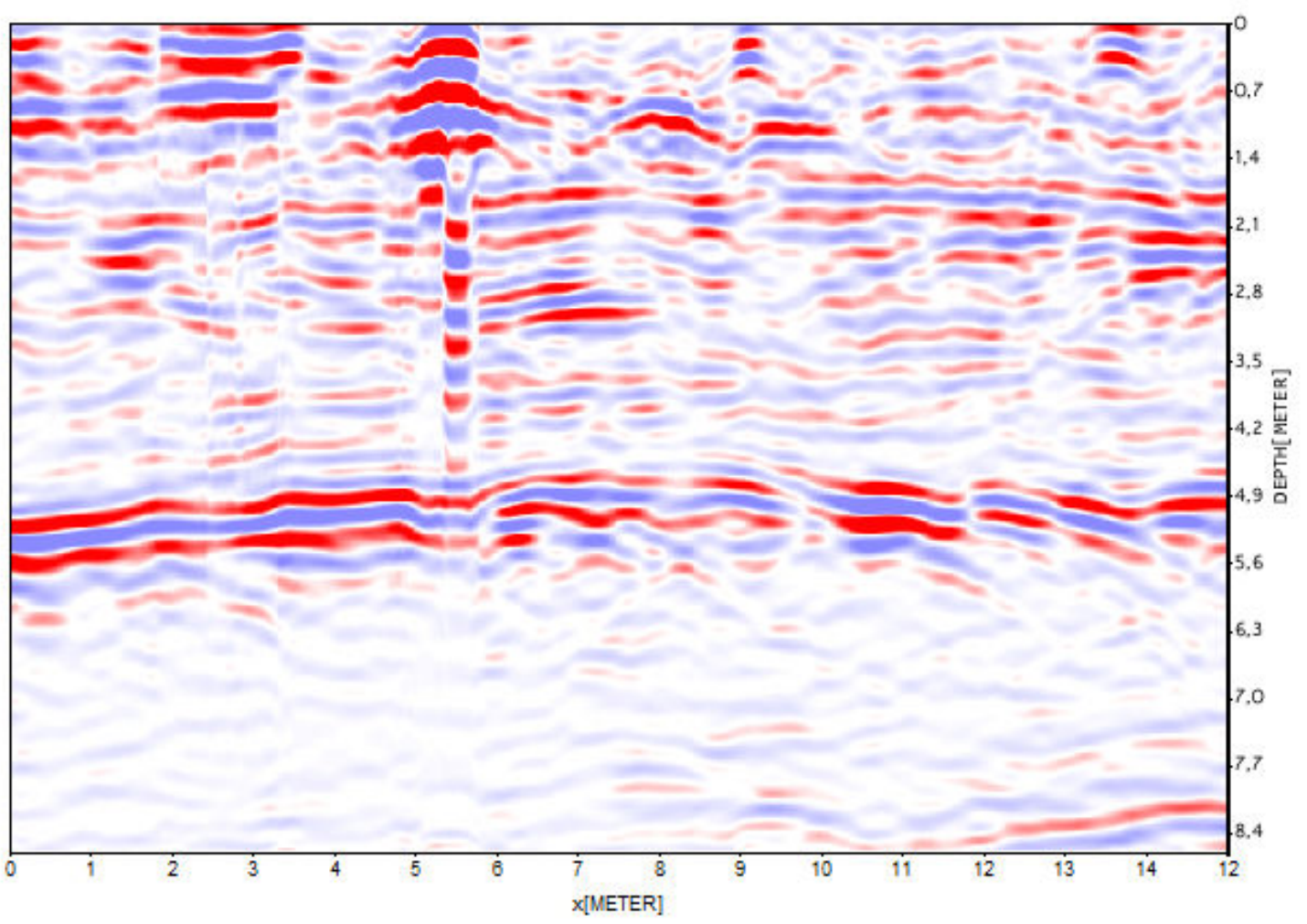

Anexo B 17 - Perfil GPR de 200 MHz número 19 na direção y para a área 2 


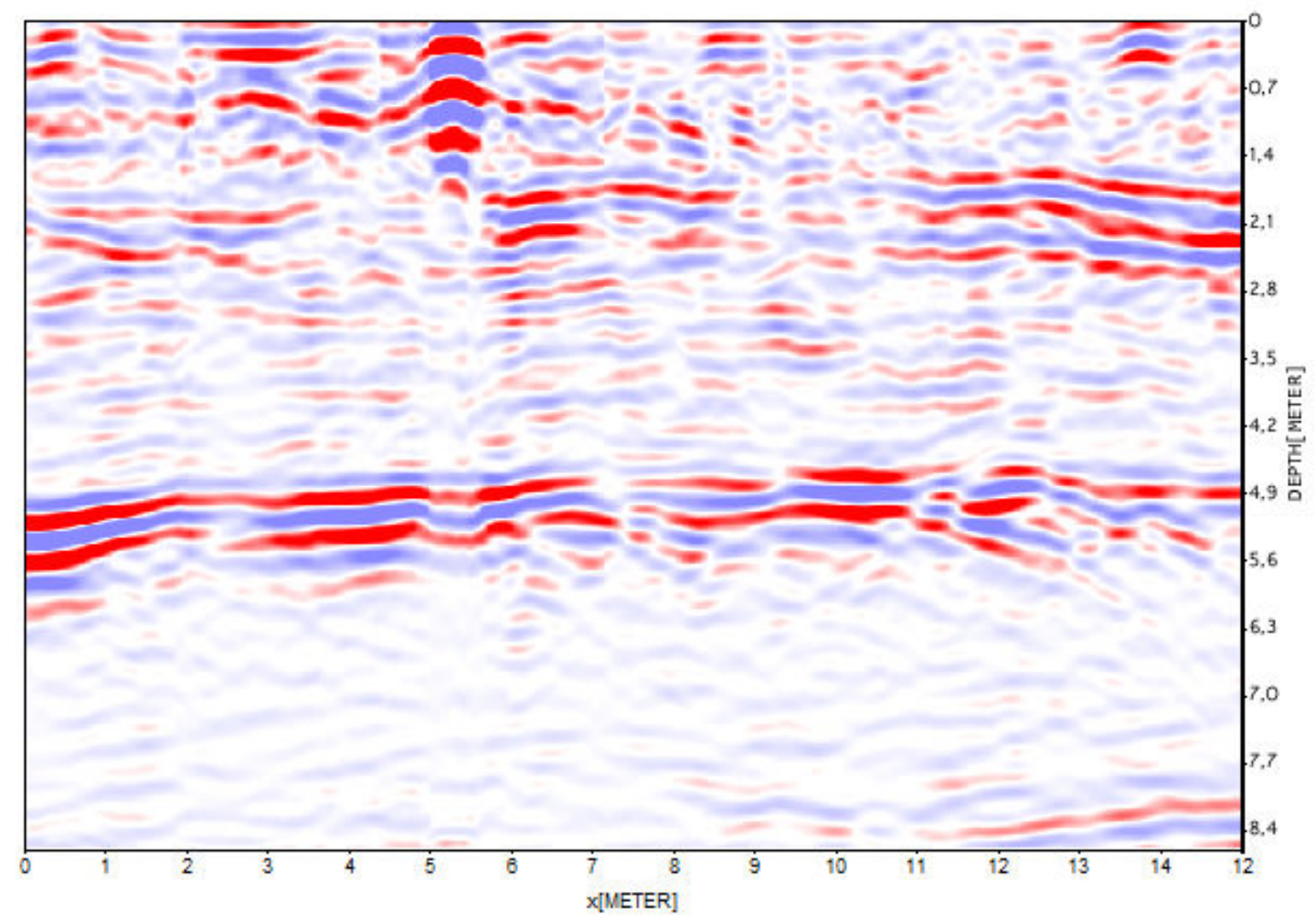

Anexo B 18 - Perfil GPR de 200 MHz número 20 na direção y para a área 2

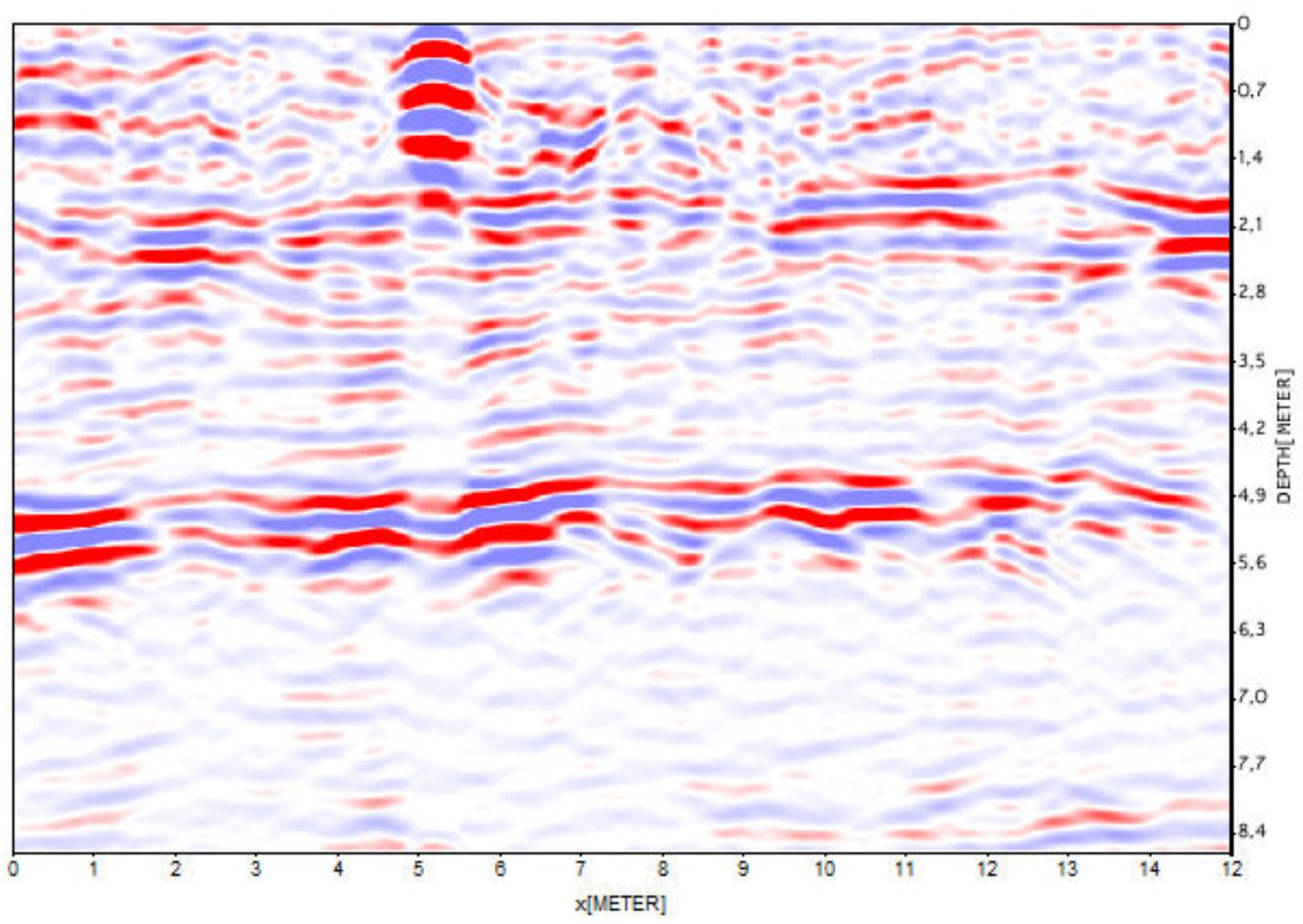

Anexo B 19 - Perfil GPR de 200 MHz número 21 na direção y para a área 2 


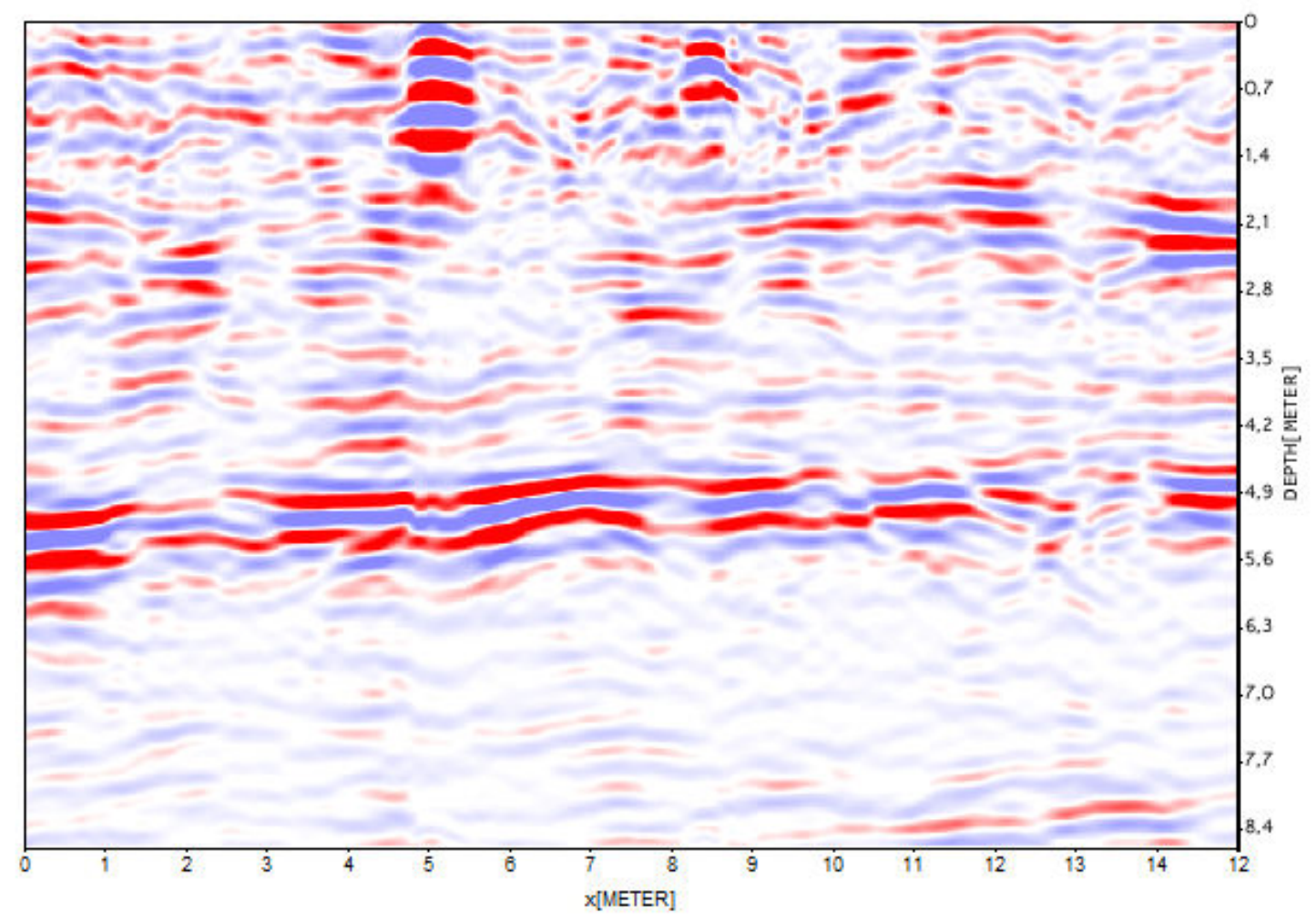

Anexo B 20 - Perfil GPR de 200 MHz número 22 na direção y para a área 2

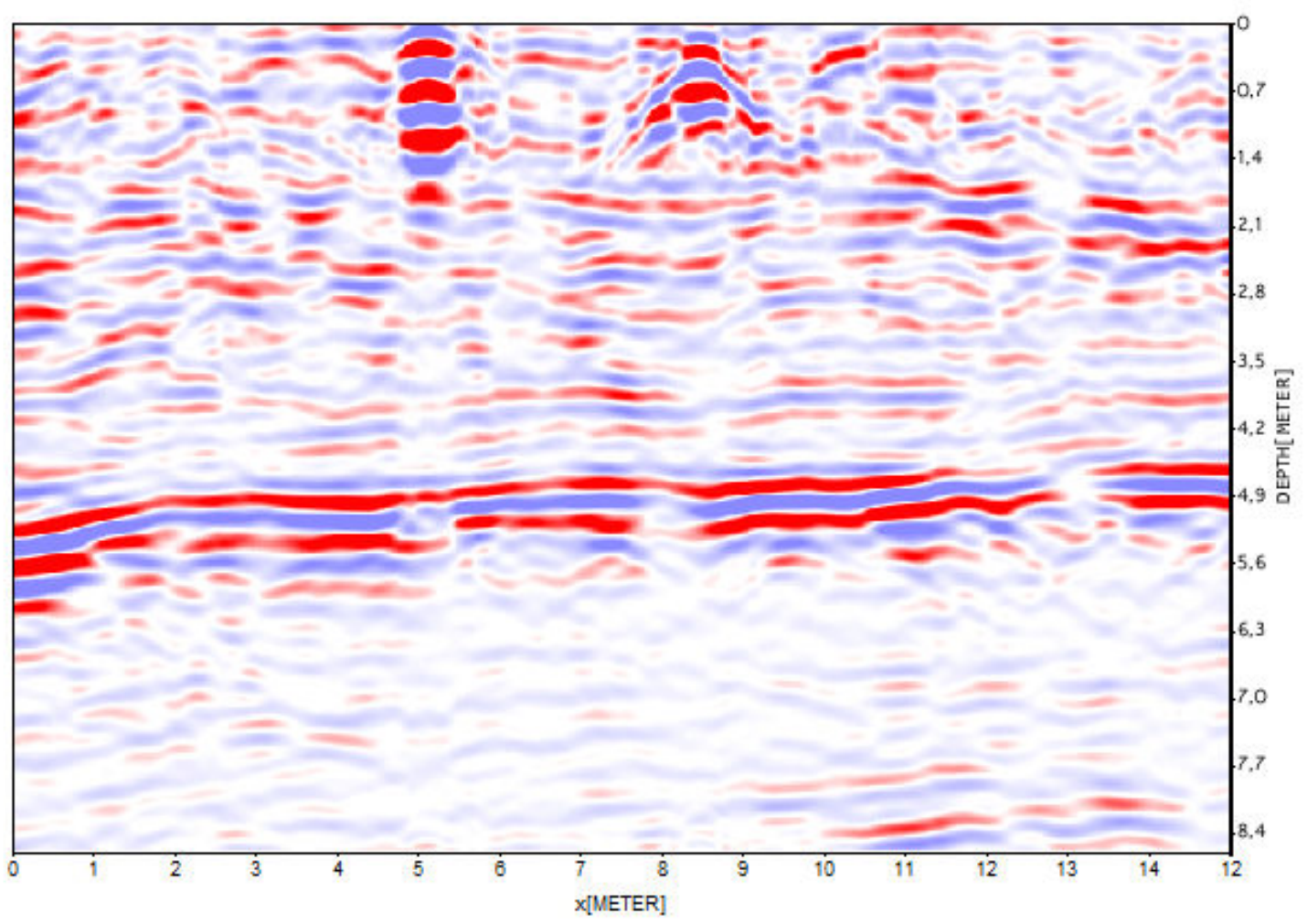

Anexo B 21 - Perfil GPR de 200 MHz número 23 na direção y para a área 2 


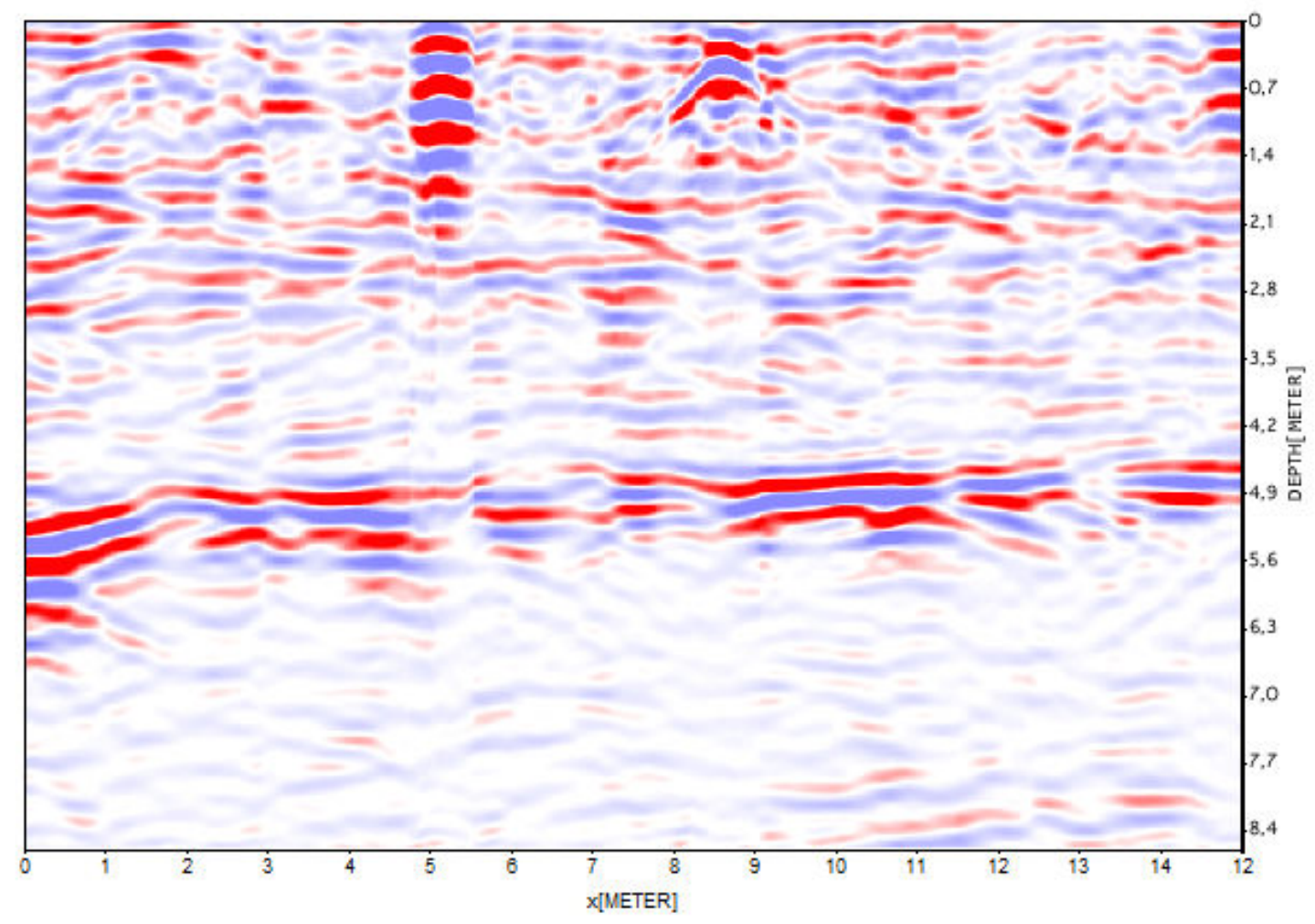

Anexo B 22 - Perfil GPR de 200 MHz número 24 na direção y para a área 2

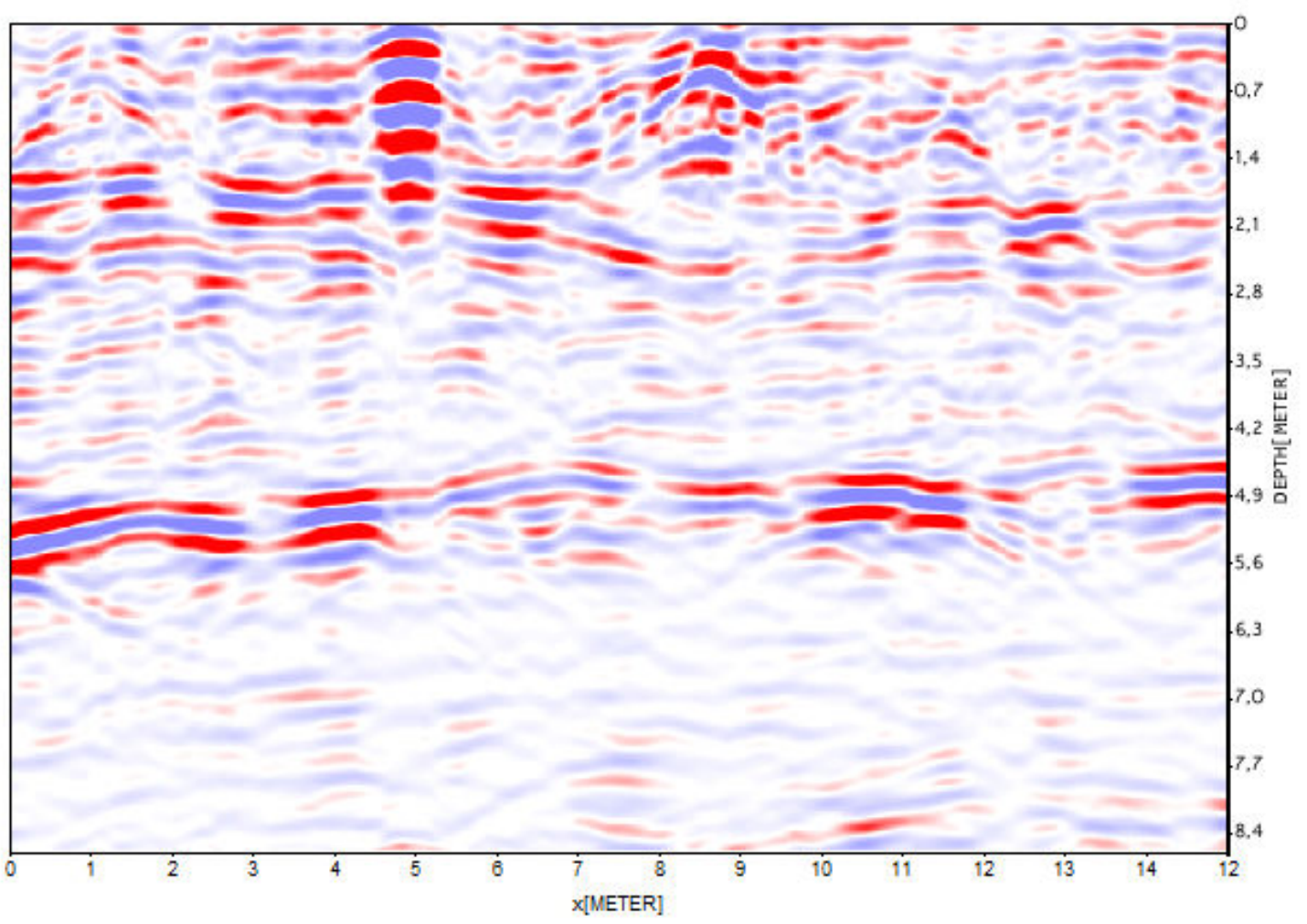

Anexo B 23 - Perfil GPR de 200 MHz número 25 na direção y para a área 2 


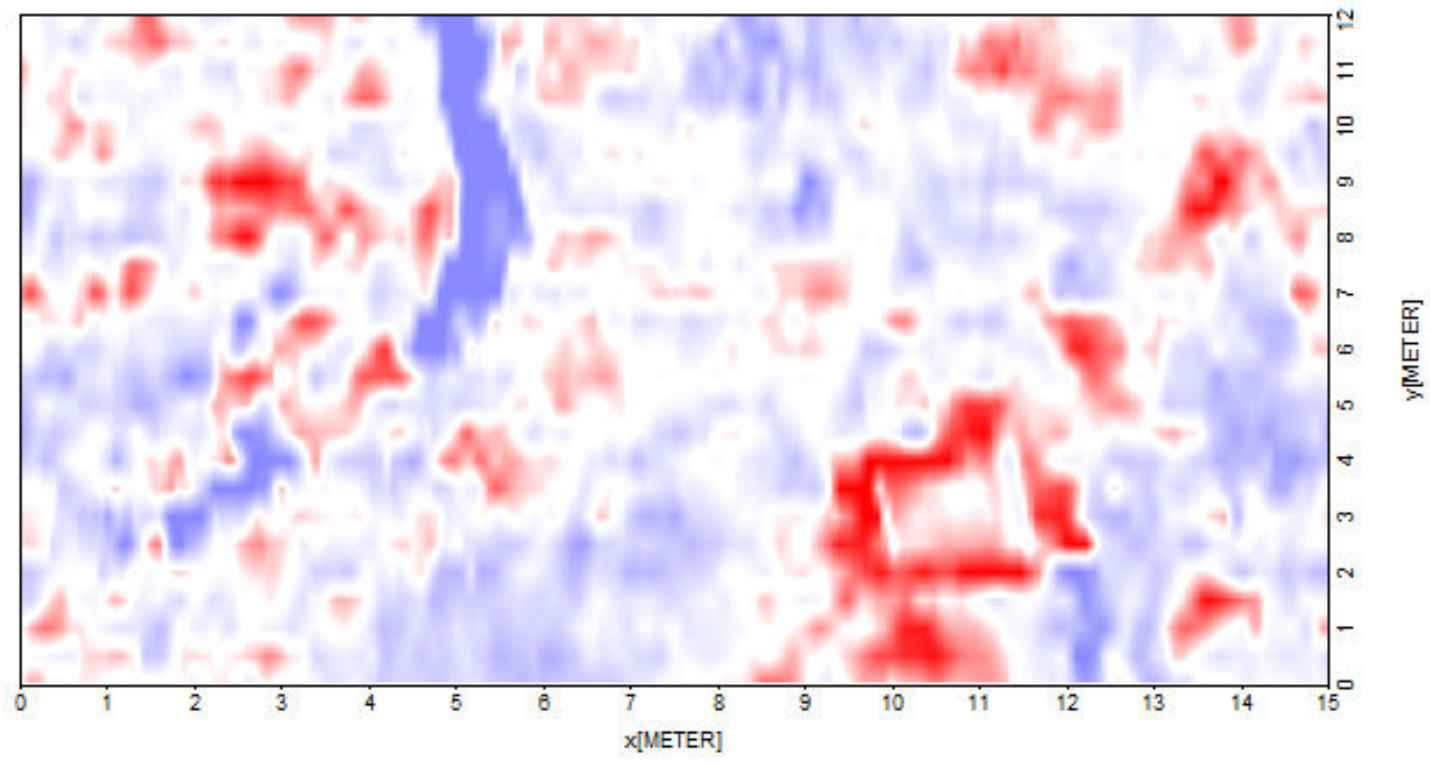

Anexo B 24 - Depth-slice GPR de 200 MHz para a área 2 (profundidade 0,1 m)

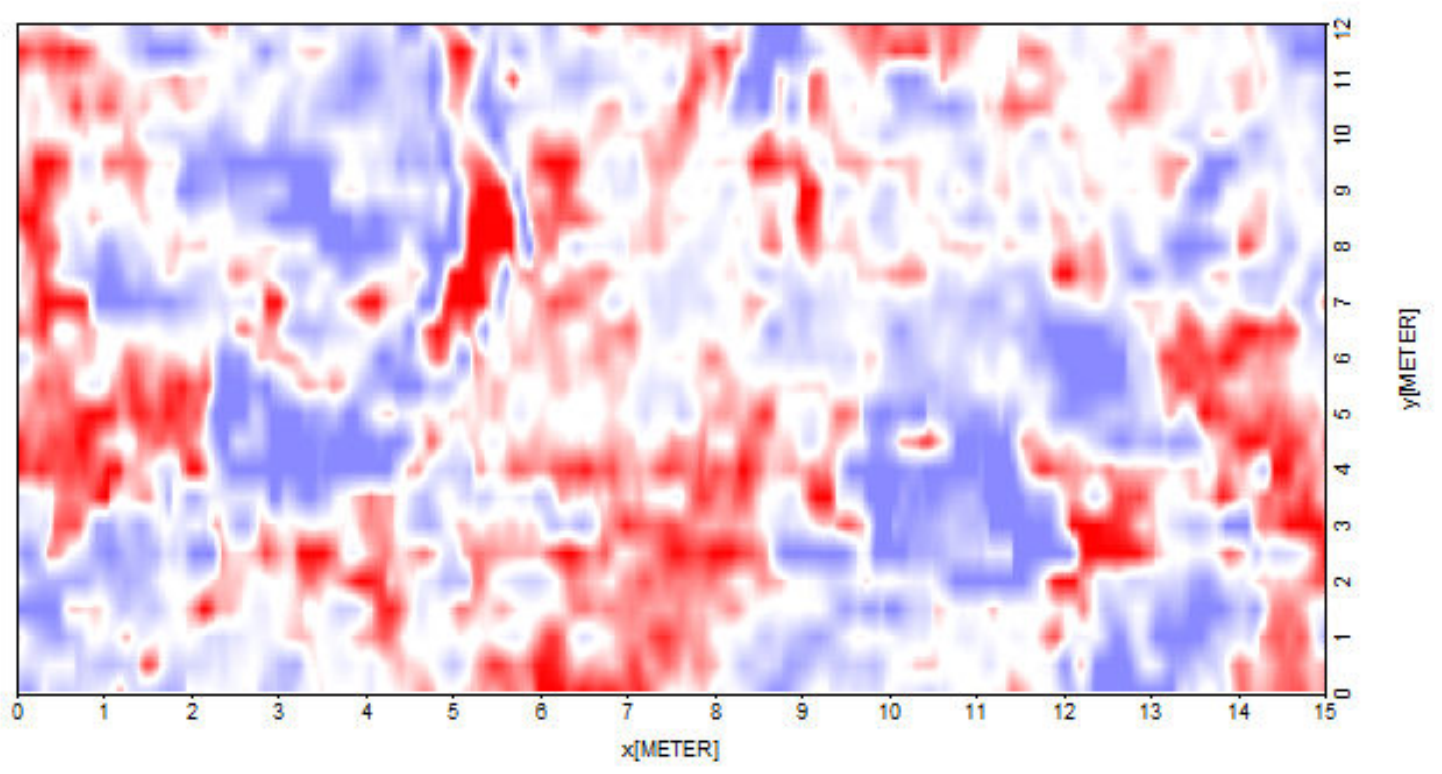

Anexo B 25 - Depth-slice GPR de 200 MHz para a área 2 (profundidade 0,2 m) 


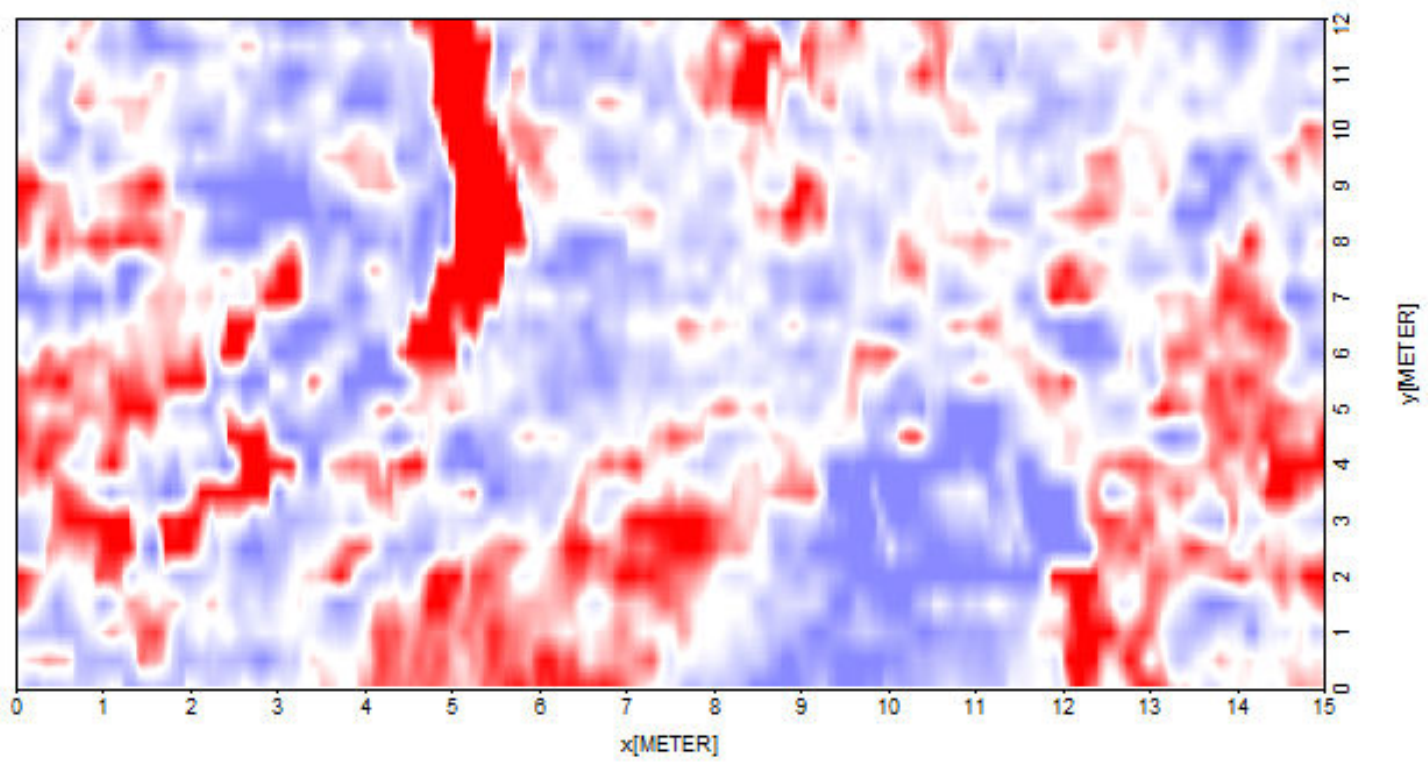

Anexo B 26 - Depth-slice GPR de 200 MHz para a área 2 (profundidade 0,3 m)

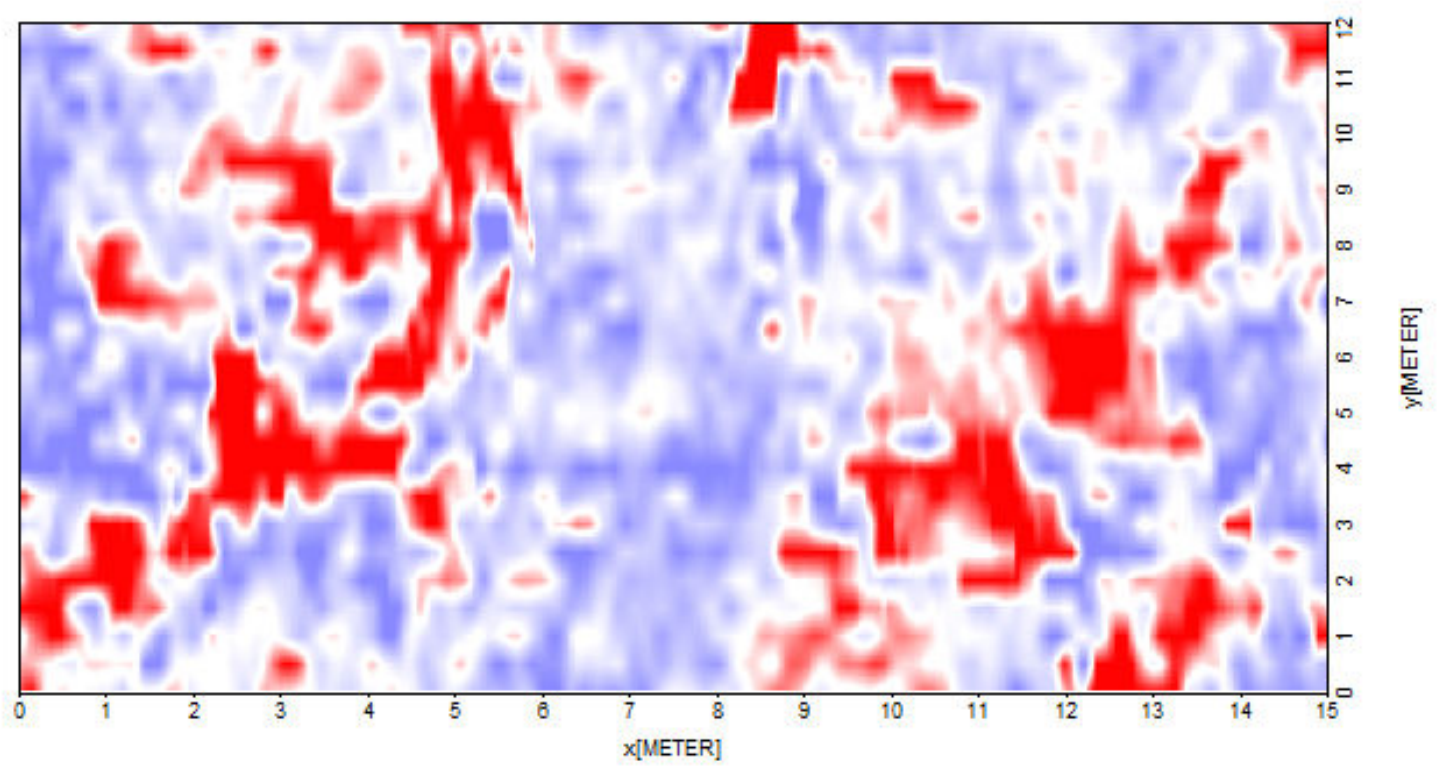

Anexo B 27 - Depth-slice GPR de 200 MHz para a área 2 (profundidade 0,4 m) 


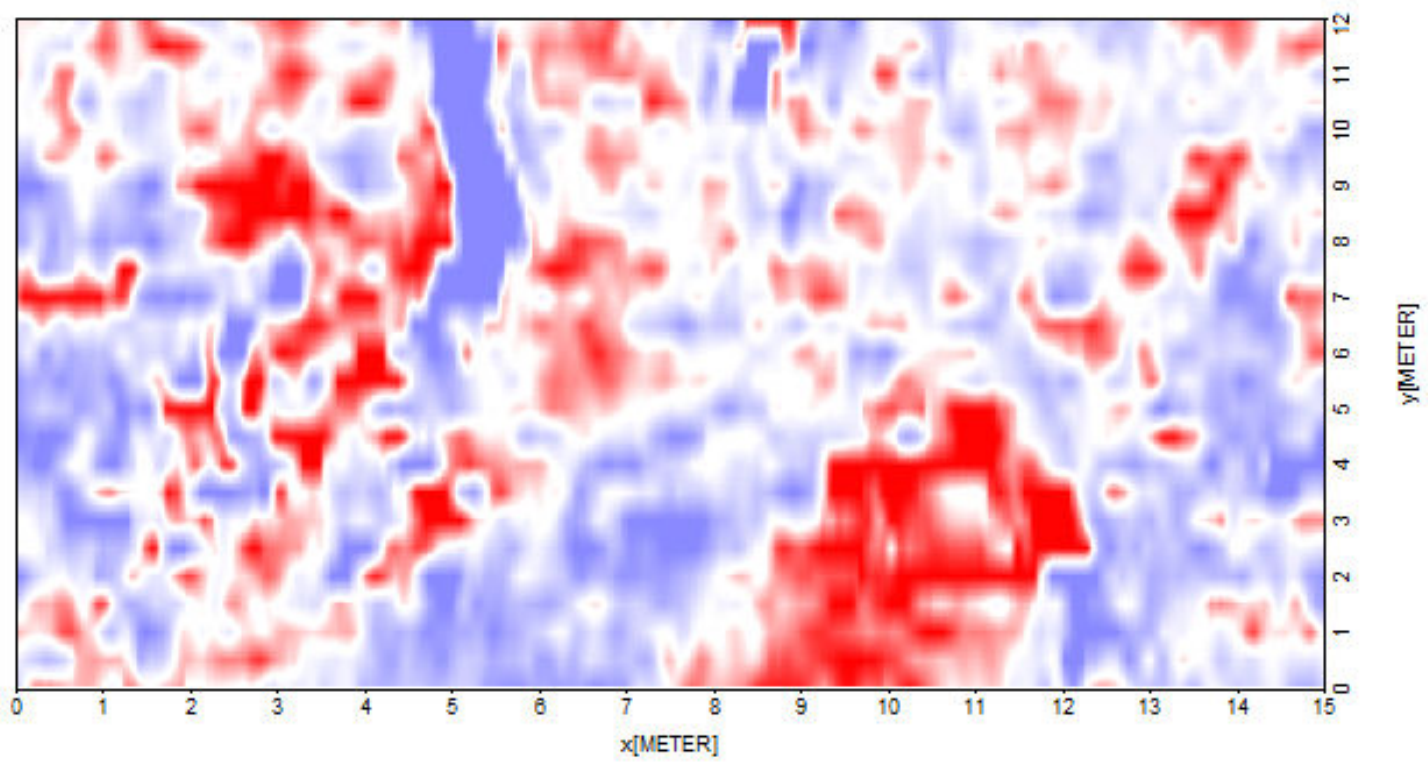

Anexo B 28 - Depth-slice GPR de 200 MHz para a área 2 (profundidade 0,5 m)

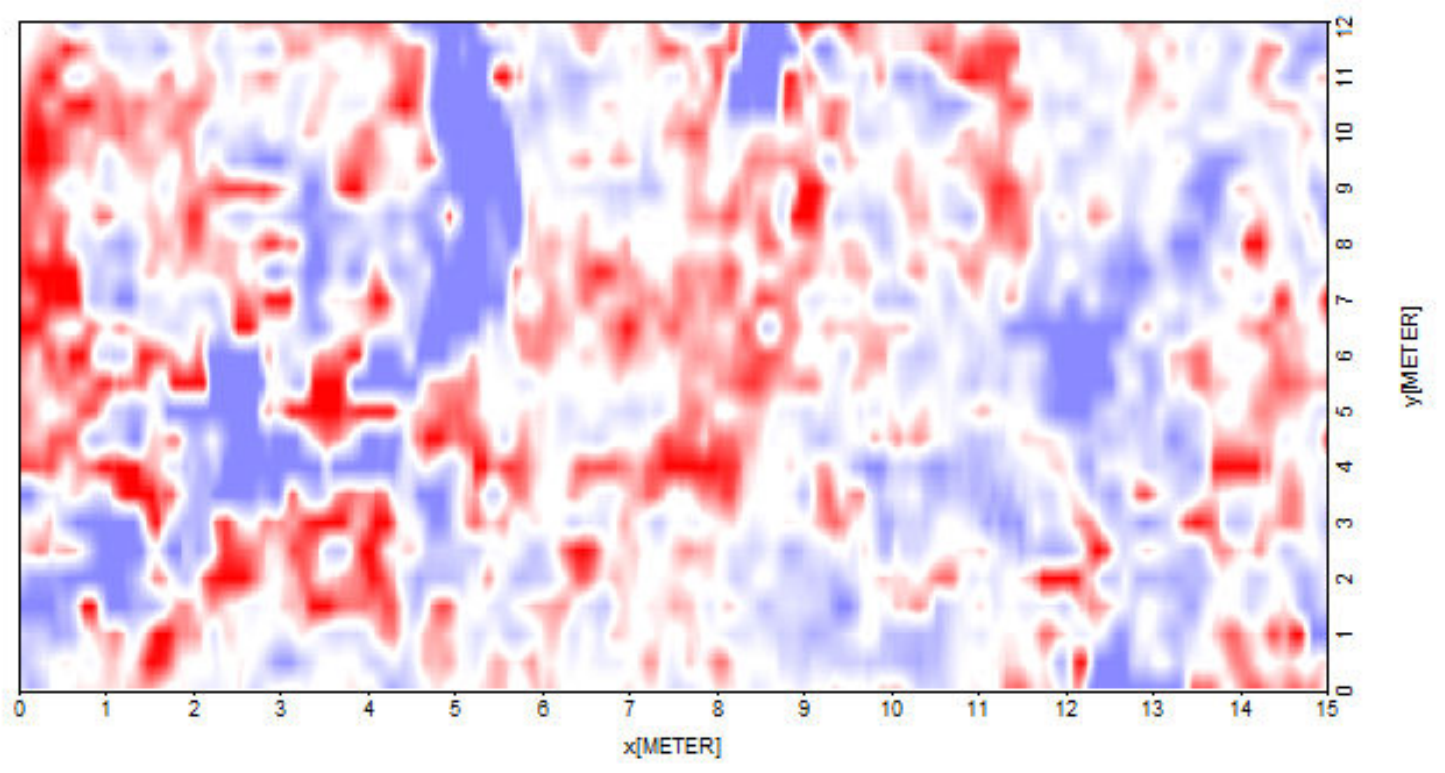

Anexo B 29 - Depth-slice GPR de 200 MHz para a área 2 (profundidade 0,6 m) 


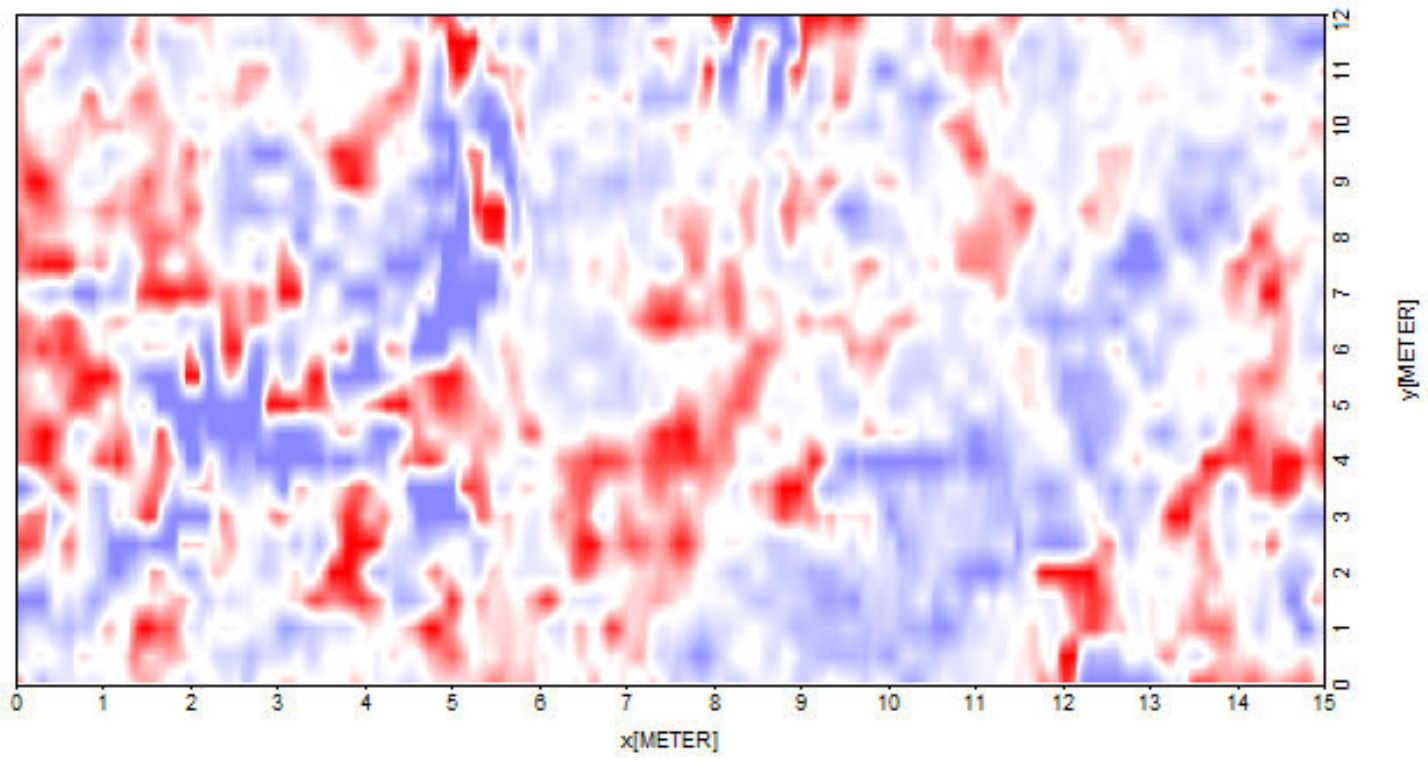

Anexo B 30 - Depth-slice GPR de 200 MHz para a área 2 (profundidade $0,7 \mathrm{~m}$ )

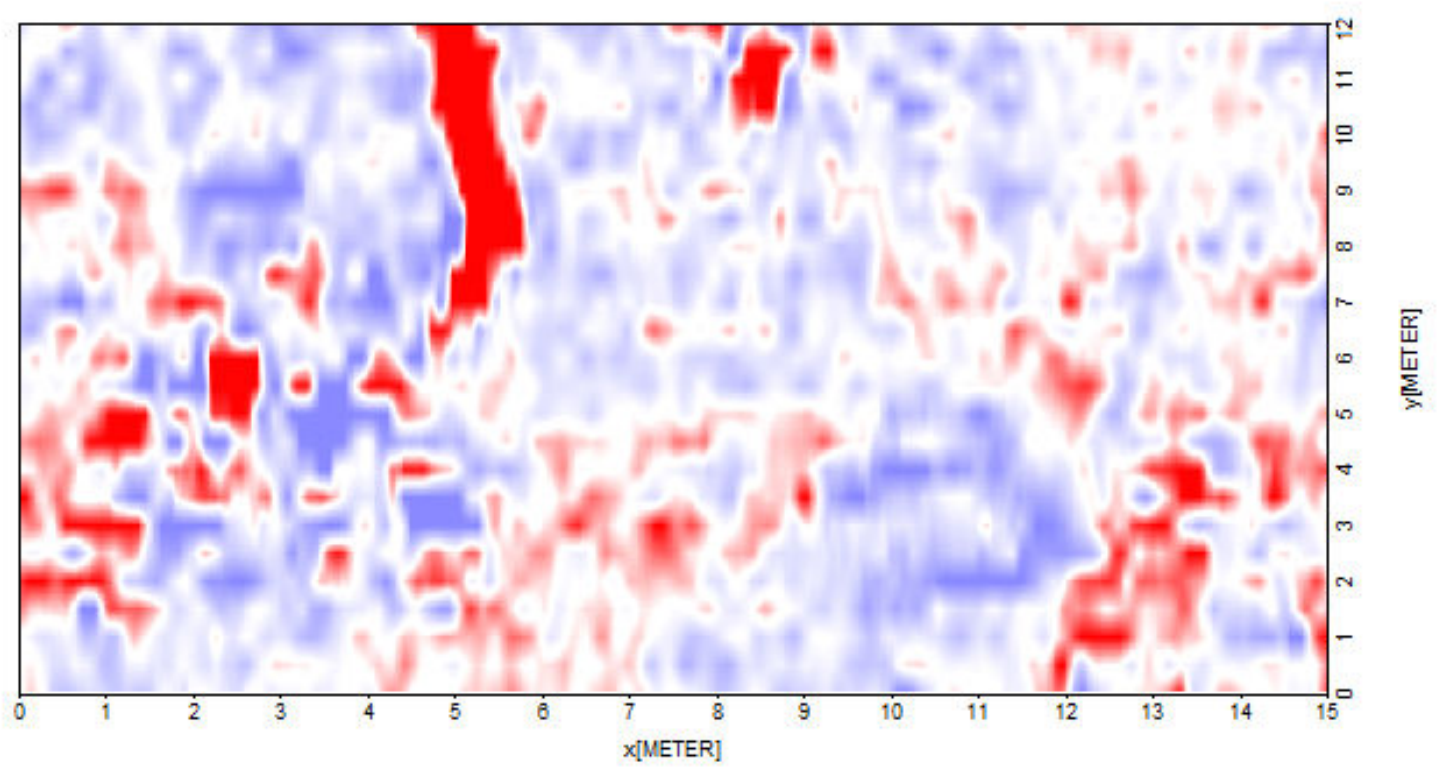

Anexo B 31 - Depth-slice GPR de 200 MHz para a área 2 (profundidade 0,8 m) 


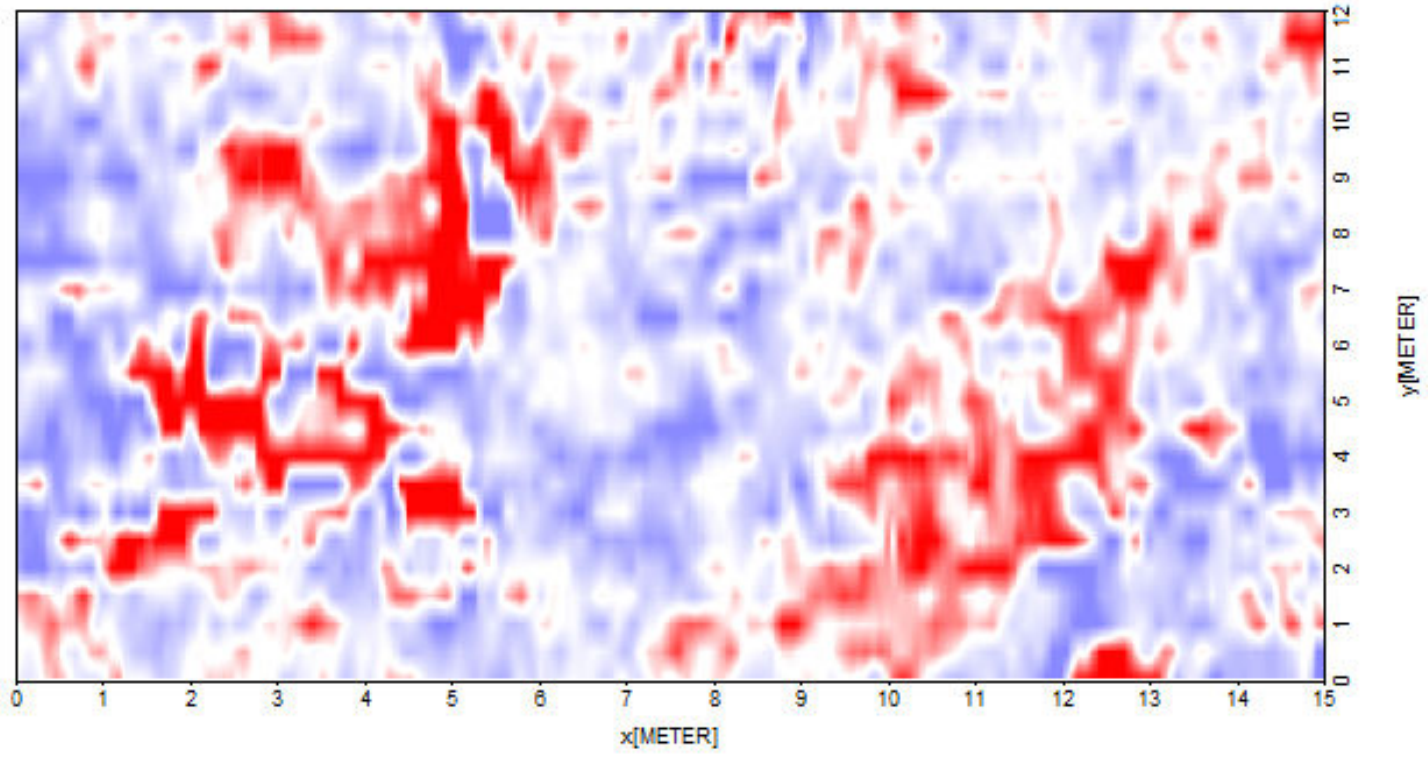

Anexo B 32 - Depth-slice GPR de 200 MHz para a área 2 (profundidade $1,0 \mathrm{~m}$ )

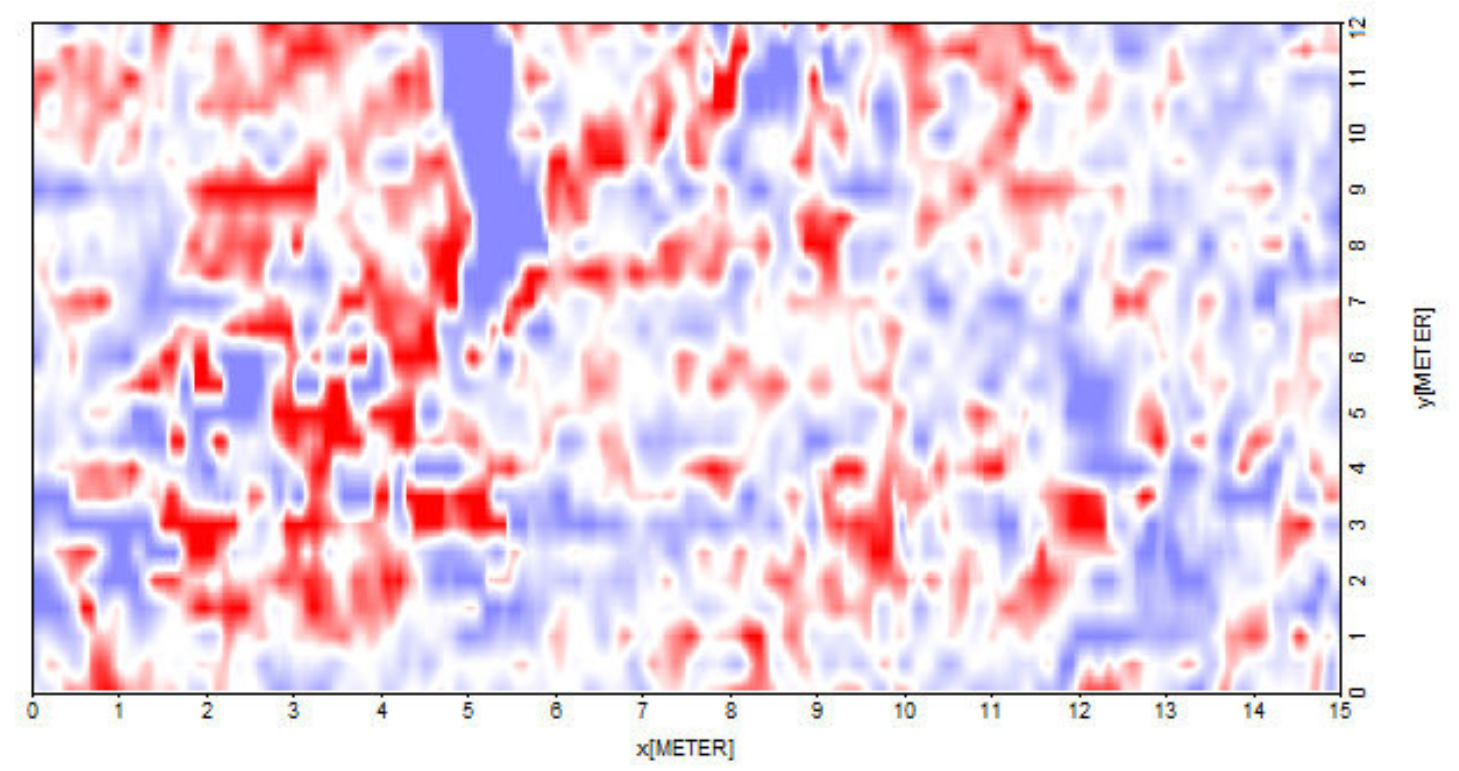

Anexo B 33 - Depth-slice GPR de 200 MHz para a área 2 (profundidade 1,1 m) 


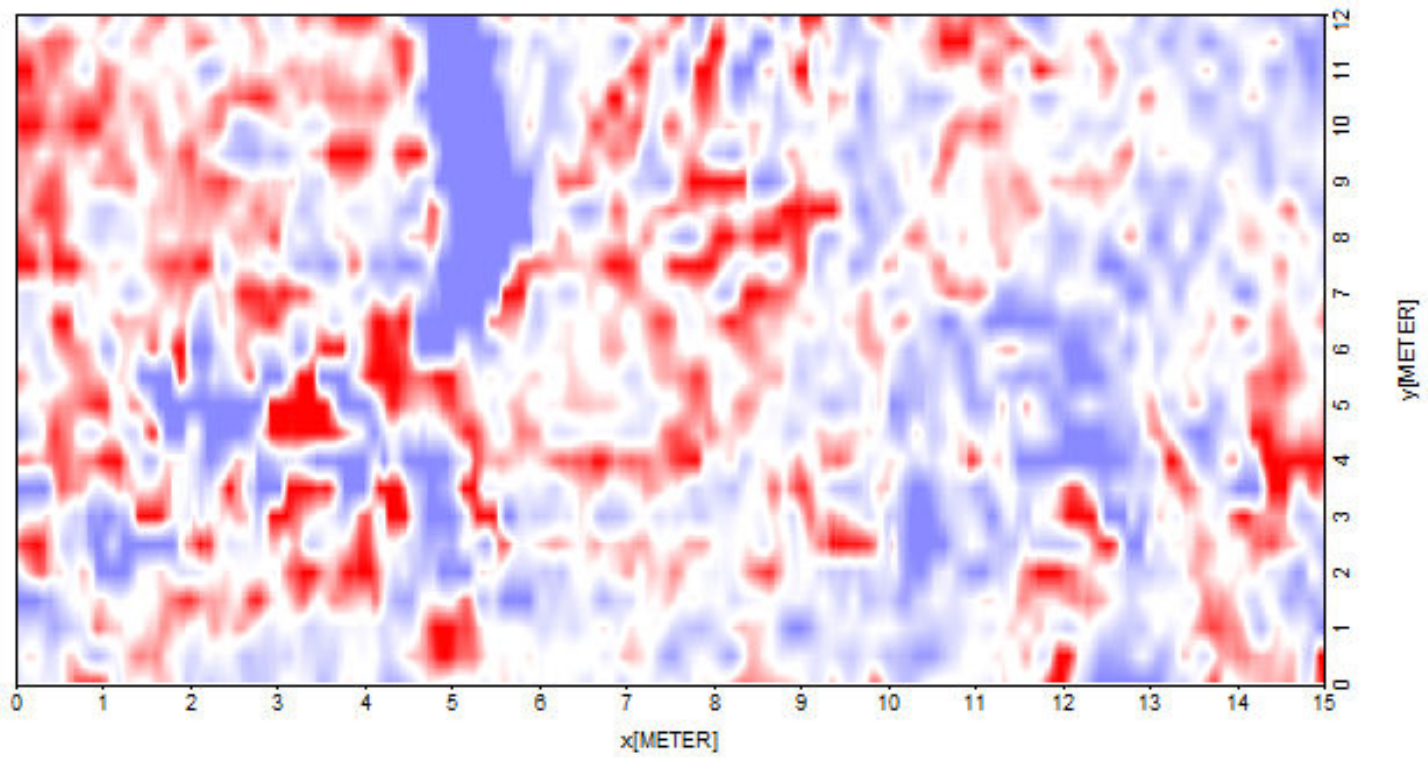

Anexo B 34 - Depth-slice GPR de 200 MHz para a área 2 (profundidade 1,2 m)

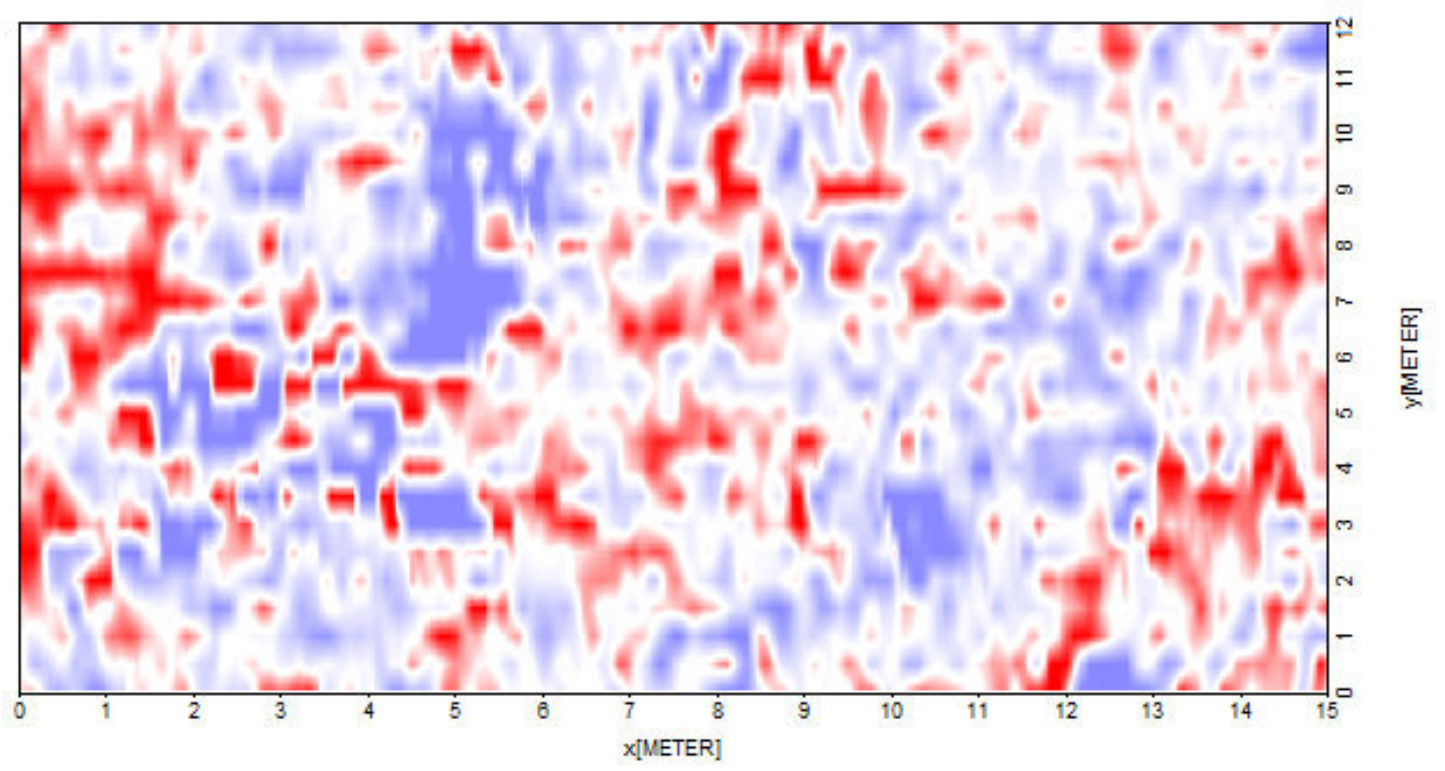

Anexo B 35 - Depth-slice GPR de 200 MHz para a área 2 (profundidade 1,3 m) 


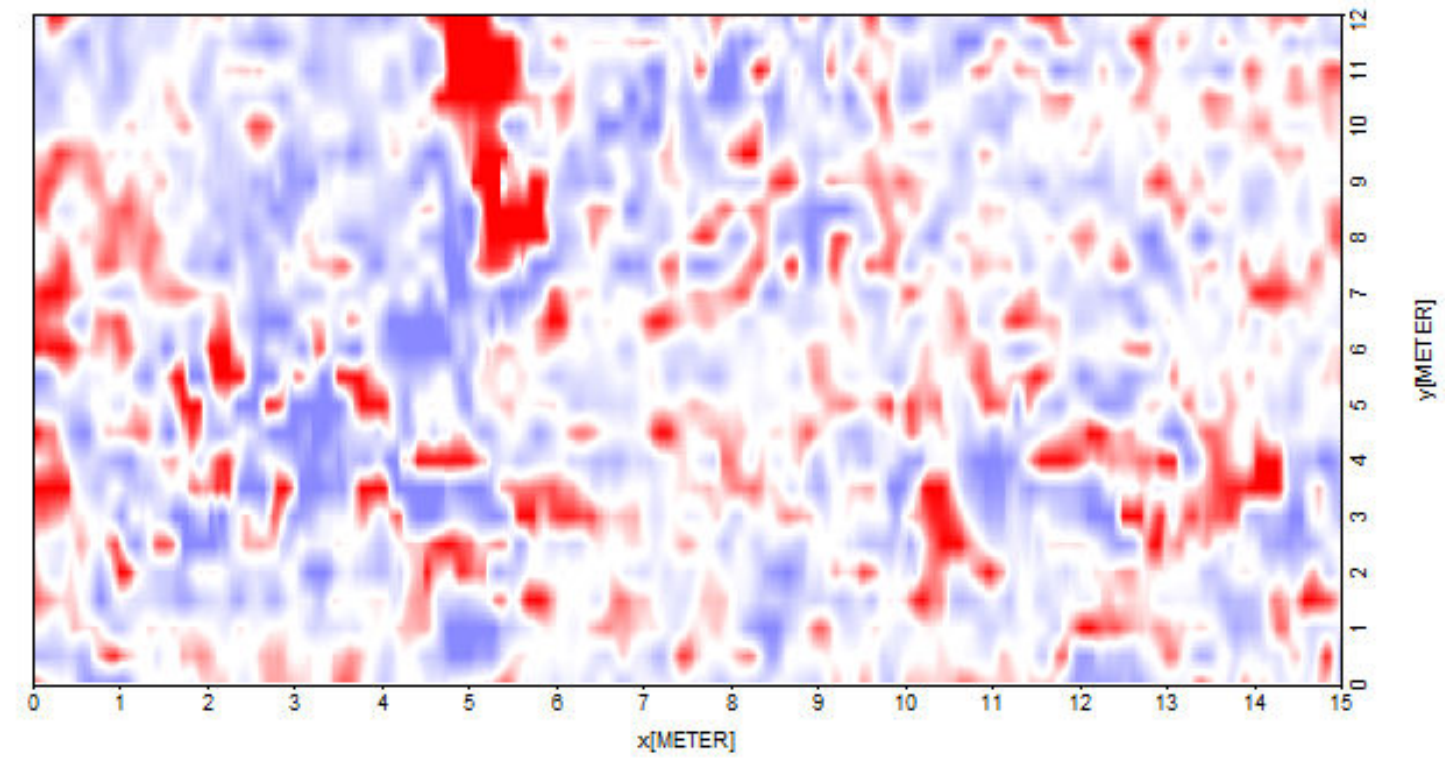

Anexo B 36 - Depth-slice GPR de 200 MHz para a área 2 (profundidade 1,4 m)

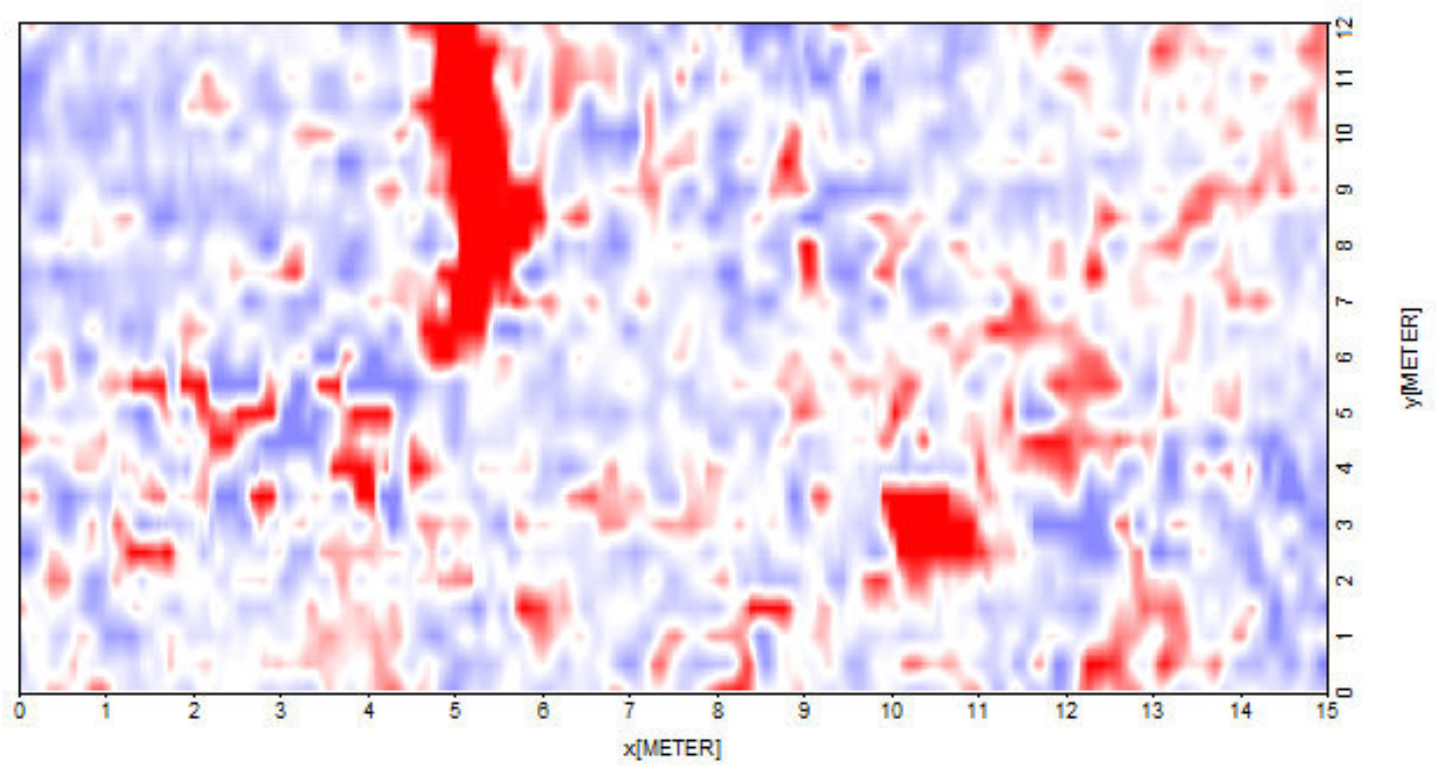

Anexo B 37 - Depth-slice GPR de 200 MHz para a área 2 (profundidade 1,5 m) 


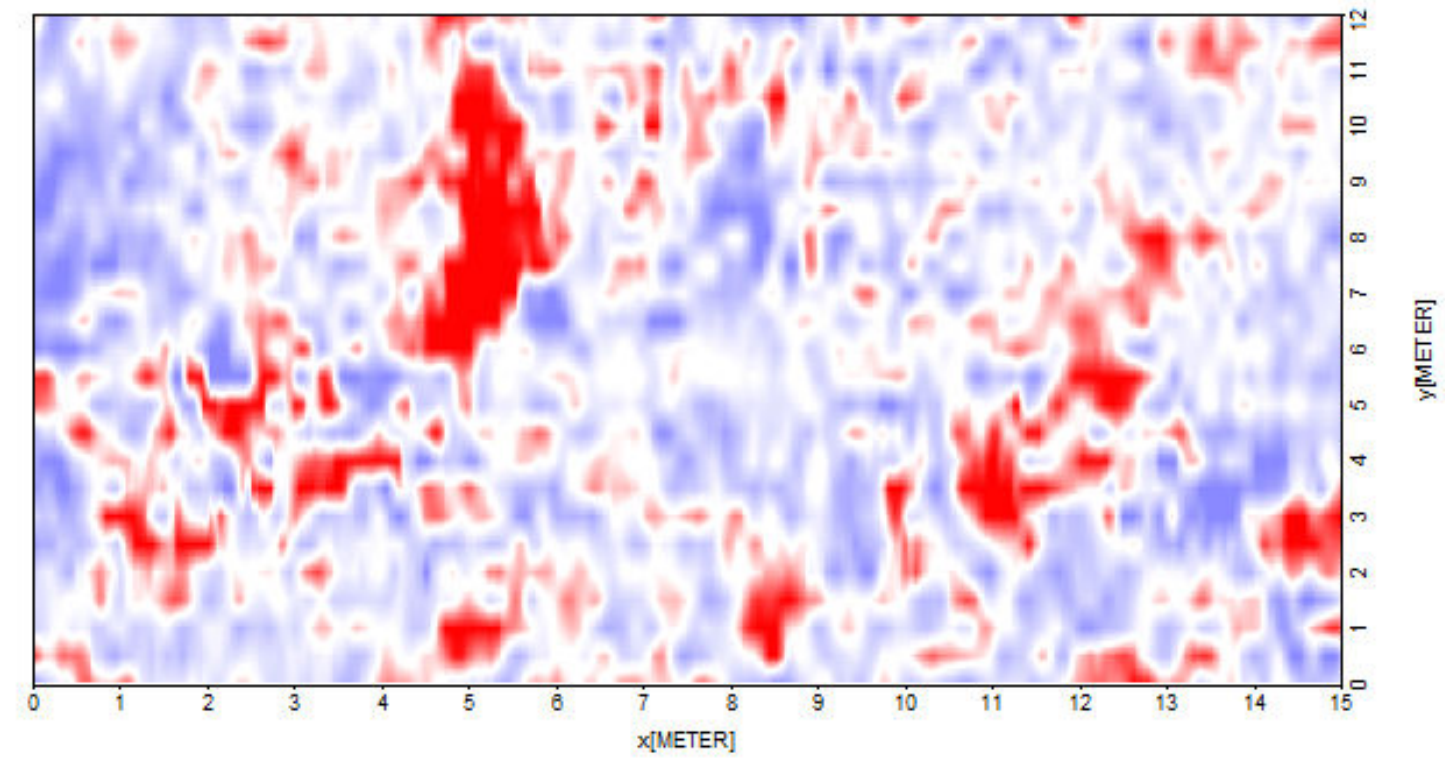

Anexo B 38 - Depth-slice GPR de 200 MHz para a área 2 (profundidade 1,6 m)

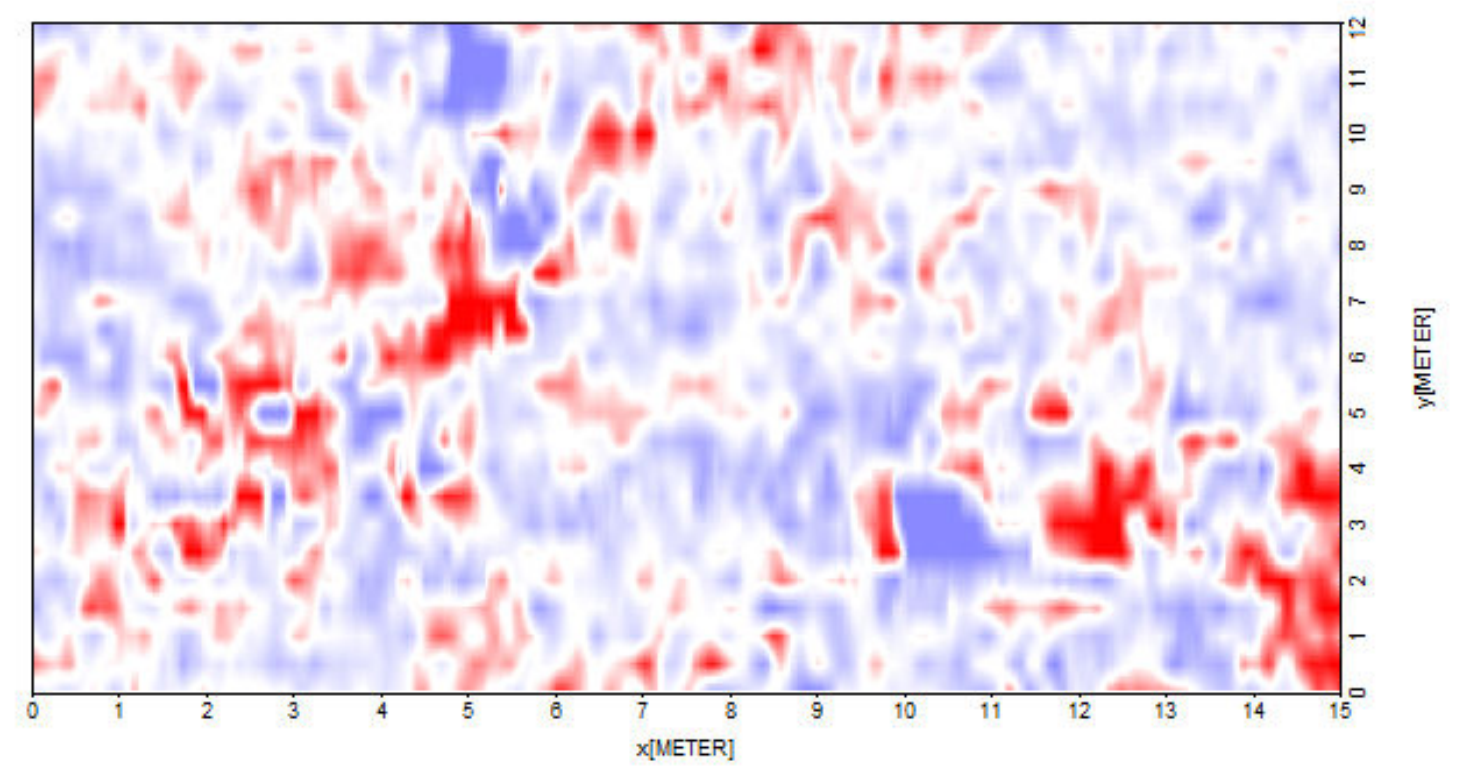

Anexo B 39 Depth-slice GPR de 200 MHz para a área 2 (profundidade 1,7 m) 


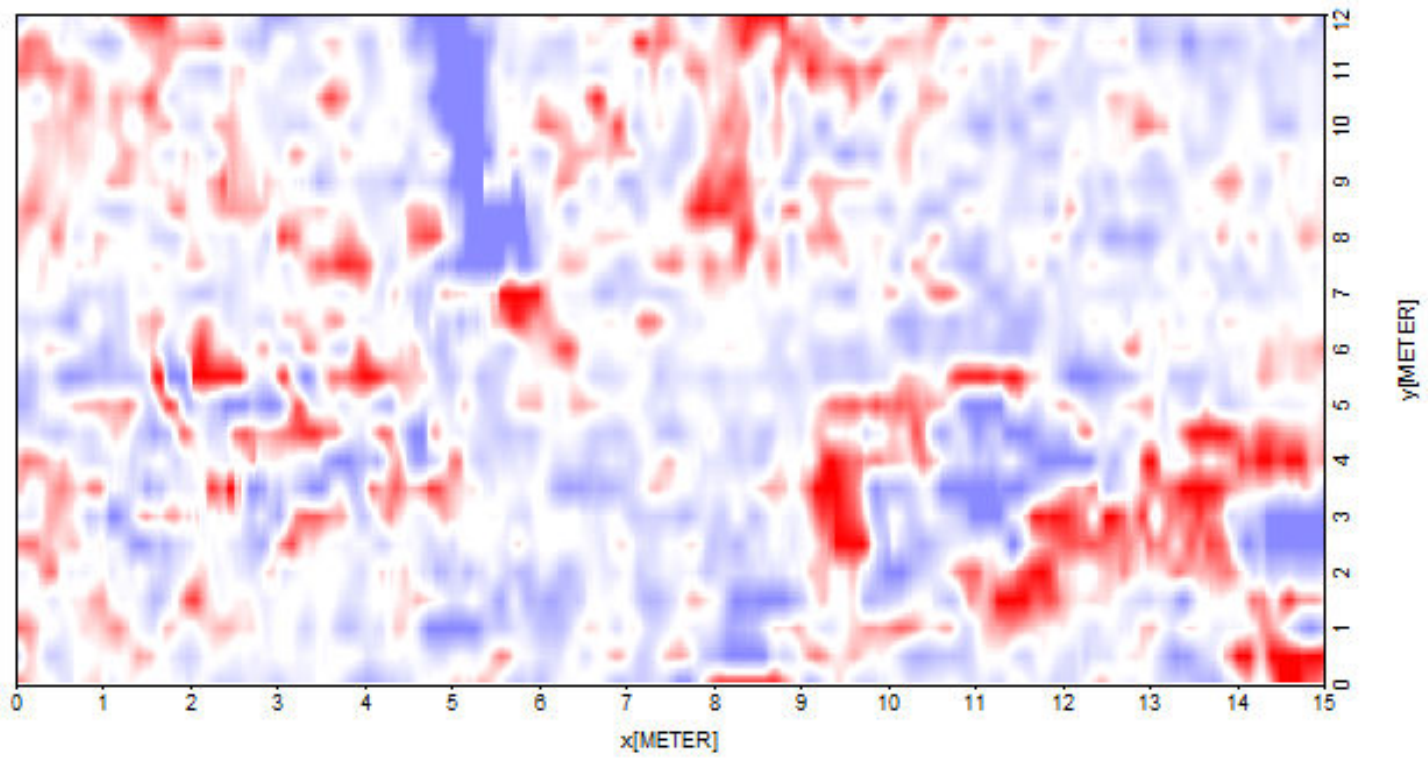

Anexo B 40 - Depth-slice GPR de 200 MHz para a área 2 (profundidade $1,8 \mathrm{~m}$ )

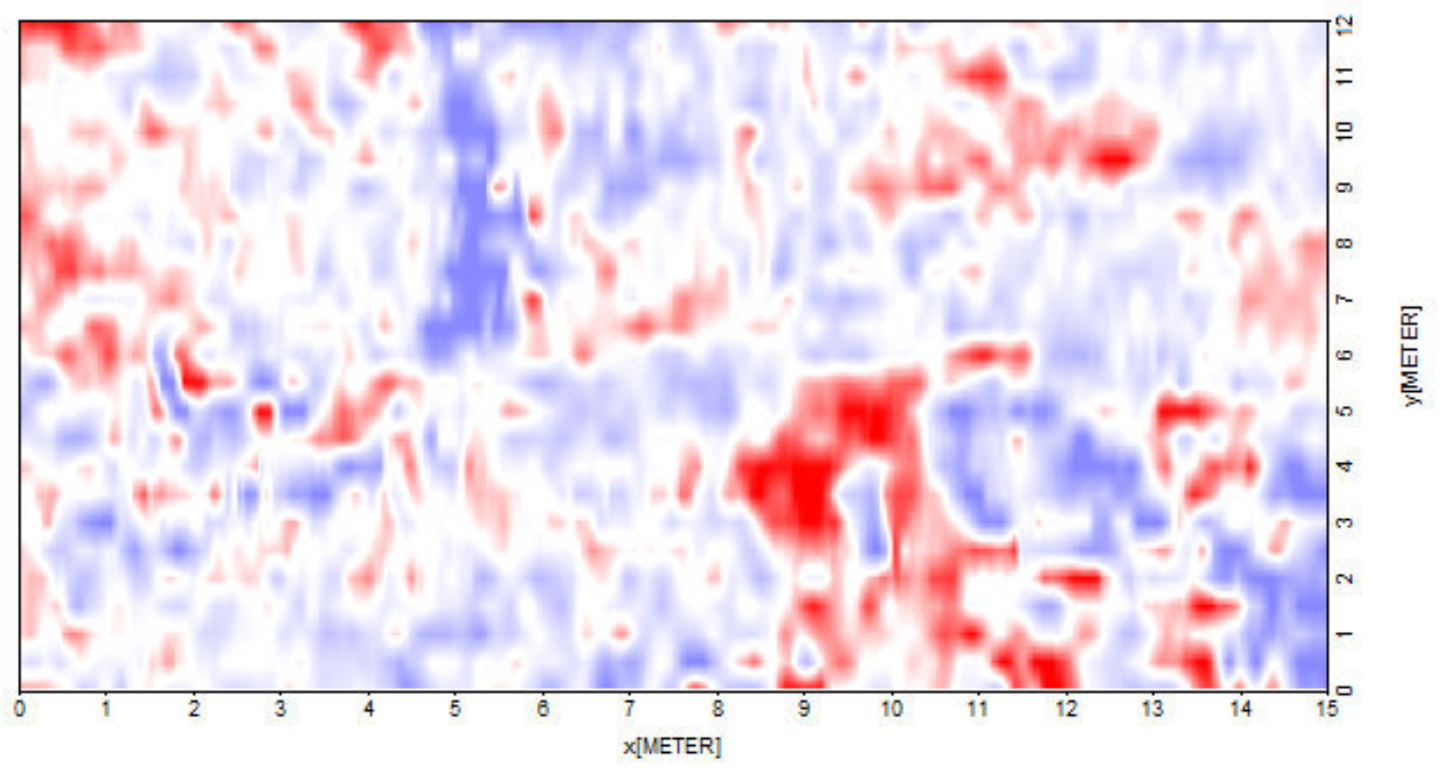

Anexo B 41 - Depth-slice GPR de 200 MHz para a área 2 (profundidade 1,9 m) 


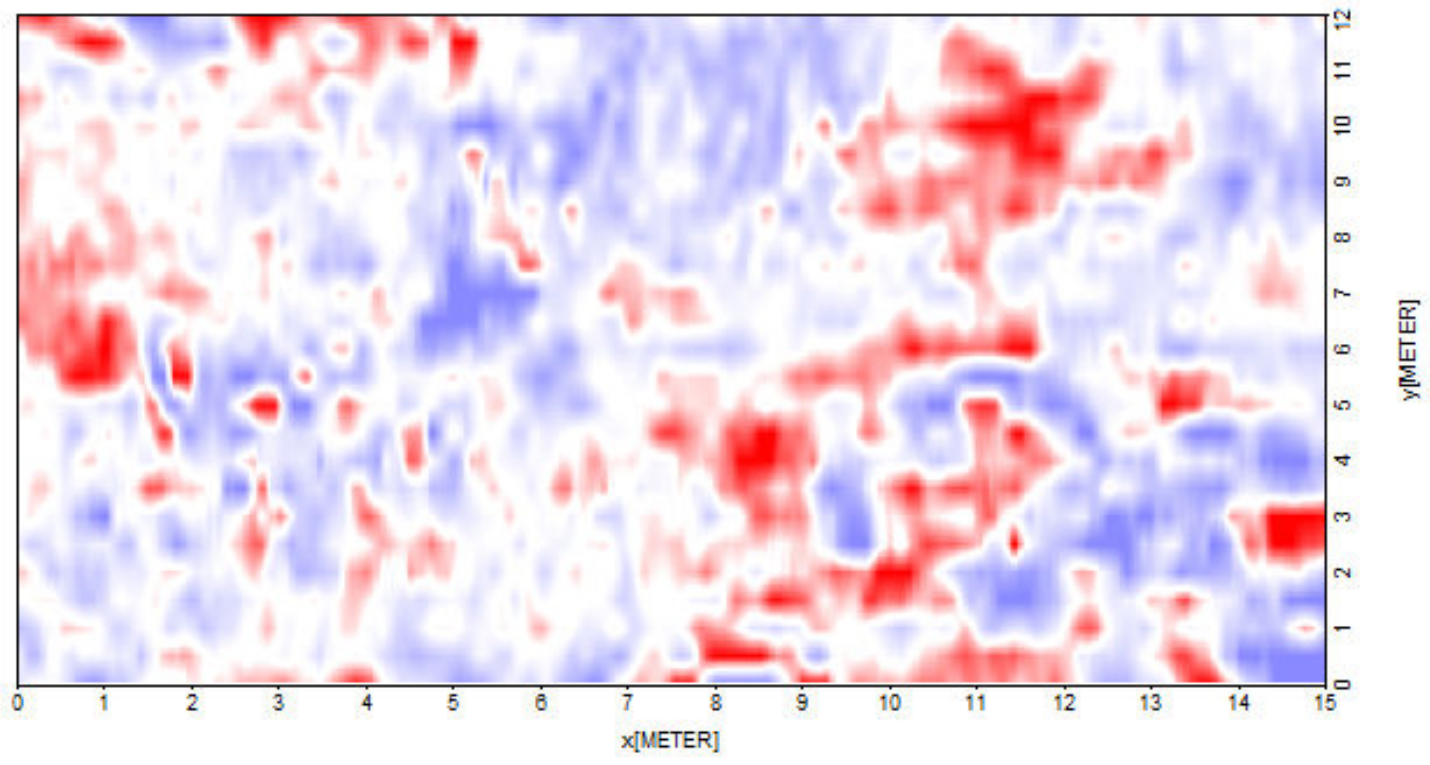

Anexo B 42 - Depth-slice GPR de 200 MHz para a área 2 (profundidade 2,0 m)

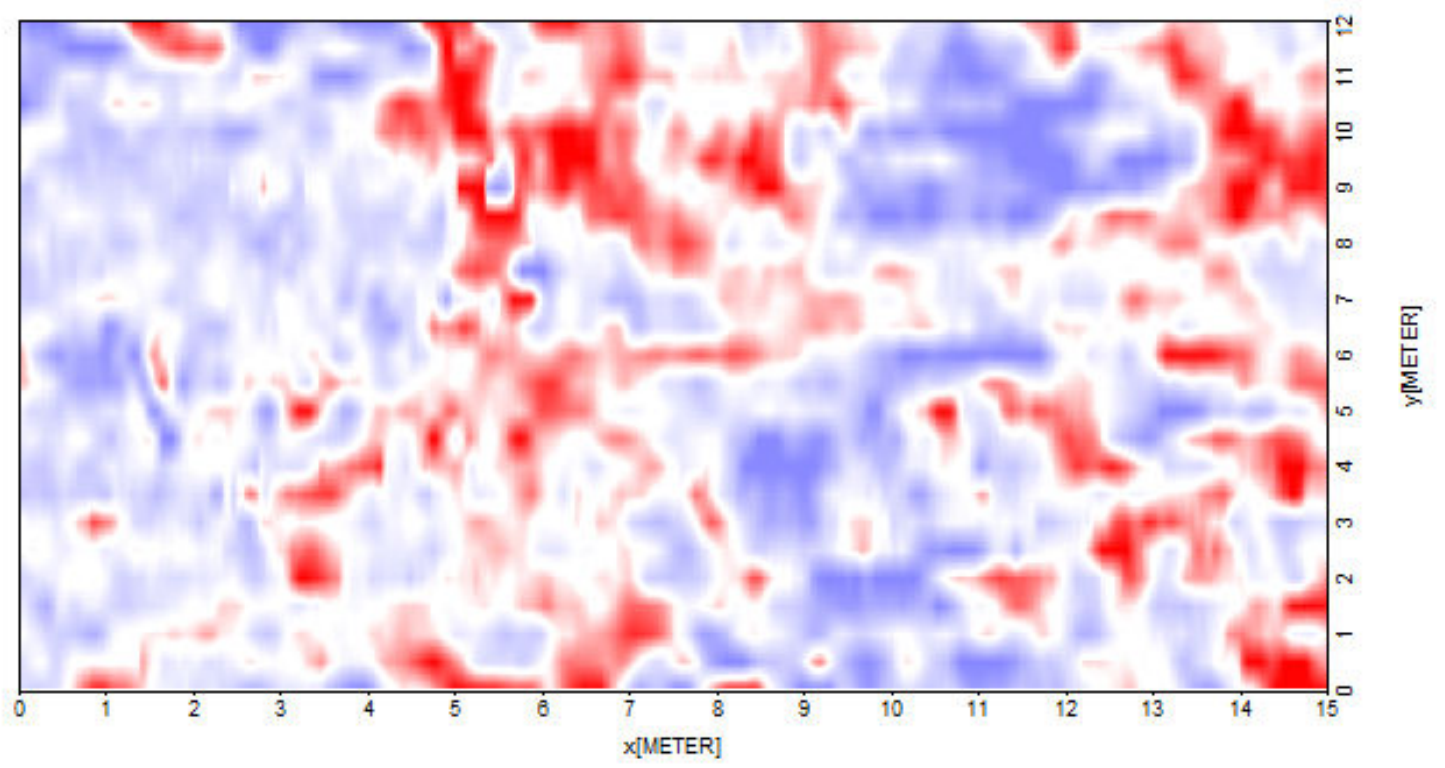

Anexo B 43 - Depth-slice GPR de 200 MHz para a área 2 (profundidade 2,2 m) 


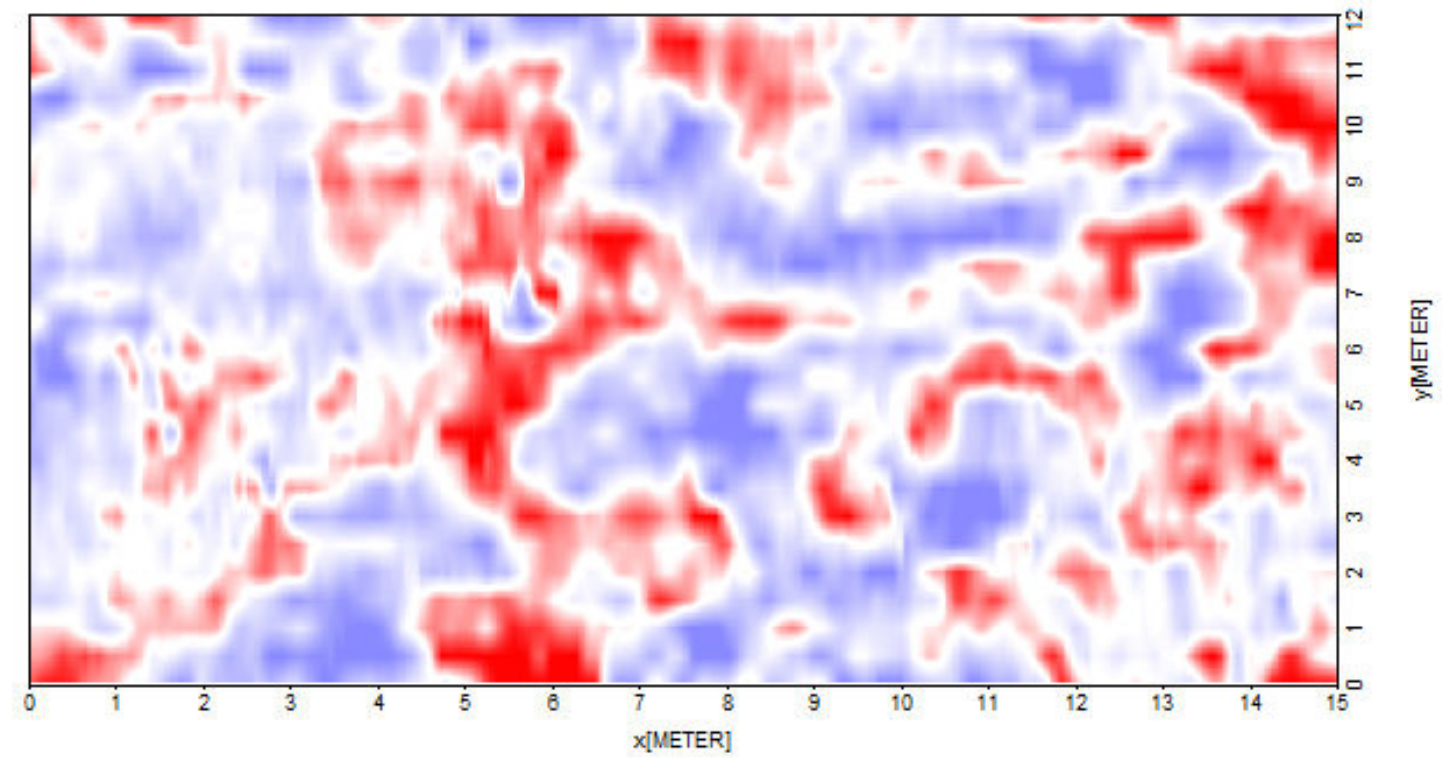

Anexo B 44 - Depth-slice GPR de 200 MHz para a área 2 (profundidade 2,3 m)

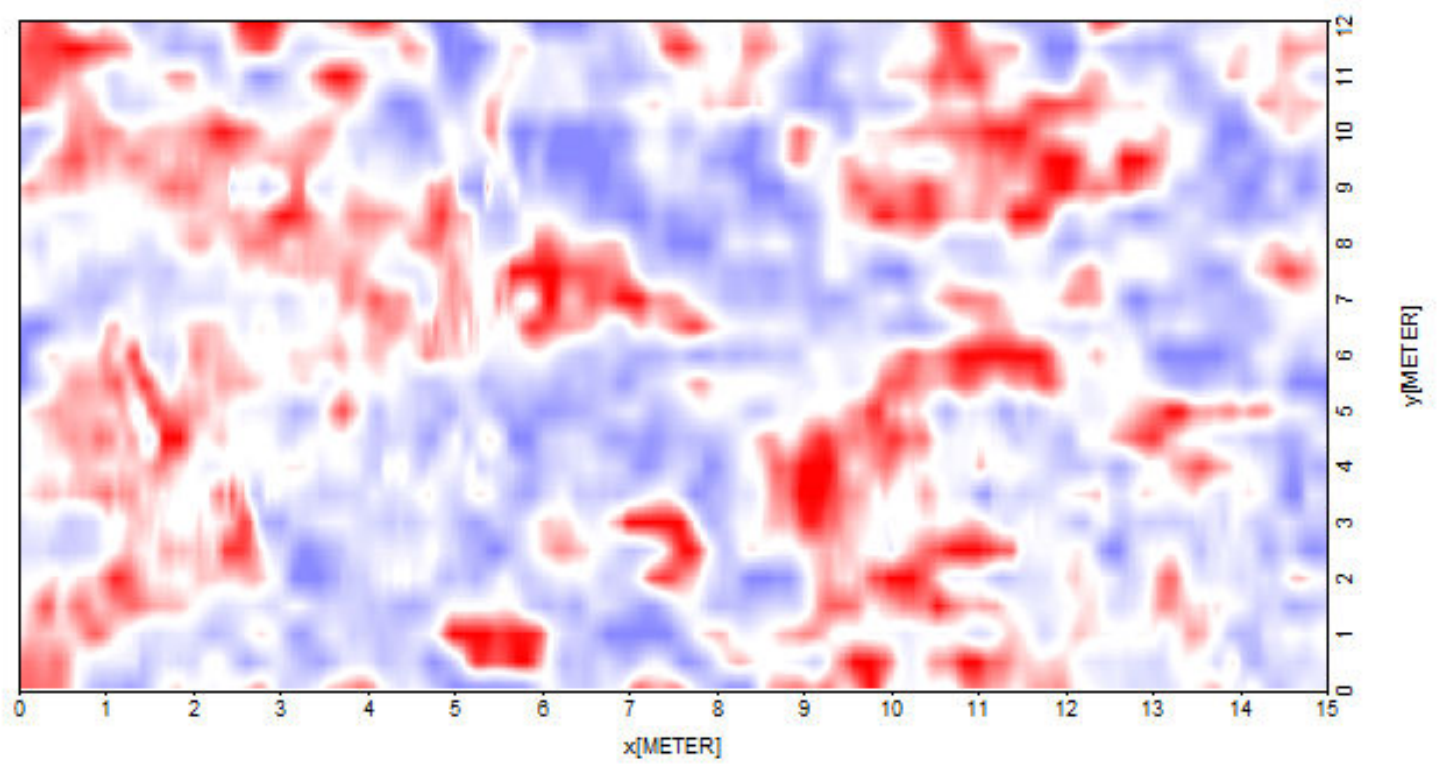

Anexo B 45 - Depth-slice GPR de 200 MHz para a área 2 (profundidade 2,4 m) 


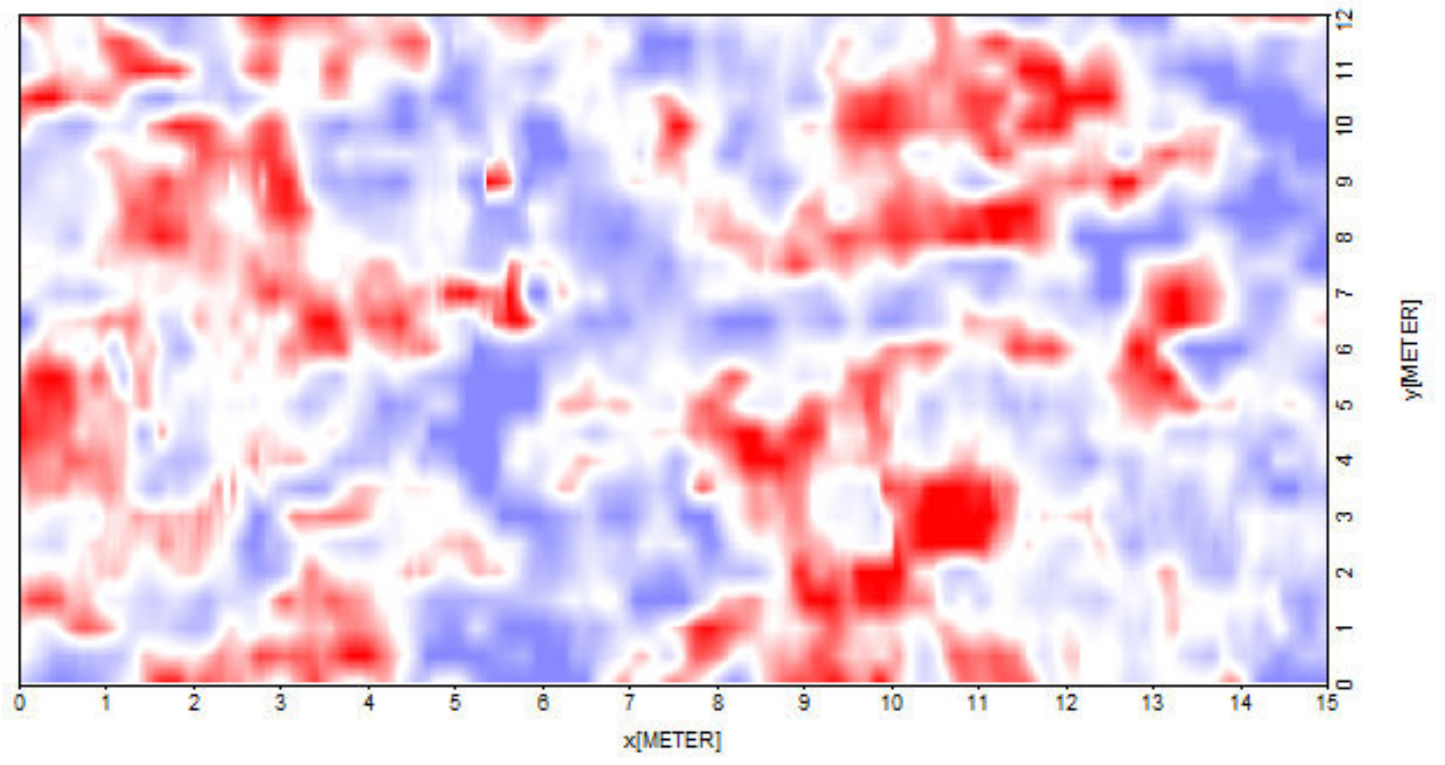

Anexo B 46 - Depth-slice GPR de 200 MHz para a área 2 (profundidade 2,5 m) 


\section{ANEXO C: ÁREA 3}

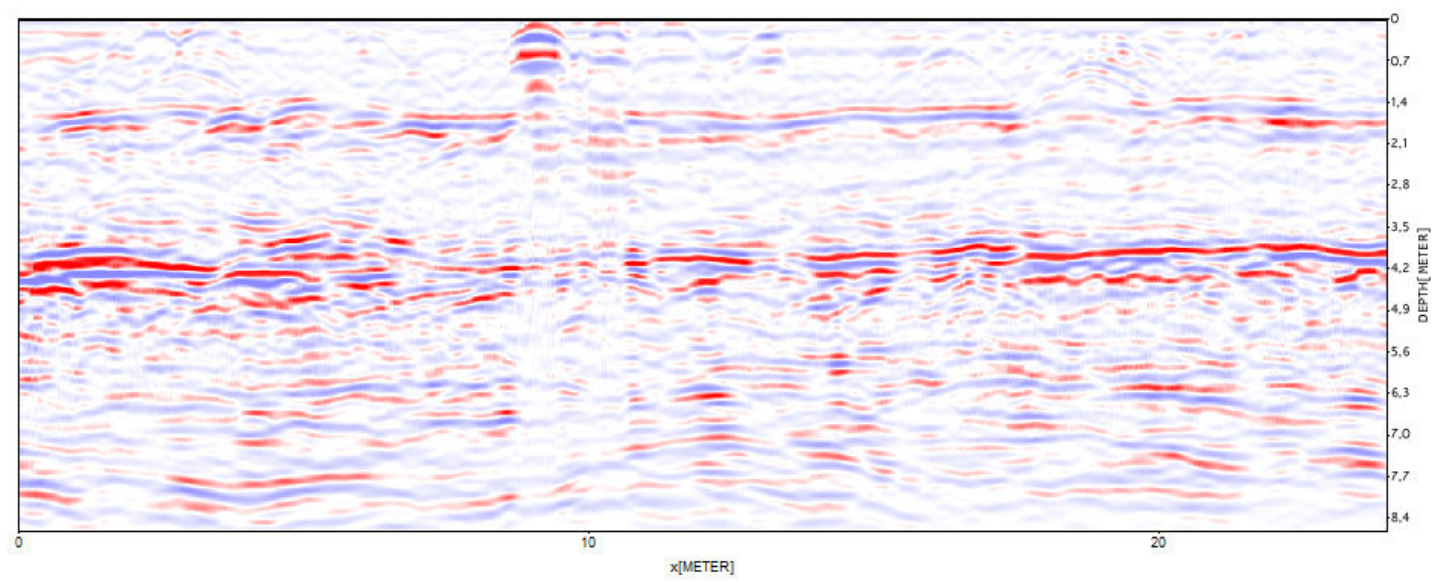

Anexo C 1 - Perfil GPR de 200 MHz número 1 na direção x para a área 3

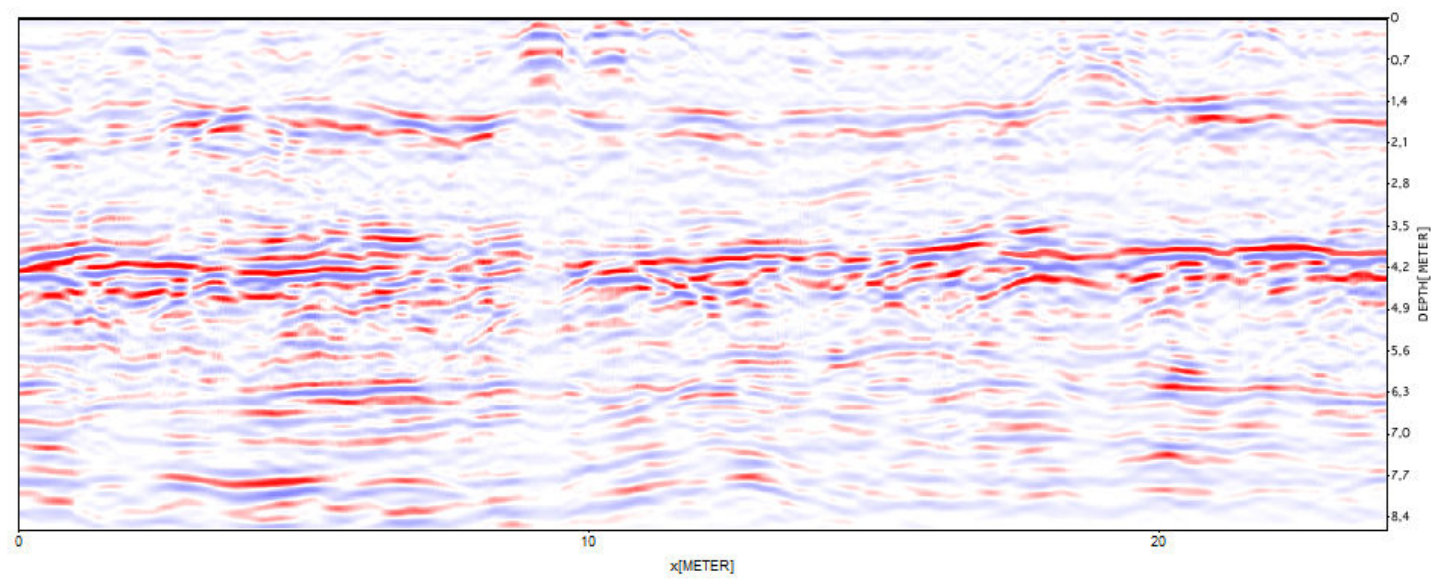

Anexo C 2 - Perfil GPR de 200 MHz número 2 na direção x para a área 3

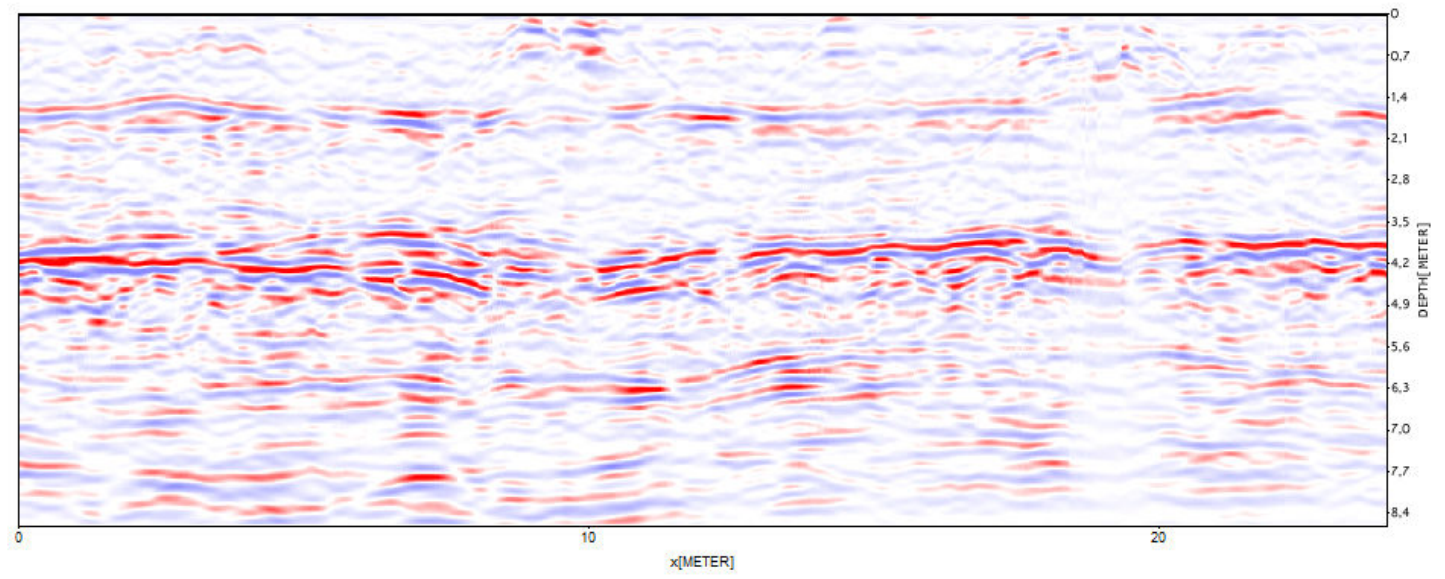

Anexo C 3 - Perfil GPR de 200 MHz número 3 na direção x para a área 3 


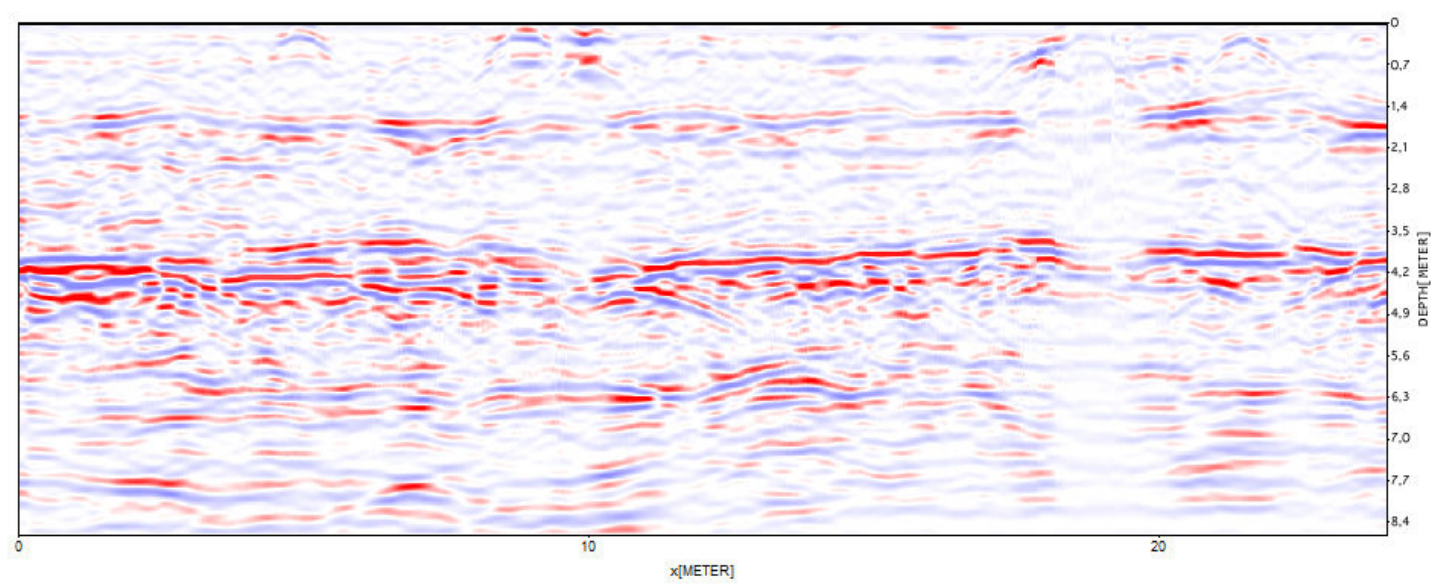

Anexo C 4 - Perfil GPR de 200 MHz número 4 na direção x para a área 3

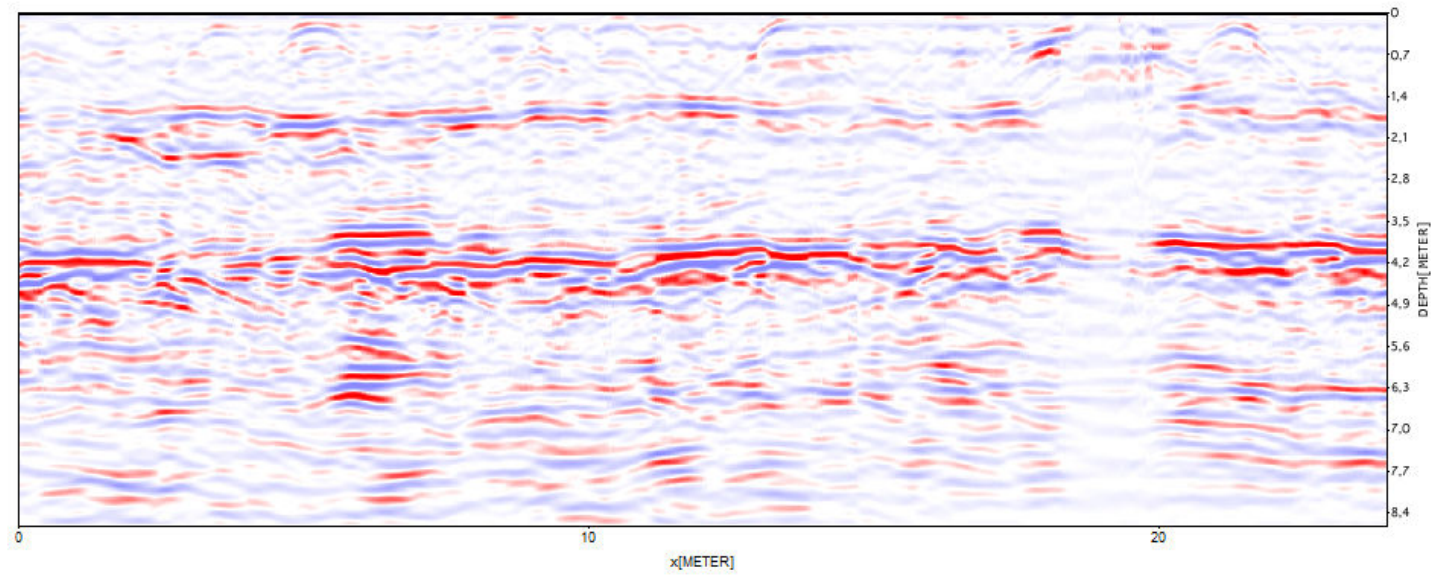

Anexo C 5 - Perfil GPR de 200 MHz número 5 na direção x para a área 3

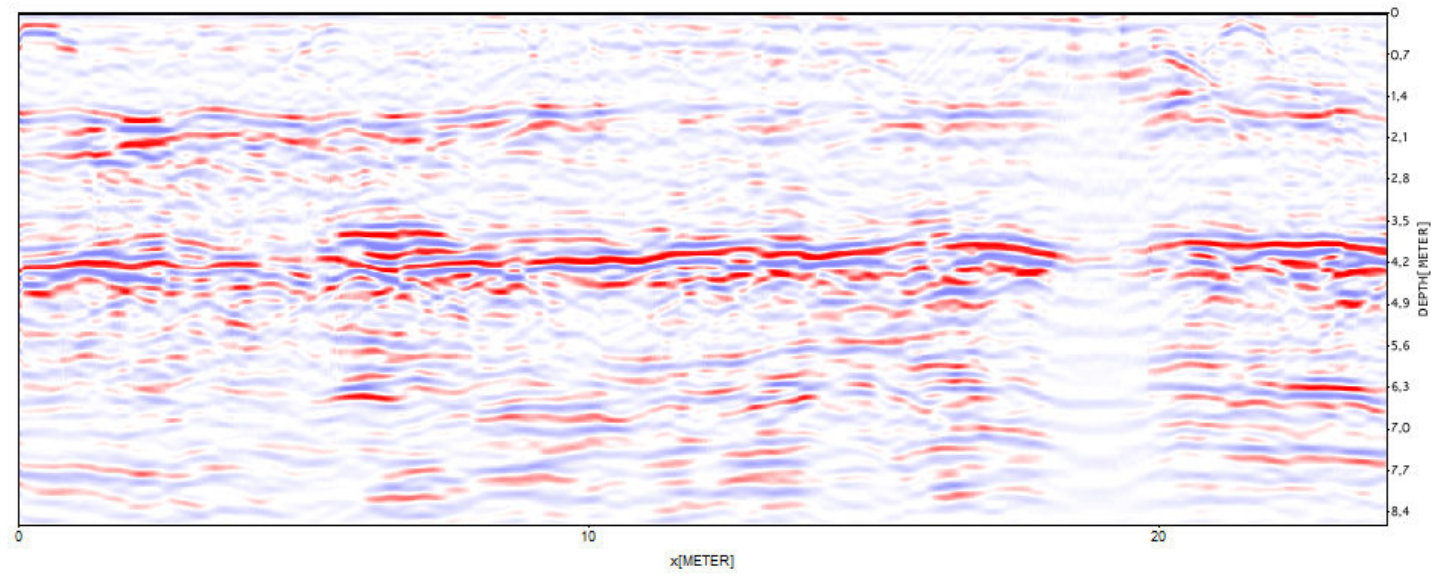

Anexo C 6 - Perfil GPR de 200 MHz número 6 na direção x para a área 3 


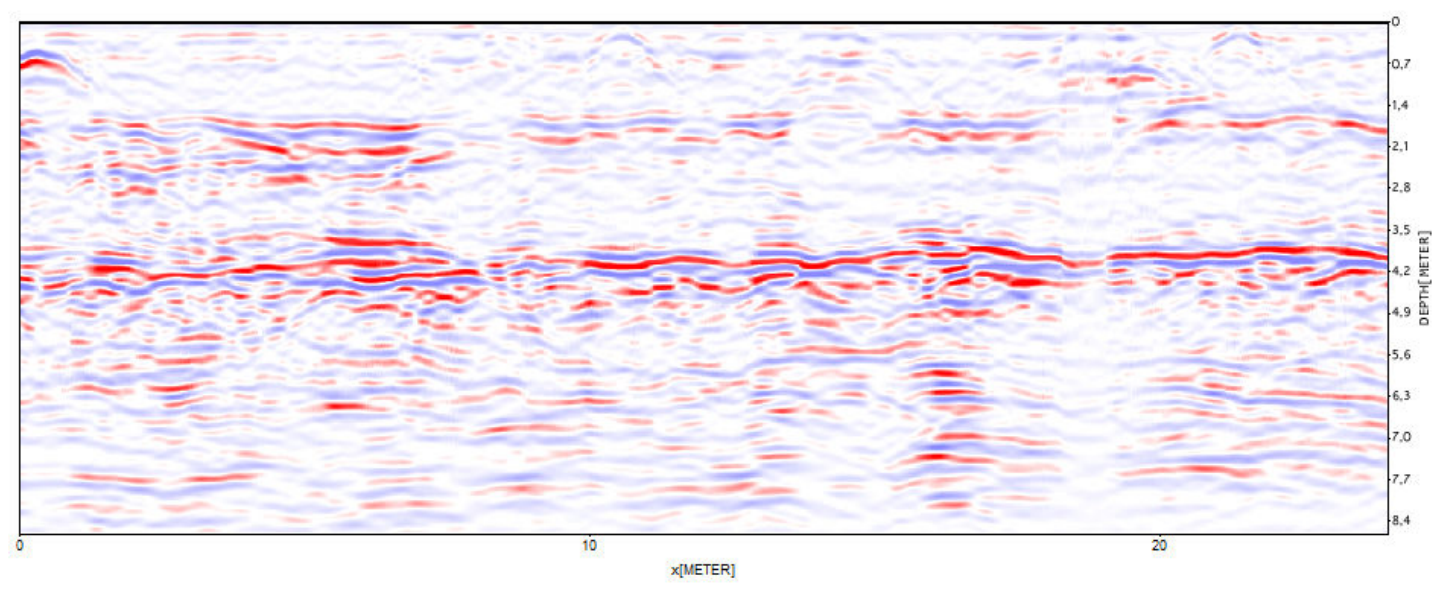

Anexo C 7 - Perfil GPR de 200 MHz número 7 na direção x para a área 3

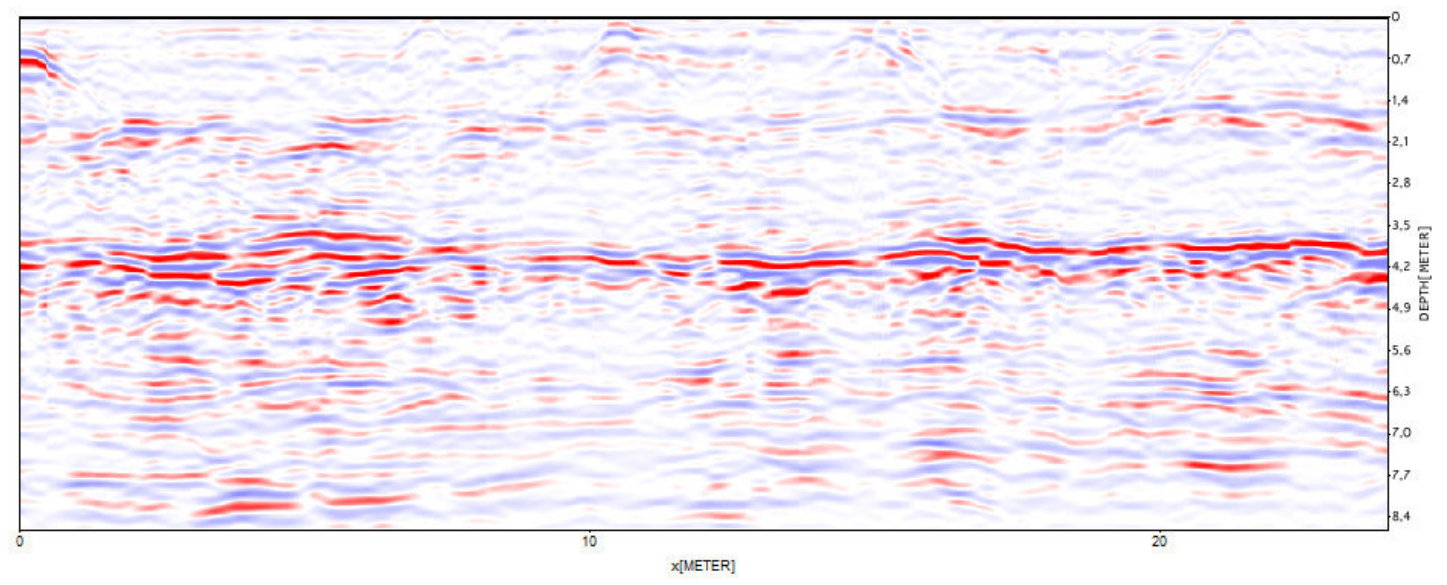

Anexo C 8 - Perfil GPR de 200 MHz número 8 na direção x para a área 3

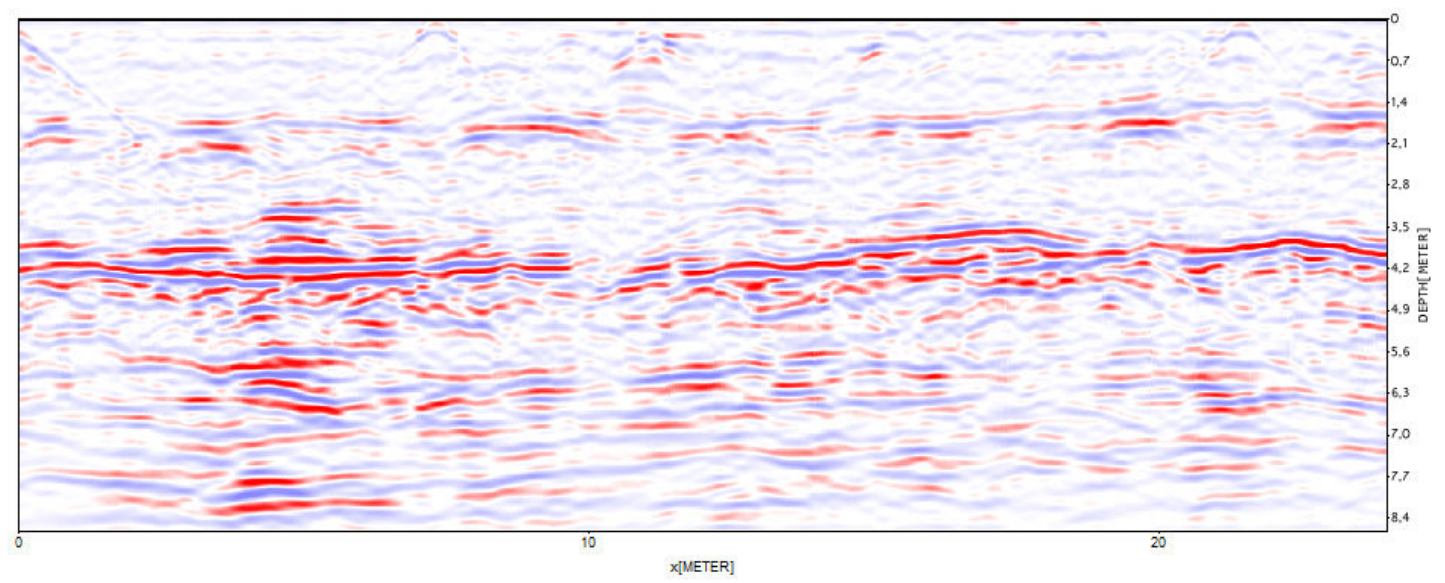

Anexo C 9 - Perfil GPR de 200 MHz número 9 na direção x para a área 3 


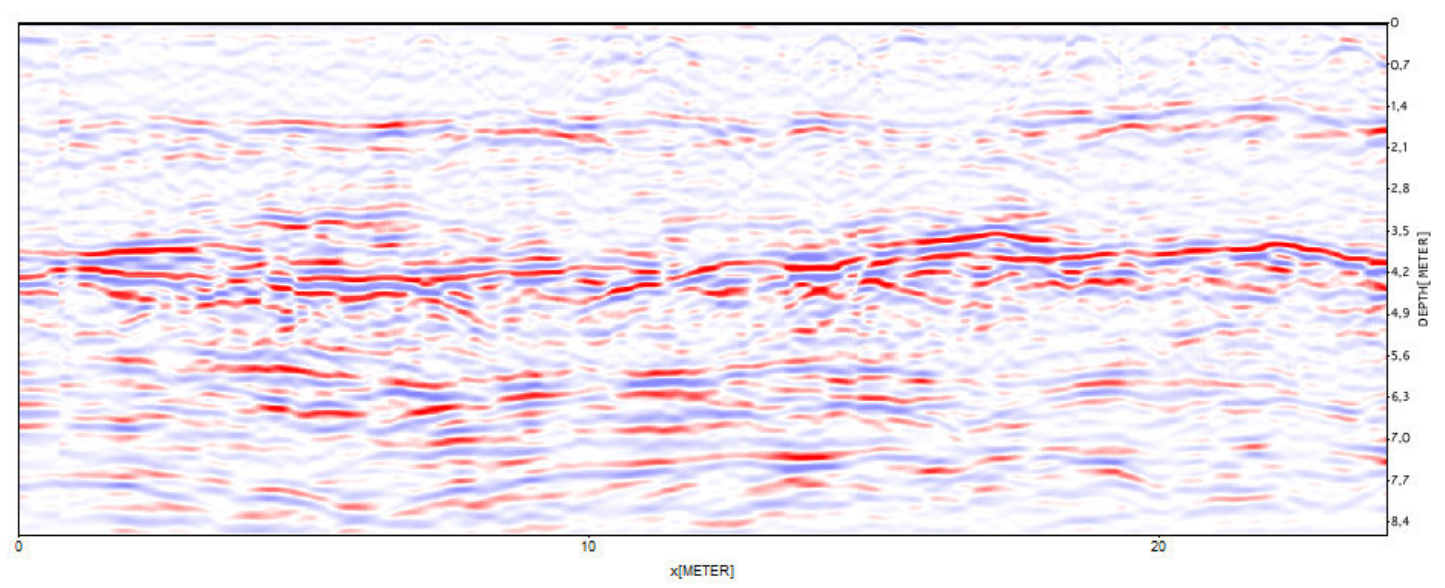

Anexo C 10 - Perfil GPR de 200 MHz número 10 na direção x para a área 3

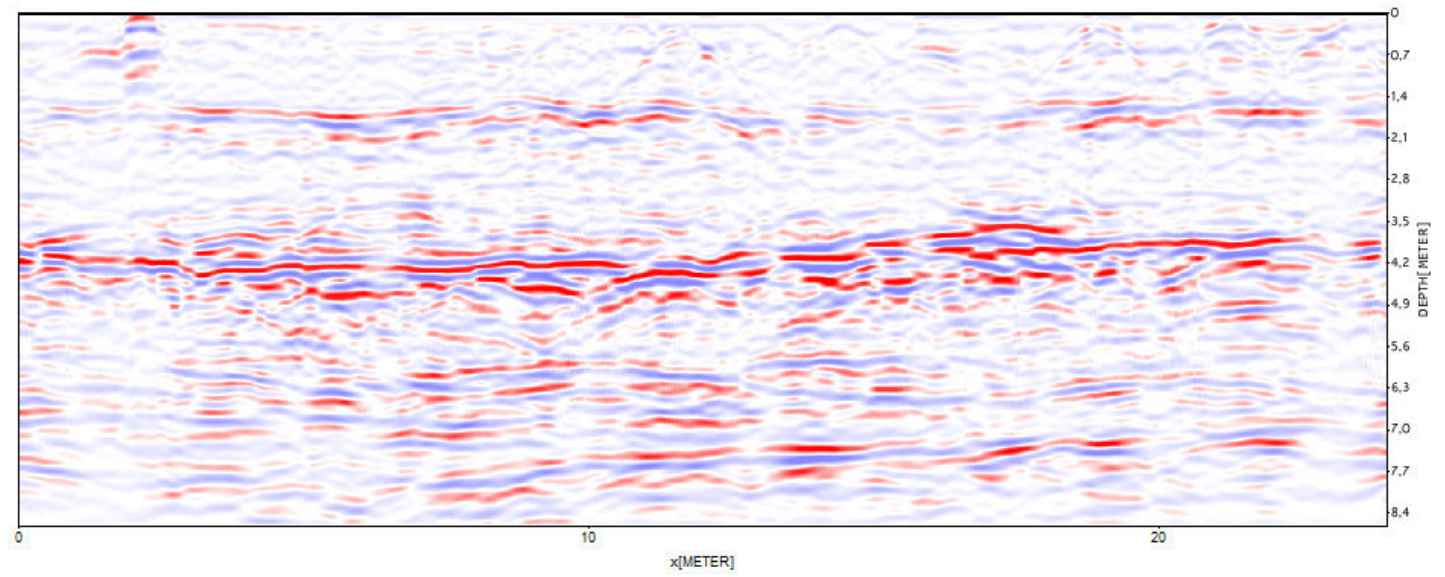

Anexo C 11 - Perfil GPR de 200 MHz número 11 na direção x para a área 3

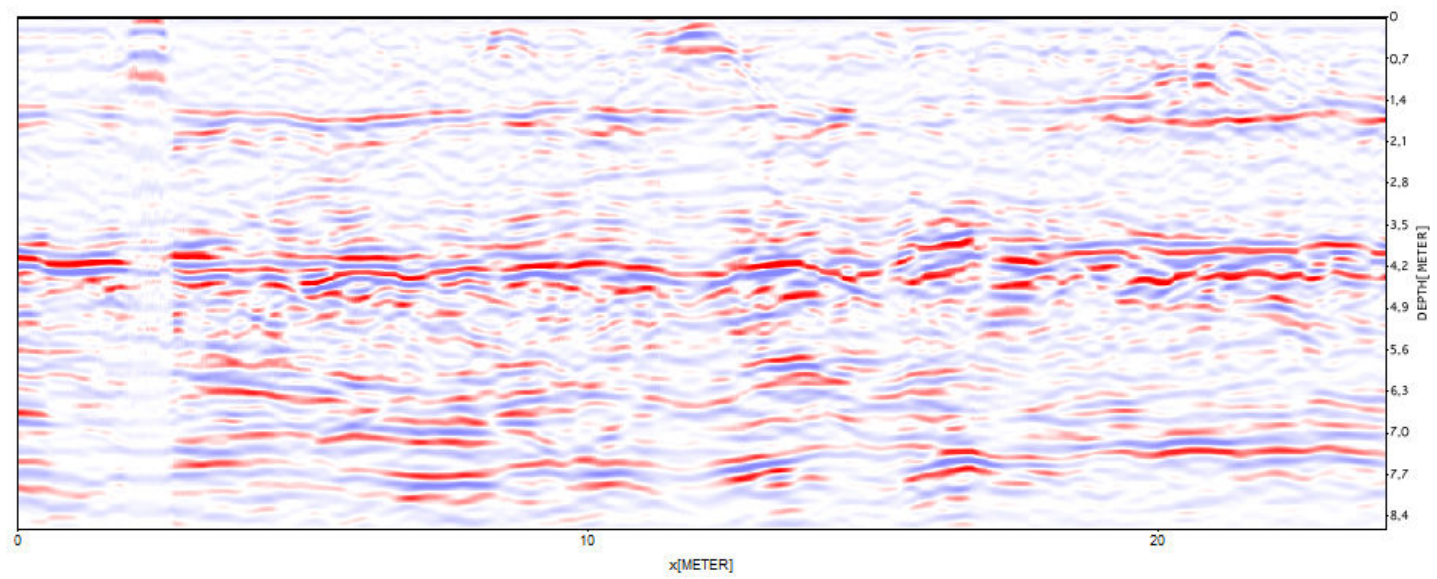

Anexo C 12 - Perfil GPR de 200 MHz número 13 na direção x para a área 3 


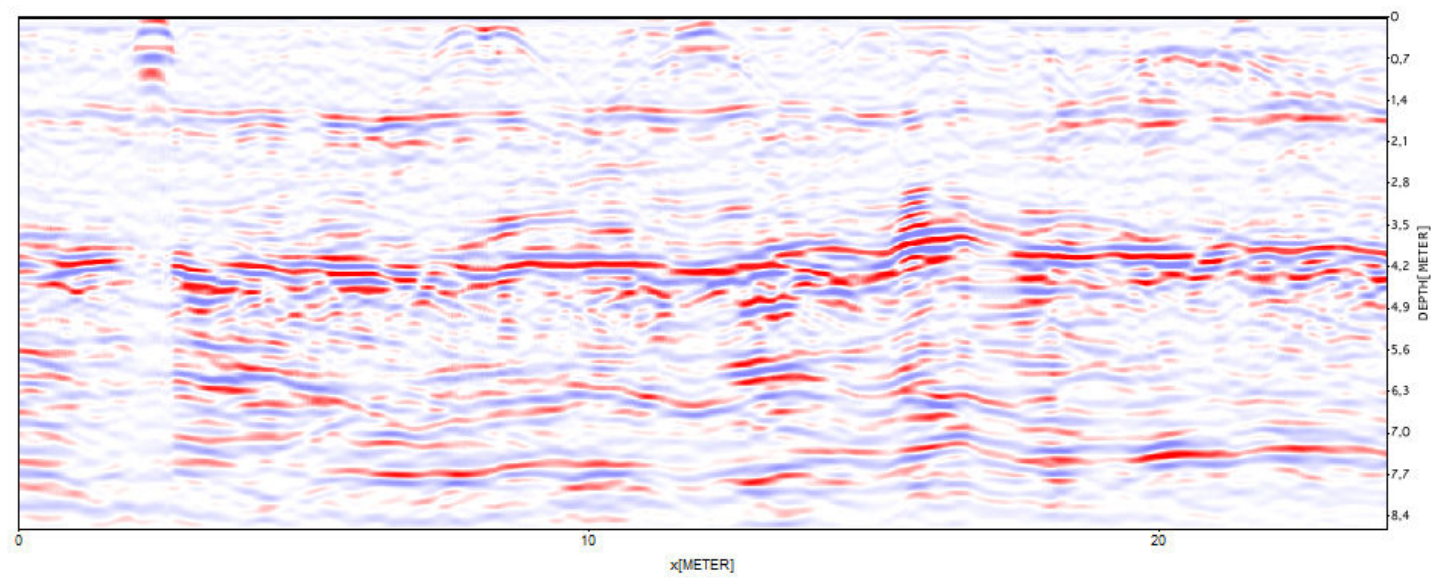

Anexo C 13 - Perfil GPR de 200 MHz número 14 na direção x para a área 3

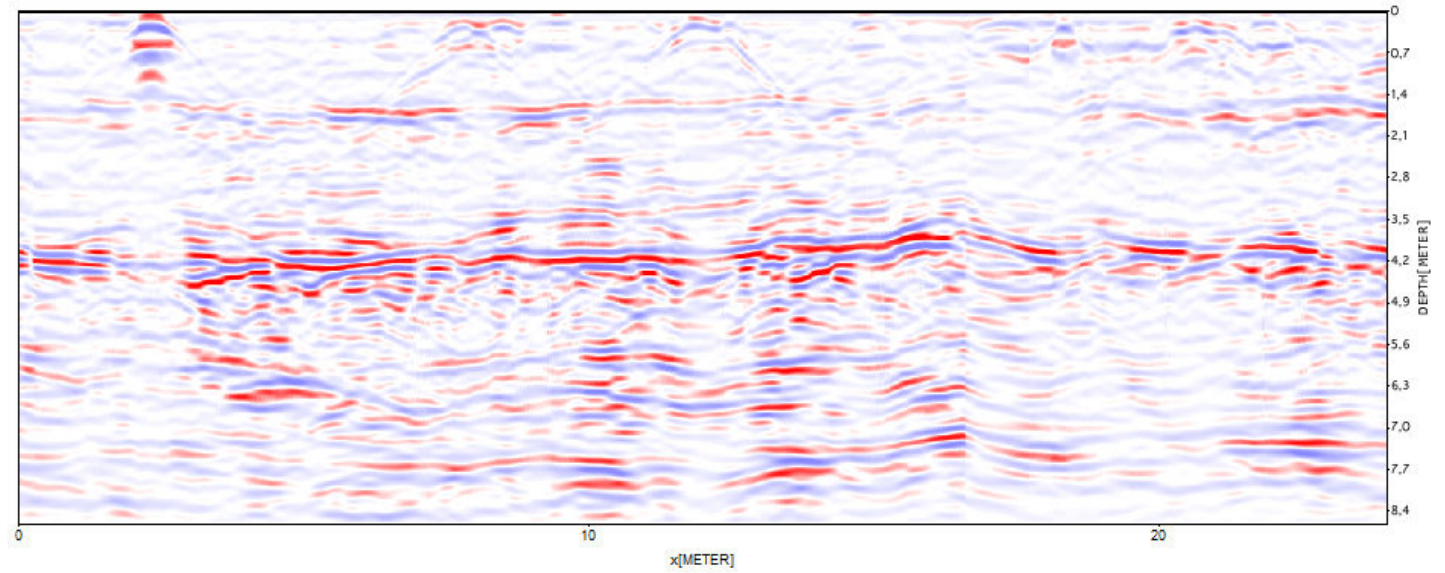

Anexo C 14 Perfil GPR de 200 MHz número 15 na direção x para a área 3

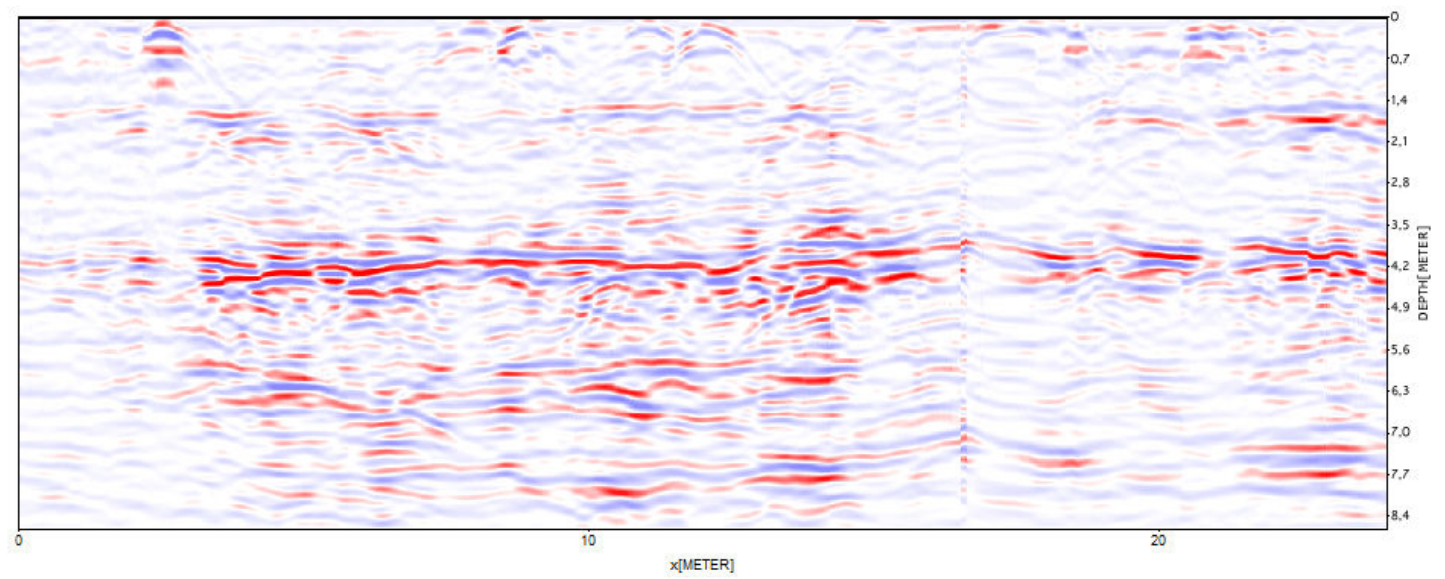

Anexo C 15 - Perfil GPR de 200 MHz número 16 na direção x para a área 3 


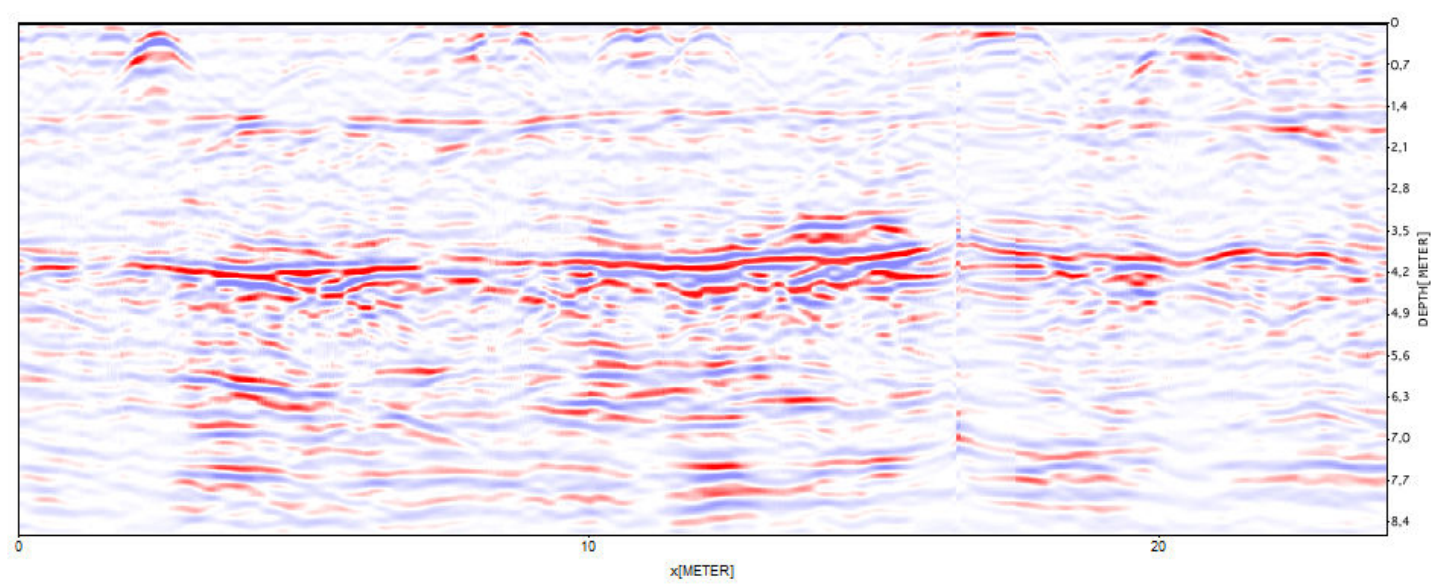

Anexo C 16 - Perfil GPR de 200 MHz número 17 na direção x para a área 3

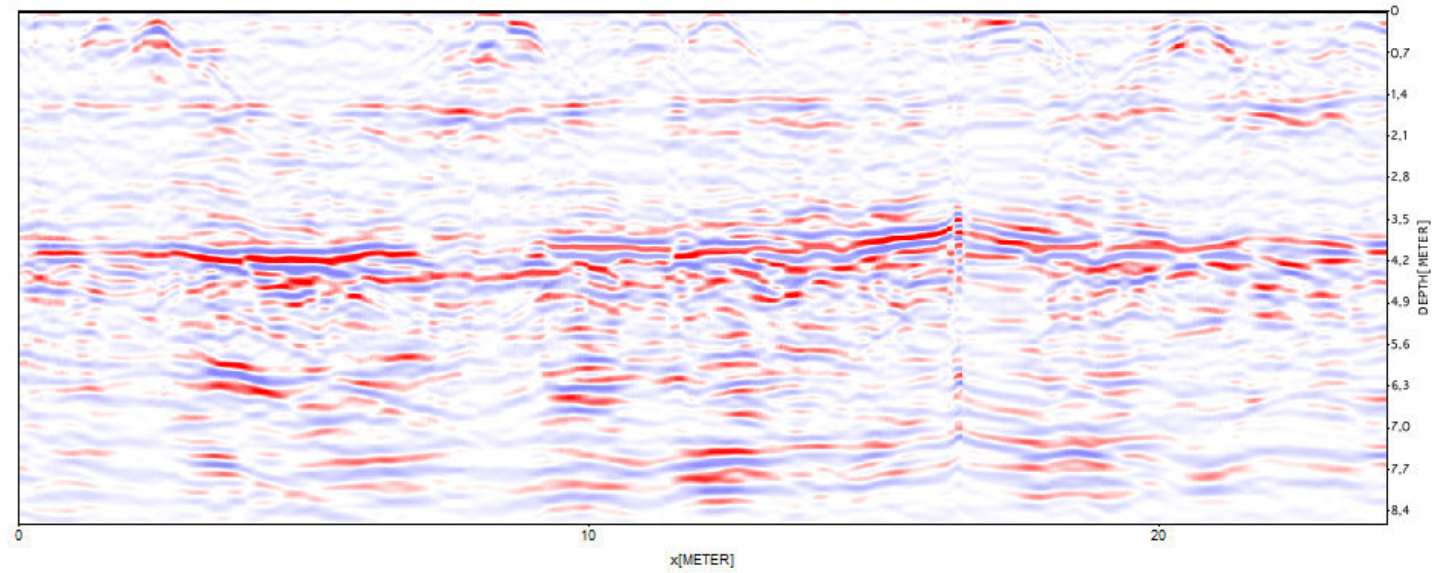

Anexo C 17 - Perfil GPR de 200 MHz número 18 na direção x para a área 3

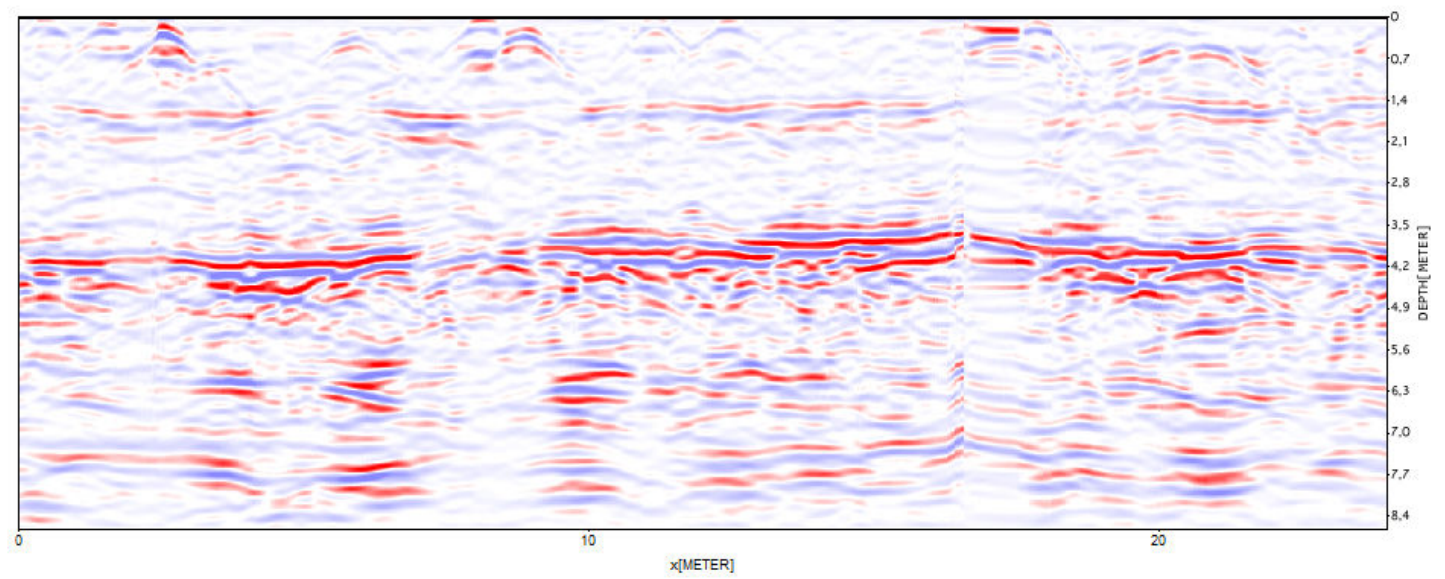

Anexo C 18 - Perfil GPR de 200 MHz número 19 na direção x para a área 3 


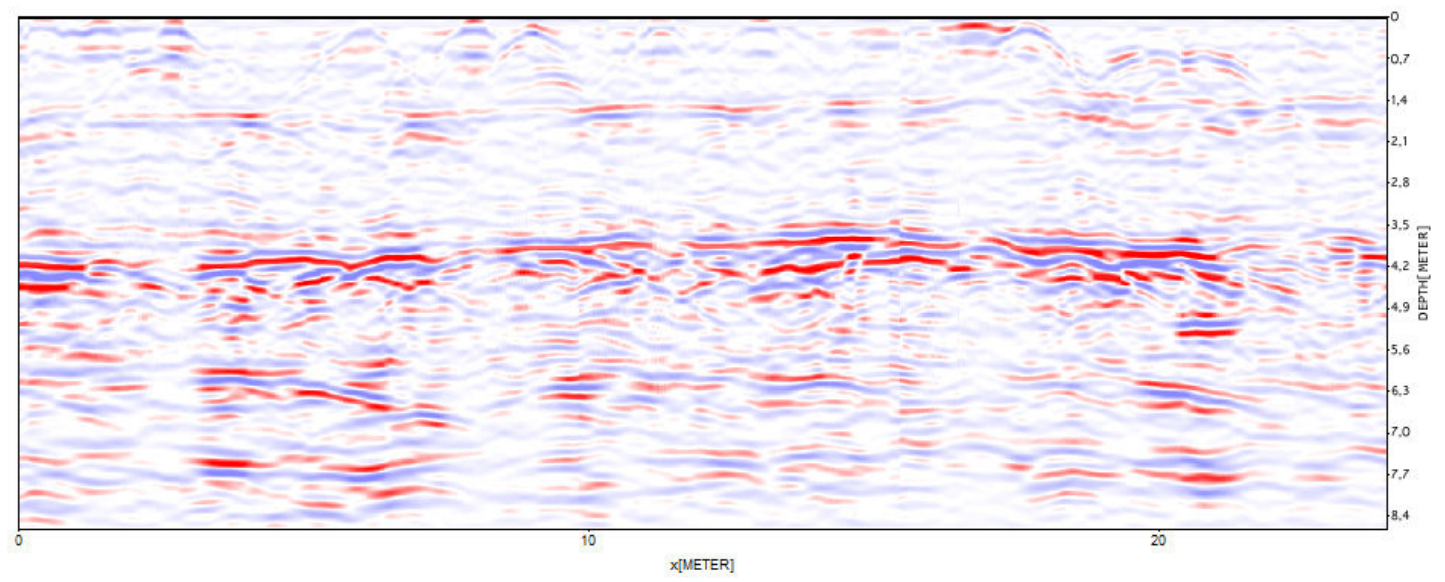

Anexo C 19 - Perfil GPR de 200 MHz número 20 na direção x para a área 3

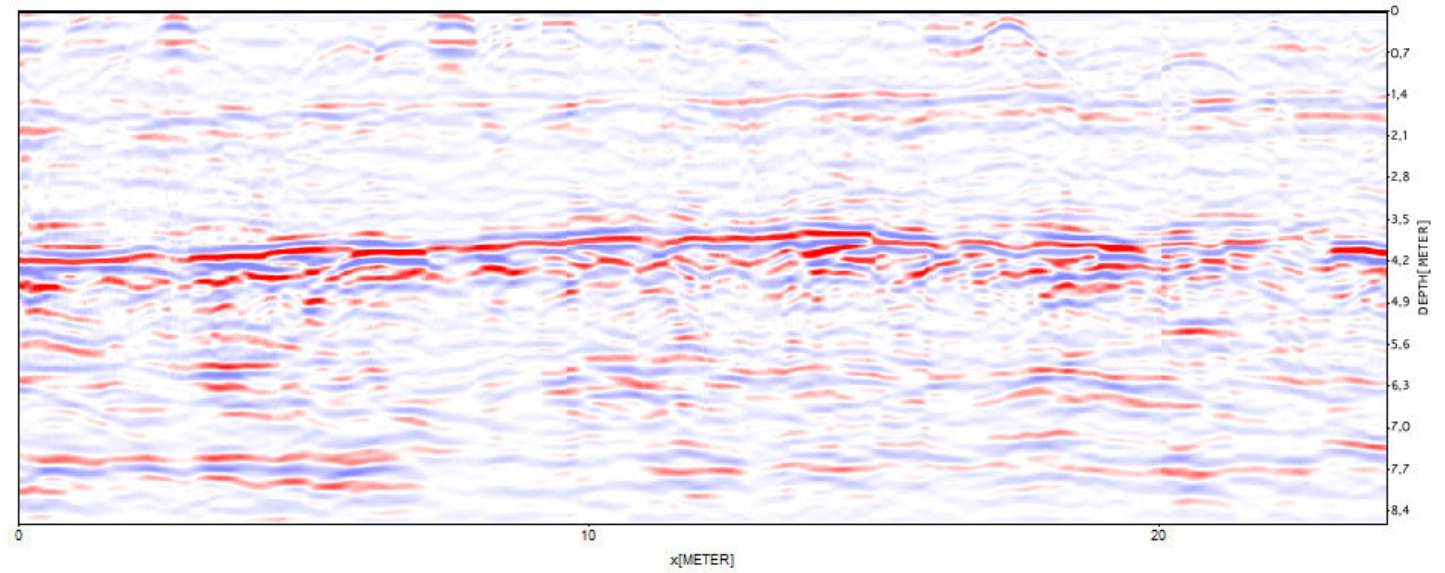

Anexo C 20 - Perfil GPR de 200 MHz número 21 na direção x para a área 3

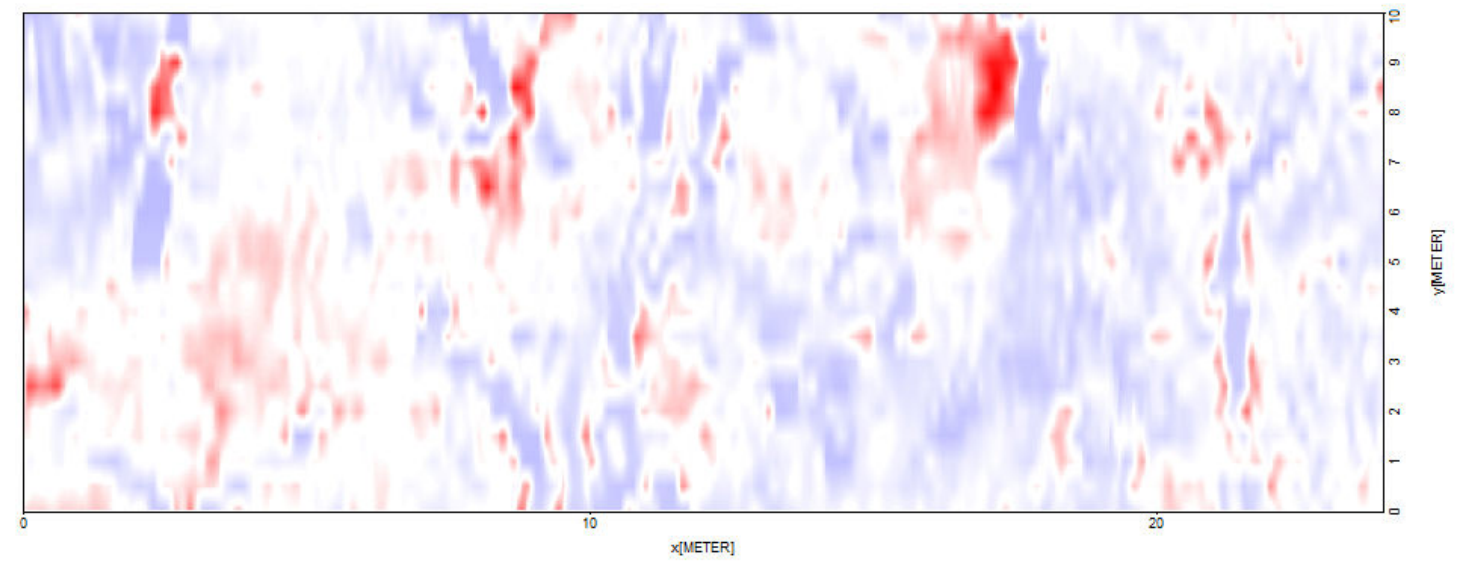

Anexo C 21 - Depth-slice GPR de 200 MHz para a área 3 (profundidade 0,1 m) 


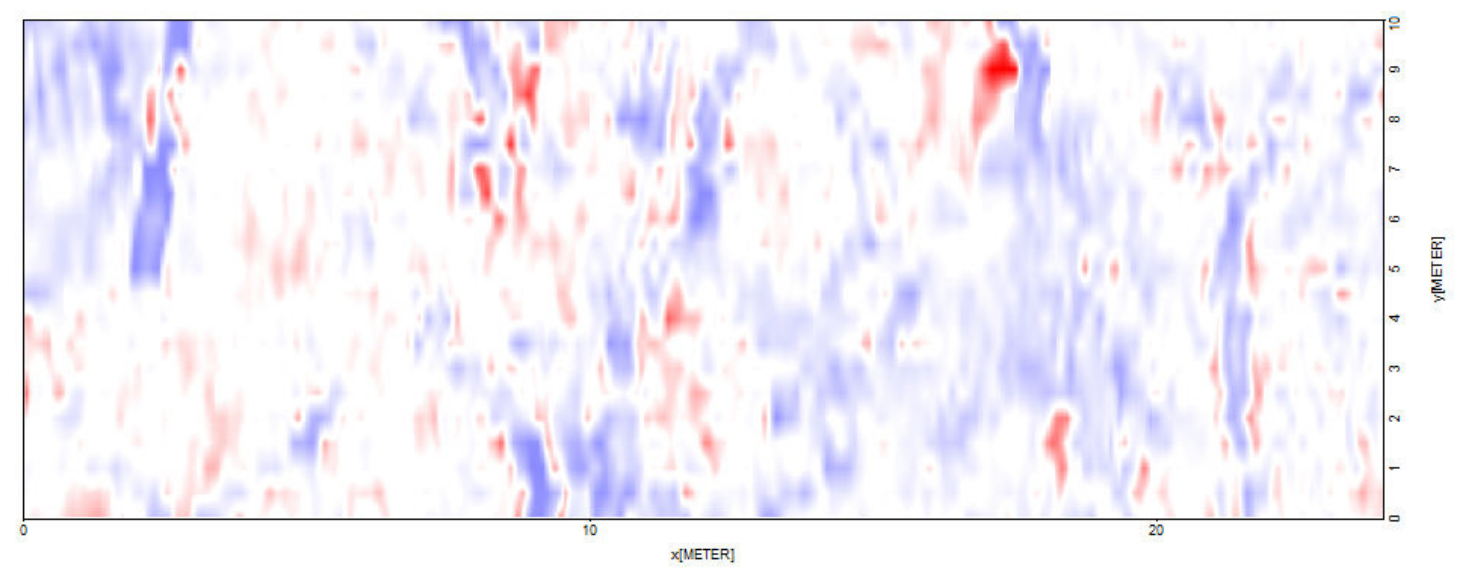

Anexo C 22 - Depth-slice GPR de 200 MHz para a área 3 (profundidade 0,2 m)

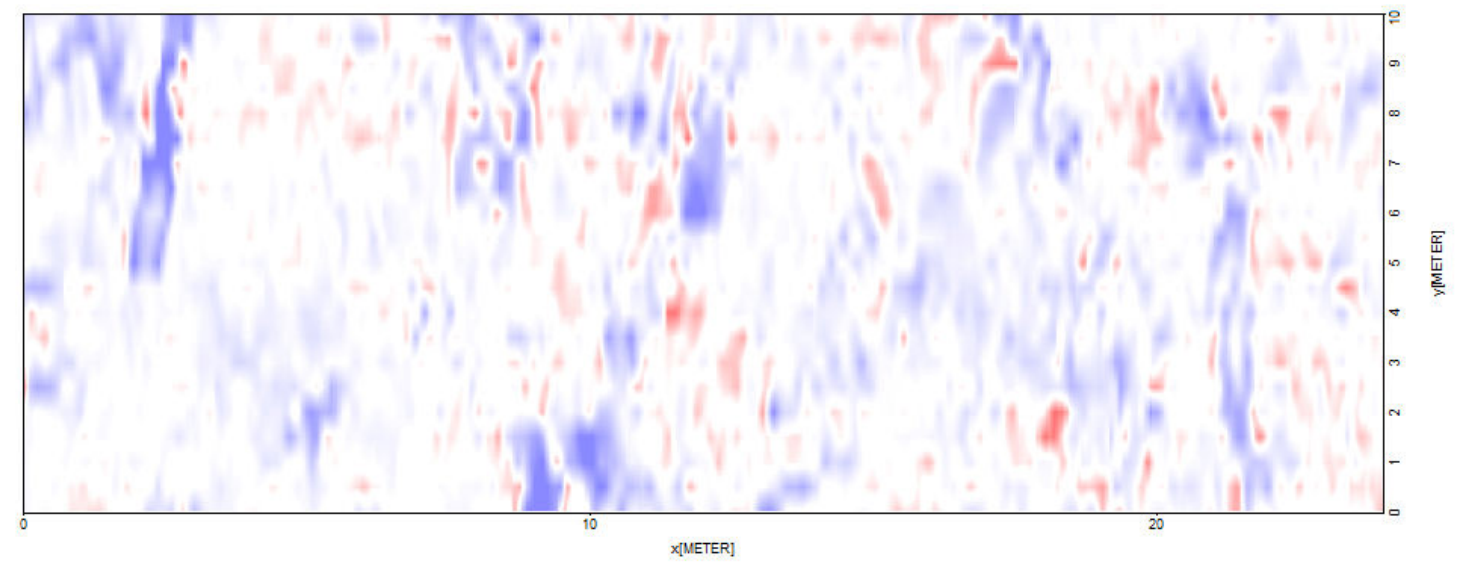

Anexo C 23 - Depth-slice GPR de 200 MHz para a área 3 (profundidade 0,3 m)

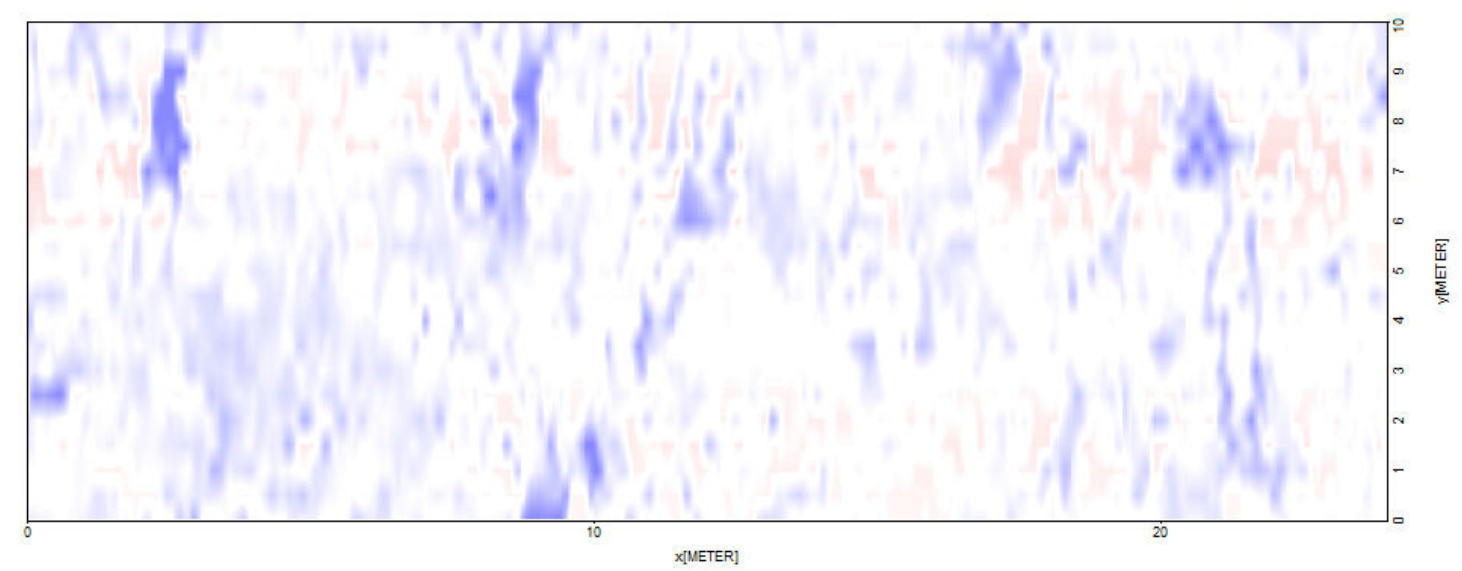

Anexo C 24 - Depth-slice GPR de 200 MHz para a área 3 (profundidade 0,4 m) 


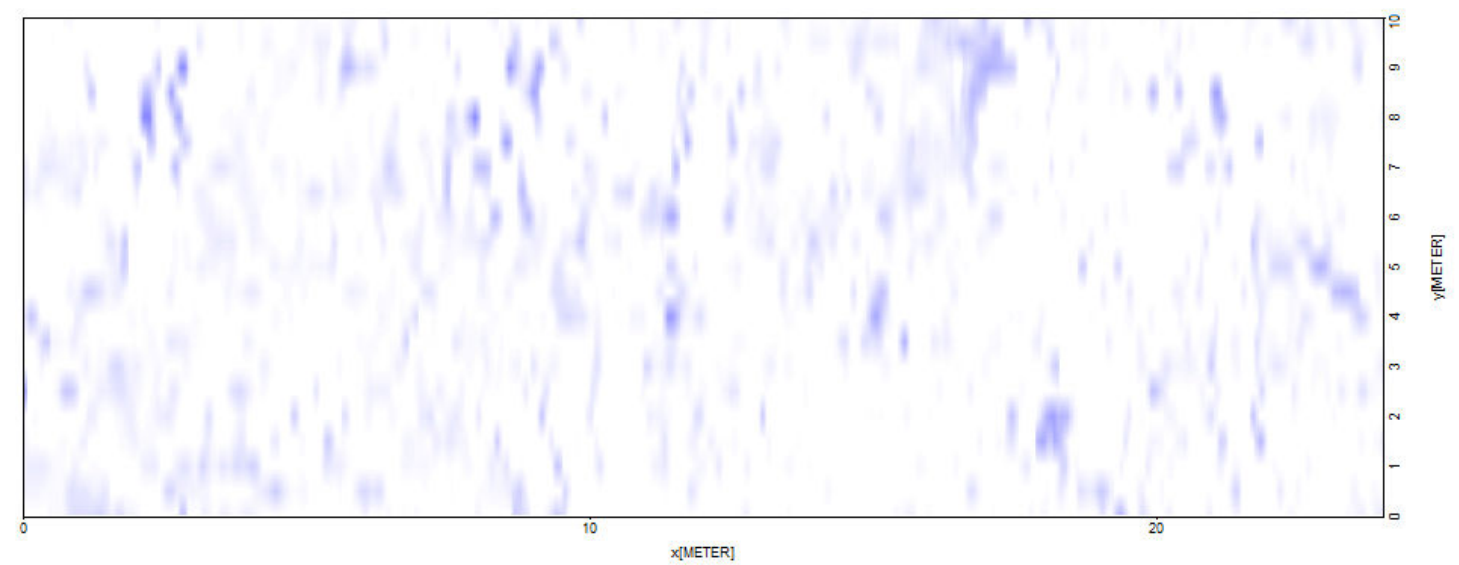

Anexo C 25 - Depth-slice GPR de 200 MHz para a área 3 (profundidade 0,5 m)

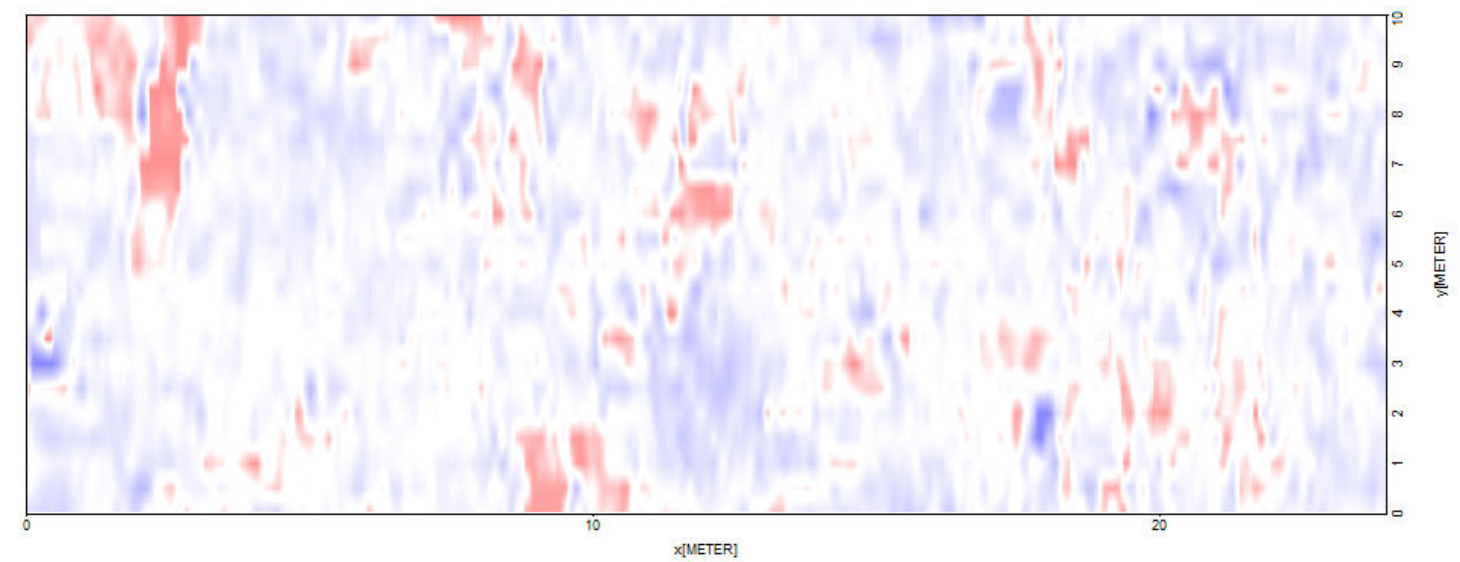

Anexo C 26 - Depth-slice GPR de 200 MHz para a área 3 (profundidade 0,6 m)

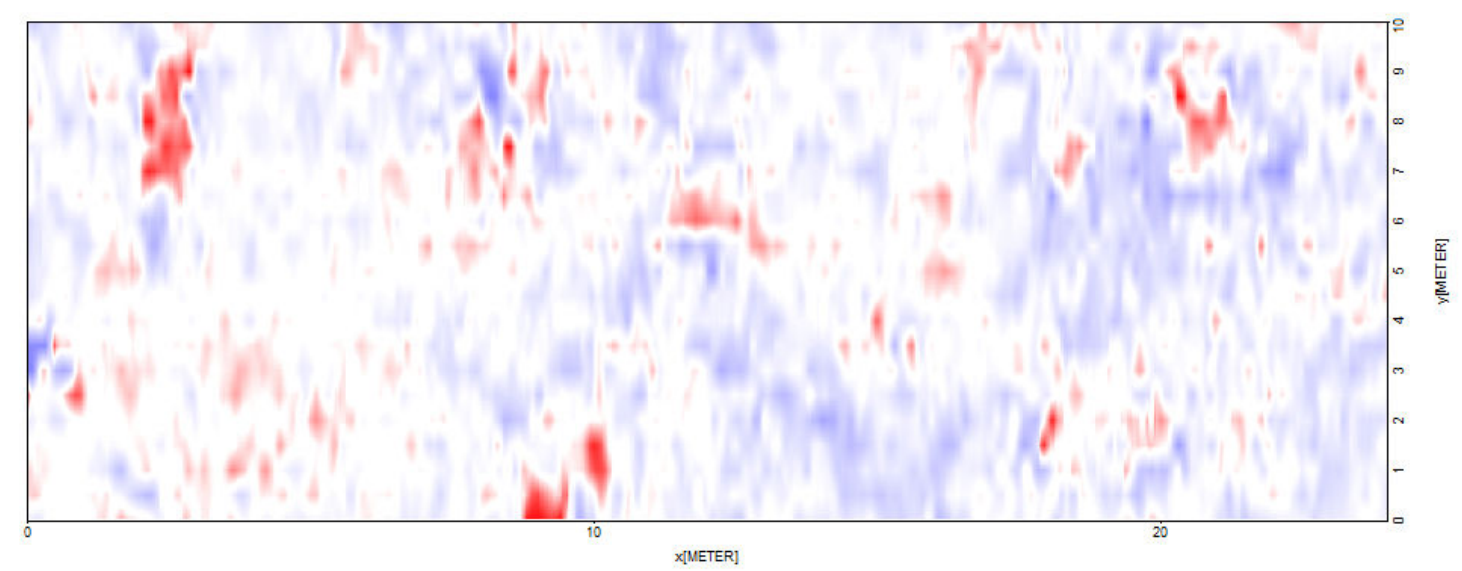

Anexo C 27 - Depth-slice GPR de 200 MHz para a área 3 (profundidade 0,7 m) 


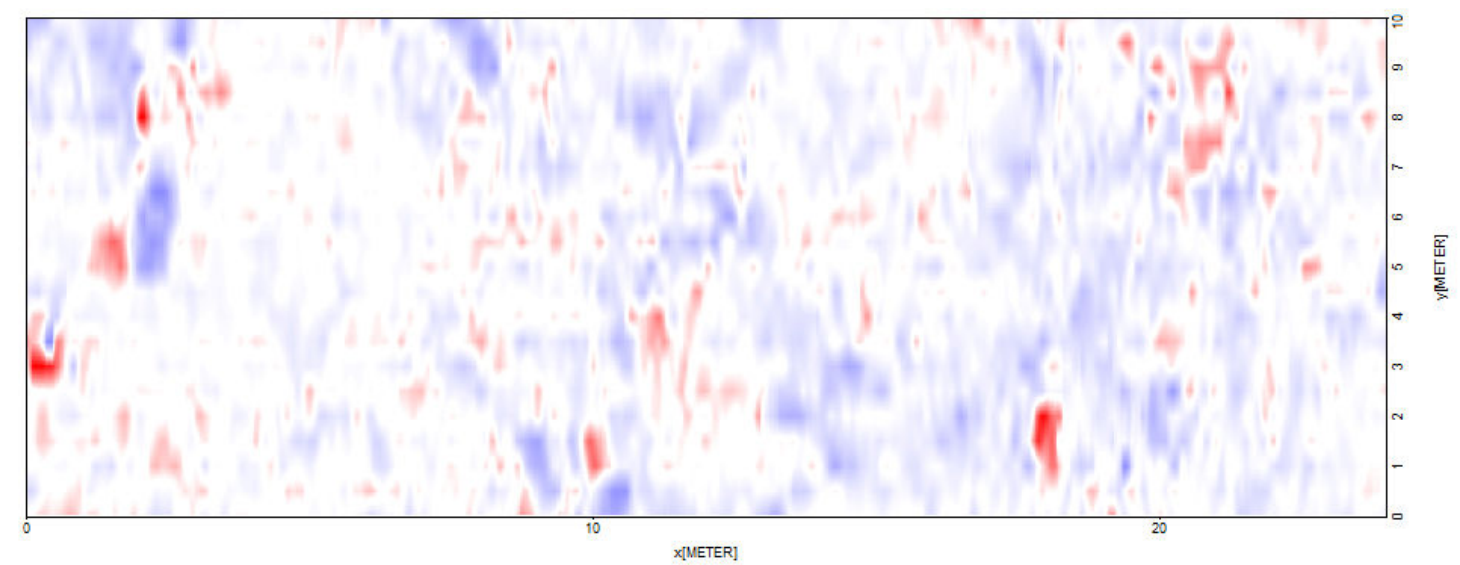

Anexo C 28 - Depth-slice GPR de 200 MHz para a área 3 (profundidade 0,8 m)

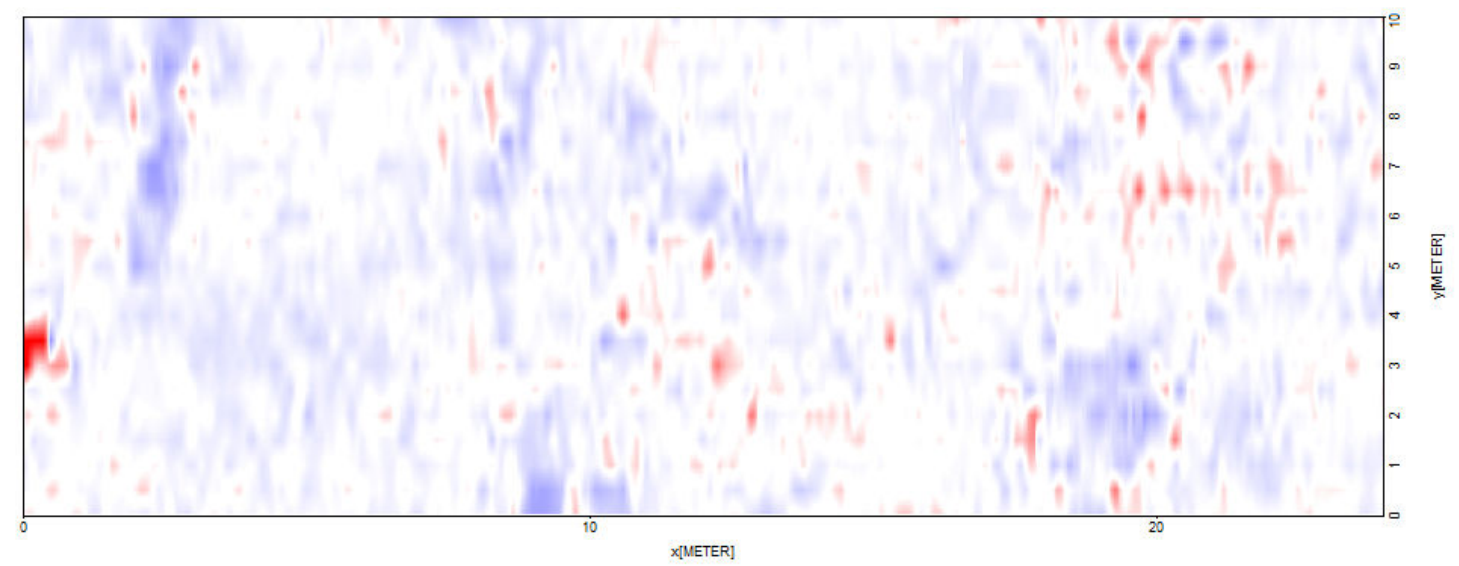

Anexo C 29 - Depth-slice GPR de 200 MHz para a área 3 (profundidade 0,9 m)

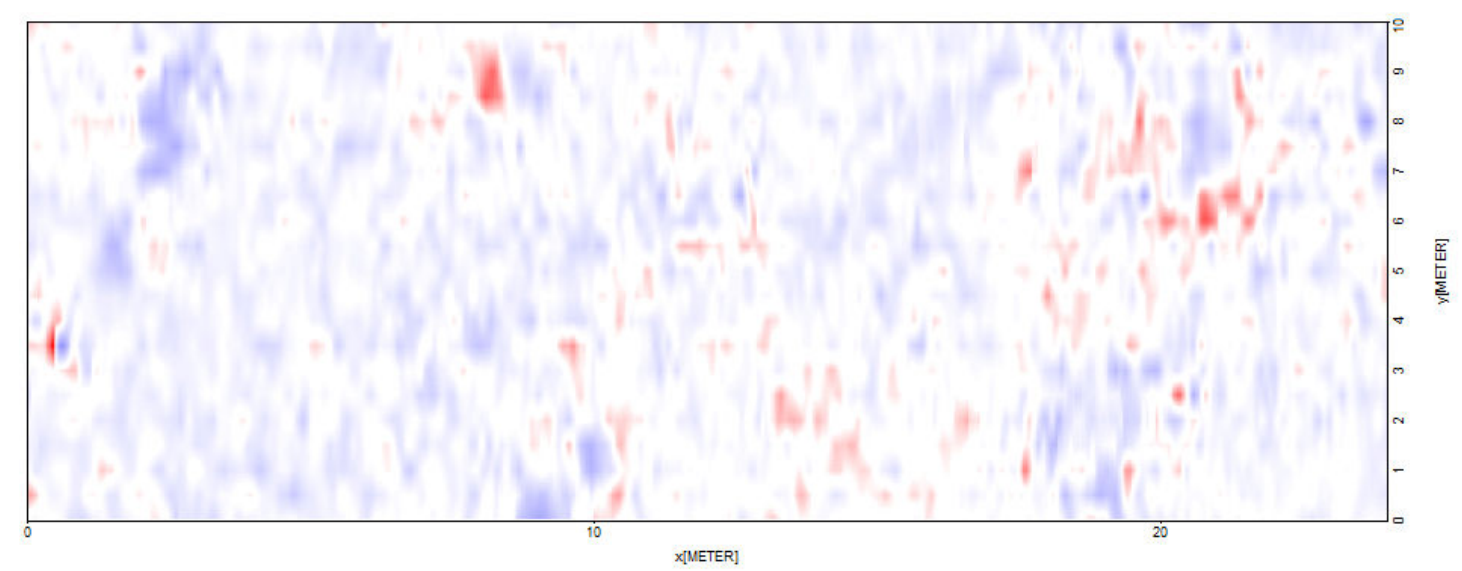

Anexo C 30 - Depth-slice GPR de 200 MHz para a área 3 (profundidade 1,0 m) 


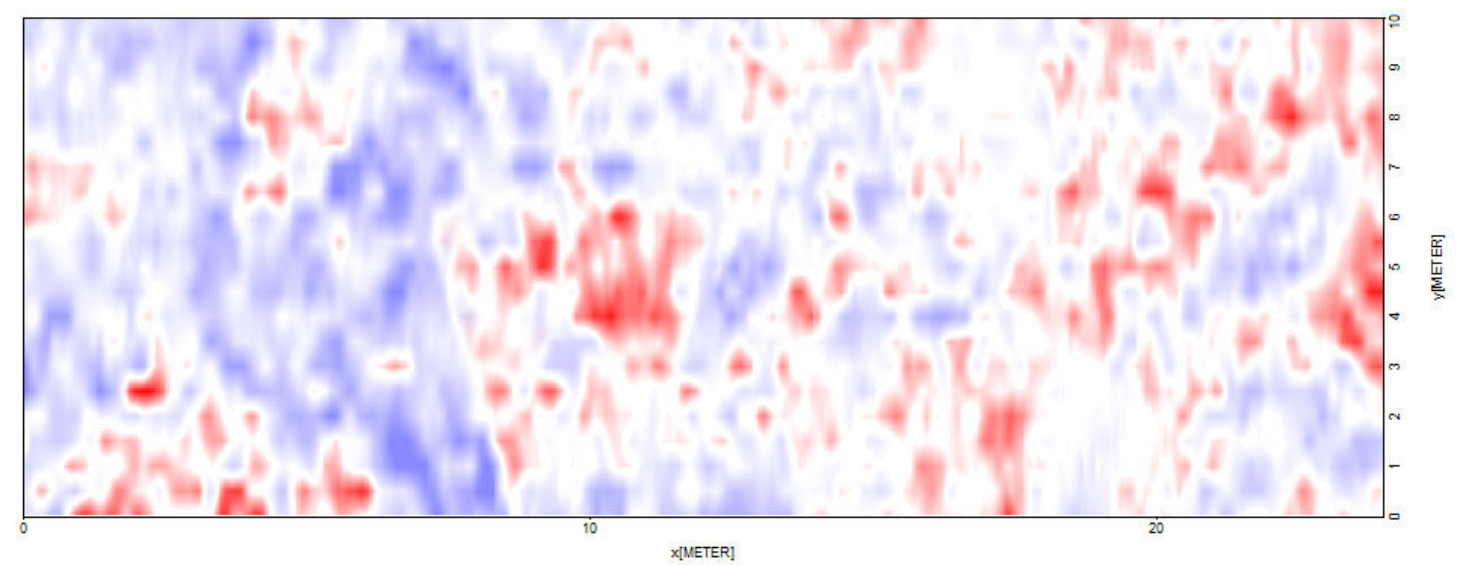

Anexo C 31 - Depth-slice GPR de 200 MHz para a área 3 (profundidade 1,2 m)

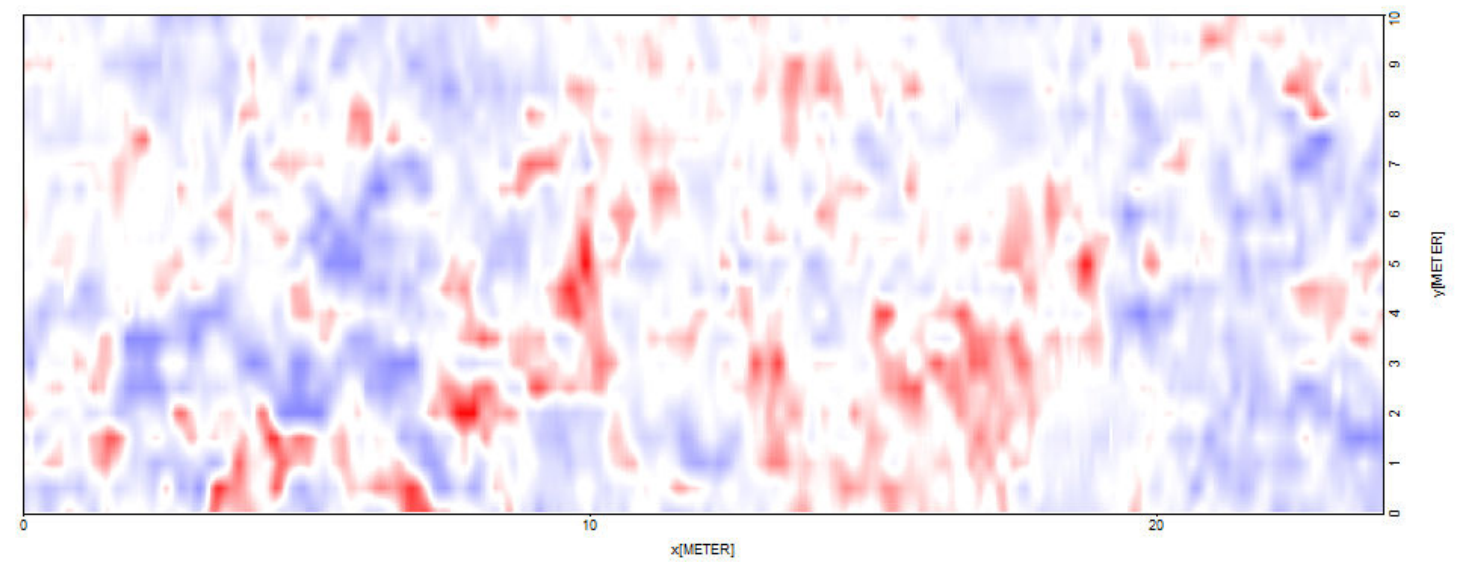

Anexo C 32 - Depth-slice GPR de 200 MHz para a área 3 (profundidade 1,3 m)

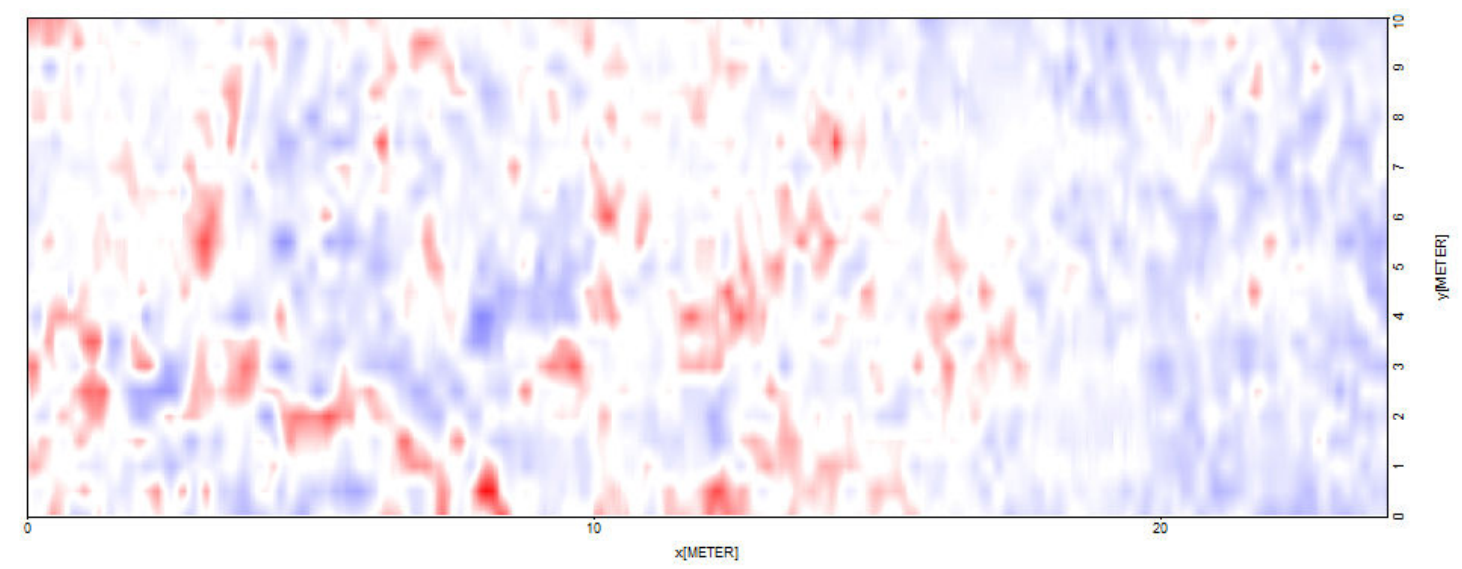

Anexo C 33 - Depth-slice GPR de 200 MHz para a área 3 (profundidade 1,4 m) 


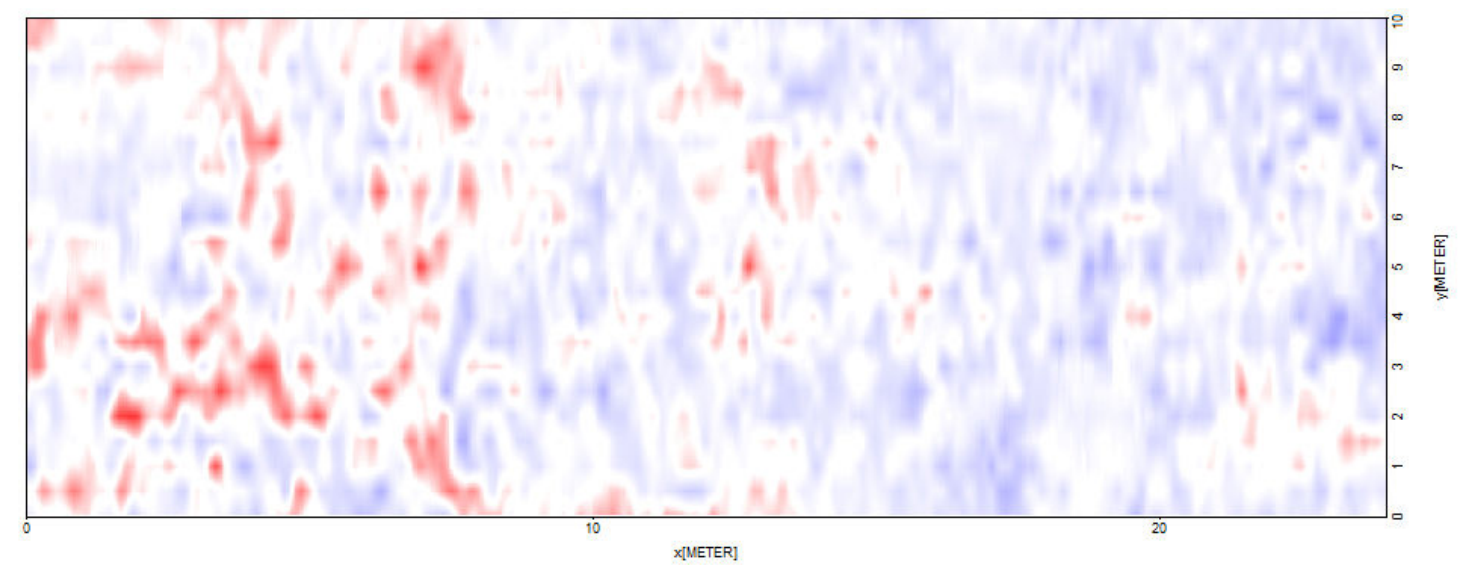

Anexo C 34 - Depth-slice GPR de 200 MHz para a área 3 (profundidade 1,5 m)

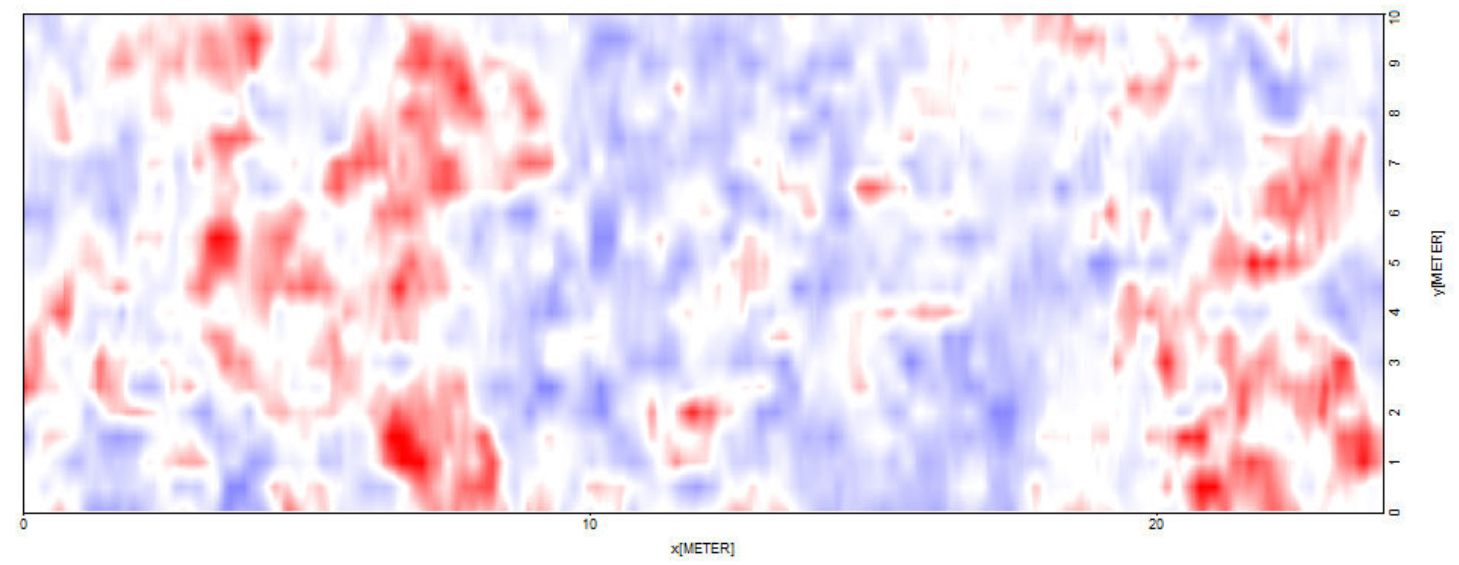

Anexo C 35 - Depth-slice GPR de 200 MHz para a área 3 (profundidade 1,6 m)

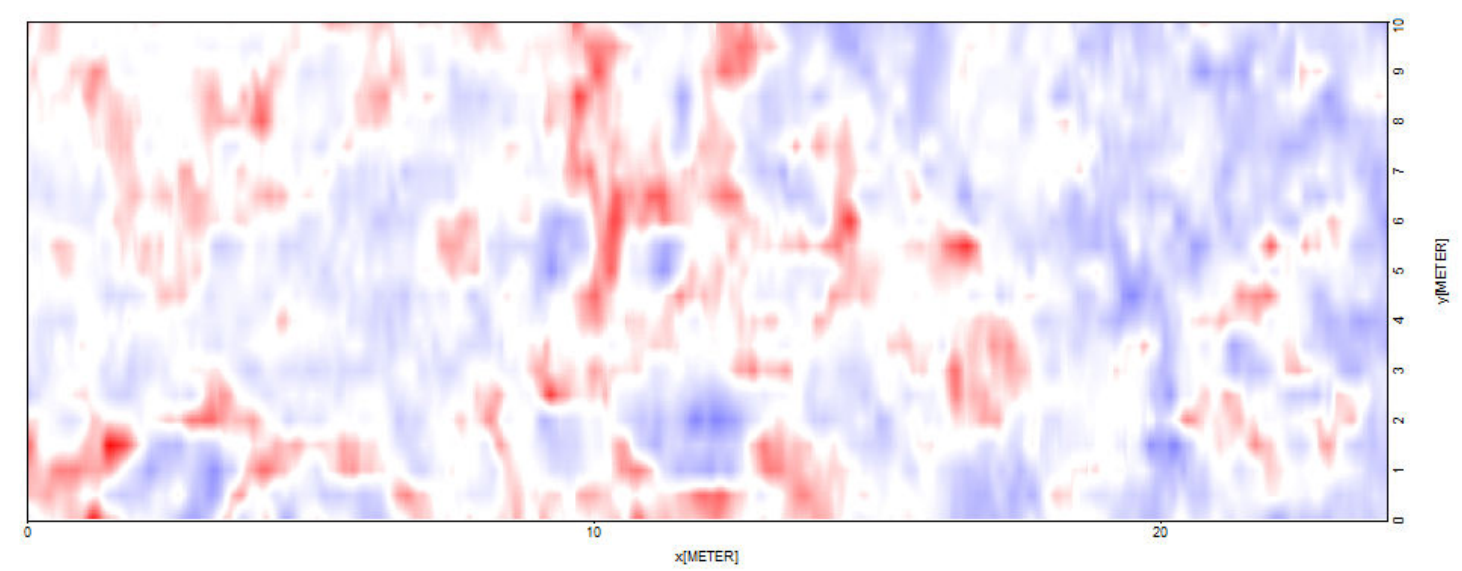

Anexo C 36 - Depth-slice GPR de 200 MHz para a área 3 (profundidade 1,7 m) 


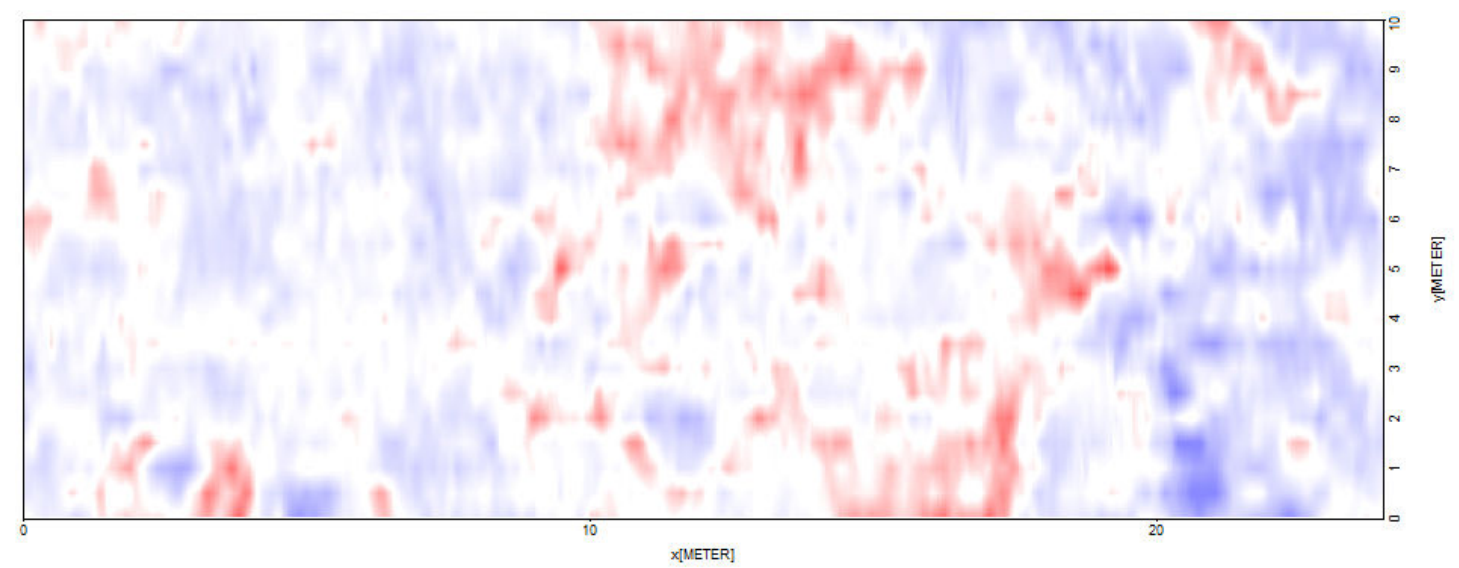

Anexo C 37 - Depth-slice GPR de 200 MHz para a área 3 (profundidade 1,8 m)

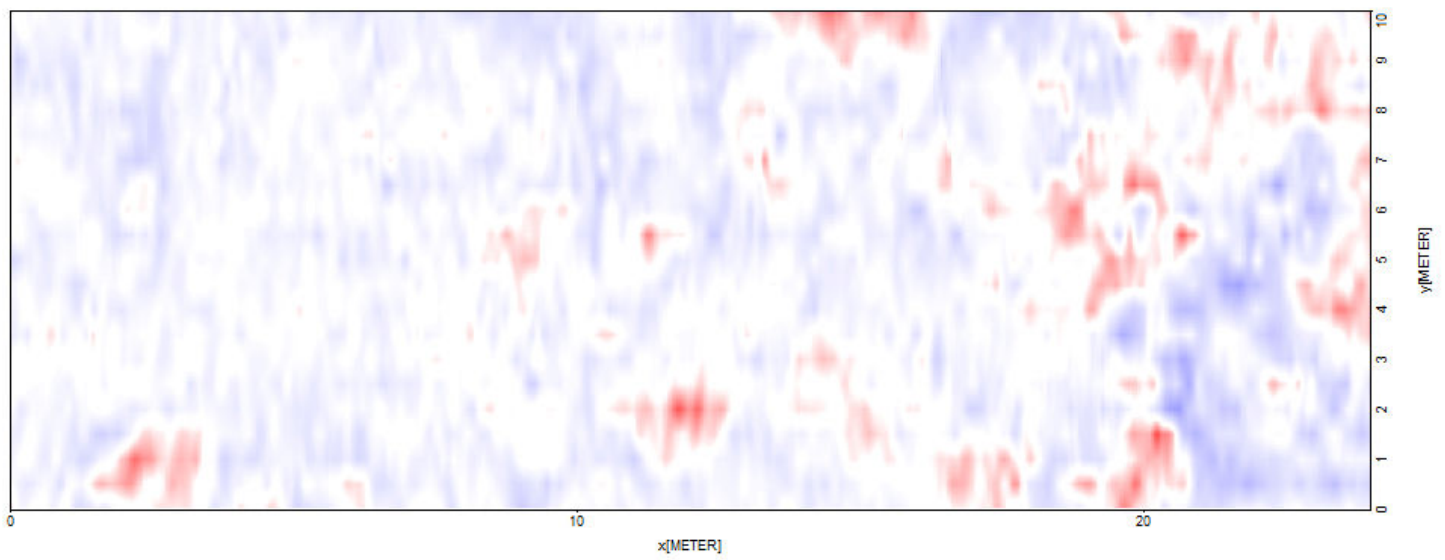

Anexo C 38 - Depth-slice GPR de 200 MHz para a área 3 (profundidade 1,9 m)

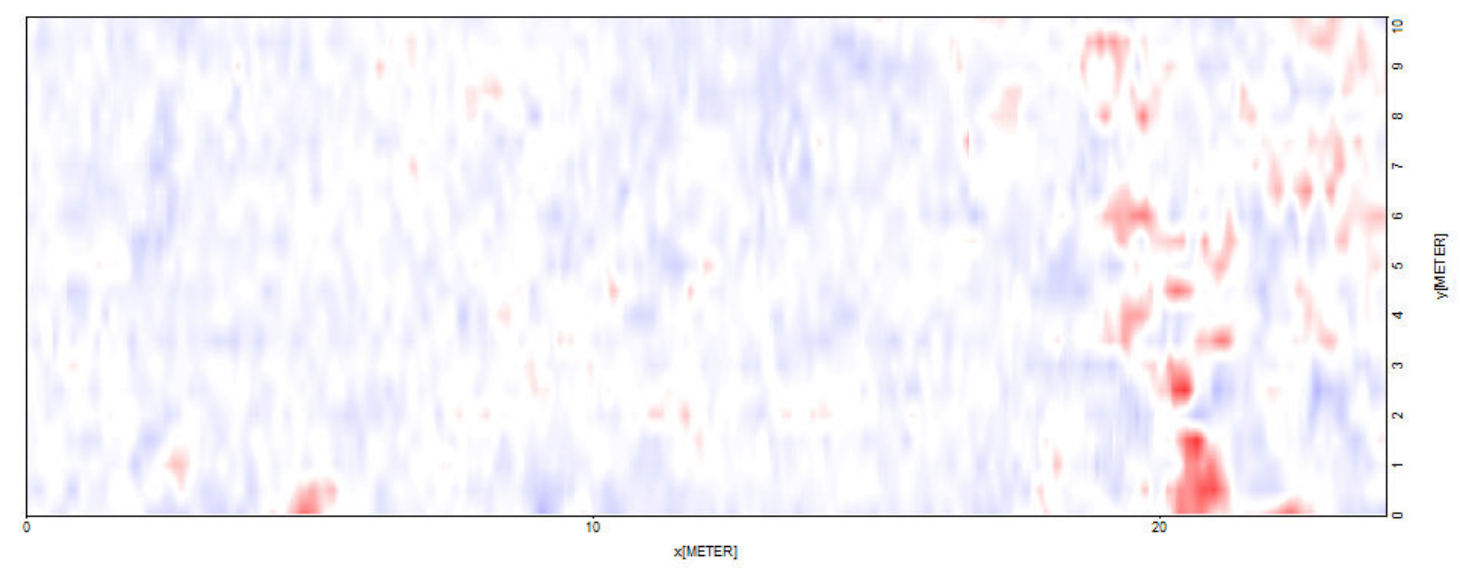

Anexo C 39 - Depth-slice GPR de 200 MHz para a área 3 (profundidade 2,0 m) 


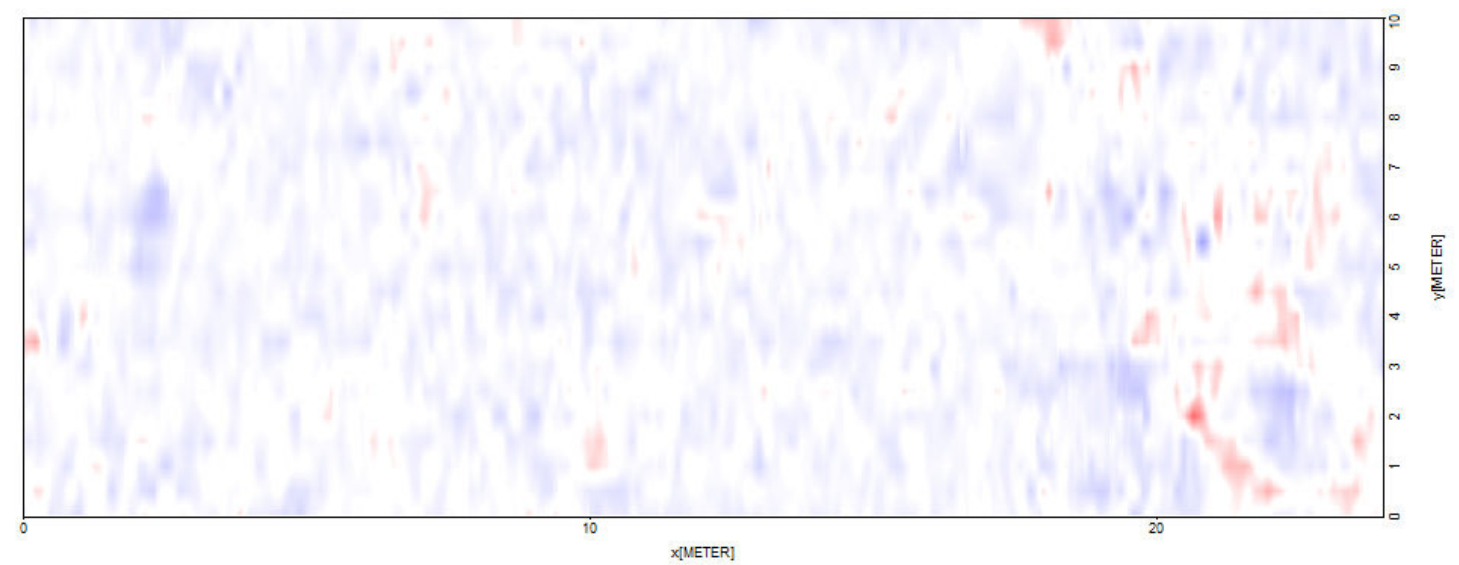

Anexo C 40 - Depth-slice GPR de 200 MHz para a área 3 (profundidade 2,1 m)

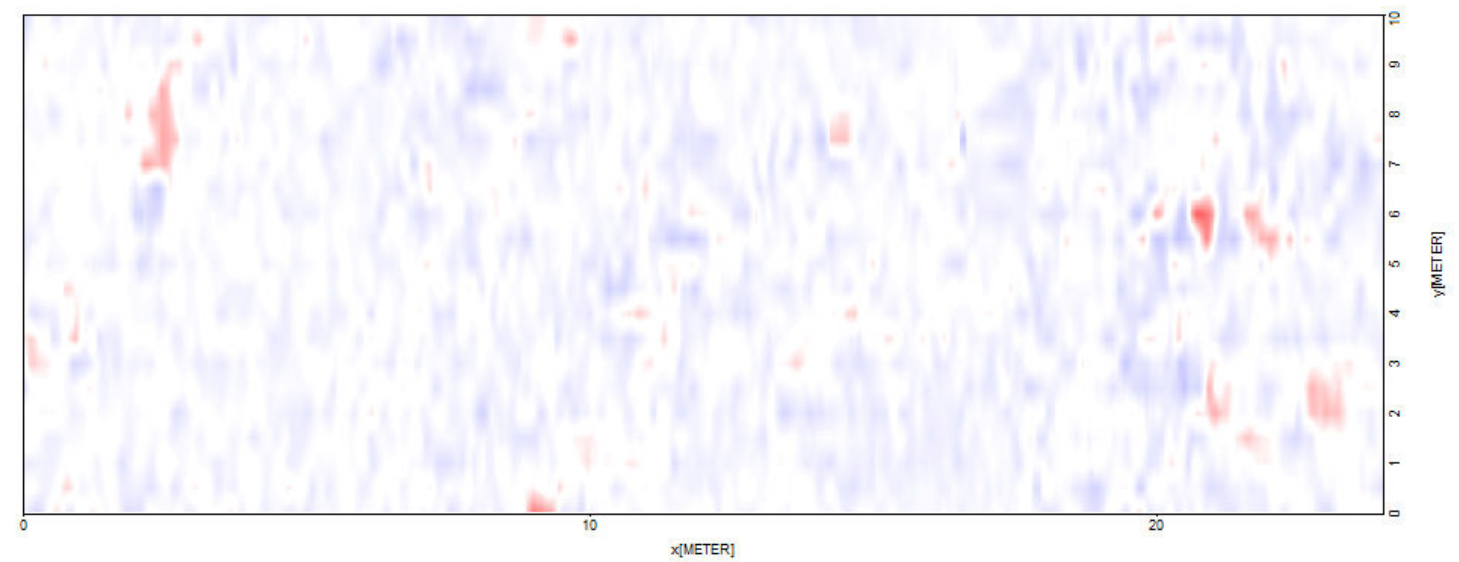

Anexo C 41 - Depth-slice GPR de 200 MHz para a área 3 (profundidade 2,2 m)

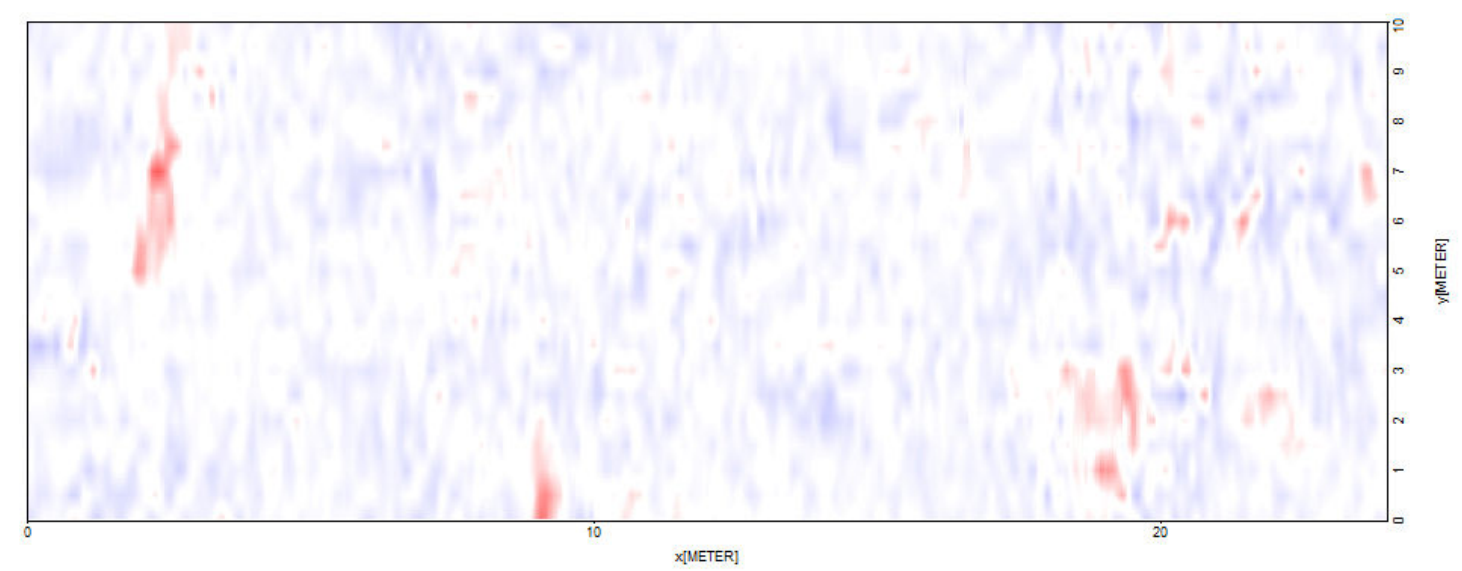

Anexo C 42 - Depth-slice GPR de 200 MHz para a área 3 (profundidade 2,3 m) 


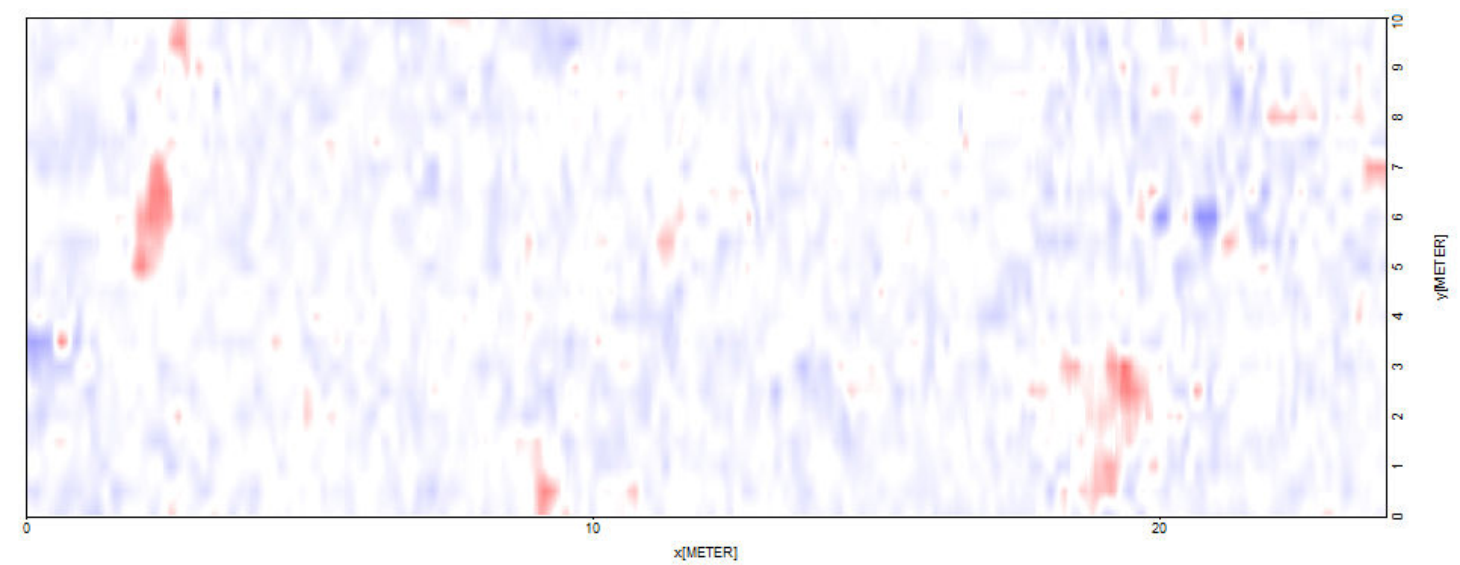

Anexo C 43 - Depth-slice GPR de 200 MHz para a área 3 (profundidade 2,4 m)

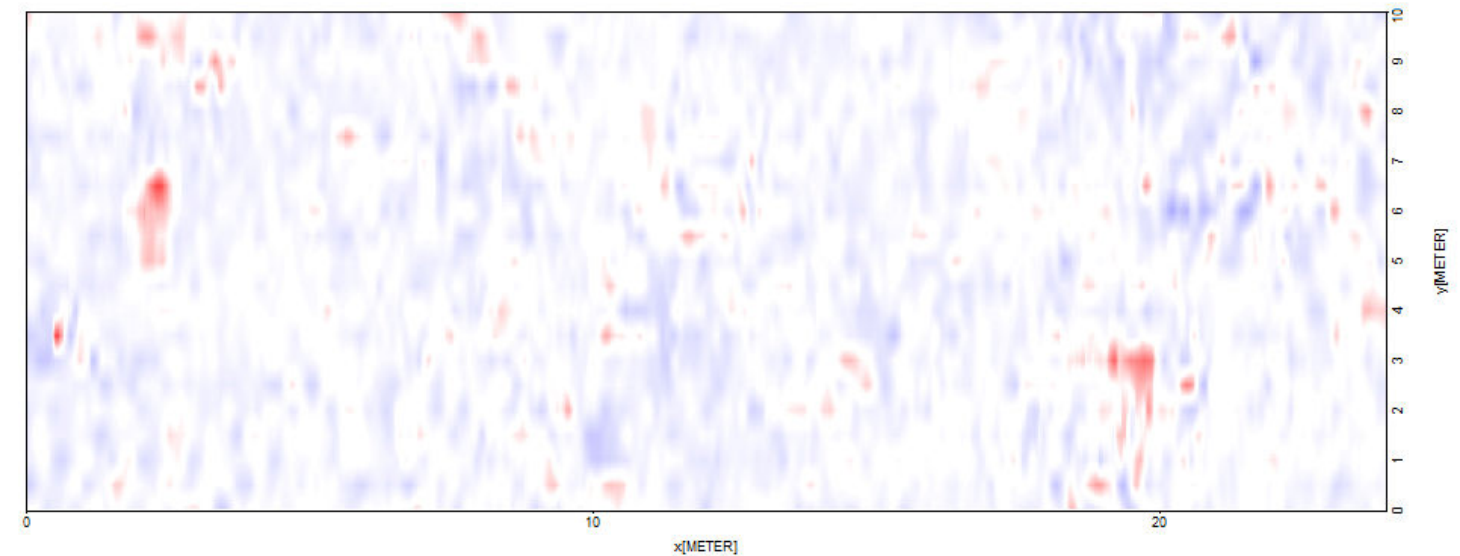

Anexo C 44 - Depth-slice GPR de 200 MHz para a área 3 (profundidade 2,5 m) 


\title{
ANEXO D: LEI FEDERAL 3.924/1961
}

\author{
A Lei Federal 3.924/1961 determinou que:
}

Artigo 27. A Diretoria do Patrimônio Histórico e Artístico Nacional manterá um Cadastro dos monumentos arqueológicos do Brasil, no qual serão registradas todas as jazidas manifestadas, de acordo com o disposto nesta lei, bem como das que se tornarem conhecidas por qualquer via.

Artigo 18. A descoberta fortuita de quaisquer elementos de interesse arqueológico ou pré-histórico, histórico, artístico ou numismático, deverá ser imediatamente comunicada à Diretoria do Patrimônio Histórico e Artístico Nacional, ou aos órgãos oficiais autorizados, pelo autor do achado ou pelo proprietário do local onde tiver ocorrido.

Artigo $8^{\circ}$. O direito de realizar escavações para fins arqueológicos, em terras de domínio público ou particular, constitui-se mediante permissão do Governo da União, através da Diretoria do Patrimônio Histórico e Artístico Nacional, ficando obrigado a respeitá-lo o proprietário ou possuidor do solo. 


\section{ANEXO E: DIÁRIO OFICIAL DA UNIÃO}

Edição Número 70 de 12/04/2007

Departamento do Patrimônio Material e Fiscalização Instituto do Patrimônio Histórico e Artístico Nacional Ministério da Cultura

PORTARIA No 128, DE 11 DE ABRIL DE 2007

Dispõe sobre a permissão para realizar o projeto de arqueologia preventiva na área de influência direta da AHE Dardanelos, no Estado do Mato Grosso.

O GERENTE DO PATRIMÔNIO ARQUEOLÓGICO E NATURAL DO

DEPARTAMENTO DO PATRIMÔNIO MATERIAL E FISCALIZAÇÃO DO

INSTITUTO DO PATRIMÔNIO HISTÓRICO E ARTÍSTICO NACIONAL - IPHAN,

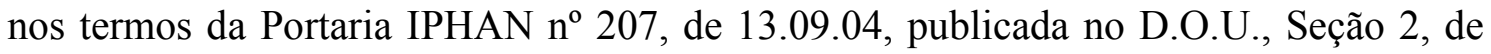
15.09.04 e de acordo com o disposto no Anexo I, do Decreto n ${ }^{\circ}$ 5.040, de 07.04.04, na Lei $n^{\circ}$ 3.924, de 26.07.61, na Portaria SPHAN no 7 , de 01.12.88, e ainda do que consta do processo administrativo $\mathrm{n}^{\mathrm{o}} 01516.000060 / 2007-60$, resolve;

I -Expedir a presente PERMISSÃO, sem prejuízo das demais licenças exigíveis por diferentes órgãos e entidades da Administração Pública, aos arqueólogos Renato Kipnis e Solange Bezerra Caldarelli para, com o apoio institucional do Instituto Homem Brasileiro, realizar as atividades do projeto de arqueologia preventiva na área de influência direta do Aproveitamento Hidrelétrico Dardanelos, localizado na margem esquerda do rio Aripuanã, Município de Aripuanã, no Estado de Mato Grosso, entre as coordenadas UTM 21 L: 225500/8879500; 225500/8872000; 235500/8872000; 235500/8879500. 
II -Reconhecer como coordenadores dos trabalhos de que trata o item anterior os arqueólogos detentores da presente permissão, cujo projeto se intitula "Arqueologia Preventiva na Área de Influência Direta do AHE Dardanelos, MT".

III -Reconhecer os arqueólogos designados coordenadores dos trabalhos como fiéis depositários, durante a realização das etapas de campo, do eventual material arqueológico recolhido ou de estudo que lhes tenha sido confiado.

IV -Determinar à $14^{\mathrm{a}}$ Superintendência Regional do IPHAN, o acompanhamento e a fiscalização da execução dos trabalhos, inclusive no que diz respeito à destinação e à guarda do material coletado, assim como das ações de preservação e valorização dos remanescentes.

V -Condicionar a eficácia da presente permissão, à apresentação, por parte dos arqueólogos coordenadores, de relatórios semestrais e final ao término do prazo fixado nesta Portaria, contendo todas as informações previstas nos artigos 11 e 12 da Portaria SPHAN n ${ }^{\circ}$, de 01.12.88.

VI -Fixar o prazo de validade da presente permissão em 18 (dezoito) meses, observada a disposição do item anterior.

Esta Portaria entra em vigor na data de sua publicação.

ROGÉRIO JOSÉ DIAS 